\title{
Irene Wiehl
}

\section{Untersuchungen zum Wortschatz \\ der Freisinger Denkmäler \\ Christliche Terminologie}

Verlag Otto Sagner München · Berlin · Washington D.C.

Digitalisiert im Rahmen der Kooperation mit dem DFG-Projekt „Digi20“

der Bayerischen Staatsbibliothek, München. OCR-Bearbeitung und Erstellung des eBooks durch den Verlag Otto Sagner:

http://verlag.kubon-sagner.de

( $)$ bei Verlag Otto Sagner. Eine Verwertung oder Weitergabe der Texte und Abbildungen, insbesondere durch Vervielfältigung, ist ohne vorherige schriftliche Genehmigung des Verlages unzulässig. 


\section{Slavistische Beiträge}

\section{BEGRÜNDET VON ALOIS SCHMAUS}

HERAUSGEGEBEN VON JOHANNES HOLTHUSEN UND JOSEF SCHRENK

REDAKTION: PETER REHDER

Band 78 
IRENE WIEHL

\section{UNTERSUCHUNGEN ZUM WORTSCHATZ DER FREISINGER DENKMÄLER}

CHRISTLICHE TERMINOLOGIE

VERLAG OTTO SAGNER · MÜNCHEN

1974 
Shuvil. Beitraige

MEINEM MAN N

ISBN 3876900891

Copyright by Verlag Otto Sagner, München 1974

Abteilung der Firma Kubon und Sagner, München

Druck: Alexander GroBmann

8 München 19, YsenburgstraBe $7^{I}$ 


$$
v \circ r w \circ r t
$$

Der AnstoB $z u$ der vorliegenden Untersuchung, die im Sommersemester 1972 vom Fachbereich Neuere Fremdsprachen und Literaturen der Philipps-Universitat Marburg als Dissertation angenommen wurde, ging von einem im wintersemester $1968 / 69$ stattgefundenen Seminar aus. Insbesondere geht sie jedoch auf eine Anregung von Herrn Prof.Dr. Hans-Bernd Harder zurück, der mir bei ihrer Ausführung Rat und Förderung bot. Dafür spreche ich ihm meinen herzlichen Dank aus.

GroBen Dank schulde ich Herrn Prof.Dr. Josef Kurz sowie Frau Dr. Zoe Hauptová und ihren Mitarbeitern (Prag), die mir ermöglichten, das Belegmaterial des altslavischen wörterbuches einzusehen, und mir manche Frage beantworteten. Ferner danke ich Herrn Prof.Dr. Emanuel Michálek (Prag) für die bereitwillig erteilte Erlaubnis, die Kartothek des alttschechischen worterbuches $z u$ benutzen. Freundliche Unterstützung habe ich daruber hinaus in den Prager Bibliotheken gefunden, wofür $1 \mathrm{ch}$ an dieser Stelle meinen aufrichtigen Dank zum Ausdruck bringen möchte. Für wertvolle Auskünfte und Hinweise danke ich auch Herrn Prof.Dr. Mikolás Zatovkaňuk, Karls-Universităt, der mir wăhrend meines Aufenthaltes in Prag hilfreich zur seite stand.

Zu danken habe ich auch den Herausgebern der "Slavistischen Beiträge", vor allem Herrn Dr. Peter Rehder, für die Veröffentlichung meiner Arbeit in dieser Reihe.

Irene Wiehl 
Vorwort

Einleitung

Hauptteil: Untersuchung des christlich-religiösen Wortschatzes 13

I. Grundlegende Erlăuterungen zur Gliederung des

sprachlichen Lehngutes ............. 13

II. Wortuntersuchungen ............... 19

A. AuBeres Lehngut . . . . . . . . . . . . 19

1. Fremdwörter . . . . . . . . . . . . . 19

2. Lehnwörter . . . . . . . . . . . . . 19

B. Inneres Lehngut . . . . . . . . . . . . 23

1. Neubildungen .............. 23

a. Lehnübersetzungen . . . . . . . . . . 23

b. Lehnübertragungen . . . . . . . . . . 33

c. Eigenbildungen . . . . . . . . . . . . . 43

2. Umprăgungen ............... 49

a. Lehnumprăgungen . . . . . . . . . . 49

b. Eigenumprägungen . . . . . . . . . . 63

c. Umschreibungen . . . . . . . . . . . 102

III. Darstellung und Auswertung der Ergebnisse . . . . . . 104

A. Gesamtübersicht (Tabelle I) ........... 104

B. Der fremdsprachliche EinfluB auf den untersuchten

Wortschatz . . . . . . . . . . . . . . . 111

1. Die Einteilung des Lehngutes (Tabelle II) . . . 111

2. Der Anteil der Lehngutgruppen am religiösen Wortschatz von Fris (Tabelle III) . . . . . . . . . . . 114

3. Verteilung der christlichen Begriffe in ihrer inhaltlichen Differenzierung auf die formalen

Gruppen . . . . . . . . . . . . . . . 114

4. Der Anteil der einzelnen Vorbildsprachen am christlichen Wortschatz von Fris (Tabelle IV) . . . . 115

C. Der Anteil der Sondersprachen am religiösen Wortschatz

von Fris . . . . . . . . . . . . . . . . 117

D. Verteilung der untersuchten wörter auf Fris I, II

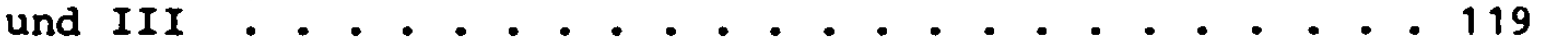

E. Die Stellung des religiösen Wortschatzes von Fris

in der asl. christlichen Sprache . . . . . . . . 123

1. Die Verbreitung der wörter von Fris in der asl. Sprache ................... 123

2. Vergleich der christlichen Terminologie von Fris mit der ubrigen asl. Ausdrucksweise 
SchluB: Zusammenfassung aller Ergebnisse . . . . . . . . . 126 Exkurse . . . . . . . . . . . . . . . . . . . . . 129

I. Die Rechtswörter in den Freisinger Denkmälern . • • • • 129

II. Die Freisinger Denkmäler und die kroatisch-glagolitische
Benediktinerregel. Ubereinstimmungen im Wortgebrauch • • 137

Alphabetisches Verzeichnis der untersuchten wörter . • . • • 139

Lateinisches Wortregister . . . . . . . . . . . . . . . 139

Griechisches Wortregister . . . . . . . . . . . . . . 140

Althochdeutsches Wortregister . . . . . . . . . . . . . 141

Abkürzungen . . . . . . . . . . . . . . . . . . . . . 142

Literaturverzeichnis . . . . . . . . . . . . . . . . 143

A. Slavische Texte . . . . . . . . . . . . . . 143

B. Althochdeutsche und lateinische Texte . . . . . . . 145

C. Wörterbücher, Nachschlagewerke . • . . . . . . . . 145

D. Sekundärliteratur . . . . . . . . . . . . . . 148

E. Historische Quellen . . . . . . . . . . . . . 159

Anhang: Faksimile . . . . . . . . . . . . . . . . . . . 161 
Die Annahme des Christentums durch die slavischen stämme stellt für die slavische Sprachgeschichte ein wichtiges, einschneidendes Ereignis dar. Bei der Christianisierung musten nicht nur die kirchlichen Hauptbegriffe ubersetzt werden, es entstand auch das Bedürfnis, das abstrakte theologische Denken mit seiner feinen begrifflichen Gliederung in slavischer Sprache auszudrücken. Das Bild, das sich als das Ergebnis der daraus folgenden Bemühungen bietet, ist auberst mannigfaltig. Das zeigt sich im Wortbestand, der sehr verschiedene Versuche enthält, das Neue sprachlich einzufangen.

Das früheste Zeugnis der slavischen christlichen Literatur ist in drei Handschriften überliefert, die in der deutschen slavistik unter dem Namen "Freisinger Denkmäler" (Fris) bekannt sind. 1 Es handelt sich um zwei Beichtgebete, Freising I und III, und um eine BuBpredigt, Freising II, die in der wissenschaftlichen Forschung die Bezeichnung "Adhortatio ad poenitentiam" erhalten hat. Die Texte sind in der karolingischen Minuskel-Schrift im Einflubbereich bairischer Schreibschulen in der Zeit zwischen 972 und 1039 aufgezeichnet. ${ }^{2}$ Textkritische Untersuchungen brachten eine literarische Abhängigkeit der Teile I und III von dem altbairischen Sankt Emmeramer Gebet zutage und rückten sie in die Nähe des Beichtgebetes im Euchologium Sinaiticum. ${ }^{3}$ Für die Adhortatio ist eine inhaltliche und lexikalische Verwandtschaft mit der Homilie von Kliment (Klim) festgestellt worden, die ihren ursprung in der homiletischen Litera. tur lateinischer Kirchenschriftsteller hat. 4

1. In der Wahl der Sigel für die altslavischen Denkmảler folgt die vorliegende Arbeit dem LLP. Die Freisinger Denkmáler werden mit Fris bezeichnet.

2. Damit ist fedoch nichts definitives uber ihre Ent stehung gesagt. Vgl. Brižinski spomeniki, Ljubljana 1937, Hrsgg. F.Ramovš - M.Kos.

3. Bei Steinmeyer 309-311; Vgl. Euchologium Sinaiticum, Lfublfana 1937, Hrsg. R.Nahtigal, 208-215, 72a-72b.

4. Vgl. Mikl Term 3-8. Als erster brachte V.M.Undol'skif die Homilie von Kliment mit Fris II in Verbindung, vgl. seine Abhandlung: ob otkrytil i izdanii tvorenij Klimenta, episkopa slovenska, auszugsweise erschienen in: Besedy Obšcestva lfubitelej rossifskof slovesnosti, I, Moskva 1867, 31-38. Mit Klim wird die bei Mikl Term 3-6 abgedruckte Homilie "Poučenie na pamjat" apostola ili mučenika" bezeichnet. Diese Homilie zăhlt nicht zu den von der Redaktion des LLP verarbeiteten Schriften. Im LLP wird mit Klim eine andere Handschrift bezeichnet. 
In einer systematischen Untersuchung des christlich-religiósen Wortschatzes der Freisinger Denkmäler, die man trotz erheblicher Unterschiede als eine Einheit betrachtet, soll gezeigt werden, mit welchen Mitteln und unter welchem EinfluB die sprachliche Aufnahme des christlichen Gedankengutes erfolgte. Dadurch wird notwendigerweise auch die allgemeine Frage nach der Entstehung der slavischen christlichen Terminologie uberhaupt berührt. Es wird daher versucht, das Verhältnis des religiösen Wortschatzes der Freisinger Denkmäler zu der ubrigen altslavischen ${ }^{1}$ christlichen Terminologie zu bestimmen. Aus dem doppelten Aspekt in der Aufgabestellung ergibt sich die zweifache zielsetzung:

1. einen Beitrag zur Untersuchung der Lexik der Freisinger Denkmäler zu liefern und

2. zur Erforschung der altslavischen christlichen Terminologie beizutragen.

In ihrer Durchführung ist die vorliegende Arbeit von der kulturhistorisch orientierten Wortforschung bestimmt. Bei den einzelnen Wortuntersuchungen wurden die jeweils in der kulturwelt liegenden Bezugspunkte in Betracht gezogen; es erschien notwendig, neben dem stark hervortretenden theologischen Aspekt, die sozialen Verhăltnisse, das Rechtsleben und soweit möglich auch den heidnischen kult zu berücksichtigen. Daraus lieben sich die Bedingungen bestimmen (oft nur erahnen), unter denen die neuen christlichen Inhalte mit den vorhandenen slavischen wötern bezeichnet werden konnten.

Die Lexik der Freisinger Denkmaler ist bisher unter verschiedenen Gesichtspunkten untersucht worden. 2 Im Mittelpunkt der Bemühungen lag das sprachgeographische Interesse mit der zielsetzung, die Texte in ihrer Einzelsprachzugehörigkeit eindeutig zu bestimmen. Im Verlauf der umfangreichen Forschung wurden folgende schritte unternommen:

1. In der vorliegenden Arbeit wird der Terminus "Altslavisch" und nicht "Altkirchenslavisch" benutzt, obwohl in dem im Erscheinen begriffenen Lexicon Linguae Palaeoslovenicae (= LLP) für den deutschen Sprachraum der Terminus "Altkirchenslavisch" gefuhrt wird. Mit "Altslavisch" wird die Alteste slavische Literatursprache bezeichnet (vom Beginn bis ins 12. Jh. hinein). Die Verwendung dieser Bezeichnung gewinnt immer mehr an Boden, da sie auch auf weltliche Llteratur angewandt werden kann. Zur Klarung des verstandnisses der beiden Texmini vgl. R.M.Cejtlin, O principach sostavlenija slovarja staroslavjanskogo Jazyka, in: Vopr.slav.jaz.,6,1962, 112-139. Der Terminus "Altkirchenslavisch" erscheint nur dann, wenn ex sich auf besprochene oder zitierte Arbeiten bezieht, in denen mit dieser Bezeichnung gearbeitet wird.

2. Vgl. Ján Stanislav, Doterajł̌le vyskumy o Frizinskych pamiatkach. In: Byzanti- 
1. Die Wörter sind vollständig registriert, ihre Formen bestimmt, und die lautliche Gestalt in altslavischer und altslovenischer Lesart rekonstruiert worden (VOSTOKOV, MIKLOSICH, VONDRÁK, KOLARIC, POGAČNIK). 1

2. Der Text von Fris I und III ist mit den althochdeutschen Vorlagen (St. Emmeramer Gebet) verglichen worden, wobei auch übersetzungstechnische Probleme erörtert wurden (VONDRÁ, GRAFENAUER, ISAČENKO) 2

3. Der Wortbestand der Fris ist mit dem altkirchenslavischen ${ }^{3}$ Wortschatz konfrontiert worden, jedoch nicht erschöpfend (ISAČENKO). Insbesondere ist Fris II mit der Homilie von Kliment verglichen worden, und Fris I und III mit dem Beichtgebet in Euch in Verbindung gebracht (VONDRÁK, JAGÍ́, GRAFENAUER). 4

4. Der Wortbestand von Fris wurde dem heutigen Slovenisch gegenubergestellt (GRAFENAUER, KOLARIČ), zum Teil auch mit dem heutigen slovakisch verglichen (ISAČ́ENKO). 5

noslavica 4, 1933, 303-331. In dem Forschungsbericht ist die wichtigste Literatur bis 1932 enthalten. Uber die weitere Forschung berichtet Joze Pogaznik in: Freisinger Denkmaler, München 1968, 3-17.

1. Als erster hat A.Ch. Vostokov den Wortschatz von Fris registriert: GrammatiCeskija ob"jasnenija na tri stat'i Frejzingenskoj rukopisi. P.J. Keppen, Sobranie slovenskich pamjatnikov nachodjaščichsja vne Rossii, SPb, 1827. Danach hat ihn Miklosich in seinem worterbuch erfabt (= Mikl LP). Ferner ist der Index in: Frisinské pamatky, Praha 1896, von $v$. Vondrák zu nennen und das Glossar von J. Pogačnik in: Freisinger Denkmăler, München 1968, dem die Wortschatzuntersuchung von $R$. Kolaric vorangeht.

2. Vgl. I. Grafenauer, Starobavarska (svetoemmeramska) molitev v starem slovenskem in v stcsl. jeziku, in: Slovenski jezik I, 1-4, 1938, 8-54, A. Isačenko, Jazyk a povod frisinskych pamiatok. Bratislava 1943.

3. Isałenko verwendet den Terminus "altkirchenslavisch" für die ălteste slavische Literatursprache in inrer Gebundenheit an die literarische Tatigkeit der "Slavenapostel" Kyrill und Method. Der so verstandene Begriff stellt eine Verengung gegenuber dem in der vorliegenden Arbeit verwendeten Terminus dar, kann also nicht ohne weiteres mit ihm gleichgesetzt werden. In diesem Zusammenhang sei jetzt schon auf die in der zusammenfassung der vorliegenden Arbeit enthaltene Schlubfolgerung hingewiesen, wonach die literarische Tatigkeit bei den Slaven noch vor dem Auftreten der griechischen Lehrer entstanden sein mub.

4. Vgl. V. Vondrák, Zur Frage nach dem Verhăltnisse des Freisinger Denkmals zu einer Homilie von Klemens, in: AfslPh 28, 1906, 256-260; ders.. Althochdeutsche Beichtformeln im Altkirchenslavischen und in den Freisinger Denkmălern, in: AfslPh 16, 1894, 118-132; V. Jagić, Meine zusătze zum Studium der Werke des slavischen Klemens, in: AfslPh 27, 1905, 395-412; 1. Grafenauer, Karolinłka kateheza ter izvor Brižinskih spomenikov in C̆ina nadb ispovédajgštudmb sę, in: Razprave znanstvenega društva $v$ Ljubljani 13, 1936 .

5. Vgl. Die Abhandlung von R.Kolarit in dem schon zitierten Band: Freisinger Denkmåler, München 1968. Auf die sprachliche Verwandtschaft der Fris mit dem Slovakischen weist Isačenko hin, Jazyk a povơd frisinských pamiatok, Bratislava 1943. 
5. Zum Vergleich wurden auch die slovenischen Dialekte herangezogen (KOLARIĆ, GRAFENAUER).'

6. Die kirchliche Terminologie von Fris ist im Hinblick auf ihre Kontinuitat in der slovenischen und slovakischen Sprache betrachtet worden (KOLARIČ, ISAČENKO). AuBerdem sind einige Termini auf ihre ursprünglichen lateinischen und griechischen Quellen zurückverfolgt worden (PIRCHEGGER, ISAČENKO) . 2

7. Uber einige Ausdrücke sind Einzelstudien angefertigt worden (GRIVEC). 3

Abgesehen von den Wortregistern ist die Lexik von Fris in den genannten Arbeiten meistens als das Argumentationsfeld für die jeweils verfochtene These benutzt worden; eine systematische, erschöpfende Behandlung des Wortschatzes ist nicht erfolgt. Daraus erhält die vorliegende Arbeit ihre Begründung. Da sie sich jedoch - durch den auberen Rahmen bestimmt - auf die Untersuchung des religiösen Wortschatzes beschränkt, stellt sie nur einen Teilbeitrag zur Lösung des Gesamtproblems dar.

Die altslavische christliche Terminologie hat bisher noch keine umfassende Darstellung gefunden. Im Jahre 1876 veröffentlichte F. MIKLOSICH seine sprachgeschichtliche Untersuchung unter dem Titel "Die christliche Terminologie der slavischen Sprachen" (in: Denkschriften der kaiserlichen Akademie der Wissenschaften. Philosophisch-historische classe XXIV. Wien 1876), für welche ihm das

1. Der Versuch, die gesamte Lexik von Fris als altslovenisch zu bestimmen, bedeutet einen Ausgriff in die ca 500 Jahre zurückliegende Vergangenheit. Mit Ausnahme der Klagenfurter Handschrift, die einen Einblick in den zustand der Sprache um 1400 gewahrt, liegt erst der Katechismus (Trubar) aus dem Jahre 1551 zum Vergleich vor. In solcher Lage ist es mehr als verlockend, auf das reiche Reservoir der einheimischen Dialekte zurückzugreifen. Das mundartliche Material stellt so etwas wie in die ramliche Ausdehnung projizierte Diachronie einer Sprache dar. Die bisherige dialektologische Beweisfuhrung (Kolarič, Grafenauer) kann nicht aberzeugen, denn, sollte die Dialektforschung in der historischen Lexikologie sinnvoll verwendet werden, so mabten bei der Erforschung einzelner Dialekte der typologische und der linguogeographische Aspekt genügend berucksichtigt werden. Erst dann konnten rekonstruierende Versuche in die Vergangenheit unternomen werden. Für ein solches Vorgehen fehlen jedoch die methodischen Voraussetzungen.

2. Vgl. S. Pirchegger, Untersuchungen über die altslovenischen Freisinger Denkmaler, Leipzig 1931.

3. Vgl. F.Grivec, Zarja stare slovenske književnosti, Ljubljana 1942; ders., o cerkvenoslovanskih prvinah $v$ drugem Frisinskem spomeniku, in: SR II, 1949, 126-137, ders., Frisingensia, in: SR III, 1950, 107-124; ders., Frisingensia, in: SR IV, 1951, 71-75, ders.. Frisingensia, in: SR VIII, 1955, 169182; ders.. Iz Cirilove književne šole, in: slovo 9 - 10, 1960, 5-13, ders.. Drugi frisinški spomenik in Cirilova književna sola, in GMS 22,1941, 106115. 
Buch von R. v. RAUMER "Die Einwirkung des Christentums auf die althochdeutsche Sprachen, Stuttgart 1845, als Vorbild diente. MIKLOSICHs Interesse richtet sich auf alle slavischen sprachen und berücksichtigt auch die altslavischen christlichen Termini. Viel Raum widmete dem christlichen Wortschatz V.JAGIĆ in seinem Buch "Entstehungsgeschichte der kirchenslavischen Sprache", Berlin ${ }^{2} 1913$. Sich auf MIKLOSICH stützend gab A.FRINTA eine Ubersicht über den tschechischen religiösen Wortschatz unter dem Titel "Náboženskê názvoslovi československén, Praha 1919. FRINTA berücksichtigt nur die wichtigsten christlichen Bezeichnungen, die Behandlung der altslavischen Termini geht über das von MIKLOSICH zusammengestellte Material nicht hinaus. Die polnische christliche Terminologie hat E. KLICH bearbeitet. Von den angekündigten drei Teilen, von denen der erste nur die Lehnworter erfast, in dem zweiten und drittem das innere Lehngut behandelt werden sollte, ist nur der erste Teil erschienen: "Polska terminologja chrześcijańska", Poznań 1927. In der jüngsten zeit hat J.ŠETKA zwei Bănde seines dreibändig geplanten Werkes herausgebracht: "Hrvatska krščanska terminologija", Bd. I, Šibenik 1940; Bd. II, Makarska 1964. Der erste Band ist den aus dem Griechischen entlehnten wörtern gewidmet, im zweiten sind die lateinischen Lehnwörter erfaBt. Die für den dritten Band angekündigte Behandlung des inneren Lehngutes liegt noch nicht vor.

AuBer den größeren Darstellungen wären noch einige Aufsătze zu nennen, die sich mit den Teilfragen aus dem Gebiet der christlichen Terminologie beschaftigen. Auch hier richtet sich das Hauptinteresse auf die Lehnwörter, wie z.B. im Aufsatz von R. RUDOLF "Die Bayernmission und die deutschen Lehnwörter in der slovakischen Kirchenterminologie", (in: Zfslph 18, 1942, 257-283) oder in der älteren Arbeit von P. SKOK "La terminologie chrétienne en slave: l'église, les prêtres et les fidèles". (1n: RES 7, 1927, 177-198).

Zum SchluB sei noch die einsam dastehende Monographie von F. BUSLAEV genannt "O vlijanii christianstva na slavjanskij jazyk. Opyt istorii jazyka po Ostromirovu evangeliju", Moskva 1848. Dieser zu Unrecht in Vergessenheit geratenen Abhandlung verdankt die vorliegende Arbeit manche wertvolle Anregung.

Technische Bemerkungen

Die $\mathrm{zitate}$ aus alten Texten werden in Originalform angefuhrt. Die behandelten Wörter werden in genormter Form wiedergegeben; die Schreibung richtet sich nach LLP. 
H a u t t e i l:

Untersuchung des christlich-religiósen Wortschatzes

I. Grundlegende Erläuterungen zur Gliederung des sprachlichen Lehngutes

Auf dem Gebiet der zwischensprachlichen Beziehungen war das wissenschaftliche Interesse bisher in erster Linie auf die Behandlung der Lehnwörter (= äußeres Lehngut) gerichtet. Das innere Lehngut ist erst später Gegenstand wissenschaftlicher Forschung geworden. Um eine sinnvolle Arbeit in diesem Bereich zu gewährleisten, war es notwendig, theoretische Voraussetzungen $z u$ schaffen. Das Verdienst, eine Terminologie zur Gliederung des gesamten Lehngutes entwickelt $z u$ haben, fällt $w$. BETz $z u$. In seiner bahnbrechenden Arbeit "Deutsch und Lateinisch", Bonn 1949, setzte er sich kritisch mit den vorhandenen Arbeiten auseinander, ordnete die gewonnenen Ergebnisse und faste die Terminologie der Lehngutforschung in ein festes System, das zur Grundlage für alle weiteren Arbeiten wurde. 1 Die dort aufgetauchten neuen Probleme gaben AnlaB zur weiteren Beschäfigung mit den theoretischen Fragen. Besonders gründlich hat sich $\mathrm{H}$. GNEUSs mit der Lehnguttheorie befaBt. ${ }^{2}$ Im AnschluB an BETZ hat er eine weitere Differenzierung des Lehngutes innerhalb der bestehenden Kategorien entwickelt. ${ }^{3}$ Eine besondere Beachtung verdient weiterhin E. COLEMAN durch ihren Aufsatz "zur Bestimmung und Klassifikation der wortentlehnungen im Althochdeutschen" ${ }^{4}$,

1. Ferner vgl. W.Betz, Der EinfluB des Lateinischen auf den althochdeutschen Sprachschatz. 1. Der Abrogans, Heidelberg 1936, ders., Lateinisch und Deutsch, in: Der Deutschunterricht 1, 1951, $22 \mathrm{ff}$. Weitere Arbeiten: E.Feist, Der religiose Wortschatz der ahd. Tatianubersetzung in seiner Abhangigkeit vom Latein der Vorlage. Studien zur Lehngutforschung, Freiburg 1953 (Diss. Maschinenschrift); M. Mehring, Die Lehnpragungen in Notkers tbersetzung der 'Nuptiae Philologiae et Mercuril' des Martinus Capella, Bonn 1957, B.0. Schwarz, Die Lehnbildungen der Notkerschen Psalmenubersetzung, Bonn 1957, L. Rittmayer, Untersuchungen zum Wortschatz der ahd. Isidor-Ubersetzung. Ein Beitrag zur Lehngutforschung, Freiburg 1958, K. Schutz, Die Lehnpragungen der Reichenauer Glossare Rb, Rc, Rd, Re und Rf, Bonn 1958, E. Coleman, Die Lehnbildungen in Notker Labeos Consolatio-Ubersetzung: Ein Beitrag zur Lehngutforschung, Barvard Univ. 1963, E. Luginbuhl, Studien zu Notkers Ubersetzungskunst, Bln.1970.

2. H. Gneuss, Lehnbildungen und Lehnbedeutungen in Altenglischen, Berlin 1954 .

3. A.a.0. 16-14. Dort auch weitere Literatur zur Lehngutforschung, s. 10-16.

4. In: Zeitschrift far deutsche Sprache 21, Heft 1/2, 1965, 70-83. 
in dem sie die Klassifikationssysteme von BETZ, GNEUSS und HAUGEN ${ }^{1}$ kritisch miteinander vergleicht und dann ihren eigenen vereinfachten Vorschlag unterbreitet.

In der slavistik ist auf diesem Gebiet wenig gearbeitet worden. Als erster unternahm es $\mathrm{K}$. SCHUMANN, das von BETZ entwickelte Ordnungssystem auf seine Elgnung im Bereich der slavischen Sprachen zu überprüfen, um, wie er sagt, "die Betzsche Einteilung zu erweitern und an einigen Punkten abzuändern". ${ }^{2}$ Das Neue, das er in die Diskussion bringt, ist der Aspekt des Typologischen innerhalb der Lehngutkategorien. AuBerdem wird von ihm die schon bei BETz vorhandene Trennung zwischen dem äuBeren und dem inneren Lehngut besonders betont. 3

Unter Berücksichtigung der genannten Arbeiten wurde versucht ein Ordnungssystem aufzustellen, das sich in der vorliegenden Arbeit praktisch anwenden lieBe. Im Gegensatz zu den germanistischen Arbeiten, die an Hand lateinischer Textvorlagen die Abhängigkeit des althochdeutschen wortschatzes von der lateinischen Sprache zu untersuchen haben, gibt es für die Freisinger Denkmäler keine lückenlosen Textvorlagen. Darüber hinaus haben auf die Bildung der altslavischen christlichen Terminologie drei Sprachen eingewirkt: Griechisch, Lateinisch und Althochdeutsch, und es gehört zu der Aufgabe der vorliegenden Arbeit, $2 u$ bestimmen, welche von diesen Sprachen an der Entstehung des religiösen wortschatzes der Freisinger Denkmäler beteiligt waren.

Ubereinstimmend mit der Ansicht von E. COLEMAN, daB "eine Uberklassifizierung und $z u$ feine Unterteilung des sprachlichen Lehngutes" im Althochdeutschen "sowie in den alten Dialekten überhaupt" vermieden werden muB, "weil man sonst aus Mangel an genügendem Beweismaterial Gefahr läuft, sich in hypothetischen spekulationen $z u$ verlieren" 4 wurde folgendes Schema zur Gliederung des Lehngutes ausgearbeitet:

1. E. Baugen, The Norvegian Language in America. A Study in Bilingual Behavior, Philadelphia 1953; ders., The Analysis of Linguistic Borrowing, in: Lg 26, 1950, 210-231; ders., Rezension zu Belmut Gneuss' Lehnbildungen und Lehnbedeutungen im Altenglischen, in: Lg 32, 1956, 761-766.

2. K. Schumann, Zur Typologie und Gliederung der Lehnprăgungen, in: $2 f s 1 \mathrm{Ph} 32$, 1965, 61-90.

3. Die direkten Entlehungen fremdsprachlichen Materials bezeichnet Schumann als Materialentlehnungen ( $=$ außeres Lehngut).

4. Vgl. E. Coleman, Zur Bestimmung der Wortentlehnungen im Althochdeutschen, in: Zeitschrift für deutsche Sprache 21 , Heft $1 / 2,1965$, S. 83. 
AuBeres Lehngut

Fremdwörter (Fw)

Lehnwörter (Lw)

\section{Inneres Lehngut}

Neubildungen

Lehnübersetzungen (Lüs)

Lehnübertragungen (Lut)

Eigenbildungen

(Ebi)

Umprägungen

Lehnumprăgungen (Lupg)

Eigenumprăgungen (Eupg)

AuBerhalb dieser.Einteilung werden als eine besondere Gruppe die Umschreibungen der christlichen Begriffe behandelt.

wie aus der schematischen Darstellung hervorgeht, läBt sich das gesamte sprachliche Lehngut ${ }^{1}$ in $a \mathrm{u}$ B $\mathrm{r}$ e $\mathrm{s}$ und $\mathrm{i} \mathrm{n} \mathrm{n}$ $r$ e $s$ e $h \mathrm{n} g \mathrm{t}$ aufgliedern. ${ }^{2}$ zum äuBeren Lehngut $z a ̈ h l e n$ alle Wörter, bei denen das Wortmaterial der fremden Sprache entlehnt wurde, daher werden sie auch "Materialentlehnungen" genannt. Hier ist die Scheidung zwischen dem "Fremdwort" und dem "Lehnwort" zu machen. Diese bezieht sich auf den Grad der auBeren Angleichung des fremden Wortes innerhalb des Wortschatzes der aufnehmenden Sprache. So sind diejenigen wörter als $F$ e $m d w o ̈ r t e r z u$ betrachten, deren Lautgestalt unverăndert geblieben ist, als $L$ e $h$ n $w r$ e $r$ sind alle diejenigen anzusehen, die ihre Lautgestalt unter dem EinfluB der aufnehmenden Sprache verändert haben. 3

Wăhrend das äuBere Lehngut nur neu erworbene wörter enthălt, läbt sich das innere Lehngut in zwei groBe Gruppen einteilen. 4 Die erste besteht aus $N$ e $u$ b 1 l d $u n g$ e $n, d . h$. aus neu entstandenen wortern, die sowohl durch den Gehalt als auch durch die Wortform etwas Neues für die Sprache darstellen. Als zweite Gruppe sind $U \mathrm{~m} p \mathrm{r}$ a $\mathrm{g} \mathrm{n} g \mathrm{e} \mathrm{n}$ zu nennen, die sich wesentlich dadurch von den Neubildungen unterscheiden, daB sie kein neues Wort-

1. Der Begriff "sprachliches Lehngut" wird in der Gegenuberstellung zum "spracheigenen Gut" am besten verstandlich (vgl. die oben zitierte Arbeit von K. Schumann, S.62).

2. Das "innere Sprachgut" faBt Betz unter der Bezeichnung "Lehnpragungen" zusammen, mit der Begrünung, dab es sich darin nicht un die Entlehnung des Wortmaterials handelt (Betz, 24,27). Diese von der Sache her gegebene Opposition veranlabt Schumann, die grundsdtzliche Trennung zwischen dem suberen (Materialentlehnungen) und inneren Lehngut vorzunehmen.

3. Vgl. Betz, 26.

4. Diese Einteilung nimmt Betz nicht vor. Für die vorliegende Arbeit erschien sie aber als vorteilhaft, da dadurch die Bereicherung des Wortschatzes unter dem fremden $E$ influB besonders klar erkenntlich wird. 
material in die Sprache hineintragen.

Die neu entstandenen Wörter lassen sich nach dem Grad der formalen Abhängigkeit von ihren sprachlichen Vorbildern in drei Gruppen einteilen, von denen als erste und allgemein bekannteste die $L$ e $h n$ u b e $r$ e $t z u n g$ e $n$ zu nennen sind. Danach folgen die $L$ e $h$ n $u$ e $r$ t $a g$ u $g$ e $n$ und als letztes die $E$ i g e $n$ b $i l d$ u $n g$ e $n$. Da im Verständnis dieser Kategorien keine Eindeutigkeit herrscht, ist es notwendig, sie genau zu charakterisieren, um einen Einblick in die Arbeitsmethode zu gewăren.

Mit $L$ e $h \mathrm{n}$ u $e \mathrm{~s}$ e $\mathrm{z}_{\mathrm{u}} \mathrm{g}$ wird eine Neubildung bezeichnet, die durch die genaue gliedweise Ubersetzung eines mehrgliederigen oder mehrteiligen fremdsprachlichen Vorbildes entstanden ist. 1 Dabei kann es sich um eine zusammensetzung aus zwei oder mehreren Wortstämmen handeln, eine zusammensetzung mit einem Präfix oder eine Worterweiterung mit einem Suffix vorliegen. Die Lehnübersetzung muB nicht notwendigerweise die Form eines einzelnen Wortes haben, sie kann aus der Verbindung von zwei Wörtern bestehen, wie das bei Adjektivkonstruktionen der Fall ist. 2 Das Wesentliche an der Lehnübersetzung ist, daB sie die Bedeutungen der einzelnen Elemente durch formal entsprechende Bedeutungstrăger in der nachbildenden Sprache wiedergibt. Die Verbindung der Einzelbedeutungen zur Bezeichnung eines neuen individuellen Begriffs ist das Bezeichnende an der Lehnübersetzung. In der vorliegenden Arbeit wird auch die Lehnwendung (Lehnübersetzung einer fremdsprachlichen Redewendung) $z u$ den Lehnübersetzungen gezăhlt.

Die $L$ e $h n$ u b e $r$ t $a g u n g$ ist eine freiere Abart der Lehnübersetzung. Die Nachbildung der einzelnen Wortglieder muB nicht formal adăquat sein. So kann für ein Kompositionsglied, das aus einem Wortstamm besteht, ein Suffix oder Präfix treten oder umgekehrt. Es kann ein mehrteiliger (aus mehreren Worten bestehender) fremdsprachlicher Ausdruck durch eine Wortzusammenziehung wiedergegeben werden, es kann aber auch der umgekehrte Vorgang eintreten (hierfür ist die struktur der sprache maBgebend). Es ist also ein Austausch zwischen den Wortkategorien (2.B. Substantiv in der Vorbildsprache, Adjektiv in der Nachbildsprache)

1. Nach Betz, 27. Vgl. auch Schumann, 62 .

2. Vgl. E. Feist, Der religiose Wortschatz der ahd. Tatianübersetzung .... 12. 164. Feist nennt solche zweiteligen worter "Lehnübersetzungen aus Lehnbedeutungen". 
bzw. zwischen den Wortbildungsmitteln (Wortstamm - Präfix - Suffix) zulăssig.

Die dritte Art der Neubildungen sind die $E$ i $g$ e $n$ b $i$ d u $n g$ e $n .^{1}$ Durch diese Bezeichnung soll zum Ausdruck gebracht werden, daB es sich dabei um eigenständige, formal unabhängige sprachliche Leistungen handelt. Die Nachahmung findet nicht im formalsprachlichen, sondern im geistigen Bereich statt. Für einen neuen, aus einem fremden Kultur- und Sprachgebiet importierten Begriff wird ein neues wort selbständig gebildet, ohne daB dabei ein fremdes sprachliches Vorbild nachgeprägt wird.

Die zweite grobe Gruppe des inneren Lehngutes bilden die U m p r ä $g$ u $n g$, schon vorhandene wörter (Erbwörter), welche neue Bedeutungen angenommen haben und im Laufe der zeit in ihrem ursprünglichen sinn nicht mehr gebraucht werden. Je nachdem ob für die Entlehnung der neuen Bedeutung der EinfluB eines fremden Vorbildes nachgewiesen werden kann oder ob der Bedeutungswandel d i $r$ e $k$ durch die Begegnung mit dem neuen christlichen Begriffsgut erfolgt, lassen sich die Umprägungen in $L \mathrm{e} n \mathrm{n} \mathrm{m}$ a $g u n g e n$ und $E i g e n u m g a ̈ g ~ n g e n$ aufteilen. ${ }^{2}$ Auf diese Unterscheidung machte TEEUWEN aufmerksam, indem er bei der Untersuchung des sprachlichen Bedeutungswandels im Latein des Tertullian auf lateinische wörter stieb, deren Bedeutung sich im christlichen sinne wandelte und zwar "unter dem EinfluB des Griechischen, wo das entsprechende wort den christlichen Sinn schon früher erhalten hatte". 3 Auch SCHUMANN spricht von "synonymer Lehnbedeutung": "Ein Wort der nachbildenden Sprache, das synonym mit einem Wort der Vorbildsprache ist, ubernimmt von diesem Wortvorbild die zweite Bedeutung" (Schumann, 67). Wăhrend TEEUWEN noch eine zweite Art Bedeutungswandel unterscheidet, der sich "direkt am lat. Worte selbst unter dem EinfluB des Christentums" vollzieht, steht diese Betrachtungsweise für schumaNN auBerhalb der philologisch-sprachlichen Fragestellung (Schumann, 67).

1. Betz nennt diese Art Entlehnungen "Lehnschópfungen". Schumann kritisiert die Betzsche Auffassung. Seiner Ansicht nach gehoren die Lehnschopfungen nicht zum sprachlichen Lehngut (Schumann, 66), da kein sprachliches Vorbild nachgeprăgt wird. Gneuss weist auf die ${ }^{1}$ schwierigkeit hin, die Lehnschópfungen in den alten Dialekten aufzudecken, da man nicht den Nachweis erbringen kann, daB das in Frage kommende Wort vor der Christianisierung und vor Beginn der schriftlichen Uberlieferung noch nicht vorhanden war. Dieses trifft für die vorliegende Arbeit auch $2 u$.

2. Vgl. Schumann, 67: "bel der Lehnbedeutung exfahrt der Bedeutungsinhalt des Wortes eine Erweiterung nach fremdem Muster".

3. Vgl. Teeuwen 21 . 
Aus verschiedenen Gründen bereitet die Einordnung der wörter in diese beiden Gruppen groBe Schwierigkeiten. Oft verlaufen die Bedeutungsentwicklungen in verschiedenen Sprachen parallel zueinander, ohne daß Abhängigkeiten nachgewiesen werden können. Dazu komut, das jede Umprăgung als eine durch Analogie hervorgerufene Erscheinung anzusehen ist. AuBerdem muBten in dieser Gruppe alle diejenigen wörter zusammengefast werden, die das Christentum verwendet, um den neuen Begriffsinhalten eine passende Bezeichnung $z u$ geben. In dieser frühen Entwicklungsstufe ist es jedoch schwierig, gelegentliche Wortverwendungen von echten Umprägungen $z u$ trennen. Die in den Dienst der christlichen Aussage übernommenen Wörter können einen Bedeutungswandel erfahren, d.h. sie können ganz oder zum Teil ihre bisherige semantische position zugunsten einer neuen verlieren - dieses wiederum in einem kurz oder lang andauernden ProzeB -, es kann sich aber auch lediglich um eine Anwendungsweise handeln, die über den figürlichen Gebrauch des wortes nicht hinausgeht. Deshalb schwanken die in der Gruppe $U$ m p $r$ a $\mathrm{g} u \mathrm{n} g$ e $\mathrm{n}$ zusammengefaßten wörter von der ubertragenden bis zur prägnanten Verwendung, von der einmaligen Anwendung bis zur durch den häufigen Gebrauch bedingten terminologischen Festigung. 
II. Wortuntersuchungen

A. $\AA$ u $B$ e $r$ e $s$ e $h n g u t$

\section{Fremdwörter}

a $m e n$ ist eine aus dem Hebräischen durch die Vermittlung des Griechischen in alle Sprachen übernommene liturgische Formel, die gewöhnlich am SchluB der Liturgie von der Gemeinde gesprochen wird. Ihre Bedeutung ist 'wahrlich, gewiB' (Bauer 90). Die Lautgestalt des hebräischen wortes blieb im griech. autv und lat. amen unverändert und so erscheint sie auch in Fris. Im Altslavischen ist die Form aminb und aminb weit häufiger belegt, amen kommt nur noch in CanMis und Clem vor (LLP I, 31).

8 a $n$ c $t u s$ adj. 'heilig'. Eine Besonderheit in der asl. Literatur ist der in nur zwel asl. Denkmälern vorkommende Latinismus sant ${ }^{1}$ und das als sigel $s \bar{c} e$ und $s \bar{c} 0$ vertretene lat. sanctus in Fris III. Das asl. Wort für 'heilig' ist svetb.

\section{Lehnwörter}

Die Lehnworter werden nicht ausführlich behandelt, weil uber sie schon zahlreiche, erschopfende Untersuchungen vorliegen. 2 Danach sind alle in Fris vorkommenden Lehnwörter nachgewiesenermaBen $v \circ r l i t$ e $r$ a $i s c h$ e Entlehnungen. Nachstehend werden sie mit den notwendigsten Angaben versehen vollständigkeitshalber aufgeführt.

$c \check{e} s a r$ b $s \quad t \quad v \quad n$. 'Königreich' bezeichnet das 'Reich Gottes', das im NT als "eine räumliche und gleichzeitig dynamische Grobe

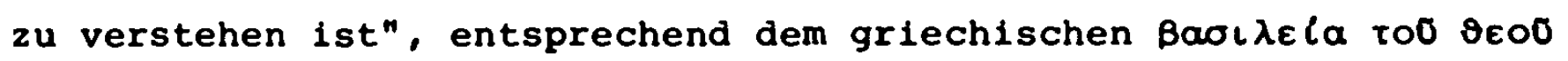
(HthG II, 414). Das in diesem Sinne sehr oft im Asl. belegte Abstraktum ist aus dem Lehnwort č̌sarb 'König, Herrscher' und dem einheimischen suffix - stvo gebildet. ${ }^{3}$ Das Wort č̌sars geht auf das lat. caesar zurück und wurde durch die gotische Vermittlung von

1. Vgl. Sobolevskij, 167. ocontb kommt nur einmal in Sav vor und findet sich auBerdem in "Tolkovanije na Apokalipsisb", erhalten in mehreren Handschriften, eine davon aus dem 14. Jahrhundert.

2. AuBer den etywologischen wörterbüchern sind noch zu nennen: Stender-Petersen, Slavisch-germanische Lehnwortkunde, Goteborg 1927; Kiparsky, Die gemeinslavischen Lehnwöter aus dem Germanischen, Helsinki 1934.

3. Vg1. Gneuss 43. Gneuss faBt solche Wortbildungen unter "hybride Lehnbildungen" zusammen. 
kaisar in das Slavische ubernommen (Stender-Petersen 351-353; Kiparsky 194). Als Synonyme für den Begriff 'Reich Gottes' wăren noch - auBer der lexikalischen Variante oésarbstvije n. - bogatbstvo n. , nebo n. , rai m. slava božija f. zu nennen.

$c r b k$ y f. 'Kirche' kommt in Fris II als Bezeichnung des Gotteshauses vor. Das wort geht auf griech. nupl(a) nobv 'dem Herrn gehörige' zurück. ${ }^{1}$ An der griechischen Herkunft des asl. Wortes crbky besteht kein zweifel, schwierig ist jedoch die Frage nach dem Weg, auf dem es in die asl. Sprache aufgenommen wurde. Bei kaum einem anderen wort ist daher so oft der Versuch gemacht worden, seine Herkunft zu erklären, wie bei crbky. 2

Andere Bezeichnungen für 'Kirche' in der Bedeutung 'Gotteshaus' sind: doms božii m., domb gospodsnb m., domb molitvbnyi m. kostelb m., chramb (božii) m.

$k r$ s $s t^{b}$, 'Christus'. $^{3}$ Die lexikalische Ausformung des Wortes für 'Christus' stellt ein Problem für sich dar. Es kommt in Fris in folgenden Formen vor: dat.sg. I,3 creztu; nom.sg. II,89 cruz; voc.sg. III,67 CriBte. Die Worte weichen in der Schreibung und Lautung voneinander ab. Die Ansichten der Forscher divergieren sowohl in Bezug auf die Herkunft des Wortes (got., ahd., lat.) als auch auf seine Bedeutung in Fris. 4

Im Altslavischen bleibt xploros gewöhnlich unübersetzt und lautet christosb, chrostosb, christb, chrbstb, wenn es nicht gekürzt geschrieben wird. AuBerdem tritt auch die Ubersetzung des griech. Wortes auf: pomazanb, pomazanikb, 'der Gesalbte' (Jagić Entst 322). Krostb stellt als Bezeichnung für 'Christus' ein hapax legomenon dar.

1. Vgl. Masser $24 \mathrm{ff}$, Stender-Petersen 424-428; Kiparsky 244-247; G. Gunnarson, Das slavische Wort für Kirche, in: Uppsala Universitets Ársskrift 7, 1937; K.H. Menges, Wieder einmal zum slavischen Wort für "Kirche", in: Orbis scriptus, München 1966, 544-545.

2. Einen Uberblick uber die überaus unfangreiche Literatur zu orbky gibt Gunnarsson, a.a.0., S. $6 \mathrm{ff}$. In der Diskussion uber die Herkunft des Wortes haben sich verschiedene Schulen herausgebildet und zwar für Entlehnung aus dem Griechischen unmittelbar und für Entlehungen: aus dem Gotischen, Westgermanischen, Altniederdeutschen, Althochdeutschen und Altbairischen.

3. Mit Stender-Petersen 420: "Das westgerm.-ahd. Krist, das daraus vielleicht entlehnte an. Krist gehen sicher auf ein got. Xristus $=$ Kristus mit gekürtem $i$ zurück. Auf dieses wort geht auch zweifellos das slav. Krbsto mit der spater verwischten, ursprünglichen Bedeutung 'Christus' zurück."

4. Vgl. Kiparsky 234 ff. ; Stender-Petersen 419 ff., Berneker I, 634; Vasmer II, 661 etc. Die jedesmal andere lexikalische Form des Wortes und die Móglichkeit, es als homonym mit 'Taufe' und 'Kreuz' anzusehen, hat $z$ u versch. Deu-

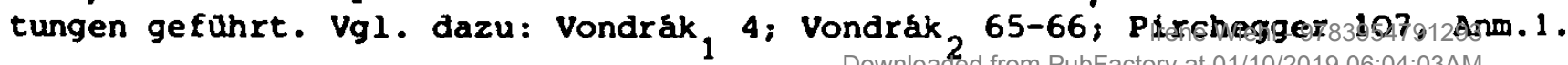




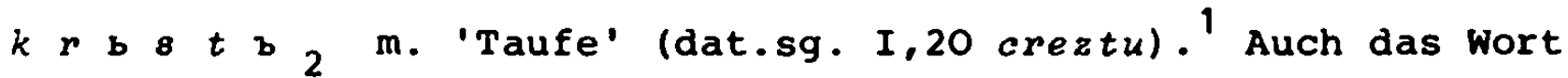
krbst' in der Bedeutung 'Taufe' stellt in der asl. Literatur ein hapax legomenon dar; dafür wird sonst krbštenije n. gebraucht (LLP I, 79).

$k r b 8 t i t i$ ipf. und pf. 'taufen' ist durch part.prat.pass. m.nom.sg. in I,13 crikken und in III,40 xpen vertreten. Das Verb wird von den meisten Forschern für eine denominative Bildung zu krbstb 'Kreuz' gehalten. 2 Die Möglichkeit einer selbständigen Entlehnung aus dem mhd. kristen, kristenen, ahd. "khristjan (?) 'zum Christen machen' wird meistens abgelehnt. 3

$p 0 s t_{b} \mathrm{~m}$. 'Fasten'. Die Bedeutung des wortes postz geht uber das bloBe Fasten im gewornlichen Sinne hinaus. Es handelt sich un die kirchliche strafe, die dem büBenden sünder auferlegt wurde. In dem Beichttext des Euch wird sie als pokaanbny postb $(69 \mathrm{~b}$ 7-8) beschrieben. In demselben sinne wird das Wort auch in der anonymen Homilie des Clozianus (Cloz 106, Dostál-Ausgabe S.134) gebraucht, wie es VAŠICA gezeigt hat. ${ }^{4}$ Da die auferlegte strafe BuBe - vorwiegend aus Fasten bestand, werden die Ausdrucke 'büBen' und 'fasten' gegeneinander ausgetauscht. So erscheint $2 . B$. in "Zapovedi sv. otbcb" (Euch 102a - 105b) abwechselnd da pokaaetb 8 e mit da postitb of. Je nach Schwere des Vergehens (= Sünde) wurden verschieden lange und verschieden strenge "Fasten" auferlegt. Es hat sich das BuBstufenwesen entwickelt, welches in zahlreichen detaillierten BuBbestimmungen, den Poenitentlalbüchern seinen Ausdruck fand. 5

KIPARSKY hält postb für eine Entlehnung des ahd. fasto (Kiparsky 261-262). STENDER-PETERSEN führt es auf got. "fasta zuruck (Stender-Petersen 431-432). So gehen auch bei diesem Lehnwort die Meinungen der Forscher auseinander.

Grivec, 14; Vondrak, 70 (Index).

1. Uber die Entwicklung der Bedeutung des Wortes krbotb zu 'Taufe' vgl. Klparsky $325 \mathrm{ff}$.; Stender-Petersen 421-422, LLP I, 79. Anders Machek 300. Er halt es für Deverbativum von krbstiti.

2. Vgl. dazu Machek 300 . Auf jeden Fall gehort krbstiti zu der Kategorie der Lehnworter, - nach Gneuss 43 "hybride Lehnbildungen".

3. Vgl. Vasmer II, 662; Kiparsky $234 \mathrm{ff}$., Stender-Petersen $421 \mathrm{ff}$. und Machek 300 .

4. Vgl. Vašica, Anonymni homilie rukopisu clozova po strunce právni, in: Slavia 25, 1956, 221-233.

5. Hier sei die Monographie von J. Grotz S.J. exwahnt: Die Entwicklung des BuBstufenwesens in der vornicanischen Kirche, Freiburg 1955. 
Für 'Fasten' hat das Asl. auch noch andere Bezeichnungen. AuBer der Wortbildungsvariante poštenije n. ist alčbba f. und alkanije n. bekannt.

$s$ o $\circ n i n b$ adj. poss. 'des Teufels' (eigentlich 'des Satans')

ist von dem Substantiv sotona m., das auf griech. Earavãs zurückgeht, abgeleitet. In der Entlehnungsfrage dieses Wortes ist wie bel den vorhergehenden keine Ubereinstimmung erreicht worden. Für eine alte Entlehnung aus griech. Earavãs, das im hebr. has $8 a \underline{t a n}$ seinen Ursprung hat, spricht sich VASMER aus (Vasmer III, 583). Diese Ansicht vertritt auch KIPARSKY (Kiparsky 130), während STENDER-PETERSEN (Stender-Petersen 430) seine gotische These verteidigt.

Uber andere Teufelsbezeichnungen s.u. unter neprijazninz. 
B. I $n n$ e $r$ e $s$ L $h n g u t$

1. Neubildungen

a. Lehnübersetzungen

$\check{c}$ b $8 t i \quad p \quad i j e m$ b ist eine syntaktische Lehnkonstruktion nach der ahd. Formel minne trinkan, "einen Abschiedstrunk mit einem teilen, als Zeichen des Verbundenseins auch nach der Trennung. Es wurde vorzüglich Johannis minne getrunken, gesegnet. 1 ...'doch wollen wir ... sand Johanns minne trinken' (fastn.sp. 860,12)" (Grimm DW VI ${ }^{\prime}$ 2239-40). Auch "Gertruden minne" (die hl. Gertrudis von Nivelle +654) war bekannt: "ze hant truog er im dô ze heiles gewinne sant Gêrtrûte minne" (Grimm DW IV ${ }^{\prime}$, 2239-40). Asl. čbstb f. bedeutet 'Ehre, Verehrung' in der Allgemeinsprache; christianisiert wird es als Ausdruck für solemnitas, natalitia, festivitas gebraucht und konkurriert als solcher mit pamętb $f$. 'Andenken, Gedächtnis, Erinnerung'2, prazdbnikb m. 'Fest, Feiertag, Gedächtnisfeier'. 3 In der entlehnten Redewendung (Lehnwendung) kommt es in Pluralform vor, denn es handelt sich um Gedächtnisfeier verschiedener Heiliger (ichb ist gen.pl. und bezieht sich auf Heilige). Pijemb entspricht genau dem altdeutschen trinkan in 1.pl. Einen kulturgeschichtlichen Kommentar $2 u$ diesem Ausdruck gab GRIVEC (Grivec, 107-114), doch der Satz "zeBtich pigem" gab grammat1kalisch und vom Sinn her Rätsel auf, und wurde verschieden gedeutet. Unbeachtet blieb in der jüngsten Diskussion die AuBerung BuSLAEVs (120). Er weist auf germanische heidnische Sitten hin, in denen man zu Ehren der Götter trank, was minni hieB. Nach der Annahme des Christentums wurde minni ein christlicher Begriff und man trank Krists minni, Michaels minni (Buslaev 120). Demgemä $B$ wird diese sitte im christlichen sinne in den Freisinger Denkmälern beschrieben als "zeBti ich pigem" (Buslaev 120)."

1. Năheres über "sanct Johannis minne" s. unter 'Johannes' Grima DW VI ${ }_{2}, 2333$

2. 'Erinnerung' ist auch die Bedeutung für minne im Althochdeutschen.

3. In Bes $37,285 a B$ 16: $i$ vb to dnb çbsti - atque ipso die natalitio (1), Bes 26,137aa 13-14: se velikago dñe čbsti prazdonujemb Ecce Paschalia solemnia agimus (Arch LLP). Auch in Kij VIb steht čbstb für lat. solemnitas, natalitia: Mócenikb tvoiohb $\vec{G}$. çbsti čbstjece molimb tje prosjece.

4. Die Sitte des Trinkens war auch den heidnischen slaven bekannt. Sie spielte im Totenkult eine besondere Rolle. Vgl. darüber Kotljarevskif 247. Aus zahlrelchen Quellen flieBen die Nachrichten, daB der slavische heidnische Beerdigungsritus vom feierlichen Mahl und Trinken begleitet war (ders. 216). In čbsti pijemb wird es sich um Feiern handeln, die aus dem Bestreben, die alten heidnischen Sitten mit neuem christlichen Inhalt zu füllen, erwachsen sind. Zugleich konnte dem zurückfallen in das heidnische Brauchtumgentgegen- 
Es handelt sich demnach um einen Germanismus, der in keinem der erhaltenen slavischen Denkmäler Nachahmung fand.

$g r \check{e} \check{s}$ b $n i k b \mathrm{~m}$. 'Sünder' ist eine Neubildung mit dem christianisierten stamm grěchb 'sünde' (s.u. unter grěchb). Es setzt sich aus der Adjektivbasis grěšn- und dem nomenbildenden suffix $-i k b$ zusammen. Während das Griechische für den Begriff des sündigen Menschen das Adjektiv duap $\tau \omega \lambda \delta_{6}$ gebraucht, ist im Ahd. die Adjektivform (später substantiviert) suntig beherrschend. ' Nach GRIMM ist die Substantivbildung sundâre auf den Glossator Notkers beschränkt, das (substantivierte) Adjektiv bis in die Mitte des 12. Jh.s allgemein im Gebrauch. ${ }^{2}$ Für die slavische Neubildung grěšbnikb kann daher nur das lat. peccator als sprachliches Vorbild angenommen werden. ${ }^{3}$ Neben dem nomen agentis findet auch das Adjektiv grěšsn in der asl. Literatur hăufige Verwendung. Wie im Ahd. wird es auch substantiviert und gibt sowohl das griech.

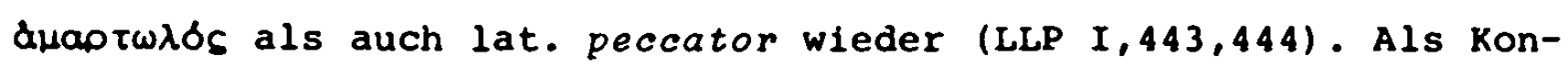
kurrenzwörter für den christlichen Begriff des sündigen Menschen können bezakonbnikb $\mathrm{m}$. und zakonoprěstqpbnikb $\mathrm{m}$. genannt werden. Beide bringen den Aspekt der Verletzung des göttlichen Gesetzes zum Ausdruck, haben aber ăhnlich wie die lat. Wortgruppe delinquere, delictum, deliquens keine terminologische Prăgnanz erfahren. 4 Diese erwarb vielmehr das Wort grěšnikъ, das wie peccator nicht nur auf eine vorübergehende Handlung anspielt, sondern die Lage, den zustand des sündigen Menschen bezeichnet (Teeuwen 18,88). $l i c h o d \check{e} j a n i j e n$. ist eine Lehnübersetzung des ahd. missatat, das auf got. missadeps (= delictum) zurückgeht, und terminologisch ein unfestes Bild zeigt. 5 Dieses wird auch durch die bairischen Beichten bestatigt. Einmal steht missatati in Verbindung mit sunta, das andere Mal aber allein anstelle von sunta:

gewirkt werden. Bezeichnenderweise wird der Todestag des Heiligen gefeiert! 1. Vgl. Schmoller 31; Bauer 87; LLP I,444.

2. Vgl. Grimm $D W x_{4}$, 1158; Steinmeyer 311 : "min suntigun ... scalh dinan ... suntikemo ... dínemo scalhe" XIII, A. 1-18; Steinmeyer 314: "dir uuirdo in suntigo pigihtic" XLIII, 1 .

3. Die Entstehung solcher nomina agentis hat zur Voraussetzung, dab das betreffende Verbum in einer Sondersprache eine spezielle Bedeutung erhalten hat, so grěěiti 'sündigen' - grěšnikb 'süner', peccare - peccator; annlich verhalt es sich mit lat. creare 'erschaffen' - creator 'schopfer'; confiteri 'bekennen' - confes8or 'Bekennex'. Vgl. daruber Teeuwen 88 u. FuBn.2, S.88.

4. Vgl. Teeuwen 71: "Deliction (delinquere) war neben peccation, peccare der geláufige Ausdruck für 'Sünde'. 'sündigen'; davon die Neubildung delinquentia fúr 'Sünde' oder 'sūndiger zustand' und vereinzelt delinquentee statt pecca-

5. Vgl. Reiffenstein 36, ferner Eggers 2138 .

Irene Wiehl - 9783954tartas. " 
"allero minero suntiono enti missatatio" (Steinmeyer 309, XLI, 1-2); "daz in in desaro uueralti minero missatato riun" (Steinmeyer 310, XLII, B. 19-20). Nach REIFFENSTEIN ist der Gebrauch von missatat vor allem auf den sưden beschränkt, seine Bedeutung jedoch nicht mit delictum begrenzt (37). Das LLP gibt für lichodějanije 'Missetat, schlechtes Handeln' als Bedeutung an $(I, 126)$. Es kommt nur in Fris III vor, wodurch die starke Abhängigkeit dieses Denkmals von seiner altdeutschen Vorlage sichtbar wird. Lichodĕjanije tritt als Allgemeinbegriff für Sünden und Delikte auf, und seine Bedeutung kann wie im Ahd. nicht eingeengt werden; es rückt in die begriffliche Năhe von 'Sünde'. Als eine bedeutungsmäBige Entsprechung kann die in Fris II enthaltene Umschreibung děla sotonina 'Teufelswerke' angesehen werden. Das erste Glied des lehnübersetzten Kompositums $2 i c h o-$ ist die Entsprechung des ahd. mis8a-. Aus den zahlreichen asl. Zicho-zusammensetzungen ergeben sich für licho- hauptsächlich zwei Bedeutungen: 'übermäBig' und 'schlecht' (LLP I, 125-128). Das entspricht nur tellweise der Bedeutungsbreite des ahd. missa-, das "eine ansehnliche Bedeutungsvielfalt aufweist (Richter 314-315). Hier kommen noch die Bedeutungen 'zahlreich, mannigfaltig, feindlich, verkehrt' hinzu. Dem zweiten Kompositumteil, dem ahd. -tat entspricht-dějanije und unterscheidet sich damit von der Ubersetzung des Euch $72 \mathrm{a} 7$ licha sbtvorenije für dasselbe ahd. Wort. ${ }^{1}$ Eine andere lexikalische Variante stellt zblodějanije $n$. dar (LLP I,687). AuBer in Fris lassen sich für $l_{i-}$ chodějanije keine weiteren Belege finden, es stellt somit ein hapax legomenon dar.

$m e \check{c} e n i k b \mathrm{~m}$. ist eine-Neubildung auf dem christianisierten Stamm des Wortes mqka f. 'Marter'(lat. passio), die in Parallele zu ahd. martyr m. zu sehen 1st: 'der, welcher das Leid auf sich nahm, der gemartert (mqčiti ipf. = martern, quälen) wurde um christi willen'. Der ahd. Ausdruck für 'Mărtyrer' martyr, entlehnt über das gleichlautende lat. martyr, martyres 'die Blutzeugen des Glaubens' aus dem griech. Ldorus (zeuge), mag zur Entstehung des asl. mečenikb verholfen haben (Mikl Term 12). Uber ahd. martyr schreibt RAUMER: "Aus dem Begriff der Leiden, die der christliche Blutzeuge zu erdulden hatte, entwickelt sich dann weiter das Verbum martaron, ... (Subst) martyra f. ..." (293). Die slavische Wortbilaung

1. Daran tritt es $k$ lar zutage, daB an diesen beiden Denkmalern verschiedene "Ubersetzer" am Werke waren. 
mqěenikz zeigt einen ähnlichen Gedankenweg. Sie erfolgte aus dem part.prät.pass. mgčens - Suffix -ikъ. ${ }^{1}$ Weder das lat. Wort oonfes$80 r$, das vorübergehend die Bedeutung 'Märtyrer' hatte (Rheinfelder, 60), noch griech. Lúptus, dem asl. sbvědětelb $\mathrm{m}$. (=Zeuge) entspricht, können als sprachliche Vorbilder für die slavische Bildung angesehen werden. Als Ubertragungen aus dem Griech. lassen sich zwei andere Märtyrerbezeichnungen der asl. Literatur erklären: strastonosbcb $\mathrm{m}$. für ådoxpoos und strastotrbpbcb $\mathrm{m}$. für a $\theta \lambda$ ins. Die lexikalische variante strastbnikb $\mathrm{m}$. (aus strastb f. = moka f.) kann aber zu močenikb in Parallele gesetzt werden. ${ }^{2}$ o $t b p 4 s t$ b $k b \mathrm{~m}$. aus otbpustitipf. (otb-pust + bkb) 'freilassen, entlassen', das zum Terminus für 'Sünden nachlassen, sünden vergeben' wurde, ist als Entsprechung für lat. remissio, ahd. $a b l \delta z \mathrm{~m}$. entstanden. ${ }^{3}$ ob bei dieser Neubildung das lateinische oder das altdeutsche Wort als Vorbild diente, ist schwer zu sagen. Mit Rücksicht auf das Genus kann angenommen werden, daB es auf ahd. $a b l \hat{a}_{z} \mathrm{~m}$. zurückgeht, wăhrend seine Wortbildungsvariante otbpuštenije n. das griech. ópeols (=Frellassung, Vergebung) zum Vorbild hat. 4

Wie so viele in den Dienst der christlichen Lehre hineingenommene wörter hat ursprünglich auch otrpustiti und otbpuštenije im Rechtsleben einen Platz gehabt und behalten. Z.B. In Mar LK 4, 19: plenbnikomb otbpuštenije ... otъpustitъ şkrušenyje vъ otъra$d e .{ }^{5}$ Auch bel SREznevsKIJ sind einige Beispiele für den rechtssprachlichen Gebrauch der Wortsippe otbpustiti zu finden: A ćto zakladnikovb vb Trržbku ili inde..., otpusti ich pró̆b. Dog. gr. Novg. ... ok. $1307 \mathrm{g.;}$ plenbnymb že viemb podastb otpustb Gref. 1260 g. (Srezn II, 808). Es geht hier um Freilassung der Geiseln, bzw. Kriegsgefangenen, kann aber auch andere im Sklavenverhältnis befindliche Personen betreffen. ${ }^{6}$ In der neuen christianisier-

1. Vgl. Nikolić 70. Ferner Čech 174-181.

2. Bei Mikl LP 889; Daničić III,183; Nikolic $56,68,71,79$.

3. Vgl. Vgl. Graff II,315. Vgl. auch Steinmeyer 341 : "unde an déro keglchte so pito hich ablazes allero minero sundeno" LIV,21-22 (Sangaller Glauben und Beichte I.

4. Die griech. femininen nomina actionis haben im Asl. Neutra auf -ije als hău-

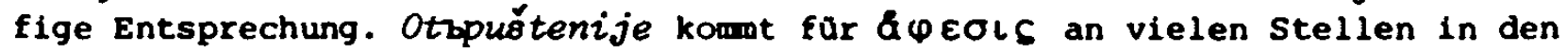
Evangelientexten vor, 2.B. Zogr Mk 1,4; LK 1,77; Sav Mk 1,4; Ostr Mk 1,4; As Ik 24,47. Die Stellenangaben sind aus Arch LLP.

5. Ebenso in As, Ostr, Sav an der gleichen Stelle (Arch LLP).

6. Vgl. dazu auch Saturnik 25. 
ten Bedeutung hat das Altrussische sowohl otbpustbkb m. als auch otspustъ $\mathrm{m}$. neben dem häufigen otъpuštenije $\mathrm{n}$. im Gebrauch: otbpustb dažb mi Christe, grěchovb moichbstichir.Novg. d. $1163 \mathrm{~g} \cdot ;$ otъpustbkъmb gréchovъ svobodi dušu jego otb muky věčbnyja Sbor. XIV v. (Srezn II,809). Die Tatsache, daB die Wortbildungsvariante otbpustbkb nur im christlichen sinne belegt ist, läBt darauf schlieBen, daB es sich um eine aus dem Altslavischen übernommene Neubildung handelt. Von dem einzigen Beleg im Altrussischen abgesehen, stellt otbpustbkb in der asl. Literatur ein hapax legomenon dar. Beherrschend ist die Form otbpužtenije für griech. Gueoıs. lat. remissio, und daneben sind noch otbdanije n., ostavljenije n., razdrěšenije $n$., oţrada $\mathrm{f}$. als weitere lexikalische Varianten für 'Vergebung, NachlaB' (der sünden) gebräuchlich. Besonders erwähnenswert ist der Ausdruck nepogonjenije n., die Negation des pogonjenije n., eines aus der Rechtspraxis stammenden wortes für 'gerichtliche Verfolgung' in Supr $3439024:$ vbzbmati otb njego nepogonjenije grěchovb našichb.(Arch LLP). Mit 'Nichtverfolgung' wird 'Vergebung, NachlaB der Sünden' ausgedrückt.'

$s$ b $p a s i t e l$ b $m$. 'Heiland, Erhalter, Erlöser' kann auch im absoluten Sinne für Gott stehen. Als Ableitung von sbpasti pf.'erhalten, erlösen, retten' $\delta b+p a s+-i t e l_{b}$ (Nikolíc 49) vermehrt es die Reihe der aus dem christianisierten stamm entstandenen Neubildungen. Als nomen agentis ist es in der Parallele zu griech.

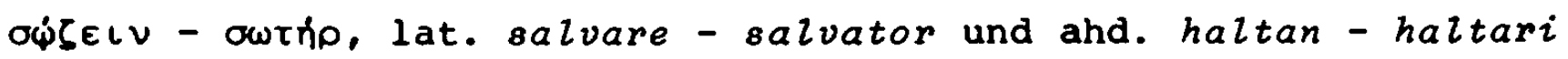
$z u$ sehen (Raumer 358). In dieser wie in vielen anderen wortbildungen tritt die indogermanische sprachverwandtschaft zutage, die sich nicht nur auf die Verwandtschaft der Laute und Flexionsformen beschränkt, sondern sich auch in der Gemeinsamkeit der Bezeichnungstechnik offenbart. Da sbpasite $l_{b}$ nur für Christus ${ }^{2}$ belegt ist, scheint es so gut wie sicher, dab es sich un eine Nachbildung handelt, obwohl es morphologisch natürlich auch ohne fremden ElnfluB entstanden sein könnte. Wenn aus der sprache kein zwingendes

1. Das Beispiel nepogorenije macht es besonders anschaulich, wie sehr die christliche BuBterminologie mit dem Rechtsdenken verbunden ist. Darüber hinaus kann der Gebrauch eines in einem bestimmten Gebiet bekannten Rechtsausdruckes wertvolle wortgeographische Hinweise liefern. Vgl. dazu Jireček HSSP 252 unter pohon, das als bohmisch und mahrisch bekannt ist.

2. Vgl. Srezn III,787. Aufgrund des reichen Wortmaterials Arch LIP kann mit Sicherheit behauptet werden, daB sbpasitelb nur für Christus gebraucht wird. Daničic III,248 führt nur sspasb m. an. 
Argument für eine Lehnübersetzung geliefert werden kann, so sprechen die Missionstatsachen für eine Nachahmung; das slavische volk war das empfangende. ' So wird sbpasite $l_{b}$ in der Gruppe der Lehnübersetzungen aufgeführt, in der es mit den anderen Ableitungen eine Sondergruppe bildet.

Uber die enge Verwandtschaft von szpasti u. sbpasati mit dem ahd. haltan s.u. unter szpasenije.

AuBer der Form szpasitelb ist der Gebrauch von 8 bpasb $m$ in der asl. Literatur verbreitet. ${ }^{2}$ Als weitere Varianten sind izbavitelb, izbavbnikb, izdrěšitels, icělitelb zu nennen.

$8 v \& t y i d u c h b$ m. ist die Bezeichnung der dritten göttlichen Person 'Heiliger Geist'. In diesem Sinne stellt es eine lexikalische Einheit dar, die aus dem Adjektiv svetyi 'heilig' und dem Substantiv duchb $\mathrm{m}$. 'Geist' besteht. Asl. duchb, ursl. *dbchb (diese Form auch im Asl. erhalten) geht auf idg. *dhous- zur Basis dheunes (lit. daũsos pl. 'Luft', ablautend dvãse 'Geist', dvêssti 'atmen') zurück. ${ }^{3}$ Aus der Verwendung des Wortes duchb in den asl. Texten ergeben sich folgende Bedeutungen: 'Wind, Atem, Hauch, körperloser Geist, geistige Stärke des Menschen' und in der Verbindung mit dem Prädikat svętyi 'Heiliger Geist' (LLP I,527). Alle diese Bedeutungen enthielt auch das lat. spiritus, welches dem griech. rveüHa folgte und letztlich auf hebr. ruach zurückgeht (Betz 2 48). Als ererbt können mit sicherheit die drei ersten Bedeutungen angesehen werden: 'Wind, Atem, Hauch'. Ob es erst unter dem EinfluB der christlichen Literatur bzw. des christlichen Gedankengutes zur Bereicherung der ursprünglichen Bedeutung um die genannten anthropologisch-psychologischen Sinngehalte kam, oder ob das Altslavische diesen Gebrauch schon vorher kannte, ist schwer zu entscheiden. Nach BuSLAEV standen die mythologischen

1. Stender-Petersen 71 weist auf die Notwendigkeit hin, bei den Lehnwortuntersuchungen nicht nur sprachliche Rücksichten zu nehmen, sondern auch kulturgeschichtliche Betrachtungen $z u$ Worte kommen $z u$ lassen.

2. Nach Buslaev 123 ist das Motiv zur Entstehung der Form 8bpasitelb im Gebrauch von szpass m. für owtho u. OWtnoi $\alpha$ zu suchen. zur besseren Unterscheidung sei es notwendig geworden, ein Wort mit einem anderen Suffix zu bilden. Die Praxis, sowohl supasitelb als auch sbpasb innerhalb eines Textes für den Erloserbegriff zu gebrauchen, laBt diesen Schlub zweifelhaft erscheinen. In Bes koment 2.B. 4 × 8zpasb gegenúber $9 \times 8$ spasitelb vor, wobei supasb $3 \times$ für Jesus und $1 \times$ für Redemptor steht.

3. Vgl. Pokorny I,268-270; Berneker 235; Vasmer I, 383; Fraenkel wo I,115; Frinta 20. 
Vorstellungen bei den Slaven in der vorchristlichen zeit mit dem Wort duchb in Verbindung (66). Die christliche Literatur brachte eine genauere Bestimmung ethischer Begriffe und seelischer Eigenschaften. Darin kommen die Worte duchb $m$. und duša f. zur differenzierteren Verwendung. Ihre eigentliche, ursprüngliche Bedeutung gründete aber in den vorchristlichen mit ihnen verbundenen Anschauungen (Buslaev 66).

Der Terminus svetyi duchb 'Heiliger Geist' steht im ganzen slavischen Sprachbereich auBer Konkurrenz im Gegensatz zum Althochdeutschen, in dem sich zwei spiritus-Ubersetzungen gegenüberstanden: die süddeutsche wiho atum und die angelsächsische heilago geist. Die erste mußte dann zu Gunsten der zweiten weichen. Sowohl das süddeutsche als auch das slavische wort für den Heiligen Geist knüpft an die physiologische Bedeutung von spiritus als 'Atem' an. Zweifellos ist daher in der süddeutschen Variante das Vorbild für svętyi duchb $z u$ sehen. Das wird auch durch die textliche Abhängigkeit der slavischen Formeln von den bairischen Beichtgebeten und anderen katechetischen Texten aus dem süddeutschen Raum bestätigt. ${ }^{1}$ Doch ist eine Beschränkung auf das ahd. Vorbild nicht ohne weiteres berechtigt, denn es stehen dem slavischen svetyi duchs das lat. spiritus sanctus und das griech. rveoua arıov gegenüber, die in gleicher weise als sprachliche Muster in Frage kommen. Als Kriterium kann nur die Wortfolge herangezogen werden - danach müBte das lat. spiritus sanctus vor dem ahd. wiher atum zurücktreten. Doch die griechischen Vorlagen zeigen ein variables Bild und ein dem entsprechendes Ergebnis in der slavischen Ubersetzung. 2 Es wäre also müBig und für die sprachliche Untersuchung unergiebig, eine Entscheidung $z u$ Gunsten einer der Vorbildsprachen erzwingen $z u$ wollen. Als eine neue nach fremdem Muster entstandene lexikalische Einheit für einen neuen Begriff ist $8 v_{\ell} t y i$ duchb zu den Lehnübersetzungen zu zählen. Was die semanti-

1. Vgl. Steinmeyer 326: "ent1 in den uuihun atum" XLVII,2. Vg1. auch Betz 49: "Ation ist die alte süddeutsche Form. Im Apostolicum des WeiBenburger Katechismus wird credo in spiritwn sanctwn mit gilaubiu in atwo wihan ... ubersetzt ... Im Athanasianum des WeiBenburger Katechismus steht nur heilago Geist, im Gloria heiBt es für cun sancto spiritu wiederum mit wihen adume. Dieses Eindringen der spimitus-Ubersetzung atwon ist für die süddeutschen Texte un 800 kennzeichnend."

2. Vgl. Schmoller 417-418; LLP I,527. 
sche Neuerung anbetrifft, so ist diese grundsäzlich durch die Be-

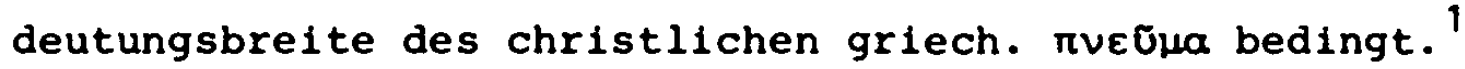

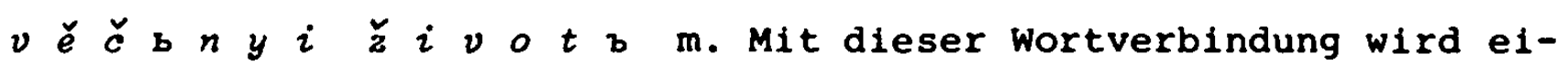
ner der Zentralbegriffe der christlichen Verkündigung bezeichnet:

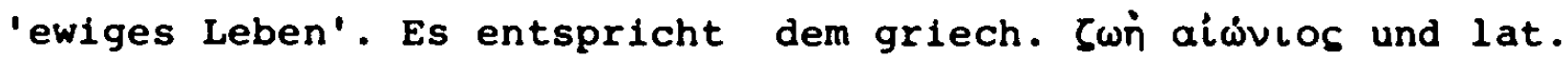
vita aeterna. Aus dem Adjektiv věčbnyi 'ewig' und dem Substantiv životъ zusammengesetzt entspricht es genau dem ahd. ewig $i \hbar b^{2}$ und zeigt durch diese Wortfolge die Abhăngigkeit vom deutschen sprachlichen Vorbild. Die ermittelten Belege aus der ubrigen altslavischen Literatur weisen meistens die ungekehrte, dem lat. und dem griech. Vorbild entsprechende wortfolge auf. ${ }^{3}$

Der biblische Lebensbegriff ist mehr als der des natürlichen Lebens. Er ist "weiter als der philosophische und medizinische ... Er ist ein prăgnanter das heiBt ein trăchtiger Begriff, meint quantitative Fülle." (BthW I, 888). Das ewige Leben - Christus verkörpert es - ist für den Christen schon gegenwärtig und eine eschatologische Größe zugleich. Wesentlich für den biblischen Lebensbegriff ist seine Gottbezogenheit, "sein Inhalt lieBe sich ebenso wie der des Gottesreiches, mit dem er identisch ist, beschreiben als Gerechtigkeit, Friede, Freude im Heiligen Geist." (BthW I, 893).

Neben dem Wort životb $\mathrm{m}$. werden gleichberechtigt im asl. Schrifttum auch žiznb f. und žitije n. für den gleichen Begriff gebraucht; später soll die Differenzierung der Bedeutung žiznb

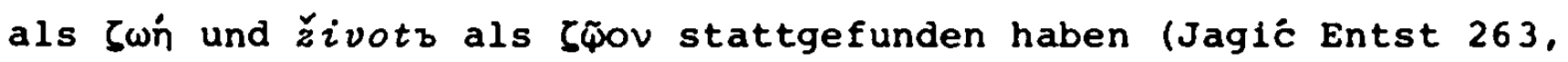
287). Die Absetzung der beiden Ausdrücke voneinander wird in "Proglas" deutlich: Tako vbsjakaja duša opadajeţ žizni, Božija ne imušči života, Egda slovese Božija ne slyšytı. 4

1. Sie ist keineswegs eindeutig. TUEŨนa kann die Wesenswirklichkeit des ewigen cottes meinen, ohne den Dreifaltigkeitsaspekt $2 \mathrm{u}$ berūcksichtigen, besagt aber auch die dritte Person Gottes "allein für sich oder in Christus wirkend oder in Glăubigen wohnend als Prinzip ihres neuen Lebens" (Neunheuser 43). Der Geist Gottes wird als heilig bezeichnet, weil er die personifizierte dynamische Heiligkeit darstellt (HthG $I, 649$ ).

2. Auch ewin, ewinig. Vgl. dazu Raumer 410; Steinmeyer 355:"Ich gloube den ewigin 1Lb" LIX, 20.

3. Vgl. LLP I,603,604,607. Die einzige Stelle, in der der Ausdruck véçbnyi životb vorkommt (in der Wortfolge Adj.- Subst.) ist in "slovo na roždbstvo Ch'sovo", einer dem hl. Kliment zugeschriebenen Homilie (Vgl. Vondrak, 144). Es ist dieselbe Homilie, in der auch das auBerhalb Fris einmalige vorkommen des Ausdrucks ime n. für 'Person' zu finden ist.

4. "Proglasb" abgedruckt in Sobolevskif, 22-27. Das zitat s. S. 25, Zeile 63,64. 
Als lexikalische Varianten für den Begriff des ewigen Lebens wären noch životb beskonbčbnyi, životb bessmrbtbnyi, žiznb věčbnaja, žiznb nebesbnaja, žiznb bqdqštija etc. anzuführen (LLP I, 603,607). Aufgrund der Identität der theologischen Aussage rücken in die begriffliche Nähe von živots věčbnyi noch andere in Fris vorkommenden Ausdrücke: věčbnoje veselije, slava božija und nicht zuletzt česarbstvo für 'Reich Gottes'.'

$v$ b 8 e m $\circ g y$ part.präs.act. 'allmächtig', ein ständiges Epitheton für Gott, ist eine Lehnübersetzung des lat. omnipotens. Die Partizipialform der slavischen Bildung entspricht ganz dem lateinischen Vorbild. Das ahd. almahtig, ein Adjektiv, konnte als Muster nicht gedient haben. Sein Ergebnis hätte *vbsemoštsnyi sein müssen, wie etwa das polnische wrzechmocny, ein dem deutschen 'allmächtig' entsprechendes Adjektiv. Da vbsemogy zum frühsten christlichen Grundwortschatz gehört, ist der darin offenkundige lateinische EinfluB besonders beachtenswert. ${ }^{2}$ Dem ersten Teil des Kompositums omni- entspricht vbse- 'alles', dem zweiten -potens folgt -mogy 'könnend'. Die sinngemäBe lexikalische Entsprechung des lat. omnipotens stellt das griech. ravtoxpdtwo dar, welches den asl. Ausdruck vbsedrbžitelb $\mathrm{m}$. geprägt hat. Diese beiden Worte sind zum wichtigen Unterscheidungsmerkmal zwischen der lat. und griech. literarischen Tradition geworden; sie haben dementsprechend ihre stellung in der westlichen und östlichen Kirchensprache eingenommen.

Eine nur einmal belegte lexikalische variante zu vbsedrzžitelb

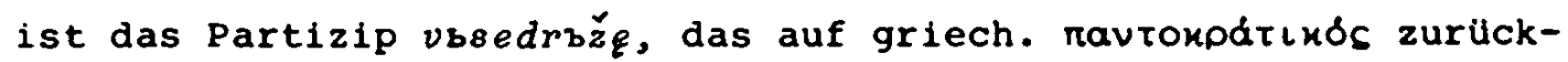
geht. AuBerdem ist die einmalige Bildung vbsevladyka m. zu beachten. Sie ist in dem Beichtgebet des Euch enthalten und entspricht dem ahd. alles uualtando im Sanct Emmeramer Gebet. 3

$z$ a $g l$ a $g \circ l$ a $t i s \varepsilon$ ipf. 'sich lossagen' ist ein Ausdruck der Abschwörungsformel, die jeder zum christlichen Glauben Bekehrte in der Taufzeremonie nachsprechen muBte. Man "widersagte dem

1. Vgl. dazu die Ausführungen unter cěsarbstvo, und slava božija.

2. Dieser Frage schenkte besonders Isačenko eine große Beachtung. Vgl. Isačenko, 60, ders. $65-66$; ders. 283-309; ders. 305. Vgl. dazu auch vašica 16.

3. Dem im Ahd. seltenen Ausdruck alles unaltando haften nach Eggers $133-135$ die Spuren des got. sprachlichen Einflußes an. Demnach wurde sich diese Spur in dem asl. vbsevladyka weiter verfolgen lassen. Vgl. dazu auch Reiffenstein 34-35. Vgl. Steinmeyer 310, XLII, A 23-24: "alles uualtenteo trohtin, kot almahtigo", B 22-23: "alles uualtanto trohtin, got almahtigo". 
Teufel und allen seinen Werken ..." wie die heute noch gebräuchAbrenuntiationsformel lautet. In dieser spezielien Bedeutung entspricht das am Anfang des Fris III stehende Iazze zaglagolo dem ahd. Ih intsago mih der Wessobrunner Abschwörungsformel. 1 Mit Recht hat ISAČENKO darauf hingewiesen, daß von den in Frage kommenden ahd. Ausdrücken sih intsagên wegen der reflexiven Form der slavischen Bildung als Vorbild anzunehmen ist. 2 Deshalb scheiden auch die lat. nichtreflexiven Verben abdicare, renuntiare als Gegenstand dieser Lehnübersetzung aus. ${ }^{3}$ Das gleiche gilt für das doppelt präfigierte $a b-r e-n u n t i a r e$.

Als synonym $z u \quad z u$ dem nur in Fris III belegten zaglagolati $8 \varepsilon$ können otbresti s\&, otbricati se genannt werden. 4 Gegen die bedeutungsmäBige Gleichsetzung des ebenfalls in Fris (II) vorkommenden zavěs̆tati sę müssen jedoch Bedenken angemeldet werden. 5 Zwar gleichen sich beide worter in formaler Hinsicht, ihr Hauptbestandteil ist ein Wort des Sprechens, doch ergibt sich aus dem Kontext für zavěštati sę ein von dem Abschwörungsverbum verschiedener sinn. 6

Zaglagolati se ist ein hapax legomenon.

1. Vgl. Steinmeyer 135, XXVIII, W, 1. Uber den lat. Sprachgebrauch vgl. Du Cange I, 28: abrenuntiare diabolo et pompis ejus, formula observata in Baptismo. Cum enim quis baptizandus ad ecclesiam venit, priusquam immergatur a sacerdote, Utrum abrenuntiet diabolo et pompis ejus. Cui respondet, Abrenuntio.

2. Andere and. Ausdrūcke sind: firsagēn, forsagēn, antsagēn. Vgl. Graff vI,101 die Wortgruppe antsagen, 103 farsagen; Schützeichel 157 : firsagēn, intsagën mit Refl.Pron. u. Gen. (?) sich lossagen von N. Vgl. Isačenko 12.

3. LLP I,633 gibt für zaglagolati sę die lat. Entsprechung se abdicare an, doch wird bei Georges I,8-9 abdicare nicht als Reflexivverb angegeben. Die mit $8 e$ angefuhrten Ablativverbindungen haben mit der Abschworungs formel nichts gemeinsam.

4. Vgl. Euch 68b 6-7:otbricajQ 8६̨; Kliment - Homilie: otricaju sja sotony (Vgl. Vondrák, 63).

5. Sowohl bondrak, 78 (wortregister) als auch Pogačnik 227,259 (Glossar) und LLP I,633 ubersetzen zavéśtati $8 e$ mit 'sich von etwas lossagen'. Mikl LP 207 gibt als Bedeutung renutiare an und verweist auf aglagolati. Auch Vostokov 42 erklărt es ahnlich: 'obreščisja, objazat'sja obetom'. Es bedeutet aber 'sich verteidigen' defendere und entspricht dem and. firsprehhan, fersprehhan mit und auch ohne Reflexi vpronomen im Gebrauch. Vgl. Graff VI, 378-379: far sprehhan, defendere etc. "sih thar tho baldo firsprah" (defendebat): "thaz er in thesen thingon firsprechan mag sich selbon" (verteidigen). Vgl. auch Schützeichel 180 . Es zeigt sich, daB zavés̆tati sę eine Lehnübersetzung des ahd. $s i h$ firsprehhon in der Bedeutung 'sich verteidigen' ist. Uber die Verwendung des furi-sprehhon als Rechtsterminus für se defendere vgl.Schulz 153. 6. Vgl. die Ubersetzung von Vašica 136: "prot: němu chránit a jemu uniknout" . 
b. Lehnübertragungen

$b \circ \check{z} i{ }_{i} \quad r a b b$ m. wörtlich 'Gottes Knecht' erscheint als Terminus für den Priester und ist in dieser Bedeutung fest an die Wortfolge Adj. + Subst. gebunden. Sowohl ISAČENKO (IsaČenko, 36) als auch VAŠICA (Vašica, 529) halten die Wortfügung božii rabb für eine Lehnubersetzung aus dem ahd. gotes scalh, wobei die Wortfolge als ein wichtiges unterscheidendes Bedeutungsmerkmal im $\mathrm{Hin-}$ blick auf den in der umgekehrten Reihenfolge auftretenden Ausdruck rabb božii erscheint. ' Der letzte geht auf die knecht-Gottes-Idee des AT, besonders bei Isaias 40-55, zurück. "In der Bibel ist wiederholt von guten Männern die Rede, die 'Knechte' (ébed) Gottes genannt werden ... Der phönizische könig Azitawadda nennt sich in ... seiner Inschrift Knecht Baals. Diese Knechtschaft schlieBt den $k$ u $l t d i$ e $n t$ ein." (Eigene Sperrung; Bthw 1,839 ) Im NT wird mit dem Titel rais $\vartheta \varepsilon \circ \tilde{~ J e s u s ~ b e l e g t, ~ j e d o c h ~ g e h o ̈ r t ~}$ diese Bezeichnung der ältesten Uberlieferung an (BthW I,844,845). Durch die Erlosungstat (den "Loskauf") werden schlieblich alle Christen "Knechte Gottes"; von der Knechtschaft des Teufels losgekauft, werden sie Gottesknechte, sie gehen in Christi Eigentum über $(1$ Kor 7,$22 ; 6,20 ; 2$ Petr 2,1$)$. Wenn man von daher die spezielle Bezeichnung für den Geistlichen als Gottes knecht betrachtet, - mag sie auf eine bestimmte Wortfolge fixiert sein - so kann nicht übersehen werden, daB eine solche Bezeichnung in uralter Tradition gründet. Konnte daher die slavische Wortverbindung boži rabb nicht aus eigener Motivation entstanden sein? Fur die Beantwortung dieser Frage wird die Vergegenwärtigung der bestehenden Gesellschaftsordnung in den missionierten Gebieten entscheidend sein. In seinem Buch "Slavische Altertumskunde" schenkt H.PREIDEL der sozialen Frage ein besonderes Augenmerk. In dem Kapitel "Die Christianisierung" beschäftigt ihn die Frage des priesterlichen Nachwuchses in den für das Christentum neu erschlossenen Gebieten. Er schreibt: "Nach der im Missionsgebiet herrschenden Gesellschaftsordnung konnten die Glaubensboten nur unter der untertänigen Bevolkerung Nachwuchs finden, indem sie junge Leute an sich zogen und heranbildeten." (Preidel $I, 138$ ). Die dafür bestimmten Knaben wurden entweder gekauft oder von ihren Herren geschenkt,

1. Als tbersetzung des griech. 60ülos $\tau$. Ecou tritt rabb božii in der abrigen asl. Literatur auf. Es bedeutet 'Sklave Gottes' = Gott untertan. Vgl. Bauer 408. 
um sie als "Knechte Gottes" ausbilden zu lassen. Für Nordeuropa ist diese Verfahrensweise geschichtlich glaubwïrdig direkt bezeugt, für Măhren und Böhmen können indirekte Hinweise genutzt werden. PREIDEL stützt seine Behauptung auf zitate aus zuverlässigen geschichtlichen Quellen. Eine Verfügung der Admonitio generalis von 789 besagt, daß niemand den knecht eines anderen $z$ um Stand eines Klerikers oder eines Mönches verlocken dürfte ohne willen und $\mathrm{zu}-$ stimmung seines Herren. 1 Eine Formulierung ähnlichen Inhalts brachte die Synode zu Frankfurt 794, ihr folgen darin noch drei weitere Kapitulare und "schlieblich faBt $818 / 819$ das berühmte Capitulare ecclesiasticum Ludvigs des Frommen im sechsten Hauptstück alle bisherigen Verfügungen zusammen und bestimmt, daB kein Knecht geweiht werden düfe und $\mathrm{daB}$ der im guten Glauben geweihte Knecht abzusetzen und seinem Herren zurückzugeben sei." (Preidel I,139). Nach PREIDEL gab es auch in Ostmitteleuropa eine festgefügte Gesellschaftsordnung, die "sich nur wenig von der ordnung im Frankenreiche unterschieden haben dürte." (Preidel I,139).

Die sachliche Begründung für die Bezeichnung der zum geistlichen Stand herangebildeten knechte mit božii rabs wäre somit gegeben. Ob dieser Terminus durch das sprachliche Medium des Ahd. in die asl. kirchliche Terminologie eingedrungen ist, oder ob er eigener Anschauung entsprang, kann letztlich nicht entschieden werden, doch liegt es sehr nahe, daB es sich um eine örtlich begrenzte Priesterbezeichnung handelt, die auf den deutsch-lateinischen EinfluB zurückgeht: ${ }^{2}$ das Vorkommen dieses Ausdruckes ist auf die mährisch-pannonischen Texte beschränkt. Für eine Lehnübertragung aus dem Ahd. spricht das Argument der Wortfolge: gotes scalh. 3 Bei der Ubertragung wurde der Genitiv gotes mit dem der slavischen Sprachform entsprechenden Adjektiv božii wiedergegeben. Die lat. Entsprechung lautet servus dei. ${ }^{4}$

Eine andere Lehnübertragung stellt das Wort zakonbnikb $\mathrm{m}$. dar; es gibt ebenso den Begriff 'Priester' wieder, für den im asl. Schrifttum noch weitere Bezeichnungen verwendet werden. Diese sind bei der Behandlung des Wortes zakonbnikb angeführt.

1. Vgl. Preidel I,139, Fußnote 330: MGH., Capit.I,55 (Nr. 22 Admonitio generalis) c.23: "...Et ut servum alterius nullus sollicitet ad clericalem vel monachicum ordine sine voluntate et licentia domini sui."

2. Vgl. dazu Isačenko, 36 .

3. Vgl. Steinmeyer 316: "gotes scalche" XLIV,2 und 15. Hăufiger wird in den Beichten der Ausdruck godes monn verwendet.

4. Isačenko weist auch auf lat. Dei servus hin, das in dieser Wortfolge in dem 
$b \circ \stackrel{r}{z} i \quad i \quad s \quad z \quad l \quad m$. gebildet aus $8 b l-a-t i$ mit dem suff. - $b$ 'senden' (Nikolić 78) und dem Prädikat božii ist die Bezeichnung für den biblischen Begriff 'Apostel'. In der Wortverbindung boži $i$ $s b l b$ liegt ein Versuch vor, diesen wichtigen Begriff mit einem einheimischen Wort in Angleichung an ahd. gotes boto wiederzugeben. Diese Lehnubbertragung aus dem Ahd. fand zwar Eingang in das kirchenslavische Schrifttum, wurde aber durch das Lehnwort apostols $\mathrm{m}$. verdrängt. Das slavische wort für den 'Gesandten Gottes' ist treffend gewählt worden, muBte aber dem Lehnwort weichen. 1 Beachtenswert dabei ist die theologische Qualitat des Vorgangs: es soll die unvergleichliche Eigenständigkeit des christlichen Begriffs herausgestellt werden.

Um den neutestamentlichen Apostelbegriff zu erläutern, der auf der Funktion des Gesandten im weltlichen Sinne gründet, muB zwischen der stellung eines Gesandten, eines Boten und eines Herolds unterschieden werden. Der Begriff des Boten wird durch die von ihm auszurichtende Botschaft bestimmt. Er ubermittelt willenskundgebungen oder Tatsachen, und mit der Ausrichtung der Botschaft ist auch seine Aufgabe erfüllt (Dombois 111-112). Der Herold verkündigt etwas, wie der Bote, Tatsachen und willenskundgebungen, doch indem er sie proklamiert, setzt er sie schon in kraft (Dombois 112). Anders der Gesandte: dieser ist ein Bevollmächtigter, ein Vertreter im Willen, der den Auftraggeber durch sein Handeln verpflichten kann, nach Maßgabe seiner Vollmacht, unter EinschluB eines weitreichenden Vertrauensschutzes. "In einem ursprünglichen Rechtssinne, insbesondere aber im volkerrecht (Gesandtschaftsrecht) repräsentiert er seinen Herren so, dab dieser in ihm gegenwărtig ist, in ihm geehrt oder mibachtet wird. Der Herr ... labt sogar im Rahmen der Vollmacht dem Gesandten Entscheidungsspielraum, in der Gewibheit und dem Vertrauen, das er in seinem sinne entscheiden wird." (Dombols 112). Auf diese Weise sandte Jesus einen Tell seiner Jünger $(M k 6,7)$ und machte sie zu seinen rechtlichen und personlichen Repräsentanten. 2 Das wird deutlich in den worten: "Wer euch auf-

Sermo 257 des hl. Casarius von Arles vorkommt. Vgl. dazu auch Hautkappe 8 . Dort werden noch folgende Textvarianten angegeben: "et tibi dei misso", "Dei servo et amico".

1. Ähnliches ist auch bei dem Versuch, den Engelbegriff mit dem slavischen Wort $k$ milatbcb wiederzugeben, zu beobachten.

2. Vgl. BthW I,63. Vgl. auch Dombois 112 ff. Dombois gelingt es, die Rechtsstrukturen der Kommunikation Gott - Mensch aufzudecken. 
nimmt, der nimmt mich auf, und wer mich aufnimmt, der nimmt den auf, der mich gesandt hat." (Lk 10,16. BthW I,64). Die Vollmacht Christus zu vergegenwărtigen pflanzte sich fort, es blieb also das Amt des Apostels, aber die Bezeichnung 'Apostel' beschrănkte sich auf die zwölf.

Die sinngemăbe Wiedergabe des griech. \&nobroגos ${ }^{1}$ mit dem Wort $8 b z_{b}$ wird anhand von Belegen aus den altslavischen, altrussischen und altserbischen Quellen bestătigt. In Supr 24,273,20 steht es für roḱBus; in Supr 47,539,24 und 48,561,20 wird 8 blb in der Bedeutung 'Gesandter' verwandt, ebenso in Nik 13,16; hăufig steht es in Bes für legatus; legatio = sbly. Es wird aber auch für nun-

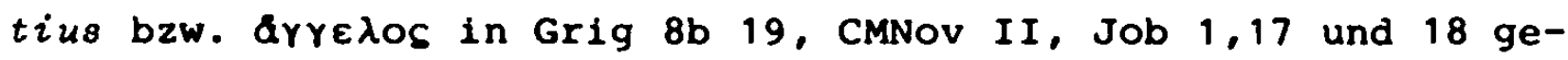
braucht. Unter den ar. Belegen findet sich bei SREzNEVSKIJ III, 741: My ot roda Ruskago sbli $i$ gostbe Dog.Igor. $945 \mathrm{g.i} i$ otpusti sly sb rekbši Pov.vr.1. $6463 \mathrm{~g}$. DANIČIĆ III, 241 führt für das Altserbische $8 \mathrm{~b} l_{\mathrm{b}} \mathrm{m}$. In der Bedeutung legatus an: da ne pošle kniga ni slě M.30; sb chteniemb tvoga sla M.30. Die Belege aus dem profanen Sprachgebrauch zeigen, daB mit dem Wort $8 \mathrm{~b} \mathrm{l}_{\mathrm{b}}$ der Repräsentationstypus des Gesandten in oben angefuhrten sinne bezeichnet wird, daB also die Bezeichnung einer bestehenden rechtlichen Institution auf die verănderte Aufgabe - die des neutestamentiichen Apostolus - ubertragen wurde.

Neben der Form $8 \mathrm{~b} l_{\mathrm{b}} \mathrm{m}$. sind noch Wortbildungsvarianten posblb m., posblanikb m., posblanyi m., posblbnikb m. anzutreffen.

$8 I a v a \quad b \circ z i j a$ f. In der Bedeutung 'Herrlichkeit Gottes' kann sowohl auf das griech. $\delta \delta E a$ tou $\vartheta \varepsilon o \tilde{~ a l s ~ a u c h ~ a u f ~ l a t . ~ g l o r i a ~}$ Dei zurückgehen. Da aber dieser Ausdruck in der gleichen Bedeutung und auch im gleichen Zusammenhang in der Predigt des hl. Kliment vorkommt, von der angenommen wird, dab sie auf ein lateinisches ${ }^{2}$ Muster zuruckgeht, kann in erster Linie an das lat. sprachliche

1. Das griech. Wort \&nborolos entstammt vermutlich der volkssprache, in der es 'Bote, Abgesandter' bedeutete (BthW I,61-62). Im klassischen Griechisch gewinnt es nur vereinzelt den Sinn 'Abgesandter, Bote'. Von den Juden, die schon ein Amt von Aposteln hatten, mag das Urchristentum den Ausdruck zur Bezeichnung gewisser Beauftragter entlehnt haben (Bauer 197; Liddell-Scott 220

2. Diese Ansicht hat zuerst Vostokov in dem Kommentar zu der Keppenschen Ausgabe der Fris geăuBert. Uber die Predigt zu Ehren des hl. Markus, die sehr eng verwandt ist mit der Predigt des $\mathrm{hl}$. Kliment (diese Entdeckung machte Undol'skij im Jahre 1867, vgl. Undol'skij 31-38) sagt ex in Grammatičeskija ob"jasnenija 217: "Neizvestno, kem sočineno sie poučenie: slog $i$ maner $v$ onom kažutsja ne grečeskie. Kak by ni bylo, sravnivaja onoe s propoved'ju slovenskoju, vpisannoju v Frejzingenskuju rukopis', čitatel' udostoveritsja, čto 
Vorbild gedacht werden.

Die Behauptung GRIVECs, daB es sich bei slava božija um einen besonders der griechischen homiletischen Tradition eigenen Ausdruck handelt, ist nicht einzusehen. ${ }^{1}$ Die in Fris II enthaltene Aussage über den Verlust der 'Herrlichkeit Gottes' im Sinne von 'Paradies' wiederholt sich in "Poučenije na pamjatb sv. Ap. Marka" mit den Worten:otlučisja slavy Božija: ${ }^{2}$ in "Poučenije na pamjats apostola ili mučenika" (d.i. die predigt des hl. Kliment) heiBt es: otluǒisja oţ slavy Božija (Mikl Term 3-6). Der Gedanke gründet in der paulinischen Theologie und findet seinen Ausdruck z.B. in Röm 3,23: "haben doch alle gesündigt und sind der 'Herrlichkeit Gottes' verlustig gegangen". Im mittelalterlichen Latein wird gloria als Bezeichnung für die 'himmlische seligkeit' verwendet (Rheinfelder 246 ). In der Benediktinerregel bedeutet gloria 'gottliche Ehre', es ist aber auch eine Umschreibung für den Himmel als Gegensatz zur ewigen Schande und Strafe der Holle. Es wird dort mit tiurida 'lieb, teuer, kostbar, wertvoll' wiedergegeben (Ibach 81, 143). Diese Tatsache ist für die Beurteilung der vermeintlichen Notwendigkeit, Fris II in Abhängigkeit von ausschlieBlich griechischer Theologie und Ausdrucksweise zu sehen, von Bedeutung. Der Begriff der 'Herrlichkeit Gottes' als paradiesischen Zustands ist auch der deutsch-lateinischen Tradition nicht fremd gewesen und fand in gloria Dei seinen Ausdruck.

Die Kriterien dafür, ob slava božija eine Lehnumprăgung unter dem sprachlichen Einflus des lat. gloria Dei bzw. des griech.

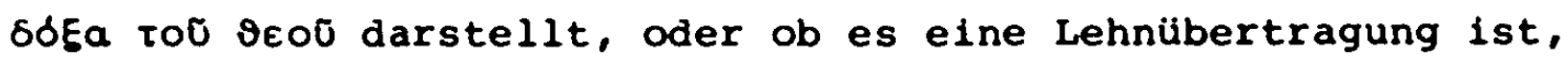
lassen sich nicht leicht bestimmen. Die Entscheidung uber die formale Einordnung hăngt davon $a b$, ob man slava božija als eine feststehende Wortverbindung ansieht, die den Wortschatz um einen neuen Ausdruck bereichert, oder ob es sich un eine umschreibende wiedergabe eines neuen Begriffs handelt, die keine Neuerung für die Lexik darstellt. Man wird sich fur das erstere entscheiden, denn

odno iz sich soćinenij peredelano s drugago, ili, sudja po nekotorym mestam, daže bukval'no spisano." Dieser Erkenntnis stimmen dann Undol'skij 37; Kopitar S. XVI; Mikl Term 7 zu. Von der Angabe der spateren reichhaltigen Literatur $z u$ diesem Thema kann abgesehen werden.

1. Vgl. Grivec, $30 \mathrm{ff}$. Seine Ausführungen, daB es sich sowohl hinsichtlich der Thematik, als auch der Ausdrucksweise vornehmlich um ostliche, auf griech. Quellen zurackgehende Tradition handelt, ist nicht aberzeugend. Besonders ist die Argumentation gegen die Abhångigkeit des Fris II von den dem hl.Bonifatius zugeschriebenen Reden nicht stichhaltig.

2. Abgedruckt in : Vostokov, GrammatiCeskija ob"jasnenija ... 2-4. 
es handelt sich um einen Ausdruck der terminologischen Prăgnanz eines božii rabz in der Bedeutung 'Priester' oder věčbnyi životb für 'ewiges Leben'. Da es sich aber mehr un eine inhaltliche denn lexikalische Neuerung handelt, liegt der Schwerpunkt der Untersuchung auf dem Wortinnern.

Will man den Bedeutungsgehalt des asl. Ausdrucks s lava boz̆ija aufschlieben, so ist man gezwungen, die Bedeutungsentwicklung des lat. gloria über das griech. 6రEa bis zum hebr. kâbód zurückzuverfolgen. Dadurch wird die innere Wandlung des Wortes slava vom profanen Sprachgebrauch zum biblischen Terminus, der auch in den liturgischen Lobgebeten einen festen Platz hat, offenbar. Das hebr. $k a b o d$, dem das deutsche Wort 'Herrlichkeit' entspricht, bedeutet im AT 'die Wucht der göttlichen Erscheinung', 'Majestät und Herrlichkeit Gottes' seine 'himmlische Lichtsubstanz' (Bthw I,707-708). Die Herrlichkeit ist unlöslich mit der Heiligkeit verbunden (HthG I,680). Im Psalm 29 erscheint die Herrlichkeit in Form eines Gewitters und ruft gleichsam als Echo bei den Engeln im Himmel und indirekt bei den Gläubigen im Tempel den Ruf "Herrlichkeit" hervor, der primăr Anerkennung, sekundăr Lob, Preis und Dank bedeutet (HthG I,682). Ahnlich wird auch die Herrlichkelt Gottes geschildert, die die Hirten in der Geburtsnacht des Herren umstrahlt und auf die jene lobpreisend antworten. Anrede Gottes und Antwort des Menschen bilden im AT eine Einheit, die sprachlich dadurch zum Ausdruck kommt, daB dafür die gleichen worte verwendet werden. Es handelt sich um sogenannte Korrespondenzbegriffe, $z u$ denen auch die 'Herrlichkeit' zählt (HthG I,680). Im NT wird Jesus der Träger der Herrlichkeit, insbesondere wird sie im eschatologischen sinne verwendet: in ihr wird der Herr bei der Parusie erscheinen, in die vorweltliche Herrlichkeit kehrt Christus bei der Himnelfahrt zurück (HthG I,684). Die Septuaginta schuf in $665 \alpha$ einen Terminus technicus, der sich vom sprofanen Sprachgebrauch scharf abhob und für das NT beherrschend wurde (HthG I,683). Im biblischen Gebrauch bedeutet $6 \delta 5 \alpha$ 'Ruhm,. Ehre, Glanz, Pracht, Abglanz'; in Aussagen über Gott: 'himmlischer Lichtglanz, Erhabenheit, Majestät'; $\delta \delta E \alpha$ kann sogar an Stelle des Gottesnamens stehen. Die lat. Wiedergabe von 6రEa schwankt zwischen claritas, gloria und maisstas, doch in den meisten Fälien wird es mit gloria übersetzt. Die Kirchenvăter schlieBen sich dem biblischen Sprachgebrauch an (Bthw I,706). Für das slavische Wort s lava sind die Bedeutungen 'Ruhm, Ehre, Glanz, 
Pracht, opinio' festzustellen (Mikl LP 854). Welchen semantischen Zuwachs das Wort in der Verwendung in Fris II erfahren hat, ist aus dem oben gesagten ersichtlich. Mit dem ererbten Wortinhalt in der parallelen Entwicklung zu seinen Vorbildern scheint es dem theologischen Anspruch eines Korrespondenzbegriffes durchaus gewachsen zu sein.

In formaler Hinsicht stellt die Wortverbindung slava božija eine für das slavische typische Bildung dar, in der für den poss. Genitiv der Vorbildsprache ein poss. Adjektiv gesetzt wird.

In Abhängigkeit von der jeweiligen Vorlage hat die asl. Literatur auch noch andere Bezeichnungen für den Begriff 'Herrlichkeit Gottes' vorzuweisen: věčbnyja čbsti (Bes 36,275 ba 20-21); chvaljenije n..chvala f. für gloria; pradědnaja čbsti (Const IV); dědnaja čssti (Const IX): rai m., carbstvo n.. cěsarbstvo n.'

$8 t \circ l_{b} b \quad b \quad \check{z} i \quad i \quad \mathrm{~m}$. ist die Bezeichnung für 'Thron Gottes'. Das Wort 8 tolb $\mathrm{m}$. ist zunächst die Bezeichnung eines stuhles oder Sitzes, dann als Symbol der herrschenden Macht im übertragenden Sinne die Benennung einer Rangstellung, mit der bestimmte Rechte und Aufgaben verbunden sind. Es findet sowohl im weltlichen als auch im kirchlichen Bereich in diesem Sinne Verwendung. Als terminus technicus iuris canonici für lat. sedes erscheint es in Pochv KM Usp 114 a: na stolb stho Andronika apla vb panonii. Für den weltlichen Thron wird stolb in Ostr 294 c 5 gebraucht: $8 a m b$

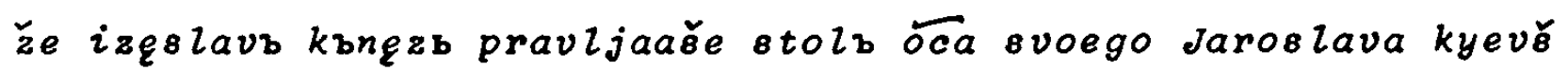
und in der gleichen Bedeutung in Ostr 294 c 6: a brata svoego stolb poreči praviti. In $\mathrm{ZK} 5$ Lavr 6,5 bedeutet stolb 'sedes patriarchalis': $i$ şgnaša i sb stola. Die Beispiele lassen sich noch weiter fortsetzen. AuBer sedes, thronus hat stolb in Verbindung mit sqdbnyi auch noch die Bedeutung tribunal: stojati predb tvoimb oudbny (!) stolomb (Nicod $1 \mathrm{~ms}$ Novg. fol. 248 aa 10). 2 Hier handelt es sich un den 'Richterstuhl' Gottes; es entspricht darin der lateinischen Bedeutung für sedes im ubertragenden sinne 'Richterstuhl' (Georges II,2570). In den altserbischen Urkunden

1. Die angeführten textlichen Varianten für 'Herrlichkeit Gottes' im Sinne von 'Paradies' betreffen letztlich das 'Reich Gottes'. Unter diesem Begriff kann man die verschiedenen Ausdrucksweisen zusammenfassen, die dasselbe Phanomen meinen und sich durch die jeweils andere Betrachtungsweise voneinander unterscheiden - je nachdem, ob man das Reich cottes ortlich, zeitlich oder qualitativ sieht.

2. Alle Belege aus Arch LIP. 
wird stolb, aserb. stolb für thronus und tribunal gebraucht (Daničić II, 176, 177). Im Altrussischen bezeichnet stols den konkreten Gegenstand, kann aber auch 'Thron' bedeuten (Srezn III,516-517). Als Bezeichnung für 'Thron Gottes' komnt 8 to $2 b$ auBer in Fris II in den Texten der mährisch-pannonischen Gruppe vor, sonst ist die Ubersetzung des griech. Opóvos prěstolz m. üblich. 1 Dieser Ausdruck ist charakteristisch für das kirchenslavische schrifttum und findet sich in den altesten biblischen Texten. 2

Aus der Allgemeinsprache herkommend, auf einen terminus technicus im staatswesen eingeengt wird das Wort 8 tolb mit dem Prädikat božii adj. versehen und so mit einem neuen christlichen Inhalt gefullt in der Bedeutung 'Thron Gottes'. Es vereinigt in sich alle oben genannten Aspekte: den der herrschaftlichen Macht, der Richterfunktion und der biblischen Vorstellung des Thrones.

Der Ansicht ISAČENKOs, daB es sich bei dem Wort stolb entweder um Entlehnung des ahd. $8 t \delta 2$ oder um Ubersetzung des ahd. $8 e$ dal handle, kann nicht zugestimmt werden (Isačenko, 38). Asl. stolb geht auf die gemeinsame idg. Wurzel *stā-zurück, es ist also möglich, aber nicht zwingend, eine Entlehnung anzunehmen. 3 Gegen eine Ubersetzung des ahd. sedal wäre nichts einzuwenden, aber der ahd. Ausdruck für' 'Thron Gottes' lautet gotes sedale. ISACENKO bringt selbst Belege dafür aus dem Tatian: "uuanta hér gotes sedal ist" Mt 5,34; "ther suerit in gotes sedale" Mt 23,22 (Isačenko, 38). Die Wortfolge des asl. Ausdruckes spricht gegen den ahd. EinfluB. Ein solcher ist vielmehr in dem lat. Vorbild $2 u$ suchen, dessen Wortfolge mit der slavischen ubereinstimmt. Es heibt in Apk 22,1-2 "de sede Dei et Agni", in Hb 12,2 "atque in dextera sedis Dei sedet". "Danach kann stolb božii als eine Lehnubertragung des lat. sedes Dei angesehen werden, wobei der griech. sprachliche EinfluB nicht anzunehmen ist. 5

1. Vgl. Isačenko, 38; Jagic Entst 294. Neben dem schon angegebenen Beispiel aus Nicod kanñ auch noch Bes 937 ba, 22 erwăhnt werden: na onomb ñbsbcèmb stolě (Arch LLP).

2. Vgl. Jagit Entst 294. Dazu auch Oblak 343: "8tolb kommt auch in Vita Simeonis vor und in mehreren der altesten altserbischen Urkunden. Stols ist ebenfalls russisch."

3. Vgl. Pakorny I, 1007 .

4. Vgl. Vulgata an der betr. Stelle, sonst auch Schmoller 239, Bauer 720.

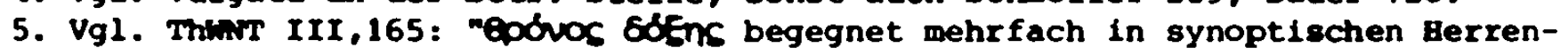
worten fur den Berrschersitz des 'Menschensohnes' wenn er in seiner wessianischen Herrlichkeit zum Gericht und zur Berrschaft erscheint". Die Verbindung eobros sofns spricht gegen das griech. Vorbild für stolz božii. Dagegen 
$z a k \circ n$ b $n i k$ b m. synonym mit božii rabb (s.o.) in der Bedeutung 'Priester' sacerdos ist eine Lehnübertragung des ahd. êwarto aus êwa 'das Gesetz' und wartên 'wachen' - 'wächter des Gesetzes'.' Die Germanen besaßen "kein aufgeschriebenes kodifiziertes Recht, sie kannten ein mündlich getreu überliefertes göttliches Recht Ewa, über das êwarto zu wachen hatte" (Tschirch, I, 103). Das Recht und die Religion waren miteinander eng verbunden; im allgemeinen stellten die völker das Recht und die Gesetze unter den Schutz der Gotter. Das traf auf die Germanen in hohem Mabe zu und wurde zumindest durch die Missionierung auch auf slaven ubertragen. 2 Da das Recht, das Gesetz (mit der sittlichkeit eng verbunden) unter dem göttlichen Schutz stehen, standen der Christianisierung des Wortes zakonb $\mathrm{m}^{3}$ keine allzugroBen Schwierigkeiten im Wege, und es lag nahe, dieses Wort für lex Dei, speziell auch für AT und NT zu verwenden. 4 Der Bedeutungszuwachs ist jedoch erheblich. Grundlegend ist zunächst die Anerkennung des alttestamentlichen Gesetzes im Urchristentum. Es wurde als Gottes Gesetz angesehen und darum heilig und gut (Bthw I,547). Das Gebot Christi, das sich im NT ausdrückt, hat seinen wesentlichen Inhalt in dem Doppelgebot der Gottes- und der Menschenliebe (BthW I,560).

spricht auch die Hăfigkeit der ubersetzungen von sobros mit préstolb in der ubrigen asl. Literatur.

1. Auf die Abhăngigkeit des zakonbnikb vom Ahd. hat schon Miklosich hingewiesen (Mikl Term 14). AuBerdem Pirchegger 110, Isačenko, 13.

2. Uber die Verhăltnisse bei den Slaven gibt es kaum zuverlássige Nachrichten. Historische Quellen sind in zwei Redaktionen erschlossen worden: Fontes historiae religionis slavicae, coll. C.H. Meyer, Berolini 1931 (nur aus griech., lat.. germ. und arab. Quellen) und Mansikka, Die Religion der Ostslaven I. quellen., Helsinki 1922. Eine kurze und übersichtliche Darstellung der Quellenlage gibt St. Urbahczyk (1-11). Vgl. ferner Wienecke 3, Preidel I,117 ff.. Polák, Brückner, 149-187. Vgl, auch das bekannte Helmold - Zitat, welches $\mathrm{H}$. Jirećek als motto des "Prove" Historicky slovar slovanského práva gewălt hat.

3. Fur das Recht ist von jeher das slavische Wort pravbda $f$. is Gebrauch, für das Gesetz zakonb m. (Jireček, I,146). Die Wuxzel ist *kon- + -ati 'etwas tun, un die Sache zur Entscheldung zu bringen'. "konec pr̆i učiniti" (Jireček, $I, 146)$ (= den Streit beenden). Weil das Urteil, die Entscheidung in einem Streitfall zum Vorbild fur ahnlichen Fall wurde, im weiteren zum Gesetz, bekam das Wort zakomb die Bedeutung 'das Gesetz' (Jireček, I, 146). Vgl. dazu auch die Etymologie bei Berneker 1,560; Vasmer 1,430; Frinta 72 : ursprüngliche Bedeutung war das Resultat der Verhandlung.

4. Nach dem Pentateuch, dem wichtigsten Teil der alttestawentlichen Schrift (=das Gesetz) wurde das ganze AT 'Gesetz' genannt (Bthw I,545). Auch fur 'Bund' Im Sinne vom felerlichen Vertrag, der zwischen Gott und den Menschen geschlossen wurde (Dombois 97) wird das Wort zakomb gebraucht, das aber als Moravismus gegenüber zavèto $\mathrm{m}$. In der ksl. Literatur angesehen wird, vgl. dazu Marešs 139. 
Das so christianisierte Wort zakonb gab die Voraussetzung zur Bildung von zakonbnikb, das die ahd. Bezeichnung éwarto frei in das Slavische überträgt: wăhrend der erste Teil des Kompositums ēwamit zakonz- wiedergegeben wird, tritt für den zweiten Teil -warto (= Wăchter) das Suffix -bnikz auf (Nikolić $60 \mathrm{ff.}$. Wie éwarto, das in ältester Zeit doppelte Bedeutung 'Richter' und 'Priester' hatte, wird auch asl. zakonbnikb sowohl für den jüdischen als auch für den christlichen Priester gebraucht. ${ }^{1}$ Jedoch in der Bedeutung 'christlicher Priester' wird es von SOBOLEvSKIJ (Sobolevskij, 94), HORÁLEK (117) und MAREŠ ${ }^{2}$ als Bohemismus angesehen. Als solcher hatte zakonbnikb eine lokal beschränkte Ausbreitung und blieb im Tschechischen und im Polnischen mit der Bedeutungsverschiebung zu 'Mönch' bestehen. In dem Wort zakonbniks 'Priester' steckt vorwiegend alttestamentliches Vorstellungsgut; einer, der das Gesetz Gottes lehrt, darüber wacht; ein Mittler zwischen Gott und Volk, ein Kultdiener. Das NT aber orientierte sich grundsäzlich an der Uberzeugung Christi, daB mit ihm der Tempeldienst und das priesterliche Amt ein Ende nehmen wird (BthW II,1117).

Im Asl. gibt es für den Begriff 'Priester' viele andere Bezeichnungen: ierei m., pops m., svęstenbniks m., svętitelb m., čistitelb m., molitvbnikb m., molbbnikb m. und žrbcb m. nur für den heidnischen und jüdischen priester. ${ }^{3}$

1. Vgl. Wesche 12, Vgl. Hinweis darauf bei Buslaev 125, 126. Vgl. ferner LuP I, 664.

2. Mares, 439. Für Fris bietet Mareš die Ubersetzung 'Schriftgelehrter' an.

3. Ergănzend sei noch bemerkt, daB im Aserb. zakonbnikb m. liber leges continens bedeutet, also 'Gesetzbuch', 'Gesetzessammlung' (DaniČic I, 359). Vgl. noch bei Daničić I, 359: po zakonbniku svetych otbcb = nach dem Gesetz der hl. vater, aber: bezakonbnikb = qui contra jus fasque agit (Daničlc $I, 32$ ). Im Ar. ist zakonanikb m. als nomen agentis nur im christlichen Sinne belegt, vgl. dazu Srezn I,923 und unter domb I,700. 
c. Eigenbildungen

$i z v \circ l j e n$ z $k$ b m. božii electus Dei 'Auserwăhlter Gottes', gebildet aus dem part.prät.pass. von dem verb izvoliti pf. $i z v o-$ ljen- + Suff. -ikz. Das substantivierte Partizip izvoljenyi tritt als Wortvariante für den gleichen Begriff auf.

Der biblische Auserwăhlungsbegriff steht zunăchst in enger Beziehung zu der Person Christi selbst; se otrokb moi egože izvolichb valjubleny moi Mt 12,18 (zogr Ass Sav) 'das ist mein Knecht, den ich erwählte, mein Geliebter'. Im Sinne einer besonders gnadenreichen Berufung kommt es in Mt 22,14 vor: "Denn viele sind gerufen, wenige aber auserwăhlt". Der Begriff der Auserwählung ist mit dem der Berufung nah verwandt, aber nicht identisch, er setzt ein bevorzugendes Herausheben, unter Umständen Aussondern einzelner Menschen oder eines Volkes (Israel) oder einer Gruppe (Apostel) voraus. Alle Glieder des durch Christus gehelligten Volkes sind berufen, aber nur wenige erweisen sich durch ihre Glaubensantwort als Auserwăhlte (LThK III,1061-62). In diesem Sinne wird das Wort $i z$ voljenikb in Fris verwandt. Das Verb $i z$ voliti erhielt durch den biblischen Gebrauch einen besonderen Sinn, und aus dem so christianisierten stamm wurde izvoljenikb als Terminus gebildet. ${ }^{1}$ Sein Vorkommen ist auf drei asl. Denkmäler beschränkt. AuBer Fris findet es sich noch in Prag und Bes. Nach MAREš handelt es sich um ein tschechisch-altkirchenslavisches Wort. 2 Beherrschend in der asl. Literatur ist das synonyme Verb $i z b b r a t i$ pf. mit den daraus abgele1teten Formen izbbranb, izbbraninb, izbbranyi (LLP I, 723).

$k r i l$ a $t$ b $c$ b m. gebildet aus krilatb 'beflügelt' + Suff. $-b c b$ wird als die frühste slavische Bezelchnung fur den christlichen Begriff 'Engel' angesehen. Bei der Entstehung einer solchen Benennung mag die Vorstellung eines beflugelten Wesens, das als Uberbringer göttlicher Botschaften zwischen Himmel und Erde in Bewegung ist, mitgespielt haben. Die Bezeichnung eines ăuBeren Merkmals wird zur Bezeichnung des ganzen Begriffs. BUSLAEV will krilatbcb im Zusammenhang mit der heidnischen Vorstellung von beflügelten Geistern sehen. ${ }^{3}$ In dem Wortschatz der Volkspoesie wurden sich

1. Vgl. Teeuwen 88 und Anm.2. Ferner s.o. S.24, Anm. 3.

2. Vgl. Mareš 225 : Mareš 136 . Vgl. auch Čech 174-181.

3. Buslaev 28-29. Sein Beispiel aus dem Igorlied zeigt aber eher den EinfluB der christlich-biblischen Vorstellung auf den wortschatz der volksdichtung. 
Spuren slavischer Mythologie erhalten haben, wie z.B. Relja krilatica in den serbischen Liedern, und vsi tri Mstislaviči, ne chuda gneada šestokrilbci im Igorlied. Von der überlieferten heidnischen Tradition spricht auch MOSzYŃSKI in Verbindung mit dem Volksglauben an vogelgestaltige, fliegende Dämonen $(I I, 683,409)$. Doch sind die Vorstellungen der Engel als beflügelte Wesen vor allem in den alttestamentlichen Schilderungen zu suchen. Die Berufungsvision des Isaias (Is 6,2 ) beschreibt Engel als sechsflügelige Wesen, die vor dem Throne Gottes (Jahwes) stehen: "Seraphe standen vor ihm: jeder hatte sechs Flügel. Mit zweien bedeckte er seine Fübe, und mit zweien schwebte er." Unmittelbar danach folgt die Stelle, welche den Wortlaut des Sanctus in der MeBliturgie bildet: "Und immerfort rief einer dem anderen zu: 'Heilig, heilig, heilig ist Jahwe zebaot, die ganze Erde ist voll seiner Herrlichkeit." (Is 6,3). Diese Stelle muBte den christlichen Missionaren sehr gut bekannt gewesen sein, und der stoff schien besonders geeignet, die Phantasie der neubekehrten vollker anzuregen. ${ }^{2}$ Die überlieferten Wortbildungen wie šestbkrilatb adj. Azb 55,30; šestokrilatbcs m. Supr 463,8; šestokrilbnyi adj. Supr 458,15; šestokrilatb adj. Euch 4a 17-18; $i^{3}$ šstokrilataja sirafimb, šestokrilbcb m. (Srezn III, 1589) sind ein beredtes zeugnis ihrer Herkunft. Aus diesem zusamenhang darf krizatbcb nicht herausgenommen werden, doch sollte die Unabhängigkeit dieser Wortbildung von literarischen Vorlagen beachtet werden, die besonders im Vergleich mit einem wortgetreuen Uberset-

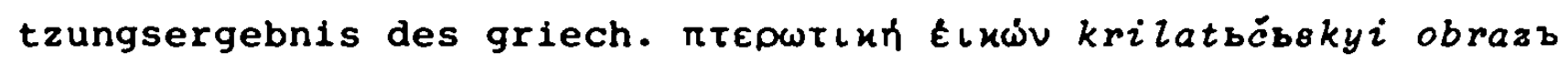
'Engel' deutlich vor Augen tritt (Sobolevskij 2 163). Auch die Komposita mit $\check{e} e s t b-, \check{s} e s t o-$ gehen auf griechische Vorbilder zurück (Schumann 2 57).

2u dem Wissen, daß Engel Gottes Boten sind, die ihm dienen, gehörte auch der Glauben daran, daß sie die Menschen an Leib und Seele beschützen. Sehr konkret betete man un diesen schutz in dem Gebet "Molitva na dbjavola" (Dijav): zakrilite me vašimi štymi plamenbnymi krily vsjudu (Sobolevskij, 45).

Die Versuche, den Engelbegriff mit einem slavischen Wort wiederzugeben, erwiesen sich als erfolglos. Sowohl krilatbcb als auch

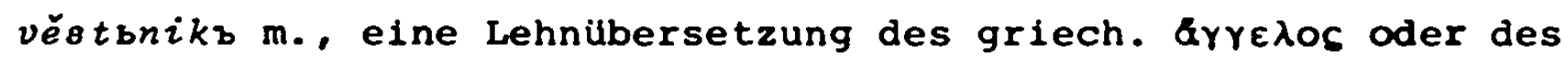

1. Der lat. Text des rómischen MeBbuches nach A.Schott: Sanctus, sanctus, sanctus Dominus Deus Sabaoth. Pleni sunt caeli et terra gloria tua.

2. Vgl. auch 1 Kón $8,6-7 ; 1$ Kón 6,27, die Beschreibung der Cherube im Salomon-

3. Alle Belege aus Arch LLP. 
lat. nuntius 'Nachrichtenüberbringer', gelegentlich auch sluga $\mathrm{m}$. und $8 \mathrm{~b} l_{\mathrm{b}} \mathrm{m} .{ }^{1}$ wurden von dem Lehnwort ange $l_{\mathrm{b}} \mathrm{m}$. verdrängt. ${ }^{2}$ Aus dem griech. aryedos uber lat. angelus entlehnt, wurde und blieb es alleinbeherrschend. Dafür wird wohl die gleiche theologische Motivation angebracht sein, wie sie bei dem wort apostolb erlautert wur-

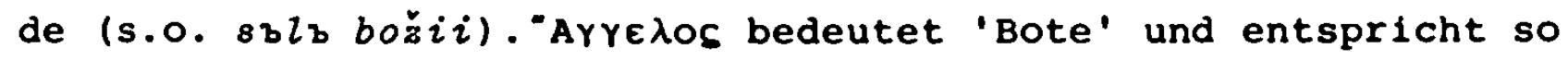
dem Engelbegriff des NT, wo nicht das Wesen, sondern die Aufgabe im Dienste Gottes (oder des Teufels!) im Vordergrund steht (Bthw I, 225). "Angelus enim officii nomen est, non naturae" erklärt Augustinus (Sermo VII,3, BthW I, 225). Dennoch werden Engel im NT als uberirdische Geister vorgestellt (Kol 1,20), es werden verschiedene Gruppen himmlischer Wesen genannt: "Măchte" (Röm 8,38). "Gewalten" (1 Kor 15,24), "Herrschaften" (Eph 1,21), was auch entsprechende wiedergabe in der asl. Literatur findet.

Das Wort krilatbcb kommt als hapax legomenon nur in Fris $I$ vor. Es wird vom Adjektiv božii begleitet und es läbt sich nicht bestimmen, ob dieses notwendig zur Engelsbezeichnung gehört. 3

$n e d \check{e} l b \mathrm{~m}$. Die Bedeutung des Wortes ist aus dem Kontext nicht eindeutig $z u$ bestimen. GRIVEc vertritt die Ansicht, dab es sich um die Bezeichnung des Feiertages, einschlieblich Sonntag handelt. 4 Darin stimmt er mit GRAFENAUER uberein, der die maskuline Form nedělb als die altere slavische Bezeichnung für 'Feiertag' gegenüber der Wortvariante nedělja f. ansieht. 5

Das Wort ist aus dem Verb dělati 'tun, arbeiten' und der Negation ne-entstanden. Uber die Entstehung bzw. Herkunft des auf die gleiche Weise gebildeten Ausdrucks nedělja f. In der Bedeutung 'Sonntag', dann auch 'Woche' herrschen verschiedene Ansichten. Nach MACHEK ist es als eine eigene Neubildung unter dem Einflub des Christentums anzusehen (321). VASMER (II,208) hălt es für eine

1. Zu der wiedergabe des angelus mit 8 blb wăre $z$ u sagen, daB sie recht selten ist, und darin zeigt sich die Treffsicherheit der slavischen tbersetzungen. S.O. unter $8 \mathrm{blb}$ zur Begriffsabgrenzung. 2. Nach Kolarič 89 wird krilatbcs im Slovenischen in der Kindersprache und in

3. Vgl. dazu Pogačnik, 150. 4. Vgl.Grivec 15: "Alverjetneje je, da je to značilni slovenski n e d e 1
(moškego spola) v pomenu p r a $2 n i k "$.

5. Vgl. Grafenauer, 69:" "Beseda nedel utegne biti $v$ slovenščini starejši kakor nedĕlja, ker so slovanska tedenska imena moškego spola (ponedeljek, torek, četrtek, petek), ... dan je pač m. sp. Pod vlivom cerkve (dies dominica) pa je zmagala zaradi razlikovanja nedelje od drugih praznikov nastala dubleta ž. sp. nedélja." vgl. auch Grafenauer 235. 
Lehnübersetzung aus lat. feria, dies feriata eher, als aus griech. ánoaktos h̀uḱpa und begründet seine Ansicht mit der Verbreitung des Wortes nedělja im Bereich des Westslavischen. BuSLAEV meint, daB sowohl der Begriff, als auch das Wort schon in der vorchristlichen zeit existierte, gibt aber dafür keine Begründung (Buslaev 126). DURNOVO hält es für möglich, daB die Wortbildung nedělja f. unter dem EinfluB des byzantinischen Griechisch erfolgte. ${ }^{1}$ In der Tat ist die tbereinstimmung der slavischen Bildung mit dem griech. Vorbild auffallend: a-mpaxtos, also verneinendes \&- und ein Ver-

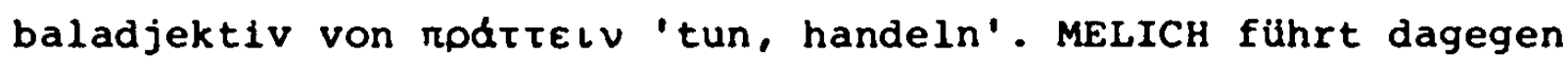
provb (provaja) und jedinb (jedinaja) als die nach dem griech.

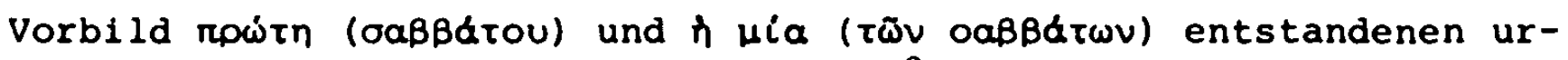
sprünglichen Sonntagsbezeichnungen an. ${ }^{2}$ Diese seien dann durch die der lat.-romanischen Terminologie angehörenden Bezeichnung nedělja (dem lat. feria nachgebildet) ersetzt worden. Allenfalls könnte die feminine Form unter dem EinfluB der lat. feria (ursprünglich 'Ruhe') und der griech. kuplakh, bzw. ihrer lat. Entsprechung dominica aus dem älteren, im slavischen vorhandenen nedělz $\mathrm{m}$. entstanden sein. ${ }^{3}$ Als Bezeichnung für 'Feiertag' ist die maskuline Form nede 2 nur noch im Karantanischen erhalten. 4

Es ist nicht mit sicherheit festzustellen, ob nedělz eine Neubildung für einen christlichen Begriff ist, doch der sinn des Wortes 'der Tag, an dem man nicht arbeitet' weist auf die dahinterstehende christliche Auffassung vom Feiertag, an dem die Arbeit verboten ist. Die maskuline Form spricht für die Unabhängigkeit von den fremden Vorbildern. ${ }^{5}$ Gerade aus dem Vergleich mit der späteren Form nedězja f. (nach GRAFENAUER als Bezeichnung des Sonntags zum Unterschied vom Feiertag) kann die Uberzeugung gewonnen werden, daB neděls $\mathrm{m}$. eine eigensprachliche Leistung darstellt.

Als hapax legomenon steht nedě $z_{b}$ als Bezeichnung für den christlichen Felertag einigen anderen wortern gegenüber, von denen

1. Durnovo RES 6,107-108: "Il est sans doute probable, que le nom slave du dimanche nedélja est une traduction du mot latin ecclésiastique feria, mais 11' n'est pas moins probable, que ce nom est un calque du mot grec arpaxtos (hufpa) 'la fete', usuel en grec byzantin, et dont on se servait aussi pour désigner le dimanche comme la fête par excellence."

2. Vgl. Melich 215,217 und Bauer 1439 unter rõ̃tos.

3. Vgl. Bauer 906 unter xuplakh.

4. Vgl. Grivec, 15; Grafenauer, 69; Pleteršnik 1,684; Vondrák, 30; Kopitar XIIII

5. Etwaige germanische BeeinfluBung kann nur sekundăr bewertet werden. 
prazdbnikb m., svetb dbnb m., trogb m., trbábstvo n., dbnb slavbnb m., zu nennen wären. Uber den Ausdruck $\chi_{b s t b} f$. lat. festivitas, solemnitas s.o. unter čbsti pijemb.

$8 v \& t_{b} v e \underline{c} e r b \quad \mathrm{~m}$. 'heiliger Abend' in wörtlicher Ubersetzung. Diese asl. Eigenbildung entspricht wohl dem ahd. vespera in der Bedeutung 'Abendgottesdienst', das ein Lehnwort aus dem Kirchenlatein ist. In diesem sinne wird das lat. vesper im kirchensprachlichen Gebrauch verstanden. 1 In der Benediktiner-Regel wird es mit abantlob ubbersetzt (Ibach 81,147 ). Unter den ahd. Beichten wird nur in der Reichenauer Beichte als Unterlassung der Mönchspflicht, das abendliche stundengebet zu verrichten, der selbstvorwurf erhoben: "daz ih mina chirichun so nesuahda duruch mammendi mines lichamen, nóh mine uespera nóh mina metdina nóh mina messa nigiloseda" (Steinmeyer 332, LI, 11-13). Da aber Fris I nicht den Typus einer Mönchsbeichte darstellt, muB für suętb večerb ein erweiterter Sinn angenommen werden: 'Vorabend eines Festtags, der mit einem Gottesdienst gefeiert wird'. In dem lateinischen Text von Scarapsus, von dem die Reichenauer Beichte beeinfluBt ist, findet sich in der Empfehlung, die Kirche oft zu besuchen, folgende Aufzăhlung der dafür gebotenen Gelegenheiten: "... Omnibus diebus dominicis, et cunctas festivitatis preclaras tam ad vespertinis vigilis (et) matutinis, quam ad missas celebrandas vos frequentate" (Hautkappe 4; Grafenauer, 70). Ahnlich ist der Inhalt der "Confessio generalis" in der Handschrift von Stična ("Stı̌ki rokopis") aus dem Jahre 1428: "Ya ze dalsam dam, kyr swete nedele swete sobothe veczeri, druge swete dny ynw veczeri neyssam nykuly taku prasnowall ynw czastil ..." (Miklosich 171$)$. Aus dem Textvergleich geht hervor, daB der Ausdruck svęt vecerb 'vigil vor den Festtagen' bezeichnet, welche feierlich zu begehen, die Christen verpflichtet waren. Man denke an den Ausdruck 'Helligabend', dessen Bedeutung auf den Vorabend des Weihnachtsfestes eingeschränkt ist.

$v \check{e} r \quad b \quad i k b \mathrm{~m}$. In der Bedeutung confessor 'Bekenner' ist wohl der erste Versuch (und auch der einzige erhaltene Beleg), diesen Begriff in der asl. Sprache wiederzugeben. In der ubrigen Literatur erscheint das Wort ispovědbnikz m. und entspricht so vollkommen dem lat. sprachlichen Vorbild. Darin mag auch der Grund zu su-

1. Vgl. dazu Tschirch, 134; Grafenauer, 70-71; Grivec, 15. 
chen sein, daß sich věrbnikz m., das eher dem lat. fidelis 'der Gläubige' gleichkommt, als Terminus für 'Bekenner' nicht durchsetzen konnte.

In der Verfolgungszeit war das von Tertullian geprägte Wort confessor sowohl Bezeichnung für diejenigen, die ihren Glauben bekannt haben, aber nicht den Tod erlitten, als auch für die Märtyrer im engen Sinn. Nach Aufhören der Verfolgungen nannte man confessores zunächst die Verteidiger des wahren Glaubens, dann auch diejenigen, die in ihrem Leben die christliche Lehre verwirklichten und Christus bekannten. 1 vor allem in letzterer Bedeutung ist confessor in der lateinischen Liturgie und in den von ihr beeinflubten volkssprachlichen Liturgien lebendig geblieben. 2

Die wortbildung věrbnikb aus der adj. Basis vĕrbnb - Suff.-ikz tritt als Kompositum inověrsnikb $\mathrm{m}$. 'Andersgläubiger', Hăretiker' in Supr 303,6 auf (LLP I,771). Mikl LP 122 führt drei Belege für věrbnikb in der Bedeutung fidelis an. Diese wird auch für věrbnikb in Fris von LLP angegeben, man ist also der Ansicht von MIKLOSICH gefolgt, daB es sich bei dem Wort věrbnikb in Fris I um fidelis 'Gläubiger' und nicht un confessor 'Bekenner' handle.

Andere Forscher haben sich fur die Ubersetzung confessor entschieden, durch seine uberzeugenden Darlegungen hat sich darin besonders PIRCHEGGER verdient gemacht. ${ }^{3}$ Seiner textkritischen Verfahrensweise kann noch eine sprachliche Motivation hinzugefugt wer den, die das Entstehen der Wortbildung věrbnikz gegenüber ispovědb. nikb rechtfertigen kann. Sieht man ispovědbnikb als eine elliptische Verkürzung von vëre ispovědati an, so ergibt sich die Möglich. keit zur Bildung von věrbnikb auf dem gleichen Wege. Hier wird dem ersten, da dem zweiten Tell die Aussage uber das Ganze ubertragen.

1. Vgl. Teeuwen $87 \mathrm{ff}$. Dort auf S. 92-93: "Erst nach Tertullian wurde 'confesso: haufiger gebraucht, und sein Begriffsinhalt entwickelte sich ... imber weiter, bis es schlieblich mit dem Martyrertum gar nichts mehr zu tun hatte und unsere jetzige liturgische Bedeutung 'Bekenner - Nichtmartyrer' annahm Der Grdzismus 'martyr' hingegen blieb für 'Martyrer' im strikten sinne bestehen und wurde so nachher als Titel der liturgische Ausdruck far die martyrer."

2. Vgl. LThK I1,142. Dazu auch Rheinfelder, 60: "... in den Bezeichnungen der Heiligen (findet man) niemals unter den verschiedensten Zusamenstellungen ein 'martyr et confessor' : gleich nach den zeiten der verfolgung ... war 'martyr' der Mensch, der fur den Glauben gestorben war, 'confessor' der Beilige, der keine Marter hatte erdulden müssen."

3. Fur confes8or sprachen sich aus: Dobrovsky, Grivec, Grafenauer, Ropitar. Vondrak und vostokov geben fidelis als Bedeutung an. In dem Glossar von Pogačnik werden beide Bedeutungen zugleich angegeben (!). 


\section{Umprägungen}

a. Lehnumprăgungen

$b r a t r i j a$ f. coll. ist die Wiedergabe des lat. fratres in der Bedeutung 'Glaubensbrüder', d.h. die Mitchristen untereinander (Teeuwen 122). Als Anrede wird es in Fris II gebraucht und findet sich auch in dieser Funktion in der Homilie zum Fest des hl. Markus ${ }^{1}$ und in der unter dem Namen "Klimentpredigt" bekannten Homille "Poučenije na panjatb apostola 111 mučenika". 2 Aus der Familiensprache entnommen wurde das wort frater, meistens im Plural verwendet, schon von Tertullian zum christlichen Terminus umgeprägt. ${ }^{3}$ Es bekam einen spezifischen religiösen sinn, in dem die Blutsverwandtschaft auf die geistige Gemeinschaft der Christen übertragen wurde. In diesem zusammenhang ist es erwähnenswert, daB die Bedeutung des idg. *bhrāter über die Blutsverwandtschaft hinausging und sich auch auf die zugehörigkeit zu einer Gruppe bezogen hatte. 4

Ahnlich dem Kollektivum wurde auch $b r a t r b$ m. 'Bruder' auf den Mitchristen, den 'Nächsten' im Sinne des lat. christlich umgeprägten proximus erweitert und so zum religiös-sittlichen Terminus ungestaltet worden.

Seitdem GRAFENAUER auf den Zusammenhang von Fris mit den katechetischen und homiletischen Schriften der karolingischen Missionstätigkeit hingewiesen hat, kann es keinem Zweifel unterliegen, daB viele Ausdrücke in Fris durch die Vermittlung der lateinischen und der althochdeutschen Sprache entstanden sind. 5 Auch die Lehnumprägungen bratrb, bratrija können als Folge dieser Beeinflubung ange-

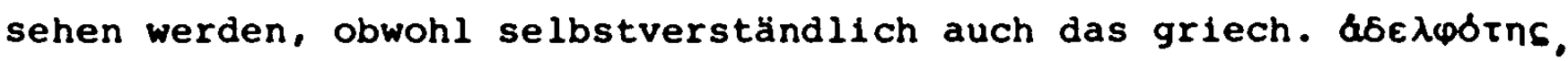

1. Vgl. Vostokov 2-4. Der Titel dieser homilie lautet: "Vb tol že denb (apr. 25) poučenije na pamjats ovjatago Apostola Marka."

2. In Mikl Term 3-6.

3. Vgl. Teeuwen 122-123: "Die Auffassung der gesamten Christenheit als familia dei lst bei Tertullian, whe uberhaupt in der Bibel, sehr ausgedehnt. Gott ist der Vater und die Kirche die Mutter. Die Taufe, die den Menschen zum Christen macht, wird secunda nativitas, regeneratio usw. genannt. - Fratres bedeutet nicht nur im Kontext, sondern auch absolut die Glaubensbroder, die Mitchristen untereinander. ... Praternitas erhalt konkret, im selben sinne wie fratres, den Kollektivbegriff 'die Christgeneinde' und abstrakt dieselbe Bedeutung wie pax ..."

4. Vgl. Benveniste 1,209: "\#hrater n'est pas non plus le frére consanguin: le grec, dans phrátēr, nous conserve mieux qu'aucune autre langue le sens de 'membre d'une phratrie', terme de parenté classificatolre."

5. Vgl. Grafenauer 12,24 ; Steinmeyer 161, xxx,14: brudera. 
das schon im NT in diesem Sinne gebraucht wird, dasselbe Ubersetzungsergebnis bringen muB.

b $r a t r$ s m. 'Nächster' proximus s.o. unter bratrija.

Als weitere lexikalische Varianten für den 'Năchsten' im christlichen Verständnis können bližbni $i$ adj. und subst., bližb$n i k b \mathrm{~m}$. $i s k r b n b$ adj. und subst., drugb m. genannt werden (LLP I, $113,519,795)$.

$d \check{e} l o n$. 'die Tat', das Werk'. Aus der Allgemeinsprache herkommend bekommt das wort délo unter dem EinfluB des lat. opus, ahd. wërk einen neuen, spezifisch christlichen Sinn. Eine reiche Bedeutungsskala weist das entsprechende griech. Eprov schon im NT auf. 2 Von der Schandtat bis zur höchsten sittlichen Leistung erstreckt sich dort sein sinngehalt (Bauer 609). Dieser wird jeweils durch das Attribut bestimmt, kann aber auch durch den weiteren Kontext erschlossen werden.

Von besonderer Prăgnanz ist der Ausdruck děla sotonina, opera Satanae, tiufales uuerchi, der eine Umschreibung für 'Sünden' darstellt. ${ }^{3}$ Ahnliche Bedeutung hat auch děla pl. in der Abschwörungsformel von Fris III,1-4. Eine wörtliche Entsprechung in "Alemanischer Glauben und Beichte" lautet: "Ich widersaig diem tiuvel unt allen sinen werchen ..." (Steinmeyer 350, LVII,1). 'Sünden' bezeichnet auch nepravdınaja děla, mrbzbkaja děla. 4 Dagegen stehen opera bona 'gute Werke', insbesondere die unter opera misericordiae bekannten Werke. ${ }^{5}$ Ihre Aufzăhlung bestimmt den Sinn von děla pl. in Fris II, 42-57.

Als Umschreibungen für sünden finden sich in der asl. Literatur noch folgende Ausdrücke: děla temnaja, bezakonbnaja děla, zblaja déla. Dagegen werden die Tugenden mit blaga děla, dobra děla bezeichnet (LLP I,549).

$i m \varepsilon n$. ist in der Bedeutung 'Person' eine Nachahmung der ahd. Wiedergabe des lat. Begriffes persona mit dem Wort namo 'Namen'. AuBer in Fris III ist es noch in der Homilie des hl. Kliment "slovo na roždbstvo chsvon ${ }^{6} \mathrm{u}$ lesen: sy ̌̌e try $i m e n$ a $8 i \operatorname{rečb}$.

1. Vgl. Bauer 32: $4 \delta \varepsilon \lambda \varphi \delta$ tns die Bruderschaft (= Glaubensgenossen).

2. Vgl. Bauer 608-609. Zum Bedeutungswandel des lat. opus vgl. Teeuwen 180 und Ibach 79,128.

3. Dazu vgl. Grafenauer, 35.

4. Vgl. Steinmeyer $327,{ }^{1}$ XLVIII, 3 wrehtero werco: $329, X L I X, 4 ; 331, L, 3$.

5. Vgl. dazu Grafenauer 36.

6. Auszugsweise in Vondrak 143. 
lica jedino jests $\overline{b \check{z}}$ tvo a tri ipostasi. Anscheinend war es den zuhörern nicht ohne weiteres verständlich, wenn es einer ergănzenden Erklärung bedurfte. Die Berechtigung, den Begriff 'Person' mit namo (auch genennida) zu übersetzen, kam aus dem biblischen Sprachgebrauch selbst. Im AT wird 'Name' im Sinne von 'Person' gebraucht; ähnlich in der Apostelgeschichte $(1,15)$ und Apokalypse $(3,4 ; 11,13)$. Als Beispiel mag Eph $(1,20-22)$ dienen: "Gott setzte Christus hoch über alle $\mathrm{N}$ a $\mathrm{m} e \mathrm{n}$, die genannt werden nicht nur in dieser, sondern auch in der zukünftigen Welt." 1

Diesen heute unverständlichen sprachgebrauch erklärt die religionsgeschichtliche Forschung mit der Frühform menschlichen Denkens, in der der Name ein wesenhafter Teil des Benannten selbst ist, nicht nur auberliche Kennmarke zur sicheren Unterscheidung (Tschirch 263). Der Glaube ${ }^{2}$, daB ein Wesen und sein Name miteinander identisch sind, läbt sich auch aus der Geschichte der deutschen Sprache belegen. Lat. persona im Sinne von 'Gestalt, Persönlichkeit, Wesen' in der Streitschrift von Isidor von Sevilla "De fide catholica contra Judeos" wird in der ahd. Ubersetzung mit namo wiedergegeben. Auch die altdeutschen Glossare führen diese Ubersetzung. So kam es auch in die Trinitatsformel als die im ganzen Mittelalter ubliche Bezeichnung für die drei gottlichen Personen: die namen drt (Tschirch 2 264-265). Dieser Sprachgebrauch in der Aussage der Dreifaltigkeitsdogmas ist eine deutsche Eigentümlichkeit, dem Lateinischen und Griechischen aber fremd. Es muB also dem Verfasser von Fris III das ahd. namo vorgelegen haben, und er gab es richtig mit ime wieder. 3

Wie grob die Schwierigkeit war, das Wort persona im Athanasianischen symbol wiederzugeben, geht aus den worten Notkers hervor: "unsenfte ist zediutenne personam" (= schwierig ist zu deuten personam) (Schmidt 91). Nicht minder war die Schwierigkeit fur die slavischen Ubersetzer; die Vielfalt in der Ausdrucksweise für die-

1. Vgl. Clemen 23.

2. Dazu schreibt Clemen 22: "Wie er entstanden 1st, lst nicht so leicht zu sagen; ... man kann ... nur annehmen, daB sie (die Namen) ursprünglich ... von dem Wesen des betreffenden Menschen oder Dinges entlehnt wurden und dann ... selbst als Teile desselben erscheinen. Jedenfalls ist das die Anschauung, die sich zunachst bei den Primitiven findet und auch bel verschiedenen Kulturvolkern nachwirkt."

3. Vgl. Steinmeyer 346, LVI: "daz die drfe nawen"; 353,LVIII: "Ich geloube die drle namin ain gewarin got" (Sangaller Glauben und Beichte III,4-5) 
sen in der theologischen Diskussion so unstrittenen Begriff gibt ein beredtes Zeugnis darüber. Neben den schon angeführten $l_{i c e} n$., und $i(u) p o s t a s b \mathrm{f}$. werden sbličije n. sobbstvije n., sobije n.. sobbstivo n., obrazb m. ${ }^{1}$, sbstavb(b) f.(m.), postatb f. gebraucht. ${ }^{2}$ $n e p r a v$ b $d$ b $n$ b adj. 'ungerecht' s. unter pravbdbnb. $n$ e p r $i j a z n i n$ b adj.poss. 'des Teufels, des Bösen' abgeleitet von neprijazns f., das ein Tabuwort zur Bezeichnung des Teufels als einer bösen, gefăhrlichen Macht ist. Allgemein wird neprijaznb für eine Lehnübersetzung gehalten. Es besteht jedoch keine Ubereinstimmung darüber, ob es sich un gotische oder althochdeutsche BeeinfluBung handelt. ${ }^{3}$ Auf die Verwandtschaft dieses Wortes mit dem got. unhulpo hat schon BUSLAEV hingewiesen und besonders vermerkt, $d a B$ beide wörter im femininen Genus übereinstimmen (Buslaev 102). Das hat seinen Grund in dem "sehr alten Glauben an eine böse Gottheit weiblichen Geschlechts ... Erst später unter dem griech. sprachlichen EinfluB wechselt unhulpō zu Maskulinum über und kommt bald im Femininum, bald im Maskulinum vor ... Die got. Form unhulpo ist sicher über die Verneinung der gnädigen Göttin Holdâ zur Bezeichnung der ungnädigen Göttin entstanden." 4 Auch ISAČENKO hält neprijaznb für eine Ubernahme aus dem Gotischen (Isačenko, 47). AUTY stützt sich auf NAHTIGAL, der an eine germanische BeeinfluBung denkt. 5 Auch HORÁLEK äuBert sich ähnlich darüber, indem er sich neben NAHTIGAL auch auf KOPITAR beruft (Horálek 117). VASMER steht der Lehnübersetzungsfrage unentschieden gegenüber, während MIKLOSICH an eine germanische Vermittlung denkt (Vasmer II,212; Mikl Term 42).

Nach STANISLAV gehört neprijaznb f. in der Bedeutung eines

1. Vgl. Sobolevskij, 69: vb obrazéchb čislo troica im Wortregister zu Bes.

2. Vgl. Mikl LP 867,868; Jagic Entst 539; Vondrák 83: vb trbchb upostasbchb; tmi upostasi vb jedinomb sustbstvé; vb tmbchb sobsstvěchb kupno; tmi sbstavi szličbno vb edinomb božbstvé.

3. Wenn es sich un eine Lehnübersetzung handeln würde, könnte es vom Standpunkt des Asl. nicht als ein Tabuwort angesehen werden.

4. Buslaev 102. Vgl. auch Kluge 806: "der germanische Teufel- und Hexenname ist das subst. Adj. whold ... 'nicht geneigt, feindlich'. Dex ursprüngliche religiose Gehalt von hold tritt dabei zutage." - Man sollte uberlegen, ob es sich nicht um zwei verschiedene Bedeutungsentlehnungen handelt: einmal des got. unhulpo f. = neprijazns (f.د m. unter dem griech. EinfluB), zum anderen des subst. Adjektivs whold = neprijaznimb adj.. im Altserbischen jedoch substantiviert, - auch die Form in Fris II,33-34 kornnte als eine solche angesehen werden und wăre dann im Text vơllig verstándlich.

5. Vgl. Auty 5: "Neprijazrs must by taken (with Nahtigal...) as a calque on oHG unholdo." 
bösen Wesens zu der ältesten Sprachschicht und tritt in der Bedeutung $\delta\llcorner a \beta O \lambda \circ S$ in der schon etwas jüngeren schicht auf (254 ff.). Zur Stütze seiner Beobachtungen können noch andere Belege angeführt werden, in denen das Wort im positiven sinne in der Form prijaznb f. In der Bedeutung amicus, benevolentia, fides amicitia in den asl. Texten vorkommt. ' L'vOV gibt auch noch differenziertere Bedeutungen an, wie: 'dobroželatel'stvo, druželubie, vera, doverie, vernost' ; für die negative Form wird von ihm das Adjektiv neprijaznivb aus Supr 328,13-16 in der Bedeutung 'neprijatnyj, nedoverčivyj' zitiert (198-199). Mit den Belegen aus Bes, wo für neprijazninb adj. lat. malignus, malus steht, können die Beispiele von L'VOV noch ergänzt werden. 2 Für das Altrussische gibt SREzNEVSKIJ auBer ' $d$ 'javol' auch noch die Bedeutung 'vražda, 210 ' für neprijaznb an $(I I, 416)$. Im Altserbischen wird dafür nur die Bedeutung inimicitia notiert, wăhrend für diabolus neprijaznins steht (DaniCić II, 148).

Wie die angefühten Belege zeigen, war das Wort neprijaznb im asl., ar. und aserb. Wortschatz in einer anderen Bedeutung bekannt, bevor es die spezielle Prägung mit dem Sinngehalt 'Teufel' im christlichen Verständnis erhalten hat. Das spricht gegen eine Lehnübersetzung in dem sinne, wie dieser ordnungsbegriff in der vorliegenden Arbeit verstanden wird. Unter dem germ. Einflub ist nicht ein neues wort entstanden, sondern ein schon bestehendes slavisches Wort hat eine neue Bedeutung angenommen.

Uber adere Teufeisbezeichnungen s.u. unter zblodei.

$o t b c b \mathrm{~m}$. 'Vater' ist ein ständiges Attribut für Gott als Bezeichnung der ersten gottlichen Person in der trinitarischen Formel. Darin findet das Vater-Sohn-Verhältnis in Bezug auf Jesus seinen Ausdruck. Die Anwendung des Wortes auf Gott stammt von Christus selbst, er nennt Gott absolut 'Vater'. Daraus resultiert die Kindschaft Gottes des christlichen Volkes. Jesus selbst bezeichnet Gott als Vater der Menschen; er leitet sie an, im Gebet Gott als Vater anzureden. ${ }^{3}$ Daraus entsteht für die Menschen die Berechtigung, sich als "Kinder Gottes". "Sobne Gottes" zu verstehen und

1. Das Belegmaterial des Arch LLP weist in Supr 36,409,1, Leg N1k 20,9, Bes 35 , 259 bB 5 fór prijaznb $f$. die Bedeutung arricus auf, was für obige Betrachtung besonders wichtig erscheint. Euch 18 a 3 prijaznb = 'Liebe'; Supr 6,82,5 benevolentia etc.

2. Bes 32,215 aB 19,22 malignus $=$ neprijaznb: 1,6 ba 9 malus $=$ neprijasnb.

3. In Mt 6,9 , Lk 11,2; Bauer 1260-1261 unter ratho. 
so auch $2 u$ bezeichnen; synovĕ bő̆ii narečemb sę heibt es in Fris II,16-17. Der Gedanke findet in der paulinischen Theologie eine besondere Beachtung. Aus dem Sohnschaftsverhăltnis erwăchst die Verpflichtung, die Vaterliebe mit der Bruderliebe $z u$ beantworten, daher auch die Bezeichnung 'Bruder' bratrb und bratrija 'Bruder' für die Christengemeinde (Bthw II, 1275).

Der Vaterbegriff der Bibel ist durch das Patriarchat bestimm, das dem Vater den Primat in der Familie (Grobfamilie) einrăumt (BthW I, 1368). Durch Benennen Gottes mit 'Vater' soll aber auch seine unermeBliche Güte, die Fürsorge und die verzeihende Liebe vor Augen gefüht werden. Mit der Berufung auf das Sohnesverhältnis bringt der Mensch zum Ausdruck, daB er Gott Leben und Dasein verdankt, seine Abhängigkeit von ihm anerkennt, daB er aber trotzdem vertrauensvoll sich an ihn wenden kann.

Das aus der Familiensprache kommende Wort otbcb ist eine Deminutivform ${ }^{1} \mathrm{zu}$ *ots $\mathrm{m} .$, idg. *ătos, ahd. atto 'Vater, Vorfahr', got. atta, Demin. Attila etc. (Pokorny I,71; Machek 345). Es wird im Verhältnis zu Gott gebraucht und bekommt im christlichen Wortschatz einen festen Platz. Es ist vom doppelten Aspekt gekennzeichnet: Gott ist Vater Christi und Vater der Menschen. Diese inhaltliche Wandlung hat sich parallel zu den Vorbildsprachen vollzogen." $p \circ k a z n$ b f. aus idg. *kueg- 'erscheinen, sehen, zeigen'; asl. kazati 'zeigen,mahnen' (Pokorny I,639). Die Substantivbildung po$k a z-n b$ aus po-kazati ist durch den zweifachen Bedeutungsaspekt gekennzeichnet: des ursprünglichen 'zeigen, mahnen, belehren, bessern' und des daraus entwickelten 'strafen'. Die sinnentfaltung von pokaznb, in der nach VLADIMIRSKIJ-BUDANOV die grundsätzliche Einstellung zum zweck der strafe sichtbar wird, läbt sich an dem Wort pokazanije, das 'strafe' u.'Belehrung' bedeutet, verfolgen. 3 Ohne das Präfix po- gehört kaznb $f$. in der Bedeutung 'Strafe' zum àltesten slavischen wortschatz (Machek 196). In Fris I entspricht pokazns dem ahd. harmscara im St. Emmeramer Gebet (Steinmeyer $310, X L I I, A$ und $B, 20)$. Es findet sich aber auch für griech.

1. Vgl. dazu Vasmer II,290: ursl. otbcb aus *otbkb. Ableitung von totb 'Vater' ist vorausgesetzt durch ar., ksl. otbnb 'văterlich'.

2. Zum Inhalt des griech. $\pi \alpha$ rho, des lat. pater, des got. atta und fadar vgl. Benveniste I,209-212. Benveniste unterscheidet zwei idg. Vater-Bezeichnungen: "Le terme "poter est pregnant dans 1 'emplois mythologique." (I,210). "atta doit etre le 'père nourricier', celui qui élève l'enfant." (I,211).

3. Vgl. Vladimirskij-Budanov $333 \mathrm{ff}$. Der philosophische Sinn des Wortes nakazanie sei Belehrung und Besserung. Der Autor erlautert die ethischen Grundla- 


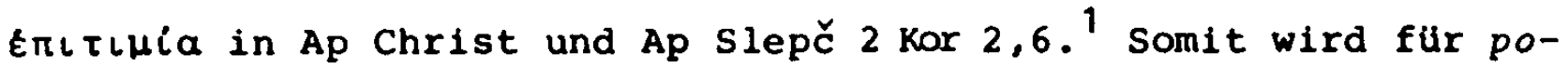
kaznb die Bedeutung 'Strafe' deutlich ausgewiesen. Das, was es aber bezeichnen soll, ist satisfactio, der eine von den drel hauptteilen des BuBsakraments, d.h. die Genugtuung, die auferlegte BuBe. Das mit Fris I verwandte BuBgebet in Euch hat an der entsprechenden stelle das Wort pokajanije n., das sonst der griech. Hetdvola entspricht. Hier wird im Ausdruck nicht unterschieden zwischen dem Bubsakrament im ganzen und einem seiner wesentlichen Teile: contritio (compunctio), confessio und satisfactio. Diese Beobachtung hat schon WEISWEILER in seinem Buch uber die BuBe gemacht. ${ }^{2}$ Er wies daraufhin, daB sowohl im Griechischen als auch im Gotischen und Altbulgarischen für satisfactio keine Terminologie entwickelt wurde. Damit wird die völlige Abhängigkeit des Altslavischen vom Griechischen sowohl in sprachlicher als auch ideologischer Hinsicht zum Ausdruck gebracht. Dem kann aber nicht zugestimmt werden, denn in der Terminologie von Fris hat sich der lateinische EinfluB

gen der Rechtssprechung, die sich in der Terminologie niederschlagen. "Nakazanie vyražaet osnovnoj vzgljad slavjan na cel' nakazanija ...".

1. Vgl. Jagic, III,23. Aber auch pokajanije n. kann in der Bedeutung 'Strafe' verwendet ' ${ }^{1}$ werden, das sonst $d$ e $r$ Ausdruck für 'BuBe' ist. Bes $40,317 \mathrm{ba}$, 4: na pokajanije = ad poenam (Arch LLP). Eine ahnliche inhaltliche Schwankung herrscht auch in der germ. Bubterminologie, wodurch die verschiedene Auffassung der satisfactio als süne und Strafe, von der inneren Haltung des buBfertigen sünders bis zu den Kirchenstrafen, zum Ausdruck kommt. Durch die Konfrontation mit der Wortentwicklung von lat. poenitentia gelingt es Weisweiler (227), die vielgestaltigkeit in der germ. BuBterminologie zu klaren. "Ursprünglich bedeutet paenitere 'VerdruB, Arger, Unzufriedenheit und dann Reue empfinden'; ... Durch die lat. Bibel, die $\mu \varepsilon \tau a v o \varepsilon i v$ mit poenitere, poeniteri ... und $\mu \in \tau$ dwola mit poenitentia ubersetzte, wurde poenitentia der Terminus für die bußfertige Gesinnung. ... (nun) geht seine Bedeutungsentwicklung der Geschichte der kirchlichen Bube parallel. Schon in der Bibel bezeichnete poenitere ... die innere Haltung des bubfertigen sünders ... (und) ihre Bezeugung nach auBen: in cillcio et cinere sedentes. ... Diese auberen Kundgebungen , ... heiBen auch $\mu \varepsilon \tau$ dvolal, bzw. poenitentiae, spater auch satisfactiones. Sie werden den Laien und klerikern vom Bischof, den Monchen vom Abt auferlegt und entwickeln sich aus freiwillig ubernomenen Leistungen zu zwangsbußen und Kirchenstrafen. Der letztere Umstand funrte dazu, daB zwei etymologisch verschiedene, aber ahnlich klingende worter in der Bedeutung zusammenfielen: poenitentia und poena." Ahnliche Erscheinung ist auch für das slavische festzustellen. Aus dem pokajati sę gebildet ist pokajanije n. ein stăndiger Ausdruck für die innere BuBe, der in diesen Sinne verwendeten $\mu \in \tau d v o l \alpha$ und poenitentia entsprechend, wird aber auch im Sinne der als strafe aufgefabten satisfactio verwendet $(5.0$.$) . So auch in$ Euch für ahd. harmscara. Die Wortbildungsvariante pokajasnb $f$. die sich klanglich noch wehr dem von inr etymologisch verschiedenen Wort pokaznb $f$. nahert, wird ebenso wie das letztere für 'Strafe' verwendet.

2. Vgl. Weisweiler 224. Der Autor weist darauf hin, daB im Gegensatz zum Russischen und Altbulgarischen, die die BuBe nicht von der Reue unterscheiden, die anderen slavischen Sprachen unter dem Einflub der lat. und germ. Termi- 
bemerkbar gemacht, dessen Vermittler die ahd. Sprache war. ${ }^{1}$ Fur satisfactio wird - dem ahd. Beispiel folgend - pokasnb verwendet. Der strafrechtliche Charakter der kirchlichen BuBordnung kommt in der Wahl dieses Wortes voll zur Geltung. ${ }^{2}$ Gleichzeitig wird aber, durch die so gewăhlte Terminologie, der Nachdruck von der religiös. sittlichen auf die sachlich-rechtliche Genugtuung verschoben, die erstere tritt $z u$ Gunsten der letzteren zurück. Dieses stellt ein theologisches Problem dar, dem heute mit einer philologisch orientierten Reflexion nachgegangen wird. ${ }^{3}$ Wenn das Wort pokasnb 'stra$\mathrm{fe}^{\prime}$ nach dem ahd. Vorbild harmscara für satisfactio verwendet wurde, so sollte man das nicht nur als übersetzungstechnisches Ergebnis werten, sondern auch auf den staats- und kirchenpolitischen Hintergrund des frühen Mittelalters real bezogen sehen. In diesem Zusammenhang muB auf die Institution der Sendgerichte hingewiesen werden. 4

nologie für satisfactio besondere Ausdrücke geprăgt haben.

1. AuBer dem schon erwahnten harmscara, das 'züchtigung, Strafe, Schmerz' bedeutet, wird allgemein das Wort buozza für satifactio verwendet. Dazu Weisweiler 226: "... in den volkstümlichen Glaubens- und Beichtformeln ... findet sich die Dreiheit Reue - Beichte - BuBe ohne theologische Definition bereits klar ausgedrückt; ... rehta riva, rehta bigihta, rehta buozza (reht weinon) ...".

2. Vgl. dazu Meurer $177 \mathrm{ff}$. Zu der Frage, ob die Pónitenz eine kirchliche Rechtsstrafe ist, führt der Kirchenrechtler eine juristische Analyse durch. Er unterscheidet zwischen dem biblischen und dem kirchlichen Begriff. Dem letzteren, d.h. der BuBe, welche dem Sunder vom kirchlichen Richter auferlegt wurde, gilt seine Untersuchung. Die Bußen sind $k$ e $i$ e Rechtsstrafen, aber "der Begriff der Offentlichkeit beruhrt nahe den Strafcharakter", denn seit Augustinus herrschte der Grundsatz, daB die crimina publica durch publica poenitentia gebüt werden sollen. "In den frănkischen Poenitentialien ist die publica poenitentia in Aufnahme gekommen ... In der frănkischen Kirche hat sich dann auch die Entwicklung der Poenitenz zur $R$ e $h t s$ strafe vollzogen."

3. Vgl. dazu Tschirch, 260-292; Kainz 101-115; Schmidt; Tschirch, 140-149; Kăhler 68-84.

4. Vgl. Koeniger $12 \mathrm{ff}$. Aus den bischoflichen Firmungs- und Visitationsreisen mit dem zweck, die Tătigkeit der Geistlichen zu überwachen und sich nach den Sitten des Volkes zu erkundigen, erwuchs die strafende Tatigkeit der Bischofe und trat bald in den Vordergrund (17). Von den Landesherren unterstützt, bekamen die bischoflichen Untersuchungen und Bestrafungen das Ansehen geistlicher Gerichtshandlungen $(15,16,19)$ und exlangten eine besondere Blute in Karolingischen Reiche (12). So stand neben dem weltlichen auch das geistliche Gericht, welches bald fast alle jene Vergehen ahndete, welche auch das Grafengericht bestrafte, nur wit dem Unterschied, daB die Kirche geistliche Strafen. BuBwerke auferlegte, dagegen "das weltliche Recht peinliche und Geldstrafen aussprach. "(19). Indem die Erforschung der Vergehen als ein selbstăndiger Akt aus den visitationsgeschăften ausschied, wurde die Grundlage für das Entstehen der Sendgerichte geschaffen. Die Aufnahme der Sendgerichtstatigkeit fallt in die Regierungszeit Ludwig des Frommen. "Wie zu einer Gerichtssitzung wird das Volk zusammengerufen und uber Straflinge wird ahnlich wie beim weltlichen Gerichte verhandelt: $(20)$. 
$p r a v b d$ b $n$ b adj. 'gerecht' - $n e p r a v b d b n$ b adj. 'ungerecht' sind kategoriale Bestimmungen für den Menschen im Hinblick auf sein Verhalten zu Gott. Beide Formen, die positive und die negative, sind abgeleitet vom Substantiv pravbda $f_{\text {., welches als }}$ biblischer Ausdruck im Sinne der Gesamtheit der alttestamentlichen Vorschriften $\mathrm{zu}$ verstehen ist. In Cloz 6a 31-35 wird vbsĕka pravbda als vbsa zakonnaě erklärt. ' Im Altslavischen bedeutet das Wort pravbda f. Im allgemeinen 'Gerechtigkeit', in der Rechtsterminologie bezeichnet es den Begriff des Rechts selbst, wie auch alle seine Erscheinungsformen, d.1. 'Gesetz, die Sammlung der Gesetze, der gerichtlichen Vorschriften' etc. ${ }^{2}$

Als biblischer Terminus entspricht pravbda dem griech. Slkalooúun der Septuaginta, welches das hebr. sddaq/sedaqa des AT wiedergibt. Dieser Terminus hat einen zweifachen Inhalt: der Mensch ist in Jahwes sdddq (Heil) aufgenommen und verpflichtet in sddaga (Rechtsverhalten) zu leben (Hthg $468 \mathrm{ff}$ ). Das griech. Olxalooúvn ist der Kernbegriff der griech. Anthropologie; man verstand darunter die Tugend des menschlichen Zusammenlebens, und darum ist es engstens mit dem bürgerlich-rechtlichen wie dem sittlich-ethischen Bereich verbunden. ${ }^{3}$ Das NT ubernimmt den alttestamentlichen Begriff. Gerecht ist derjenige, der die Gebote Gottes erfullt. "Der sittlich-religiöse Inhalt dieser Bezeichnung wird dann besonders deutlich, wenn das Adjektiv 'gerecht' mit anderen Adjektiven der sittlich-religiösen ordnung zu einem einzigen sinnganzen verbunden wird: heilig und gerecht, gerecht und gottesfurchtig, edel und gerecht." (Bthw 514).

In dieser Bedeutung wird pravbdbnb auch in Fris I gebraucht. Es ist gleichwertig mit svetb adj. 'heilig' des Fris III und steht als substantiviertes Adjektiv 'der Gerechte' in Fris I dem subst. Adjektiv 'Heiliger' der ahd. bzw. lat. Texte. 4

Die Bedeutungsentlehnung des asl. pravbdbnb im christlich-religiösen Sinne läßt sich auf keine der Vorbildsprachen einengen

1. Vgl. Zogr, As, Sav, Ostr vsěkg praubde rãoav olxalooúunv Mt 3,15.

2. Vgl. dazu Vašica 158 , Vašica 15 .

3. Vgl. HthG 472, Bauer 389-390, ${ }^{2}$ Ferner Bthw 514: "Gerecht ist, wer gegenuber Gott und den Menschen die rechte Baltung einnimmt und entsprechend lebt und handelt".

4. Nach Auskunft der Red. LuP ist dex Gebrauch von praubdbrb im Sinne von sanctus nur im westlichen 1it. Bereich bekannt. Bes 40,319 bB 14 fuhrt pravbdbnb für beatus, electus. 
(auch die Ubersetzung des griech. Sixalos brachte dasselbe Ergebnis), doch liegt es nahe, das in Fris in erster Linie das ahd. reht u. unreht neben dem lat. justus, injustus, besonders in der negativen Form, die in den ahd. Beichttexten oft belegt ist, einwirkte. ${ }^{1}$ Es muB jedoch hervorgehoben werden, daB die sinnerweiterung des Wortes pravbdbnb bis zur Bedeutung 'heilig' eine eigene Entwicklung darstellt, wie es aus dem Vergleich mit den ahd. Texten hervorgeht. Dort kommt das Wort reht für diesen Begriff nicht zur verwendung.

$8 \& d$ b $n y i \quad d$ b $n$ b m. Mit dieser festen Wortverbindung von Adjektiv sqdbnyi, gebildet aus $8 g d \mathrm{~b} m$. 'Gericht, Urteil, gerichtliche Untersuchung' (Vasmer III,39) und dbnb m. 'Tag' wird lat. dies judicii, griech. ñuḱpa noioews und ahd. tuom(es)tag wiedergegeben. Die sachliche Begründung für die Wahl dieses Ausdruckes für das Jüngste Gericht ist wohl in der Institution der Königsboten, der sogenannten "Missi" im Karolingischen Reiche zu sehen." Diese, ein Vertreter des Staates und einer der Kirche, hielten besondere Gerichtstage ab, ahd. suontag, tuomestag genannt. ${ }^{3}$ Diese Bezeichnungen sind als kirchliche Termini überliefert worden, als Rechtswörter waren sie bald untergegangen (Schnerrer 286 ff.,258). Sofern die slaven der karolingischen Jurisdiktion unterstanden, war ihnen die Bezeichnung des Gerichtstages in ihrer sprache als sqdbnyi dbnb bekannt, zumindest kann das aus guten Gründen unter Berufung auf den heutigen stand der Geschichtsforschung angenommen werden. 4 Die kulturhistorischen Gründe sprechen auch dafür. daß der slavische Ausdruck für den Gerichtstag die Bedeutung 'das Jüngste Gericht' von dem ahd. tuomestag entlehnte, obwohl vom Wortmaterial her sowohl der lat. als auch der griech. Ausdruck gleichberechtigt stehen. Ein Kriterium für die sprachliche Abhängigkeit scheint in der Wortfolge gegeben zu sein. Der erste Teil des Kompositums tuom(es)- (bzw. suon-) wird durch das vorange-

1. Vgl. Steinmeyer 310, XLII,11,13,15, XLVIII,2,3,4,11,12 etc. Ferner Bauer 388-389 unter bikalos.

2. Ausfürlich handelt darüber Freudenthal 187.

3. Vgl. Freudenthal 187: "Diese sind als eine Art Konigsgerichte zu betrachten. Diese Königsboten fuhrten den Vorsitz an den verschiedenen Gericbtsstatten des Reiches. Ansonsten hielten die Grafen, die den Gauen vorstanden, die Gerichte ab." Vgl. dazu auch die Ausführungen über die Sendgerichte auf $s$. 56. FuBnote 4 der vorliegenden Arbeit.

4. Es sei 2.B. auf das Samelwerk "Das GroBmahrische Reich" hingewiesen. 
stellte Adjektiv sqdbnyi wiedergegeben, dem dann dbnb -tag folgt. In der lat. Sprache ist die wortfolge immer ungekehrt, ebenso in der griechischen. Als festgeprägter, allgemein bekannter Terminus kommt sqdbnyi dbnb in den asl. Texten häufig vor und wird auch dann verwendet, wenn die entsprechende stelle der lateinischen oder griechischen Vorlage eine andere Bezeichnung für den Jüngsten rag fuhrt, wie z.B. : extremum judicium, futurus dies, examin, judicium etc. In diesen Fällen behält er seine Wortfolge. Diese wird verändert, wenn nach dem fremden Vorbild eine genaue Wort für Wort - Ubersetzungsarbeit geleistet wird; dies judicii und

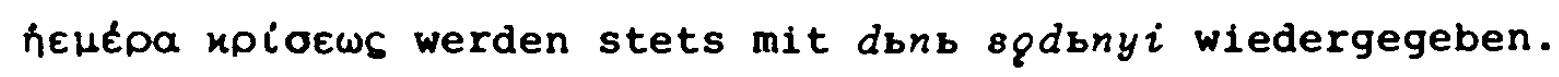

AuBer dem asl. Rechtswort $8 q d b n y i$ dbnb kennt die asl. Literatur noch andere Ausdrücke zur Bezeichnung des Jüngsten Tages. Darunter gibt es auch Umschreibungen, die das Gericht in der alttestamentlichen Vorstellung vom schrecklichen Tag des Zornes betonen. Aus dem reichen Belegmaterial des Arch LLP können hier einige Beispiele gebracht werden: na strašněmb s(u)dišti Vind $\mathrm{A} b, 4-5$; $v_{b}$ denb strašbnaago spda Euch 82 b 16-17; strašnago dnĕ Nom 48 d 2;

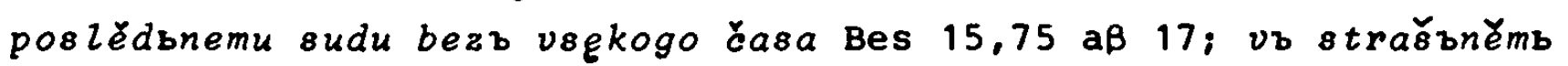
$i$ trepetsněmb sqdišti Euch 66 a 11; prěd sudištemb christovomb ك́ís 2, Kor 5,10; prědb tvoimb sudnimb préstolomb Nicod 1 stojanović 89, 31. In der Kapiteluberschrift von Mar Mk fol. $44 a 2$ erscheint der Terminus sqdbnyi dbnb in der theologischen Explikation: 0 sqdbnémb dbne si rečs o konbéinè.

8 b $t \quad v \circ r i$ t $i$ pf. in der besonderen Bedeutung 'erschaffen'. davon 8 btvoritelb $\mathrm{m}$. 'der Schöpfer': gebildet aus tvoriti mit dem Präfix su-gehört das Verb in der Semasiologie zu den verallgemeinernden wörtern, und seine Bedeutung läBt sich je nach der Art und Bedeutung des mit ihm verbundenen objekts sehr nuanciert auffassen. So bekommt es in Verbindung mit 'Himmel und Erde' die spezielle Prägung 'etwas erschaffen, was vorher nicht war' (Frinta 58). Die so verstandene Schöpfung durch den willen und das wort Gottes, der das Nicht-seiende ins Sein ruft (Röm 4,17), findet ihre philosophische Ausprägung in dem Begriff der creatio ex nihizo (BthW II, 1219).

während das Hebräische zur Bezeichnung der schopfertätigkeit Gottes mehrere wörter verwendet, benutzt Septuaginta $x \tau l \zeta \omega$, das auf den originellen Akt eines vernüntigen willens hindeutet und den Gedanken an ein Material der Schöpfung weitgehend ausschliebt

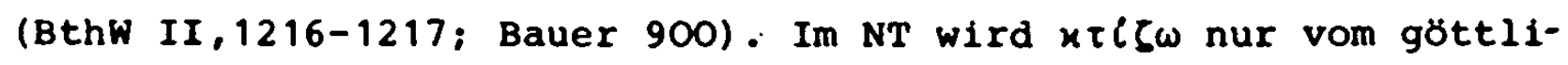


chen Schaffen verstanden (wenn dafür auch nגdoow verwendet wird) und diese spezialbedeutung wird vom lat. condere und dann creare übernommen (Raumer 353; Teeuwen 21; BthW II, 1220). Dem entspricht im Ahd. das Verb skaffon 'formen, gestalten, schaffen' (skepfant, schephare 'Schöpfer')', von dem das asl. sbtvoriti diese neue Bedeutung entlehnt. ${ }^{2}$ Seine terminologische Prägnanz kommt auch in den davon abgeleiteten Nominalbildungen zum Ausdruck: sbtvorite $\imath_{b}$ m. tvorbcb m. für creator; tvorenije n. für creatura; tvarb $f$. creatura, res creata (Mikl LP 958,984).

Für 'erschaffen' kennt das Asl. auch sbděti pf. u. sbzbdati pf. mit der entsprechenden daraus abgeleiteten schöpfungsterminologie. 3

8 y $n$ b $\mathrm{m}$. 'Sohn'. Das wort ist als Bezeichnung der zweiten göttlichen Person zum festen Bestandteil der Trinitätsformel geworden und hat dadurch eine besondere Bedeutung erhalten. (zur theologischen Aussage über das Vater-Sohn-Verhältnis s.o. unter otbcb.) Durch die Menschwerdung Christi sind Menschen "Söhne Gottes" synove božii geworden. Zur Bezeichnung des Kindschaftsverhältnisses wird in Bezug auf die Menschen auBer syn: auch das Wort čedo $n$. gebraucht. In Bezug auf Christus komnt auch otrokb m. für griech. raĩs vor (zogr, As, Sav Mt 12,18 ).

Die Deminutivform von synz

$s y n b k b \mathrm{~m}$. tritt in der pluralform $s y n b c i$ auf. GRAFENAUER hat nachgewiesen, daB diese als Anrede für die Christengemeinde verwendete Form auf das lat. Vorbild filioli zurückgeht, das in den Mahnreden und Synodalbeschlüssen gebraucht wird. 4

$v r b a h$ b $n$ adj. 'höchster' als Epitheton für Gottvater ist nur in Fris II belegt. Sonst kommt es in der Bedeutung 'oberer, höchster' im konkreten sinne vor. ${ }^{5}$ In Fris wird es zur Bestimmung der höchsten stufe in der hierarchischen Rangordnung der himmlischen Mächte gebraucht. Der Versuch, vrbchbnb als Epitheton für Gott in diesem sinne $z u$ verwenden, hat sich nicht durchgesetzt und steht in dieser Funktion in FD II einmalig da. Für die Prä-

1. Vgl. Steinmeyer 326,LIII,1-2: "der schepare ist himeles unte erde"; XLVII,3: "der scuof himil enti erda".

2. Miklosich hălt es für einen Pannonismus, vgl. Mikl Term 37.

3. 2.B. in den Homilien von hl. Kliment, Vondrak, 76,85: tvorbca angelbska $i$ vseja tvari sodételja; iže jestb sbtvoril otb nebytija vb bytije.

4. Vgl.Grafenauer, 46; 120, Anm. 108,109; 162 .

5. Vgl. LLP $1,361-362$ unter vys̆bnii; iLP 1,226 unter vmbchßnb. 
aikation des Apostels Petrus wird die Variante vrbchovbnb fur lat. princeps verwendet (Sinsluz 1b 11 sq; VencNik 2,14. LLP I,225). In einem altpolnischen liturgischen Text findet sich wyrzchny kaplan für summus sacerdos (Klich 20). Auch fur vrbchbnb ist die lat. Entsprechung summus anzunehmen.

Als Synonyme sind die Adjektive vysprbnb, gorbnb zu nennen; beherrschend ist aber vyв̌bnb, vy̆̈bnii, das als elliptische Bildung zur Bezeichnung Gottes selbst wurde. 'Der Ausdruck vyšbni $i$ ist mit der bulgarischen literarischen Tatigkeit eng verbunden. Er begleitete in den Evangelien den Namen Gottes und erwarb so eine besondere Stellung.

$v$ b $s$ t a $t i$ pf. 'auferstehen' gehört der Allgemeinsprache an und bekam in der Entsprechung des lat. (re-)surgere die prägnante christliche Bedeutung: 'von den Toten auferstehen'. Von dem lat. Wort haben die deutschen Verben ar-, uf-standan, ar-, ufstān den neuen Sinn entlehnt und den Grundstock zur Weiterbildung der Auferstehungsterminologie gelegt. ${ }^{2}$ Das slavische Verb stati und das ahd. stān bzw. stantan, standan haben das miteinander gemeinsam, daB sie nicht transitiv gebraucht werden können. Das unterscheidet sie grundsatzlich von dem lat. resurgere und von den in der griech. Terminologie gebräuchlichen Verben Guiornul 'aufstehen, aufstellen'

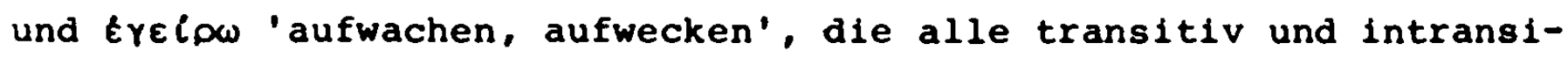
tiv sind (Bauer 138,425). Um der theologischen Relevanz dieser Tatsache gerecht $z u$ werden, ist in der Anlehnung an das griech. Eyeiow mit dem asl. Verbpaar vbskrbsnqti - vbskrěsiti ein anderer Terminus geschaffen worden, der die ksl. Literatur beherrscht hat. ${ }^{3}$ Für die Umprägung des asl. vbstati kann also in erster Linie der ahd. sprachliche Einflus geltend gemacht werden, wenn auch, wie so oft, eine direkte lat. Einwirkung nicht auszuschlieben ist. Der innere Wandel vom sinnlich wahrnehmbaren, mechanischen 'aufstehen' zum christlichen Begriff 'auferstehen' beruht auf der vor-

1. Vg1. LLP I,361-362: vys̈bnii substantivi vice fungitur - Deus: 8b bqdetb velii.i $8(y) \mathrm{mb}$ vyśbneago narečetb se $\mathrm{Lk} 1,32$ zogr Mar As Ostr.

2. Vgl. Raumer 363-364. Die Ableitungen urstendi f., urstendida f., erstontionuga f., arstantnissi f. etc. bezeichnen die Auferstehung. Auch im Asl. ist das Substantiv vbstanije $n$. für 'Auferstehung' geblldet worden, jedoch wenig vertreten, es kommt nur in Supr 425,2 und 318,1 vor. Vgl. LLP I,338. Vgl.

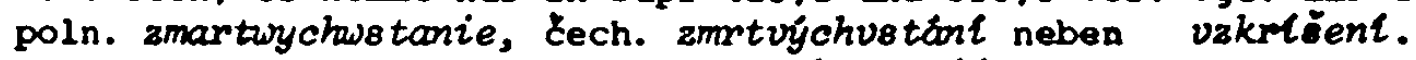

3. Davon auch die Verbalsubstantive vbskmoenije n. 'Auferstehung' und vbskré¿̌enije n. 'Auferstehung' eigentlich Auferweckung. Vgl. LLP I, 326, 327 . 
stellung - die auch in der bildenden Kunst ihren Ausdruck fand -, daB die Toten ihre Gräber verlassen werden, um vor dem Gericht Gottes zu erscheinen. 'Auferstehen' im christlichen Sinne, das sich ganz auf Christi Auferstehung stütz, besagt Neuschöpfung der materiellen Substanz des Menschen (BthW I, 100-101).

Die Einengung der allgemeinen Bedeutung 'aufstehen' auf den speziellen christlichen sinn 'auferstehen' (von den Toten) ist durch den Wegfall der Ergänzung zustandegekommen. In der asl. Literatur wird vbstati oft mit otb mrbtvyichb oder iz mrbtvyichb (bei der Auferweckung des Lazarus otb groba) erganzt, besonders, wenn es aus dem Text nicht ganz klar hervorgeht, worum es geht. In den Perikopen nach dem Tode Christi zeigt sich eine merkliche Tendenz zum absoluten Gebrauch. 1 Es mag sich schon sehr früh zum Terminus verfestigt haben, wenn es in Fris I in der Bedeutung 'auferstehen' ohne weitere Ergănzung als allgemein verständich vorausgesetzt wurde.

1. Dieses ergab sich aus der Sichtung des Belegmaterials des Arch LIP. Vgl. dazu auch LLP I, 339. 
b. Eigenumprăgungen

$b \circ g \mathrm{~b} \mathrm{~m}$. 'Gott' aus idg. 'bhag- 'zuteilen', ai. bhaga 'Zuteilung' oder personifiziert 'Gott, zuteilung', jungaw., altpers. baga 'Gott' (Pokorny I, 107; Vasmer I,98; Berneker 66-67) bedeutete ursprünglich im Urslavischen 'Anteil, Glück, Reichtum, Fülle' (Brückner SEJP 33; Meyer 26; Frinta 6-7; Fick II,590).

Uber die Herkunft des Wortes bogb $\mathrm{m}$. als Bezeichnung für Gott ist keine endgultige klarheit zu gewinnen, jedoch scheint sich die Ansicht durchzusetzen, daB nicht eine Bedeutungsentlehnung von den iranischen skythen vorliegt, sondern daB es sich um eine selbständige Bedeutungsentwicklung handelt. 1

Eine ausführliche studie $z$ u dieser Frage von B. MERIGGI ergab, daB ursprünglich der Begriff 'Gott' den Slaven unbekannt war (Meriggi, 33-34). In einer bestimmten Phase ihrer Entwicklung haben sie (viel wahrscheinlicher ein Teil von ihnen, nämlich die südund Ostslaven) mit dem Wort *bogu den domovoj (= lo spirito domestico)'den Hausgeist' 2 bezeichnet. Sie haben ihn als ein Wesen begriffen, welches am Feuer sitzt und fähig ist, den Lebendigen das Gute und das Böse zuzuteilen. Diese Eigenschaften kamen der christlichen Gotteskonzeption sehr entgegen. So wurde im suldslavischen Gebiet der christliche Gott bogb genannt, von dort hat sich das Wort in seinem neuen semantischen Wert auf andere slavische Gebiete ausgedehnt. Diese Hypothese von MERIGGI deckt sich in vielem mit MOSZYŃSKI's ethnographischen Forschungen. ${ }^{3}$ Die von ihm angeführten weibrussischen und ukrainischen Benennungen des Feuers bahač (weiBr.), bohač (ukr.) und das ukr. Wort bahatt'a für das Grobfeuer in der Johannisnacht sowie die besondere Verehrung des Feuers bei den slaven uberhaupt kommen den SchluBfolgerungen MERIGGI's sehr entgegen. Auch die Tatsache, daB der slavische Glau-

1. Vgl. Urbańczyk in SSS I,157 unter "bóg". Nach Ansicht von Prof. B. Schlerath (Berlin) kann sich die Entwicklung des Gottesbegriffes im Indoiranischen und im Baltoslavischen nicht unabhangig voneinander vollzogen haben, und es ist auch nicht an eine skythische Entlehnung zu denken. Im Lichte des Materials von $B$. Arntz: Sprachliche Beziehungen zwischen Arisch und Baltoslavisch, 1933 mochte man eher an eine nachindogermanische, aber voreinzelsprachliche slavisch-iranische gemeinsame Entwicklung denken. Dieser Schicht müBte auch schon die ethische Farbung dieses Wortes angehoren.

2. Vgl.dazu Ohijenko 85-86,124: "Bohom domovoho vohnyśča stav u nas 'domovyk" čy 'domovof'. ščo vytvoryusja $z$ najdaunišoho ćasu; $v$ davnich 'slovach' vin zvet'sja 'choromožytel' '.

3. Vgl. Moszyński II, 499, ferner Buslaev 49. 
be an Dämonen ihre Elgenschaft als Reichtumsspender und -vermehrer besonders hervorhebt, spricht für die obigen Uberlegungen (Moszynski II,642).

Die ursprüngliche Bedeutung des Wortes bogb 'Reichtum, Glück' hat in der asl. Sprache und in den heutigen slavischen Sprachen deutliche Spuren hinterlassen. Aus den asl. Wortern bogatb adj. 'reich', u-bogb adj. 'arm', poln. nieboszczyk m. (aus *niebozec + $i k)$, niebogi, ubogi adj., apoln. zboze n. 'Reichtum' und 'Getreide' zboing adj. 'glücklich' elgentlich 'reich' geht die alte Bedeutung hervor.' Auch in der tschechischen Redensart na ty bohy 'Glückauf' und im slovenischen Dialekt aus südostkrain zlego boga vživa 'es geht ihm schlecht' (er geniebt ein böses Geschick) ist der frühere Sinn des Wortes noch spürbar. Nicht zuletzt soll noch der slavische Göttername Dažbdbbogb erwăhnt werden, dessen Sinn als 'Reichtum spendend' angesehen wird (Pokorny I, 107, Berneker I,66-67).

Die Ubernahme des Wortes bogr für 'Gott' setzt voraus, daB die Entwicklung von *bogu 'Reichtum, Fülle' zu 'Reichtumsbesitzer', 'Reichtumsspender' schon vorangegangen war, wenn auch bogz der Inhalt aller drel Begriffe inharent ist.

Mit dem mutmaBlichen Inhalt des slavischen wortes bogb ist notwendigerweise die Frage des slavischen Polytheismus verbunden. Nach MERIGGI ist es durchaus möglich, daB der viel umstrittene Svantevit auf Rügen der Hauptgott war (Meriggi, 15-22). WIENECKE hält an einem slavischen Polydämonismus fest (55-56), URBAŃCZYK hălt für wahrscheinlich, daß die Verflechtung (= pol. splot) Himmel (Donner), Sonne und Feuer als Hauptgottheit des slavischen Hei. dentums anzusehen ist, spricht sich also für Henotheismus aus (14 ff.). Sehr eindringlich stellte aber die christliche Kirche den e $i \mathrm{n}$ e $\mathrm{n} h$ o $c h s$ e $n$ Gott heraus. Es ist bemerkenswert, $\operatorname{da} B$ sein diesbezügliches Epitheton vyšbni im Asl. zum stehenden Ausdruck für Gott selbst geworden ist. Der monotheistische Gottesglaube muBte etwas total Neues fur die heidnischen slaven gewesen sein, und es konnte deshalb nicht oft genug betont werden, daB es nur einen höchsten Gott gibt. Als Gott der Lebensfülle, als der strafende oder belohnende Gott deckt sich der Gottesbegriff der christlichen Lehre in etwa damit, was bogb früher bedeuten mochte. was an neuem Inhalt dazu gekommen ist, macht die christliche Theo-

1. Vgl. Brũckner SEJP 33: poln. nieboszcayk 'der Verstorbene', der an dem Reich tum, am Besitz keinen Anteil mehr hat. 
logie aus.

Uber die andere verloren gegangene Gottheitsbezeichnung des slavischen Heidentums, die sich wie in allen idg. Sprachen aus der Wurzel *jēu- herleiten muste, ist andeutungsweise in der Behandlung des Wortes nebo die Rede. Beachtenswert ist die zugehörigkeit der von slav. "divb - idg. *deiunos 'Himmelsbewohner' abgeleiteten wörter zur "himmlischen" Sphăre im Sinne des Ubernatürlich-Geisterhaften: Čech. divooák m. 'Feld-oder Waldgeist'2, divoženka f. 'Wasser-,Waldfee' poln. dzivozona, bulg. (samo)diva 'böse Vile' ein dămonisches weibliches Wesen ${ }^{3}$, ar. divъ (im Igorlied belegt) 'Unheil verkündender Vogel'.4

Es liegt nahe, dab in *divb der Begriff 'Dämon', 'Gott' verborgen ist, was durch die lit. Gottesbezeichnung diẽvas gestützt werden kann. 5 wahrscheinlich war es als Bezeichnung einer bestimmten Gottheit so mit heidnischem Inhalt belastet, daB es für den christlichen Glauben unannehmbar war und deshalb verschwinden mubte.

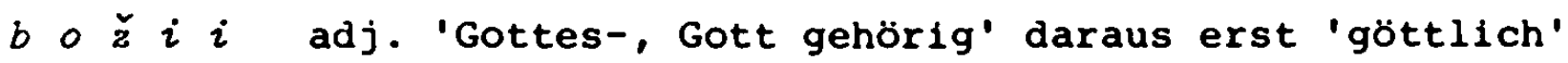
als poss. Adjektiv von bogb + Suff.-bjb $\rightarrow i i$ gebildet. Mit dem Attribut božii sind einige feste Wortverbindungen entstanden, die wichtige christliche Begriffe bezeichnen. Danach richtet sich sein Inhalt: von ' $z u$ Gott gehörend, Gott ergeben, Gott dienend' bis 'von Gott geheiligt, heilig'.

$\check{c} i s t b$ adj. 'rein' gehört der Allgemeinsprache an und bekam durch die Anwendung im religiösen Bereich sittlich-religiöse Gültigkeit. Je nach Kontext kann es 'makellos, frei von slinden, hei-

1. AuBerdem ist die Sonne-Feuer-Verehrung mit den christlichen Kultelementen schon in der Antike verschmolzen. Man denke an das Licht als Symbol Christi. So kamen auch in der Hinsicht in dem Wort bogb gemeinsame Inhalte zur Dekkung. Vgl. Urbańczyk $14 \mathrm{ff}$.

2. Vgl. Jungmann I, 371; Machek 88 unter divy; 87 unter div 2 .

3. Vgl. Machek unter divg; Moszynski II,477.

4. Vgl. Dal' I,435: divs = 'zloveščaja ptica', Srezn I,664:'gryphus'. Ob in den Pflanzennamen poln. dziewanna, čech. divizna für 'Himelsbrand' die Bedeutung 'gottlich, himmlisch' festgehalten ist, lst schwer zu entscheiden. Vgl. dazu Kowalikbowna in: JP 51,4 S. 270-278 und Fraenkel I,95.

5. Vgl. Fraenkel I,93, Urbanczyk in SSS I,157 unter b6g. Vgl. Ohijenko 112: "Davni pam'jatky zhadujut' pro boha Dyv, ale ne podajut' joho znacennja. v odnomu rukopysu cytajemo: 'Ovb Dyju żbretb a druhil Dyvil. Trebu kladutb Dyvi, Perunu, Chorsu.' ...Doslidnyky pryjmajut' boha Dyv za drakona, zmija, veleta, čudovy̌̌ce ..." Auf dem Hintergrund der baltoslavischen Sprachgemeinschaft können die von Ohijenko angefürten Beispiele ein Licht in das Dunkel des ganzen Fragenkomplexes zu werfen. 
1ig, aufrichtig' bedeuten. So hat čistb in Bes zwölf verschiedene lat. Entsprechungen: purus, castus, certus, incorruptus, mundus, purgatus, sacer, seeurus, simplex, verus, venerabilis, innocens (Belegmaterial Arch LLP).

Nach MOSZYíSKI ist seither in aem BewuBtsein des Volkes der Begriff der Heiligkeit stark mit dem der Reinheit verknupft (Moszyński II,716). Bulgaren und Serben nennen den Teufel nexist'. eine der Priesterbezeichnungen ist dagegen cistite $l_{\mathrm{b}} \mathrm{m}$. (s.o. s. 42). In der Theologie des NT tritt die rituelle "Reinheit" völlig zurück $z u$ Gunsten der inneren Lauterkeit. ${ }^{2}$ so ist auch der neue Inhalt von čistz in Fris zu verstehen.

$d u \check{s}$ a f. aus idg. "dhous $i_{a} \bar{a}^{3}$ 'seele' . "das weibliche Gegenstück" zu duchb m.. mit dem es "eine Doppelheit bildet, die der lateinischen von animus und anima nicht gleich, aber ahnlich ist." (Meyer 262). Das slavische Wort für 'Seele', formal und inhaltlich mit dem für 'Atem' und 'Hauch' eng verbunden, gründet in der Beobachtung, daB mit dem letzten Atemzug auch das Leben entweicht (Clemen 27: Buslaev 67-74). So entstand der Glaube an eine vom körper unterschiedene und nach seinem Tode fortlebende Seele. Uber den Seelenglauben bei den slaven, der sich sprachlich in dem wort duřa manifestiert, gibt es verschiedene zeugnisse. 4 In erster Linie wären die von den Archăologen sichergestellten Totenbeigaben in den altslavischen Gräbern zu nennen. Auch die ethnographische Forschunc kann mit reichem Material aufwarten, das den alten heidnischen Seelenglauben illustriert (Buslaev 67-74; Moszýnski II,596-604). Besonders hervorzuheben wäre der Glaube an die Seelen der verstorbenen Ahnen, deren Platz hinter dem ofen war, die als schützende und auch böse Geister auf das Schicksal der Familie einwirkten (Meyer 262). Man stellte sich die Seele als ein leichtes fliegendes Wesen - in der serbischen Volkspoesie in dem ständigen Epitheton laka (duša) tradiert - als Vogel. Schmetterling oder Marienkäfer vor. Sie verläBt den Körper des Verstorbenen, indem sie durch das Fenster, die Kaminöffnung oder sonstwie entfliegt. Die Spuren

1. Vg1. Wróblewski in SSS 1,337 .

2. Vgl. BthW II,1187. Damit erklart sich die Austauschbarkeit von čistb mit neporočbmb 'makellos', praubdbnb 'gerecht', bezblobbni 'unschuldig, gut', bezgrě̈̌rbrb 'sündenlos'.

3. Vgl. Meyer 262; Slawsk1 I,181; Vasmer I,383; Berneker I,239.

4. Vgl. Kotlfarevskif 188-189: "In der asl. Sprache hat dieses Wort die konkrete Bedeutung 'Atmen' (dychanie), 'Lebensodem' (žiznennyj vetr) = moh ... u. 
dieser Vorstellung sind in dem alttschechischen Wort produch erhalten.' Als sterne und Irrlichter stellten sich die Lausitzer, Tschechen, Polen und Russen die Seelen vor (Buslaev 67-74). Daher die Namen bludniki, bludne swieczki.

KOTLJAREVSKIJ, der sich in seinen Forschungsergebnissen über die Begräbnissitten der heidnischen slaven auf schriftlich überlieferte, zuverlässige Zeugnisse berufen kann, stellt die Behauptung auf, daB der Glaube an eine unsterbliche seele in dem religiösen Leben der slaven einen wichtigen Platz einnahm. ${ }^{2}$ Auch aus den Verboten der kirchlichen Organe, auf den Gräbern heidnische Feiern abzuhalten und den Verstorbenen Opfer zu bringen, geht hervor, daB der Seelenglaube sehr stark eingewurzelt war. ${ }^{3}$

Unter den verschiedenen slavischen Namen für dämonische Wesen labt das Wort vily begriffliche und formale Verwandtschaft mit dem lit. wéles 'die Seelen der Verstorbenen', lett. wels 'der Hauptgott der Verstorbenen' später 'Teufel', sowie lit. vé Inias m. 'Teufel', vếlés 'geisterhafte Gestalten Verstorbener, Geister' zu (Buslaev 21: Niedermann 250-251). An einer solchen Bedeutungsentwicklung läßt sich die bekannte Tatsache ablesen, daB die christlichen Missionare die heidnischen Götter oder Dämonen als böse Geister, als Teufelshelfer hinstellten."

Zusammenfassend kann gesagt werden, daß das asl. Erbwort duša dem heidnisch-religiösen Wortschatz angehörte - wenn auch aus dem Sprachgebrauch sich die konkrete Bedeutung ebenso ablesen läBt -, und daB seine Ubernahme in das christliche Gedankengut nicht ohne

.. das abstrakte $\psi u \times h$. In allen mundarten hat das wort die materielle Bedeutung behalten, vor allem in den Ausdrücken, wo das Bild des Sterbenden gegeben wird: Zelovek ispuskaet duch, vypuskaet, otdaet dusu, dußa vychodit, uletaet, vyskakivaet iz tela; ...".

1. Vgl. Machek 101: produch 'Offinung', ursprönglich wohl for die Geister duchy, die Seelen der Verstorbenen, damit sie besser herein- und herauskomen konnten. Auch im Ukr. produch 'Luftloch, రffnung', vgl. Kuzela-Rudnytkyj 911.

2. Vgl. dazu Kotljarevskif $189 \mathrm{ff}$. Die Gesandten des Fursten Igor' haben den Friedensvertrag mit den Griechen durch den religios-juristischen Eid bekraftigt: da budut rabi vo $8 \mathrm{~b}$ vékb $i$ us buduécij 'auf dab sie sklaven sein sollen in dieser und in der zukünftigen Welt', wenn sie vertragsbrochig werden sollten.

3. Vgl. ein tschechisches Poenitentiale aus dem XII.Jh. bei Kotljarevakif 247, ferner Bruckner, 172-173, Mansikka 246-247.

4. So kann auch dié ukr. Bezeichnung far den Teufel erklart werden: didko, (dědko $m$. Im worterbuch von P.Berynda) 'Teufel'. Der décb 'der Ahne' murde als Bausgeist verehrt (Brückner, 168, Kotljarevskif 247, Buslaev 21) und muBte spster in die Kategorie der Teufelshelfer abwandern. Vgl. auch Klich 15: "BOgowie poganow dyabli (daemonia)" aus dem "Psalterz Floriafiski" 95,5. 
Widerstreben erfolgt war. Ist doch das Heidnische in dem Volksglauben noch lebendig und der Totenkult reichte ins hohe Mittelalter. - Andererseits war auch vieles gemeinsam. wuxh bedeutet im NT 'Leben', 'Sitz und Trägerein des irdischen Lebens'. Als solche kann sie das Heil empfangen, kann jedoch auch verloren gehen (Bauer 1765-1766).

$g \circ s p \circ d b \mathrm{~m}$. ist das biblische Attribut Gottes in der Bedeutung 'Herr'. Es tritt meistens in Verbindung mit bogb, otbcb, christb auf, kann aber allein für 'Gott' stehen. Für die Etymologie gibt es einige Erklärungen. BERNEKER $(I, 236)$ verbindet ursl. ${ }^{\star}$ gospodb m. mit lat. hospes (hospitis < hostipotis) und hält es für eine Abkürzung aus ursprünglichem gostb-pot(d) als Folge des hăufigen Gebrauchs. VONDRÁk (Vondrák, I, 478-479) lehnt den Ursprung von hostipotis ab und plädiert für die gotische Herkunft des Wortes aus dem got. *gasti-faps. 1 Da die gotische Form unbelegt ist, lehnt KIPARSKY diese Entlehnung als unwahrscheinlich ab (67).

Im profanen Sprachgebrauch bedeutete gospodb 'das Haupt der Familie, der sippe oder des Stammes' und bezeichnete ebenso wie vladyka m. keine institutionalisierte Stellung. ${ }^{2}$ Als Entsprechung

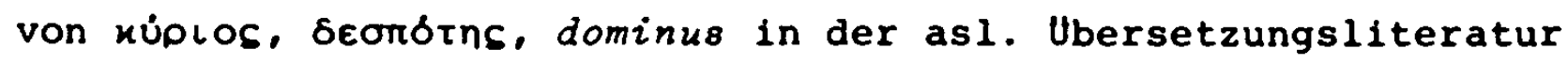
wird sein Inhalt mit rei possessor, hominum dominus und paterfamilias bestimmt (LLP I, 425). AuBerdem wird es als Titel oder Anrede gebraucht, wie es auch in Fris III,39 vorkommt.

Die Vorstellung, die sich mit gospodb verband, wird nun auf Gott ubertragen, andererseits wird es durch diesen sprachgebrauch innerlich ungeprägt, bekommt die terminologische Prägnanz in der Bedeutung 'Gott', so daB es im Verlauf der späteren sprachentwicklung aus dem profanen Bereich ausscheidet. Als Gottesbezeichnung entspricht gospodb xúplos-Veós, dominus - deus und dem ahd.

1. Vgl. aind. patis 'Herr', griech. nóls, lat. potis. Vgl. dazu Frinta 25; Fraenkel in ZfslPh 20, $51 \mathrm{ff}$ :; Krogmann $253 \mathrm{ff}$; Porzig 133. AuBerdem noch Trautmann 208: baltosl. "pati 'Herr', lit. päts 'Ehemann' und 'selbst', ferner viêspats 'Herr'. Die Hauptschwierigkeit macht das $d$ in der slav. Form, welches die unmittelbare Herkunft aus dem Idg. verbietet, da ein Wechsel $t: d$ unmoglich ist. Nach Porzig (133) konnte gospodb nicht gemeinindogermanisch gewesen sein, denn der erste Bestandteil ist nur germ., slav. und italisch.

5. Vgl. Jiretek, I, 156 und 197, Benveniste I, 92,95. 
truhtin, doch bleibt die Entsprechung auf die Ubernahme der Funktion beschränkt, denn sowohl die Begriffe als auch die Bezeichnungen waren voneinander verschieden. 1

Die Form gospodinz $\mathrm{m}$. wird auf Gott nicht angewendet - auBer zwei Ausnahmen ${ }^{2}$-, nach BUSLAEV gibt das Suffix -inb dem Wort einen gewissen Abhängigkeitssinn, wie z.B. ljudinz m. 'einer der Leute' (Buslaev 123). Sehr selten kommt auch vladyka $m$. in Verbindung mit Gott vor und bleibt nur ein Attribut; uber das einmalige Kompositum vbse-vladyka m. s.o. unter vbsemogy.

$g r \check{e} c h$ b $m$. 'Sünde', davon abgeleitet sb-grěšiti pf.'sündigen'. Uber die Etymologie des Wortes gibt es keine einheitliche Meinung. VASMER ( $I, 307)$ will es in Verbindung mit $r$. gret' sehen, wobel die Sünde als das 'Brennen des Gewissens' aufgefaBt wird. Diese Möglichkeit wird auch von MIKLOSICH erwogen und zwar mit dem Hinweis auf aind. ghr-, asl. grěti, gorěti (Mikl Term 43). Eine solche Erklärung kann jedoch nicht befriedigen, da sie eine nachträgliche interpretatio christiana des Wortes grěchı darstellt. Uberzeugender und auch theologisch annehmbar ist die von BERNEKER und

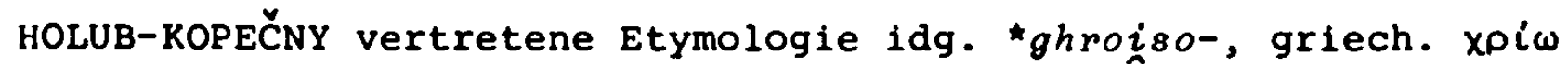
mit der Bedeutungsentwicklung von 'streifen - streichen - vergessen'. ${ }^{3}$ Daraus lieBe sich auch die frühere Bedeutung der Wortsippe grěchs erklären. Ännlich dem griech. duaprduelv und lat. peccare konnte auch asl. grěšiti ' (das Ziel) verfehlen, abirren, einen Fehler machen' dann auch 'sich vergehen' bedeuten. 'Der vorchristliche Gebrauch von grěchı und grěžti in diesem Sinne ist neben der christlichen Bedeutung 'Sünde, sündigen' im Asl. noch erhalten, wenn auch die Belege dafür naturgemäB spärlich sind. Asl. grĕchomb steht für griech. \&xovoiws 'unabsichtlich', obxelows 'unvorhergesehen. ${ }^{5}$ Im Altrussischen wird der Gebrauch von grěchb und grěriti (-sja) in der Bedeutung 'Fehler, Irrtum, Versehen, sich irren, daneben treffen' reich belegt. AuBerdem ist in verschiedenen slavi-

1. Vgl. dazu Eggers, I,114-117, Ehrismann, 173 ff., Tschirch 282.

2. Vgl. LLP 1,424 . Êne Ausnahme stellt dêr Text von Bes dar? Als Gottesbezeichnung ist asl. gospodinb sicher ein Bohemismus. Vgl. Weingart, 91 , Mareš, 417451. Uber den Gebrauch im AČech. vgl. Frinta 24 : "Hospodin je biblické ... epiteton Boha ve významu Pán (toto previddd $v$ Kral.NZ) již v nejst. pambtce literarni: Hospodine, pomiluj ny = Kúple Ėehoov!

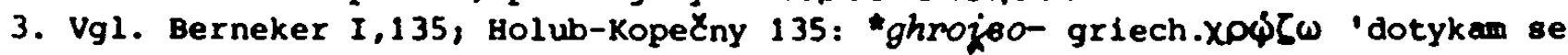
povrchu'.

4. Walde-Hofmann II, 269, Georges II,1526, Frisk I, 87, Lidell-Scott 2007.

5. Mikl Term 43; Mikl LP 147; LLP I,442: po gréchu 'leider'. 
schen Sprachen der Wortstamm grěch- in seiner alten Bedeutung noch lebendig: bulg. grę̧ka 'Irrtum', slov. greziti pot 'den rechter: Weg verfehlen' etc. 1

Der nichtchristliche Gebrauch des Wortes grěchb und der Wortbildungsvarianten prěgrěšenije n. sbgrěšenije n. ist jedoch nicht auf das Allgemeinsprachliche beschränkt. Verschiedene altslavische Belege weisen auf den strafrechtlichen Charakter dieser Wortgruppe hin, wodurch ihre zugehörigkeit zur Rechtssprache ausgewiesen wird. In Bes 39,307 bB 99 entspricht vb grěsechs dem lat. in scelere; ebenso in Venc Nik 19, 62,60 für lat. scelus grěchb; Nom Ust' 32b 8 für griech. altia, sud Ust' 61a 7; 60b $19 \mathrm{sq}$ für griech. uoina und lat. culpa, iudicium steht grěchъ. ${ }^{2}$ Der Rechtscharakter der Wortsippe grěchb wird auch durch den sprachgebrauch im altrussischen Strafrecht bestätigt, indem der Begriff der Gesetzesubertretung in der Ubersetzungsliteratur aus dem Griechischen mit sıgrĕženije neben prokaza f. wiedergegeben wird. ${ }^{3}$ SREZNEVSKIJ gibt für prĕgrĕšenije die griech. Entsprechung riaioua lat. delictum an (II, 1627). Annliches ist auch im Altserbischen festzustellen: i jako sьgrěse kralevsstvu mi, da se sudomb ispravlamo kako je po zakonu (Mon Serb 50). Für delictum gibt DANIČIĆ sbgrěcha und sьgrěšenije an (III,231).

Dem christlich-religiösen Begriff der Sünde, deren Wesen in der freiwilligen Verletzung der göttlichen Gesetze (Lex Dei) gesehen werden kann, kommt grěchı als Bezeichnung des Vergehens, der Gesetzesübertretung sehr entgegen. Die enge Verbindung der beiden Begriffe wird in der synonymen Verwendung der Wörter grěch b und bezakonije n. für 'Sünde' besonders augenfällig. Ausdrücklich heiBt es in Christ, slepč, šiš $1 \mathrm{~J} 3,4$ : vspkb tvoręj grĕchb $i$ bezakonije tvoritb $i$ grĕchb jestb bezakonije. Bezakonije bedeutet aber in erster Linie 'Gesetzlosigkeit, gesetzwidriges Handeln, Frevel, Unrecht'. Hieraus ergaben sich noch andere Versuche, den christlichen Begriff 'Sünde' im Slavischen verständlich $z$ u machen:

1. Vql. Srezn 1,604. Ebenso Daničic für Altserbisch: ako se po nekojemb grechu nanese pogoreti manastyrju M.98; aśte kto popasetb žito gréchomb (invitus) 2.35,49. (1,243). Vgl. auch Machek 148; Holub-Kopečny 135; Pleteršnik 1,250; sławski $1,368$.

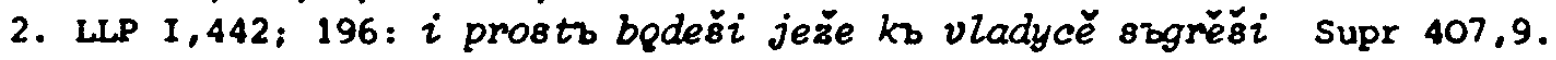

3. In "Dogovor Olega". Vgl. darüber Vladimirskij-Budanov 295. Der Russkaja Pravda ist der Begriff der Ubertretung des Gesetzes fremd und daher auch der Terminus dafúr unbekannt. Der Terminus der Russk. Pravda ist obida. 
nepravbda f. und krbvbda f., sie haben jedoch wie lichodĕjanije $n$. und zblodějanije n. keine terminologische Festigung erfahren.

In der Tat, die Sünde ist Unrecht, böses Handeln, Gesetzlosigkeit, doch darüber hinaus ist sie "Verletzung und Beleidigung Gottes" Indem sie den "Bund zwischen Gott und dem Menschen" bricht. Sie besteht in der Abkehr von Gott, denn nach christlicher Ethik ist der Mensch Gott gegenuber zum Gehorsam verpflichtet (BthW II, 1292,1295). Mit diesem neuen, andeutungsweise umrissenen Inhalt wird das Wort grĕchb gefüllt, es verliert seine stellung in der Rechtssprache und geht ganz in den speziellen christlich-ethischen Wortschatz über.

i s p o v è d a t $i$ s $\ell$ ipf. 'bekennen' s.u. unter ispovèdĕti pf. $i$ s $p o v \check{e} d \check{e} t i$ pf.. ispověděnb byti pass. gebildet aus asl. věděti 'wissen', po-věděti 'wissen lassen' (Brückner SEJP 615; Vasmer $I, 176)$. Mit dem vorangesteliten weiteren Präfix is- entspricht asl. is-po-věděti dem griech. (EE-) ouodoreiv lat. confite$r i$, ahd. bi-jehan 'bekennen'. In Verbindung mit dem objekt grěch b (-y) bekommt ispověděti den speziellen sinn 'Sünden bekennen, beichten', so das es in der weiteren Entwicklung auch ohne objekt als Terminus für 'beichten' absolut gebraucht wird. In diesem Sinne ist in Fris der Sprachgebrauch von ispověděti noch nicht terminologisch. Auch die refl. Form ispovedati se ipf. In Fris II steht in Verbindung mit einem Objektsatz.

Unter Berufung auf Mikl Term 46 weist FRINTA auf den EinfluB des ahd. bijehan bel der Entstehung des asl. ispověděti 'belchten' hin (74). SREZNEVSKIJ fuhrt es dagegen auf das griech. sprachliche Vorbild zurück, wăhrend SchuManN eine griech."Lehnbedeutung" darin sehen will (Sreznevskij, 84; Schumann 236 ). Es gibt aber keinen zwingenden Grund, fremde Vorbilder für die Wortbildung anzunehmen. Das zweifach präfigierte asl. Verb steht sowohl fur das griech.

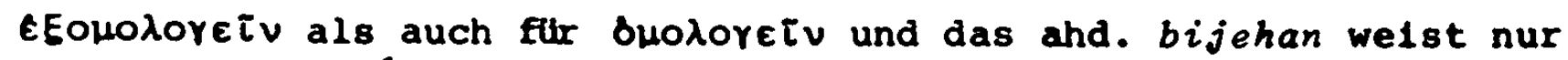
ein Prafix auf.' Die Tatsache, das nur ein Wort fur 'bekennen' im Gebrauch ist, labt nur eine geringe Wahrscheinlichkelt einer griech. Lehnbedeutung zu. Die Ubersetzung des lat. confiteri bzw. des and. bijehan muste dasselbe Ergebnis bringen: das schon vorhandene ispovědĕti (ispovĕdati - $8 \xi$ ). Dem griech. und dem lat. Sprachgebrauch folgend hat es die dreifache Bedeutung In der Xirchenslavi-

1. Vgl. LLP I,806 unter ispověděti. 
schen Literatur: 1. 'Glauben bekennen', 2. 'Sünden bekennen' und 3. 'lobpreisen'. 'Sowohl im Griechischen als auch im Lateinischen gehorte 'bekennen' der Gerichtssprache an. ${ }^{2}$ Auf Grund zahlreicher Belege kann nachgewiesen werden, daB die Wortgruppe ispověděti auch im Altslavischen der Rechtssprache angehörte; z.B. ispovědaitesę dobrym ispovědanijems prèd mnogy svěděteli in Ap Ochr $1 \mathrm{Tim}$ 6.12; podobajetb vprašati ichs i primati otb nichb ispovědanije tvbrdo in Nom Ust' 33b 8-9. Hier handelt es sich um 'aussagen' bzw. 'bekennen' vor Gericht oder einer Untersuchungsinstanz.

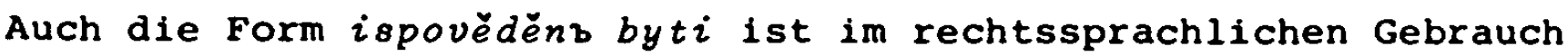
belegt. Auf das Vorkommen dieser Form in einem Rechtsdenkmal hat schon VAILLANT hingewiesen (77-78). Es ist "Syntagma XIV titulorum" 3 und die stelle lautet: iže ispovědbni budutb protivibăe $8 \varepsilon$

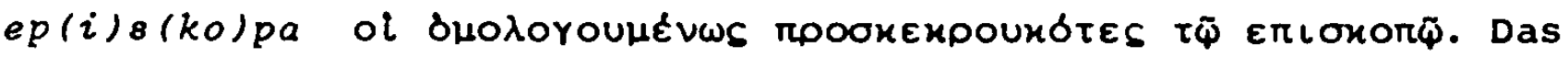
Wort ouodoroumévws im griech. Paralleltext wurde von slavischen Ubersetzern nicht verstanden, doch die stelle ist für sich im $\mathrm{zu}$ sammenhang mit dem übrigen kontext verständlich, wenn sie auch den Sinn des griech. Textes nicht wiedergibt. 4 sie bedeutet: "diejenigen, die sich dem Bischof widersetzen, werden zur Rede gestellt werden (sie werden verhört werden)" Somit wăre die Form ispověděnz byti im Dienste einer juristischen Aussage zur Klärung der Rechtsverhältnisse in einem kanonischen Text belegt.

Die engen Beziehungen zwischen der Beichtsituation und dem Ablegen eines Geständnisses vor dem Gericht schufen günstige Voraussetzungen für die Wahl der Wortgruppe ispověděti zur Bezeichnung des sakramentalen Schuldbekenntnisses. Ahnliche Erscheinung ist auch im Ahd. zu beobachten. "Im Inquisitionsverfahren des BuBsakraments muB das Beichtkind 'geständig sein' bigihtig werden. Das 'Bekennen' ... gilt als der wichtigste Akt des prozesses und hat dem Ganzen den Namen gegeben ... Als 'Richter' fungiert der ur-

1. Vgl. Rheinfelder, 56: "Scire debes triplicem esse cofessionem, laudis, fidei criminis." Ein zitat aus Caesarius von Heisterbach $(+\mathrm{ca} .1240)$.

2. Vgl. Teeuwen 89; Bauer 548 und 1125 ; ठ ein Geståndnis ablegen'. Vgl. auch Rheinfelder, 56: "Das Wort confitemi gehort der Sprache des Gerichts an, wird aber im alten Rom auch schon auberhalb des Tribunals verwendet und heiBt 'gestehen, of fenbaren, zeigen."

3. Syntagma XIV titulorum, I. Petropoll 1906. Ed. V.N. Beneševič, S.85, 1.25-26

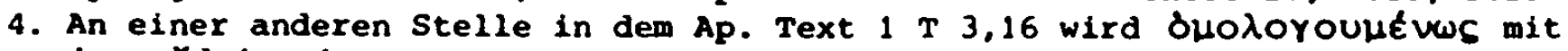
ispovèdajemaja part.prăs.pass. übersetzt, der sinn jedoch ist ein anderer, nach zorell 392: "sine controversia, sine dubio" (Ap. Text aus Christ). 
sprünglich unpersönlich, als Gericht oder Obrigkeit gedachte 'Beichtvater'. Er fällt das Urteil (ego te absolvo) und bestimnt das StrafmaB ... Noch der Codex Juris Canonici, Can 880 \$ 1 nennt den Priester in seiner Funktion als Beichtvater iudex." (Weisweiler 252).

$i s p \circ v \check{e} d$ b f. gebildet aus ispově-děti + Suff. -b. 'Bekenntnis'. Im absoluten Sinne 'Sündenbekenntnis, Beichte' wird es nur in Fris II gebraucht (sonst kommt es nur mit dem Gen.Obj. von grěchb 'Sünde' vor) und hat zugleich eine Bedeutungserweiterung zur Bezeichnung des ganzen BuBsakraments erfahren. Dieses ist ke1ne eigene slavische Entwicklung, sondern hat seinen Grund in der griech.-lat. Kirchenterminologie. Die EEoHodornoıs bedeutete im engeren Sinn das Sündenbekenntnis, umfaste dann aber auch die Genugtuung, Lossprechung und die Aufnahme in den Kirchenfrieden (Weisweiler 241). Als griech. Lehnwort wurde die exomologesis von lat. Kirchenschriftstellern in diesem erweiterten sinne gebraucht. Im neunten Kapitel seines Traktats "De Paenitentia" gibt Tertullian eine ausführliche schilderung dieser exomologesis, die "non sola conscientia praeferatur, sed aliquo etiam actu administretur" (Weisweiler 241). "An die stelle des Fremdwortes exomologesis trat poenitentia, das die Begriffe exomologesis, absolutio, reconcilia-

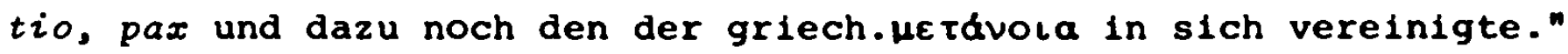
(Ebd.)

Der Gebrauch von ispovědb $f$. In dem erweiterten sinne (d.h. für die drei Hauptteile des BuBsakraments: contritio, confessio, satisfactio) findet sich auch in Bes 20, 11 3b 1-2: da grěsniky ǐe grěchomb jestb mbrtvъ ispovědbju oživetb ... per conversionem vivat (hier eine Ubersetzung des griech. Hetávola' Sinnesanderung, Umkehr' (LLP I, 805).

AuBer der Form ispovĕdb $f$. ist in der asl. Literatur die Wortbildungsvaralante ispovědanije $n$. sehr oft vertreten und In rechtssprachlichen Gebrauch belegt. 1

Für 'BuBe' als Terminus fur das ganze BuBsakrament let im Alt-

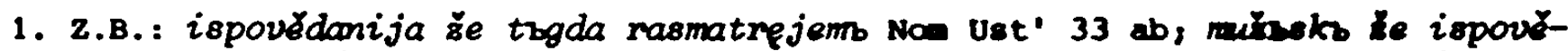

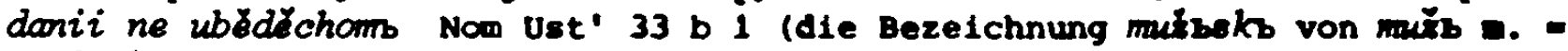
posluchb d.1. nach vladimirskij-Budanov 642 "ein Mann, der beil Gericht ein zeugnis nach dem, was er gehort hat, ablegt"), $l_{i}$ ispovedanije javiti jestb podobno Nom Ust' 34a 23-24. Belegmaterial Arch It.P. 
slavischen der Ausdruck pokajanije n. beherrschend. Im Altrussischen wird sowohl ispovědanije n., ispověds f. als auch pokajanije $\mathrm{n}$. In dieser umfassenden Bedeutung gebraucht (Srezn I,1128-9). $i z b a v i t i$ pf. 'befreien, erlösen' ist in der asl. Erlösungs. terminologie als gleichwertig (jedoch nicht gleichbedeutend) mit sbpasti pf. anzusehen. Wăhrend sbpasti (s. unter szpasenije, sspasite $\left.i_{b}\right)$ auf $\sigma \dot{\phi} \zeta \varepsilon \iota v$ zurückgeht, entspricht izbaviti dem lat. redi-

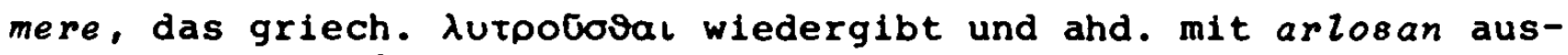
gedrückt wurde. ${ }^{1}$ Seine inhaltliche Năhe $z$ u otęti pf., das dem lat. eripere entspricht, ist hervorzuheben. Oft werden die beiden Ausdrücke miteinander ausgetauscht, wie z.B. in der abschliebenden Bitte des Paternoster in der Petrusliturgie der Chil Handschrift (Vašica 44): nz izbavi nasb ot(b) lukavago, in Kij 5,21 dagegen otsmi ny otb lqkavb(st)va. Dasselbe Verhältnis zwischen den beiden Ausdrücken ist auch im Text von Fris I und III zu beobachten: I,27-28 "BoBe ti pride zenebese... Dabini zlodeiu otel" gegenúber III,67-70 "Cribte boBi zinu... grebnike izbaviti ot zlodeine ob$\operatorname{laz} t i^{n}$.

Neben izbaviti wird in der asl. Literatur auch iskupiti pf. 'loskaufen' als eine getreue Ubersetzung des lat. redimere gebraucht (LLP I,795). Auch das Ahd. hat in koufan, archaufan diese Entsprechung (Raumer 368). Für 'erlösen = heilen' steht icěliti.

Alle drei Verben izbaviti, iskupiti und otgti haben in der Bedeutung das Befreiungsmoment miteinander gemeinsam, sie bringen in erster Linie die Erlösungstat Gottes zum Ausdruck, wăhrend sbpasti und sb-, u-chraniti pf. die schützende und erhaltende Macht Gottes meinen (vgl. die Ausführungen unter szpasti). Dementsprechend steht izbaviti nicht nur fur redimere in der asl. Ubersetzungsliteratur, es gibt auch eruere, eripere, liberare (und die entspr. griech. Ausdrücke) wieder (LLP I,718).

Von der allgemeinen Bedeutung 'befreien, erretten' wird izbaviti auf die speziell christliche 'erlösen' eingeengt. Die Wandlung des Wortinhalts vollzog sich ahnlich wie bei dem Terminus sbpasti beschrieben.

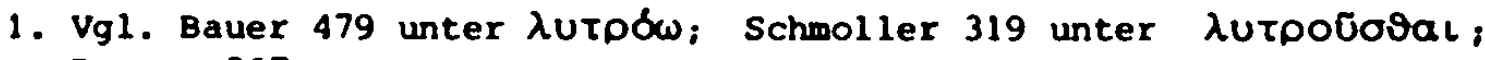
Raumer 367. 
$i z v 0 l j$ e $n y i$ m. subst.part. 'der Auserwählte' electus (Dei) konkurriert in der asl. Literatur mit iabbranyi; s. o. unter $i z v o l j e n i k b$. Das Verb izvoliti entspricht dem griech. alpeiooal und lat. eligere, gibt aber noch viele andere lat. und griech. Ausdrủcke wieder; daher läBt sich die Abhängigkelt seiner neuen christlichen Bedeutung auf keines der Vorbilder mit sicherheit einschränken (LLP I,727).

$k$ a $j a t i s e$ ipf. aus idg. *kuei- 'worauf achten', daraus einerseits 'ehren', andererseits animadvertere, 'strafen, răchen, büBen', abg. kajati se 'Reue empfinden', pokajati se 'BuBe tun'. okajati 'bejammern', russ. kajat' 'tadeln', -8ja 'Reue empfinden' (Pokorny I,636-637), ist der asl. Ausdruck für 'büBen, BuBe tun', lat. poenitere, poenitentiam agere, griech. Heravoeiv. MACHEK ermittelt fur das Ursl. "kajati 'strafen', weist auf skr. kajati 'rächen' und aind. cayate' 'rächt, straft' hin.' MIKLosich gibt für asl. kajati 8 e' 'sich selbst tadeln, sich Vorwüfe machen, sich strafen' als vermutliche ursprüngliche Bedeutungen an. 2 Vom sinn her entspricht es also dem ahd. hriuwan, abair. riuun, dem nhd. 'bereuen, Reue empfinden'. Diese Ausdrücke haben sich in der ahd. Bubterminologie ihren Platz erobert, wurden aber spater von der Wortsippe bußßen verdrängt (Weisweiler 206,210 ff.). Der ethischen und der Gefühlssphare angehörend, erfullte das asl. Wort kajati 8 \& die Forderung, welche von dem lat. contritio, einem der Hauptbubakte ausging. In seinem ursprünglichen sinne wird es auch in den biblischen Texten gebraucht und entspricht so dem griech. Hetavoeiv und lat. paenitere, lamentari wie z.B. kaje 8

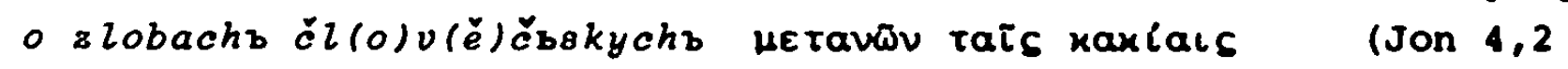
Grig Lobk): ty bo jesi b(og)b kajgštiichb se kaje se o v'sĕchb

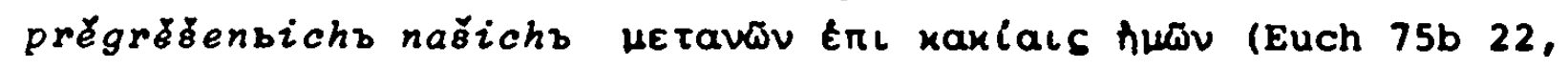
LLP II, 18-19). Das letzte Beispiel macht es besonders anschaulich, wie das Wort kajati se über seine ursprungliche Bedeutung 'traurig, betrubt sein, bereuen' zu 'büBen' im biblischen sinne hinausweist. In einem Satz steht es in der ursprünglichen Bedeutung und wird zugleich als Terminus für 'büBen' deutlich von ihr abgehoben: "denn du bist Gott der Bubenden, betrubt (seiend) wegen aller unserer

1. Vgl. Machek 195; Frinta 30; Vasmer I,544, Berneker 469.

2. Vgl. Mikl Term 45. Seine Vermutung findet im Arch Lup keine Unteretatzung. 
Sünden" .

Auber 'betrübt sein' ist für kajati se keine andere rorchristliche Bedeutung im Asl.belegt. Es ist fraglich, ob es berechtigt erscheint, mit BERNEKER vom skr. kajati 'răchen' auf die alte Bedeutung 'strafen, răchen' zu schlieben.' In diesem Falle würde auch dem slavischen Terminus die für das germ. 'büBen' bezeichnende juristische Färbung anhaften (Weisweiler 215).

Das von dem Verb po-kajati se abgeleitete substantiv pokajanije $\mathrm{n}$. bezeichnet die gesamte Institution des BuBsakraments. zur Zeit der Entstehung der BuBterminologie waren einzelne BuBakte begrifflich noch nicht so streng untereinander differenziert, wie das später in den vom Tridentinum vorgenommenen Definitionen zum Ausdruck kam (Weisweiler 219). Daher wurden die Bezeichnungen für die drei hauptteile des BuBsakraments contritio, confessio, satisfactio auch auf das ganze übertragen. "Die griech. Hetdvola bezeichnete... nicht nur die Reue, sondern auch die BuBübungen und in jüngerer zeit auch das BuBsakrament." (Weisweiler 240).

$k i$ a $n j a t i \quad s \&$ ipf. steht neben modiiti se als Ausdruck für die Gebetshaltung. In seiner Grundbedeutung 'sich verneigen' gehorte es sicherlich $z u$ dem wortschatz der heidnischen religiosen Terminologie. BUSLAEV sieht in den lateinischen worten pronis vultibus adorare der Helmold - Chronik, mit denen der heidnische kult beschrieben wird, eine Bestätigung dafür (122). Der Gebrauch des Wortes für Ehrerbietung im weltlichen Bereich zeigt, daB klanjati se nicht nur auf die religiöse sphäre eingeschränkt war. ${ }^{2}$ Im serbischen Mittelalter bedeutete das Substantiv poklonb $\mathrm{m}$. 'corporis inclinatio, donum' (Daničić II,346). Auch in der russischen Chronik ist das wort poklonb $\mathrm{m}$. belegt: povědořa svjatoslavu, jako pridoša Grbci si poklonomb d. h. 'mit dem Geschenk'. Auch im Altpolnischen bedeutet pokion $\mathrm{m}$. und pokzona f. 'Gabe, Geschenk'. 3

1. Vgl. Berneker I,469; Weisweiler 215. Auf die Vermutung Miklosichs gestützt, vergleicht Weisweiler das aus der germ. Klostersprache kommende 'sich büBen' in der Bedeutung 'sich strafen' mit dem asl. kajati se.

2. Vgl. LLP II,25: klanjati se = cwn reverentia ac supplicio salutare; deo sive imperatori honorem exhibere.

3. Vgl. Ciszewski I,100. Ciszewski erlautert die rechtliche Natur des im Glossa rium von Brandl mit "oblatio, quae dicitur poclona, salutatio" bezeichneten Begriffs: "Im serbischen Mittelalter hat man unter poklonb ausschlieblich eine freiwillige Gabe verstanden, unter obrokb aber pflichtgabe. Bulg. bedeutet poklomb 'Geschenk' (Gierov, Rě̌nikb)..." (eig. Ubers.) Weiter fahrt er fort: "Darzagcy pana poddany wkrada się przez swoje dary w panska laskę... Strona obdarzona na dar taki nie odpowiada... nie darem. ...lecz swoja paf- 
Es ergibt sich daraus, daB klanjati se nicht nur inclinari, Korperbewegung, sondern auch Darbietung von Gaben bedeuten konnte. $\mathrm{DaB}$ zwischen moliti $8 \&$ und klanjati se nicht streng unterschieden wurde, darauf hat BuSLAEV hingewiesen. 1 Doch meint das Erste das Sprechen des Gebets (fruher auch das Opfern), das 2 weite die Gebetsgeste. In der synonymen Verwendung zu moliti of hat klanjati $s \xi$, ein dem heidnischen Kult entspringendes Wort, seine stellung in der christlichen Frömmigkeitsausübung eingenommen. In Fris wird es in Bezug auf die Verehrung der Heiligen gebraucht.

$m i l o s t$ b f. 'Gnade, Barmherzigkeit', davon milostivyi adj. 'gnädig, barmherzig'. Ursl. *milb, verwandt mit lit. mýlas und mŁelas 'lieb, angenehm', méilè f. 'Liebe', geht auf die idg. Wurzel méi-mit $l$-erweitert zurúck (Pokorny I,712, Machek 296). Im Asl. bedeutet $m i l_{b}$ adj. 'erbarmenswert, bemitleidenswert, entschuldbar' (LLP II,209). Das aus milb + Suff. -ostb gebildete Abstraktum milostb f. findet in der asl. Literatur mannigfache Verwendung, es steht für lat. misericordia, gratia, benevolentia, benignitas, clementia, largitas, pietas, venia, commiseratio, compassio und für entsprechende griech. Begriffe auBer xap $\varsigma^{5} .^{2}$ In Fris wird milostb sowohl für ahd. ganada als auch miltida gebraucht, wăhrend Euch an den betreffenden stellen genau die ahd. Ausdrucksweise beachtet und $z w i s c h e n$ ganada = gratia und miltida = misericordia unterscheidet. Fur ganada steht dort milostb und miltida wird mit štedroty pl. wiedergegeben. ${ }^{3}$ In Fris hat milostb also zwei Bedeutungen: 1. bezeichnet es den zentralbegriff des christlichen Glaubens 'Gnade' lat. gratia, griech. xoros und

ska laska... Dar poddanego obliczony jest zatym na zdobycie pahskiej laski ... Dar, który czlowiek niewolny 1 podlego rodu sklada panu ... staje sie jawna oznaka uleglosci, poddania się, najwyzszego uszanowania, czolobitnosci. zmieniajac calkiem pierwotny charakter. I wowczas zmienia sie rownoczesnie jego miano... W Polsce zwat sie on poczyna poklonem w. albo poklona $z$."

1. Buslaev 122: "DaŽe u Nestora vstreX̌am ešce klanjatbsja vosto molitbsja: $i$ edinoju po obyčaju, nastav8ju veðeru poda klanjatbsja, poja psalmy, oli $i$ do polinošbja Lavr. str.82."

2. Vg1. LLP II,208. Far X\&pls steht nur blagodatb, blagodëtb, das den Inhalt des griech. Wortes genau wiedergibt, denn Xols bedeutet zundchst die huldvolle Gesinnung des Hohergestellten, dann das aus diesem Wohlwollen erhaltene Geschenk: die Gnade. Vgl. dazu Wahmann 132. Wichtig erscheint es festruhalten, dab die wiedergabe des griech. Xdols nicht milostb sondern blagodatb, -dĕtb ist, für gratia aber beldes stehen kann. Daraus erhellt, dab der Gebrauch des Wortes milostb für 'Gnade' auBerhalb des griechischen literarischen Einflusses steht.

3. Vgl. die Gegenüberstellung des Textes von St. Emeramer Gebet und des Beichtgebetes des Euch 72 a bel Vondrá 15. 
2. 'Barmherzigkeit' lat. misericordia, griech. EגEos.

Im Folgenden soll milostb als Gnadenbegriff betrachtet wercen. Bevor es in die christliche Terminologie in dieser Funktion ubernommen wurde, trat milostb im profanen Sprachgebrauch auch als Rechtsbegriff auf. Aus seiner stellung im vorstrafrechtlichen Stadium lassen sich Bezugspunkte in der Analogie des fruheren Rechtsbegriffes und des späteren christlichen Terminus für 'Gnade' finden. 1 Es handelt sich un die die Blutrache ablösende Periode, in der der fingierte Racheakt, die sogenannte "Sühnezeremonie", die wirkliche Blutrache ersetzte. Diese formale Rache hieB bei den Polen und Tschechen, aber auch bei den Russen pokora und entsprach darin dem lat. Terminus gratia. ${ }^{2}$ JIREČEK weist daraufhin, daB in einem tschechischen Text aus dem 14. Jh. diese pokora als Bezeichnung für die sünnezeremonie auch milostb genannt wird. ${ }^{3}$ Die verschiedenen Benennungen derselben Sache sind durch den doppelten Aspekt des Vorgangs $z$ u erklären. Einmal zeigt sich die demütige, um Erbarmen flehende Haltung des Ubeltäteters (in der christlichen BuBpraxis - des bubenden sünders), was in Fris mit milb se tvori$t i$ (synonym dazu pokoriti $8 \ell$ ) ausgedrückt wird, zum anderen die gnädige zuwendung des zur Rache berechtigten (bzw. verpflichteten) "Rächers" (Gottes), der das Leben (Heil) des sich ihm unterwerfen-

1. Von der vergleichenden Rechtswissenschaft und volkerkunde sind soziale und rechtliche Entwicklungsstufen erschlossen worden, die schematisiert 4 Perioden ergeben: 1. Religiós-ethisch-rechtliche Rachepflicht des Geschădigten uni seiner Sippe. 2. Der Geschădigte kann sich sein Racherecht durch moralische und materielle Ersatzleistungen vom Missetater abkaufen lassen; der Missetater kann durch ideelle und materielle Leistungen an ihn die Missetat suhnen. 3. Die Leistung der BuBe durch den missetater und ihre Annahme durch den Geschadigten ist verbindlich und die Hohe gesetzlich bestimnt; Selbsthilfe ist nur erlaubt, wenn die BuBe verweigert wird. 4. Abschaffung der Selbsthilfe des Geschadigten, der Friedlosigkeit des Missetăters; Der Staat verschafft dem Geschadigten Genugtuung und Schadenersatz und bestraft den Missetater (Buße - Strafe). (Verkürzt aus Weisweiler 166).

2. Vg1. Kadlec, 115: "Potem następowala fikcya zemsty, czyli ceremonia, któa formalnie zemste rodowa wyobrażala. U Czechów 1 Polaków nazywano ja pokora (Xać. gratia)." Vgl. ferner vladimirskij-Budanov 314.

3. Jirečk $I, 171$ gibt die in der "Kniha Tovačovska" 15. Jh.., enthaltene Schil. derung des "pokora-Ritus" wieder: "Vinnik má ku pokoře jiti bos, bez pasu, a na hrob(zabitého) křižem lehnuti, a přitel (sopernik) nejbližšl ma meč mezi jeho plecima koncem doluov držeti a tžikrát se jeho otázati: 'Již-1i jsem tal mocen hrdla tvého, jakož ty byl bratra mého?' A když di po tłikrate: 'Již, ale prosim, živ mne!' Tehdy di: 'Živim tĕ pro Pána Boha!' a ma jemu odpustit: Krome peněz, měl pokořený také službami pomocen by̆ti těm, kterým zabil přibuzného, až do sve smrti, aby tak řikaje svou osobou nahrazoval padiého." In "P̌̆ldavky k Dalimilově kronice" 14. Jh. findet sich der Satz: "Rudoltivici se jim na m 1 l 0 s dachu." Nach Jireček wird hier der pokora-Ritus mit dem Wort milost bezeichnet. 
den Missetäters in der Hand hat. 1

Fokora und miloetb stehen sich gegenüber. Von hier aus ist es nicht schwer, den Schritt zum christlichen Begriff der Gnade zu tun. Das Grundverhaltnis Gottes zum Menschen kommt darin zur Sprache (HthG I,548). Im AT wird Gnade als die huldvolle Zuwendung Gottes zum Menschen, als selne erbarmende Huld und das verlabliche Handeln am Volk (Gottes) geschildert. "Diese zuwendung findet ihren Ausdruck in unbedingter Treue zu einmal geschlossenem Bund zum einmal gegebenen Wort, das auch bei menschlicher schuld und gottlicher strafe nicht zuruckgenommen, sondern in der vergebung erneuert wird." (HthG 1,548 ). Das hebr. chên wird in der Septuaginta mit griech. xdols wiedergegeben. Charis des NT bleibt auf der von AT vorgezeichneten Denkbahn, bekommt aber durch die Verwendung im Heilsgeschehen ein neues Profil und wird durch Paulus zum Kardinalbegriff der neutestamentlichen Theologie (BthW I,601).

Die inhaltichen Voraussetzungen des Wortes milostb, die seine Wahl zur Bezeichnung des christlichen Gnadenbegriffes bestimmt haben, bekommen im Lichte der von DOMBOIS unternommenen Untersuchung uber die Rechtsstruktur der Gnade eine besondere Geltung (81). Es zeigt sich darin, wie sehr das Rechtsdenken das Verhältnis zwischen Gott und dem Menschen bestiment. 2

AuBer dem allgemeinen Rechtscharakter des Wortes milostb ist noch seine verfassungsrechtliche Bedeutung des lat. privilegium in den altserbischen Quellen bezeugt. In den Privilegienurkunden des Stephanus Urǒ̌, Serbiae rex aus der Mitte des 13. Jh. heibt es: stvori milostb kralevbstvo mi gradu Dubrovbniku - im lat. Titel wird das mit folgenden Worten wiedergegeben: Stephanus Urö, Serbiae rex, privilegia mercatoribus ragusinis concedit (Mon. Serb. LIII. 1240-1272, 51).3

In den alttschechischen Texten wird milostb als Ausdruck fur einen besonderen Typus der Rechtsgemeinschaft verwandt: "mnozl p\&-

1. Dazu 8. ausfürlicher unter vèra.

2. Vgl. Dombois 171-175. Als Rechtsakt bedacht 1st der Gnadenakt grundsatzlich unkonditional, deklaratorisch und konstitutiv, er vexpflichtet zum wohlverhalten. Durch den Vergleich mit anderen Rechtsinstituten, den der Schenkung und der Erbeinsetzung wird sein Wesen besonders deutlich. Auch diese sind grundlos, ohne Anspruch, sine causa seitens des Bopfingers, bedingungsfrel, doch daraber hinaus ist Gnade Restitution eines zerstorten, Neuinstitution eines alten Verhaltnisses, sie kann nicht verlangt, sondern nur erbeten werden und setzt ein Uber- und Unterordnungsverhaltnis voraus.

3. Elne weitere Spezialisierung erfahren die Ausdrocke milostbnikb 'der Privi- 
ni uheršt1 ... již jsu se nám (Alžběte) na milost dali a $k$ nám přistupili"1; "Tu jest jiho (Knotka) panl milost otazala: Múžeš11 to ... provésti; a on řekl, že nemohu, 1 dal sě jest panı milostivé na milost"2, "mluvili, aby je kral na milost přijal" ${ }^{3}$.

In dieser Bedeutung ist milosts auch im Altrussischen und im Altserbischen belegt: $U$ sebè ja dbržă̌e vb m(i) l(08)ti (Srezn II,138); $i$ daju imb milostb do života moego (Mon.Serb.LI, 1240-1272, 50).

AuBer im Beichtgebet des Euch kommt milostb in der Bedeutung 'Gnade' gratia auch in Bes vor. In der kirchenslavischen Literatur wird dafür gewöhnlich blagodats f.,blagodětb verwendet, wăhrend milostb vor allem misericordia bedeutet (Mareš, 439). Für misericordia, griech. Ėeos 'Barmherzigkeit' steht auch štedrota f. und milosrbdije $n$., das entweder auf das lat. Vorbild oder auf das ahd. armiherzida, armaherzi zurückgeht (Vasmer II,134).

$m i l \quad 0 \quad s \quad t \quad v y i$ adj. 'barmherzig', gnădig', eine der wichtigsten Eigenschaften Gottes. S. unter milostb.

$m i l$ b $8 \&$ t $v \circ r i t i$ ipf. 'abbitten', wörtlich 'sich erbarmenswert machen'. Es ist schwer zu sagen, ob es nur die innere Haltung des BüBers, oder auch die sich nach auBen bekundende BuBubung bezeichnete. Jedenfalls gehörte das Wort zur Terminologie der sühnezeremonie, von der unter milosts und věra ausführlich gehandelt wird. Bemerkenswert erscheint, dab an den stellen, wo es sonst nocr in der asl. Literatur vorkommt, meistens mit dem Verb pripadati in Verbindung steht: pros̆q ot (z) tebe $i(m) i l_{b}$ sq dèje pripa(dajQ) Ryl 7ba 20; tembàe $i$ azb milb sę dějQ b(o)gu pripadaje ti o(tb) ze Euch 68b 24. Das demütige Flehen um Gnade, Erbarmen ging mit der Unterwerfungsgeste des zu-Boden-Fallens einher.

Formal ist milb se tvoriti ein objektives Reflexivum und stellt eine feststehende Wendung besonderer Begriffspragung dar (Brăuer 128): das Verb tvoriti wird uberwiegend durch das synonyme dějati ersetzt, wie die Belege aus anderen asl. Texten zeigen."

legierte', milostbnaja kniga, lists milostbni 'litterae fidelitatis'. Vgl. Daničit II,66-67.

1. Listăr a Listinắ Oldřlicha z Rožmberka. Vyd. B.Rynešova Sv. II.c. 165, r.15, r.1441. Belegmaterial Arch Sčsl.

2. Sved Bydz p.15 (1462) (Kapras 9 23). Belegmaterial Arch SČs1.

3. Arch C 7, 225 (1458). Belegmaterial Arch SCS1. Im heutigen Tschechisch valt koho na milost = 'Begnadigung', vgl. Siebenschein. Česko-nemecky slovnik I, 378-379.

4. Vgl. dazu Brăuer 126: "Wie bei tvoriti, können auch manche wendungen mit dèjati einen mehr oder weniger feststehenden phraseologischen Charakter erhalte 
AuBer in Fris kommt die Bildung mit tvoriti nur noch in einem Text des Psalters aus dem XII Jh. vor. 1

Im asl. Text der petrusliturgie wird supplices te rogamus der lateinischen Vorlage mit m(0) $2 i m b$ se $i$ mili se děemb übersetzt (Vašica 4 17). Supplex bedeutet 'sich demütigend, demütig bittend, demütig flehend', esse supplicem 'jemanden demütig bitten' (Georges II, 2963).

Der ursprüngliche sinn von supplex ist "der besiegte Feind, der sich dem Sieger zu FüBen wirft und mit erhobenen Händen um sein Leben fleht" (Heinze 98). Ahnlich wurde auch in altester zeit im privaten Strafverfahren der Friede von dem gekränkten Menschen erfleht, um der Rache vorzubeugen. Wăhrend im mittelalterlichen germanischen Recht der Abkauf der Rache durch demütigende Sühnezeremonien und BuBleistungen quellenmäBig belegt ist, labt sich das im römischen Recht nur noch aus der Wortgeschichte ablesen. 2 zur zeit der Missionierung wird für die slaven eine der germanischen ăhnliche Phase in der Rechtsentwicklung angenommen (Kadlec, $114 \mathrm{ff.}$. So ist milb se tvoriti zwar kein technisch-juristischer Ausdruck, wurde aber in seiner Funktion zur Regelung der persönlichen Rechtsverhältnisse verstanden. In der Anwendung auf das Verhältnis zu Gott bekommt es eine religiose Bedeutung in der BuBterminologie und allgemein als die demütige Haltung des Menschen gegenüber Gott schlechthin.

Als synonym zu milb se tvoriti läBt sich in der asl. Literatur 8 bměriti se und pokoriti se nachwelsen. Das letztere gab den Namen für die sühnezeremonie. 3

1. Belege bel Mikl LP 368: mila se tvorešta psalt.-theod. und Vostokov mat IV, 423 .

2. Vgl. Heinze 96-97. In der Darstellung der Wortgeschichte von lat. Bupplicilon, das BuBleistung und Strafe bezeichnet, deckt Heinze den konkreten Sachverhalt auf, zu dessen Bezelchnung die Ausdrücke supplex, supplicare, supplicem es8e gebraucht wurden. "...ursprünglich (hat) gewib nicht das wsegeld selbst suppliciun geheiBen, sondern die Bitte des von der Rache Bedrohten um Frieden und Versohnung, deren notwendige Erganzung ... die Bubgabe ist ..." In der Sitte des supplicion sieht Beinze "ein Uberbleibsel, das letzte lebendige eines altesten vorkriminalistischen zustands, eines rein privaten Strafverfahrens, das kein Eingreifen der Gemeinde, sondern nur die Rache des verletzten. ... oder die Ablosung der Rache durch vereinbarte Buße kennt."

3. Als Beisplel für Verwendung von szmériti sę vgl. $i$ smĕrichb oję ur berakonnych svoichb Ps Sin 105,43. Auch hier wird die demütige Baltung des um Gnade flehenden Sünders ausgedrükt. 
$m \circ d l i t i \quad s \quad l$ ipf. 'beten' aus idg. *meldh- 'rituelle Worte an die Gottheit richten' mit dissimilatorischem Schwund des ersten - l- von *mold-lă zu *modlá 'Bitte', čech. modla 'Götzenbild, Tempel', poln. modla für 'Gebet' (schon im Psałterz Florianski), alter 'Götzenbild, Brandopfer' wird im Asl. mit-dl-s-l- moliti 'bitten', refl. 'beten'. 1 Das Wort ist allen slaven gemeinsam und drückte sowohl Bitten als auch magisches Beschwören aus (Moszyński II,234 ff.). Dieses war meistens mit Opfern verbunden (Urbańczyk 73). Von einer bestimmten Gestik begleitet, bildete alles zusammen die wichtigsten Elemente des heidnischen Kults. Wie mit dem Wort modliti (se) sowohl das Sprechen, Loben der Gottheit als auch das Opfern zugleich ausgedrückt wurde, so vereinigt auch ein anderes uraltes Wort žbrti beides in sich (Moszynski II,242).

BUSLAEV weist besonders auf die ursprüngliche allgemeine Bedeutung des wortes modliti 'sprechen' hin. Er sieht es in Verbindung mit got. mapljan 'sprechen', ags. madlan, madalian. Wăhrend es bei den Deutschen in den Bereich der Rechtssprache ubergeht, wird es bei den slaven zum religiösen Terminus. Im alttschechischen wort modia sind sogar noch beide Bedeutungen vereinigt. In einem alttschechischen Text wird modia für 'Versammlung' gebraucht und entspricht dem got. mapl (Buslaev 119-122). Auch für'sich ver beugen' roookuveiv wird in einem alttschechischen Text aus dem 14 . Jh. modliti se verwendet. Ahnlich auch bei Nestor tritt anstelle von moliti se klanjati se auf (Buslaev 122). Daraus ergibt sich, daB modititi se das Sprechen und Opfern und die rituellen Gebarden im heidnischen Kult umfaBte. Auch im AT gehören Gebet und Opfer zusammen, wie die Grundbedeutung der Verben he'ethir und thodsh im Hebr. zeigt (BthW I,456). Ebenso wird die alttestamentliche Gebetshaltung von Gesten begleitet (sich niederwerfen, auf die knie fallen lassen, Knie beugen), aber eine "irreligiöse Zwangsausübung auf Gottes Willen durch das Gebet gibt es nicht." (BthW I,457). Dieses sei jedoch mit sicherheit für die heidnische Gebetsverfassung anzunehmen (Wesche 35). Für das slavische Heidentum können die in Euch noch erhaltenen "Gebete" dienen; der in ihnen erhaltene Charakter der Beschwörungsformeln ist offensichtlich. 2

1. Vgl. Pokorny 1,722. Nach Berneker 1,66 ist die Grundanschauung 'Opfer'.

2. Vg1. Dazu Moszynski II,239. Dort werden Beispiele von Krankheitsbesprechungen, Gebeten gebracht, die eine seltsame Ahnlichkeit mit dem Gebet des Euch aufweisen. 
kult wurde in Heiligenverehrung "umgesetzt", mošti wurde ein christlicher Begriff, der nicht nur die Uberreste der Korrper der Heiligen und der Seligen umfabte, sondern auch alle Dinge, die jene wăhrend ihres Lebens benutzten, einschloB (LThK 8,1218).

Der frühe Brauch, in der Nahe des Märtyrergrabes die Eucharistie zu feiern, führte dazu, das man die Märtyrergebeine zum Altar der Gemeindekirche brachte und später diesen Brauch zur Vorschrift werden lieB. 1 In diesem Sinne werden die Reliquien (des Altars) in Fris III genannt, mit dem Glauben an die Wunderkraft, die von den Gräbern der Heiligen ausging, verband sich auch das Vertrauen auf die Vermittlerwirkung der Heiligen bei Gott. 2

AuBer dem Wort mošti gibt es im Asl. noch einige andere Ausdrücke für Gebeine im allgemeinen und für die Reliquien im besonderen; sie geben wörtlich die lat. oder die griech. Bezeichnungen

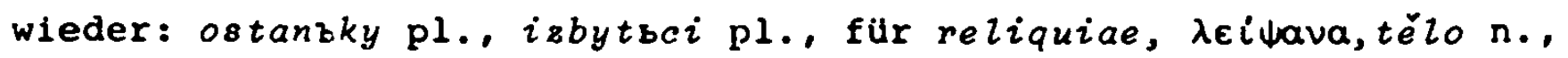
tělesa pl. für ownara, oder sie gehen auf konkrete Vorstellungen zurück wie kosti pl. 'Knochen, Gebeine', pepelz m. 'Asche' (Arch LLP).

$n e b \circ$ n. aus idg. *nebos, aind. nabhás n. 'Nebel, Dunst (Himmel)', lat. nebula, ahd. nebul 'Nebel'. ${ }^{3}$ Der Wechsel zwischen 'Wolke' und 'Himmel' ist schon vorslavisch, und in der altslavischen Mythologie lassen sich keine Spuren von einer göttlichen Verehrung des Himmels finden (Meyer 268). Aus ethnographischen Quellen ist über den Himmel auch nicht viel zu erfahren (Moszyński II,434); daher läbt es sich nicht entscheiden, ob der Grund für den Verlust der eigentlichen Bezeichnung für 'Himmel' eín religiöser war. 4 Im früheren religiösen Glauben spielte nicht der Himmel an sich,

1. Vgl. LThK 8,1218: "Ende des 6. Jh.s ist es eine Seltenheit, wenn in einem Altar keine Reliquien vorhanden sind ... Vorschrift wurde es durch Konzil (II) von Nikaia 787."

2. Die Anrufung der Reliquien erfolgt in nur zwei ad. Beichten: in der Sachsischen Beichte, Steinmeyer 318, und in der Lorscher Beichte., Steinmeyer 323 , wobei beide auf einen lat. Text, Morinus, Comentarius de sacramento poenitentiae $572 \mathrm{ff}$. zurückgehen, der in der betreffenden stelle folgenden Wortlaut hat: "Ego confiteor, deus coell et terrae, coram hoc altare tuo sancto et istius loci reliquils ..." zum Schlub wird diese Anrufung noch einmal wiederholt. Aus diesem Text geht es deutlich hervor, daB es sich hier um Altarreliquien handelt.

3. Vg1. Pokorny I, 315, Vasmer II, 205, Machek 320-321, Trautmann 195: baltoslavisch nebes- $n$. 'Wolke, Himel', lett.debess f. 'Himmel', debesis m. 'Wolke'.

4. Wahrscheinlich ist idg. "djez- der leuchtende Taghimmel und idg. "nebho- der Wolkenhimmel (Mitteilung Prof. Dr. B.Schlerath, Berlin). 
sondern der sogenannte 'Gott des Himmels' eine Rolle, wobei zwischen dem Gott des Himmels und seinem Aufenthaltsort keine Grenze zu ziehen möglich ist. 1

Die Vorstellung davon, das 'Gott der Schopfer' den Himmel bewohnt, ist auch im Christentum erhalten geblieben. Der bisherige Inhalt des Wortes nebo 'Himmelsgewolbe' wird um die Fulle des $\mathrm{sich}$ im Christentum mit dem Himmel verbindenden Gedankengutes vermehrt, die neue Bedeutung 'Reich Gottes' steht neben der ursprüglichen 'Himmel' gleichberechtigt da. Der Himmel ist sowohl ein ort als auch ein zustand. "Es fehlen uns die Moglichkeiten, un diesen ort rein geistiger und übernatürlicher Existenz lokalisieren zu können ... Der Himmel ist in einem Teil der offenbarungsaussagen sicher ein wort fur Gott, dessen Namen die Juden auszusprechen sich scheuten; wer im Himmel ist, schaut Gott, wie er ist, ... ist mit ihm eins, ist in einen Lebensaustausch mit ihm getreten, der zugleich die Form der ... hobchsten Verherrlichung Gottes darstellt." (HthG I,331-332). "Das ist das ewige Leben, daB sie dich erkennen und den du gesandt hast, Jesus Christus" $J 17,3$. Hier wird die Gleichwertigkeit (s.o. unter slava božija, věčnnyi životb) verschiedener Ausdrücke (da auch verschiedener Aspekte) für denselben Begriff, den man unter 'Reich Gottes' zusammenfassen konnte, deut$11 \mathrm{ch}$.

Neben der singularform, die Fris vertreten ist, erscheint im Asl. auch die Pluralform nebesa, die auf lat. coeli, griech. obpavoi (beide in Anlehnung an das Hebräische, wo samaim ein plurale tantum 1st) zurückgeht (Mikl Term 48; Schumann, 73). "Das Ahd. folgt dem Lateinischen. Coelum gibt es durch himil, coeli durch himila; regnum coelorum durch himilo richi. Der plural mus jedoch der ahd. Sprache nicht recht genehm gewesen sein. Denn mehrfach findet sich der Versuch, ihn, wo er im Grundtext steht, durch den singular zu ersetzen"(Raumer 411). Dieser Hinweis von RAUMER berech tigt zu der Annahme, daB die singularform nebo den Einflus des ahd.

1. Vgl. Moszyhski II,434: "Die uralte Frage nach dem Urgrund der welt funrte zu seiner Personifizierung als 'Schöpfer der Welt' und 'Himelsherx' unter dem $e$ auf dem Gebiet Eurasiens, wo die Urheimat der 1dg. Sprachen lag, bekannt gewesen sein mub. Davon geben zeugnis die aus derselben wurzel stamenden in den verschiedenen 1dg. Sprachen erhaltenen Bezeichnungen für cott." (eigene (bersetzung). - Eine Spur der ursprünglichen slavischen Himbel sbezeichnung kônnte man in dem asl. Wort db̌̌db (russ. došd', poln. des8cs, ačech. déšć) erblicken, das auf die Ablautstufe idg. "diu- zurükgeht (aus *duz-diy ) 'schlechtes Wetter' a 'schlechter Himel' (Pokorny I,184-185). 
himil zeigt. Das bestätigt auch das Vorkommen der Singularform in der Vorauer Beichte: "der scuof himil enti erda", und Benediktbeurer Glauben und Beichte I: "der schepare ist himeles unte der

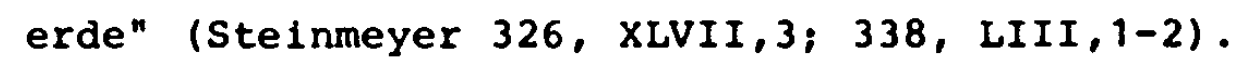

$o b \check{e} t b \quad m$. aus $o b-v e ̌ s ̌ t a t i ~(b v>b)$ oběštati 'verkünden, versprechen' (oběs̆tati se steht auch für moliti se 'beten') (Jagić Entst 290,372). 'Gelübde, feierliches Versprechen' votum, danach auch 'Gebet'; VONDRÁk (Vondrák, 19 Glossar 73) und VAŠICA (Vašica 3 136) lesen jedoch obettb f. sacrificium, munus 'Opfer, -gabe', das dem čech. obět' $f$. in dieser Bedeutung entspricht. Aus dem Text allein ist über die Lesart und Bedeutung dieses Wortes keine endgültige klarheit zu gewinnen. In der über diese Frage geführten Diskussion, auf die hier nicht năher eingegangen werden kann, ist die theologisch-historisch begründete stellungnahme PIRCHEGGERs hervorzuheben (Pirchegger 141; Nahtigal, 117; Grivec, 16; Grafenauer 29 ; Mikl Term 31; Mikl LP 485). Er weist daraufhin, daB den Heiligen in der katholischen Kirche keine 'Opfer', sondern nur $v$ o $t$ a dargebracht werden. Durch den Vergleich mit einer stelle in "Slovo bolęštichb radi" kann diese Erklärung bestätigt werden (Sobolevskij, 100-103). Dort werden Anweisungen für die Kranken erteilt, die inre Heilung von Gott erbitten wollen. Wichtig ist die dort verwendete Terminologie. Danach soll der Kranke eine Opfergabe bringen' $i$ da prinesetb prinosb vb črkvb o(t) brašna $i o(t)$ s věč 'aus Speisen und Kerzen' bestehend. Dann soll er noch weitere Gaben $z u$ opfern versprechen: $i$ da oběštajetbse obětomb... suěštami že $i$ inemb imbže možetb 'Kerzen ... und was er sonst geben kann'. Wenn er geheilt wird, dann vbzdastb oběty svoja $\overline{b u}$ 'erfültt er seine Gelübde Gott gegenüber'.Von dieser frommen Ubung gibt auch Fris II, 38-40 Kunde: I obeti naßBe im nezem 0 zcepabgenige telez naßich $i$ duB nabich. Besonders wichtig ist die Präposition $0=$ 'für, um'. Um die Heilung zu erlangen, werden den Heiligen als Vermittlern be1 Gott Gelübde abgelegt, obeti naBBe im nezem entspricht oběštajetbse obětomb aus "slovo...". Nach der Genesung wird das Versprechen eingelöst, die Gaben werden dargebracht, das Wort dafur ist prinosb $\mathrm{m}$. Die lateinische Bezeichnung einer Votivmesse ${ }^{1}$ kommt

1. Vgl. Wetter 56. Die lat. MeBtexte bel Férotin = Le liber ordinum en usage dans l'église wisigothique et mozarabe d'Espagne du cinquiéme siècle, ed. Férotin in Monumenta ecclesiae liturgica, ed. Cabrol et Leclerque $v$, Paris 1904. Wetter bringt noch andere Belege aus dieser Quelle. Der Wortlaut der 
der Ausdrucksweise von Fris II sehr nahe: "missa pluralis pro eis qui in natalicia martyrum vota sua domino offerunt". Innerhalb des erreichbaren asl. Belegmaterials geht die Bedeutung von obětb $\mathrm{m}$. und der Wortbildungsvariante obětovanije $n$. über votum $\varepsilon \hat{x} \times \hat{h}$, promissio etrarredia nicht hinaus. '

Uber eine weitere vorchristliche Bedeutung von obětb läBt sich auf Grund seiner Verwendung in den asl. Texten nichts ausmachen, dagegen bieten das Altrussische und das Altserbische auBer der allgemeinen 'Versprechen' auch noch andere Bedeutungen an. Im Sinne von 'Strafe, Beitreibung' ist es in der Novgoroder Urkunde aus dem Jahre 1471 belegt (Srezn II,590). SREZNEVSKIJ gibt auch die Bedeutung testamentum an. In den aserb. Vertragsurkunden wird obětb in der Bedeutung 'verbindliche (rechtsverbindliche), feierliche versicherung' lat. sponsio verwendet (Daničlć II,198-199). Es ist durchaus möglich, daB im Asl. obětz auch der Rechtssprache angehörte. AuBerdem liegt die Vermutung nahe, daB es ursprünglich eine der christlichen ähnliche, heidnisch-religiöse Bedeutung hatte. ${ }^{2}$ JAGIĆ weist daraufhin, daB im Psaltertext obětz neben und an stelle von molitva verwendet wird (Jagić Entst 372). Dort kommt auch oběs̆tati se im Sinne von moliti se vor.

o $t e t i$ pf. (otb-jeti) in der Grundbedeutung 'wegnehmen, entreiBen' ist ein weiterer Ausdruck für 'erlösen', der den Aspekt des EntreiBens aus der Macht des Bósen (des Teufels) wiedergibt. Es steht meistens für lat. eripere, das hăufig in der paulinischen Ausdrucksweise anzutreffen ist. Als Ausdruck für 'erlösen' bedarf das Verb oteti stets der dativischen Ergänzungsbestimmung 'Teufel, die Macht des Bösen, des Teufels'; auBerdem ist es immer auf den Menschen objektbezogen. 3

Im Hinblick auf seinen herkömmlichen Inhalt ist oteti synonym mit vychytiti pf., wobei es sich, wie es scheint, um eine Dialekt-

liturgischen Darbringungsgebete in den altesten Sakramentarien erinnert sehr an die stelle in Fris II, 38-40: "...qui tibi offerunt hoc sacrificium laudis pro se suisque omnibus, pro redemptione animarum suarum pro spe salutis et icolumitatis suae, tibi reddunt vota sua aeterno deo et vivo..." Wetter 31

1. Das Belegmaterial für oběts war nur teilweise zugănglich im Arch LuP.

2. Polak 125 setzt das ursl. *vetjati - véštati 'verkünen' auf die Liste der vermutlichen heidnisch-religiosen Ausdrücke.

3. Vgl. priimete m grěšnago $k$ sebe $i$ otimete me ot vraga mojego "Molitva na abjavola". Sobolevskij, 41,7, pridb bo ... otb kletvy zakonnyje oteti rodo çky cloz I 283. 
variante handelt. 1

Uber die Stellung von otgti in der Erlobsungsterminologie s. 0 . unter $i z b a v i t i$.

$p \circ m \circ \check{s} t$ b f., na pomošti byti. Das Wort pomoštb, das zunăchst 'Hilfe, Hilfeleistung' bedeutet und auf die idg. Wurzel "magh'können, vermögen, helfen' zurückgeht, weist im Kontext von Fris II iber den allgemeinen Sprachgebrauch hinaus (Pokorny I,695). Sein Inhalt besagt jene Hilfe, die der sündige Mensch von Maria und den Heiligen erhält bzw. erfleht, um bei Gott Gehör und Gnade zu finden. Mit "Fürsprache" wird es in der Sprache der Liturgie bezeichnet. In dem Verhältnis Mensch - Gott geht es um 'Vermittlung, Vertretung, Verteidigung, Beistand', wie die verschiedenen Ausdrücke im Altslavischen zeigen, die zur Bezeichnung dieses Sachverhaltes dienen: chodataistvo n., zastppljenijen., zaštištenije n., pomoženije n.

Für das Asl. läBt sich auf Grund des zugänglichen Belegmaterials keine andere Bedeutung auBer der allgemeinen auxilium 'Hilfe, Beistand, Unterstützung' ermitteln (Mikl LP 620; Sad-Aitz Hwb 92). In der altrussischen Rechtsterminologie wurde mit pomoztb eine besondere Art von "Hilfe", "Beistand" bei der Gerichtsverhandlung bezeichnet. Dem germanischen Rechtsbrauch ähnlich durfte der Beklagte Eideshelfer stellen (Götz III,87). In der Russkaja Pravda hieBen sie pomočbnici, wurden auch porotniki, očistnici genannt (Götz III,86). Die Benennung der Hilfsgebühr war pomočbnoje (Götz III 21, 97). Nach der Schilderung von VLADIMIRSKIJ-BUDANOV erschienen gewöhnlich bei der Gerichtsverhandlung zahlreiche Verwandte und Nachbarn, um durch ihr aktives Auftreten die Hauptstreitenden zu unterstüzen, am Rechtsstreit teilzunehmen. ${ }^{2}$ GOTz hat auf die Verwandtschaft der aruss. mit der ačech. Terminologie hingewiesen (Götz III,98). Der Gebrauch des Wortes pomoc im rechtlichen Sinne wird auch durch die Belege aus dem Arch sčsl bestätigt. Dem aruss.

1. Aufschlubreich hierfür ist der Ausdruck otrica fur raptus mulieris. Nach Kadlec, 103 ist es ein sudslavischer Ausdruck, wahrend das Altrussische dafür zomyčbka, wmykanije verwendete. Bei Jireček uSSP wird otmica als ein serbisches Rechtswort charakterisiert. "Otmica pochodl ze slovesa ot-imati, eripere, ot-jeti, ot-ma = demere."

2. Vgl. Vladimirskif-Budanov 635. Diese Einrichtung hielt sich bis zur Herausgabe der "Sudnyja gramoty". Die Pskov.gramota verbietet mit "Hilfe" (Beistand) = pomočbju zum Gericht zu gehen. Beachtenswert ist, daB in der Novgoroder Urkunde die Freudenmenge, die zur bilfe kam, mit navodka bezeichnet wurde. 
pomočsnoje 'Hilfsgebühr' ("komu pomogut", der soll pomočsnoje zahlen) entspricht die mit pomocné benannte Einrichtung im bohmischen Recht. So in den "Statuta ducis ottonis" (1229-1237): "..quod pomocné vulgariter appellatur." (Gotz III,98).

AuBer der Hilfe beim Gericht wird mit dem Wort pomoc, pomočb, pomoć die in dem ungeschriebenen Gewohnheitsrecht verankerte Einrichtung der nachbarlichen Hilfe bei bestimnten Arbeiten bezeichnet. 1

Bei der Verwendung des Ausdruckes na pomošti byti für die Fürsprache im christlichen sinne mus in erster Linie an seine stellung als Terminus im Prozebrecht gedacht werden. Das geht aus dem Vergleich mit den in dem gleichen oder ahnlichen sinne verwendeten wörtern hervor. Sie alle kommen aus der Rechtssprache und beziehen sich auf die Person (-en) des Vermittlers, Vertreters oder des Verteidigers bzw. auf das Handeln selbst, je nach dem Charakter der Rechtssache und der Rechtssitte: i prěslaunim' blaženije Marije vinu d(ě)vi chodataistvomb ot(́) nastoješče iabav(i)ti se tugi $i$ v(ř) čn(a)go uăivati veselie (Misal kneze Novaka 1368, f.176 auszugsweise bei $\left.\operatorname{Vašica}_{4} 23\right), \tilde{d n b}_{b}$ rodi $8 \beta$ namb chodatainica $i$ smirenije sb bogomb (Sobolevskij, 161). Solche Vergleiche sind, wenn auch unausgesprochen, auf das schiedsgerichtliche oder strafrechtliche Verfahren begründet. 2 Dicht nebeneinander stehen aufeinander bezogene Ausdrücke aus dem Rechtsbereich: chodataistvo n.'Bürgschaft, Mittlerschaft', tuga f. 'Klage, Beschwerde', chodatainica f. 'Vermittlerin', smirenije n. 'Beilegung des Streites'. 3

Für Christus erscheint im biblischen Gebrauch das griech. na-

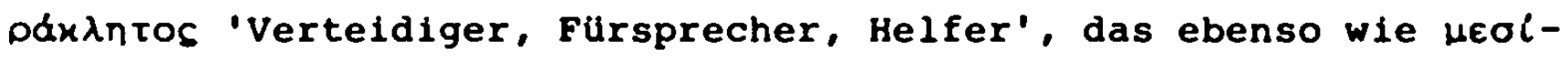
ins mit chodatai m. ubersetzt wird. Im Christ $1 \mathrm{~J} 2,1$ heibt es: $i$ ašte kto szgrěšitb chodataja imamb kb ocju, İs chsa, pravbdbnika (Arch LLP). Hier wird Christus als Vermittler, Verteidiger beim

1. Vgl. Saturnik 182, § 24, Pracovnl asociace, S. 190: "U Rusú jwenuje se pomoc (pomočb u Velkorusú) nebo toloka (u Malorusú)." S. 192: "Táž forma kooperace je znama jižnlm slovanim (moba,... tlaka nebo prostè jen pomor, bulh. tlbka, tlaka, pomošcb ... U Polakü ... řiks se takové pomoci wygodzenie, poratowanie, dospomozenie ...".

2. Das zeigt auch der Gebrauch der entsprechenden Termini im Griechischen. Vgl. Bauer 1226 unter rapduintins und 1002 unter Heolins.

3. Vgl. dazu Saturnik 198, $\$ 26$, Smir. Unter $8 m \mathcal{l} r$ wird die in einer Vergleichsverhandlung erreichte Beilegung des Rechtsstreites verstanden. In Russkaja Pravda kommt smirjatb vor, in den aserb. Texten sbmirenije, apoln. smyr für lat. concordatio, compositio (als Rechtsform schon seit d. 11. Jh. bekannt). Vgl. dazu auch $\mathrm{Kadlec}_{3} 129 \mathrm{ff}$. 
Gottvater vorgestellt, er ist der Fürsprecher vor dem Gericht Gottes. In demselben Sinne wird auch in $\mathrm{Kij} \mathrm{5,17} \mathrm{Christus} \mathrm{angespro-}$ chen: a ty samo pomočbjq tvojejq věčnojq oder in Ryl 7 bB 6: tvoeq pomoštbje und in Euch 72b 5-6 bqdi mi pomoštbnikb. In der Gegenüberstellung der äquivalent verwendeten Ausdrücke pomoštb - chodataistvo, pomor̆tbnik - chodatai zeigt sich die Doppelgleisigkeit in der asl. Ausdrucksweise, die auf verschiedene Ubersetzungstraditionen zurückgeht. Diese unterscheiden sich in ihrem Bezug auf konkrete Tatsachen oder Einrichtungen voneinander. Dem pomoštbnikb liegt wohl die Vorstellung des Eideshelfers zugrunde, wăhrend chodatai von dem Vermittler seinen Ausgang nimmt.

In allen angezogenen Beispielen geht es un die Fürsprache bei Gott, sie wird verschieden ausgedrückt, aber geschopft wird jedesmal aus dem Rechtswortschatz.

$p \circ \check{s} t \& d i t i$ pf. 'sich erbarmen, verschonen, Gnade erweisen' ist inhaltlich mit der sündenvergebung und der gnadigen Haltung Gottes dem reuemütigen Menschen gegenüber verbunden. Die Form poštęditi ist vorwiegend in den schriften der măhrisch-pannonischen Gruppe belegt, die griech. Entsprechung ist peiбeobal, lat. parcere, misereri. 1 Aus dem gleichen stamm, ohne Präfix po- ist das Substantiv štedrota f. gebildet, das 'Erbarmen, Barmherzigkeit' (Gottes) bezeichnet. In dieser Bedeutung kommt es in Euch $72 \mathrm{~b} 3$ vor: ěkože tvoję štedroty sptz (Jagić Entst 362).

$\mathrm{Ob}$ das aus der Allgemeinsprache kommende Wort auch im Rechtsbereich eine besondere Funktion hatte, lieb sich nicht feststellen. Als einziger Hinweis darauf könnte die synonyme Verwendung des Wortes poštęditi mit pomilovati, milb byti, sbmiliti se dienen, da diese Ausdrücke in unmittelbarer Bezlehung zu dem pokora-Akt stehen.

$8 \& d i t i$ ipf. 'richten' ist im Sinne der richterlichen Tatigkeit Gottes am Jünsten Gericht gebraucht. Als Rechtswort ist $8 Q^{-}$ diti in den Dienst der christlichen Aussage getreten, ohne seine Stellung in der Rechtssprache $2 u$ verlieren. Seine religiose Bedeutung hat es besonders durch die Aufnahme in das Glaubensbekenntnis erhalten.

1. Im Altserbischen ist die Form postediti fü parcere belegt. Vgl. DaniŽt II.407. 
- $t r a d$ a $t i$ ipf. 'lelden' pati, cruciari, naveiv wird für 'Marter erleiden' im Sinne des christlichen Martyriums gebraucht. Seinen spezifischen christlichen Sinn hat das Wort stradati durch die Elnengung der allgemeinen Bedeutung erhalten. Derselbe Vorgang ist auch bei dem Substantiv strastb f. $2 u$ beobachten.

s $t r a s t$ b f. 'Marter' passio, cruciatus, ndios bezeichnet in Fris II das aus Bekenntnistreue $z u$ Gott ertragene Leiden der christlichen Martyrer. Es wird im Asl. auch für den Opfertod Christi gebraucht. Das Konkurrenzwort ist mqka (s.o.).

8 s $g r \grave{e} \check{s} i t i$ pf. 'sündigen' s.o. unter grěchs.

8 b $p$ a $s$ e $n i j e n$. 'Erlosung (Erhaltung)' nomen actionis von dem Verb sbpasti pf. aus $1 \mathrm{dg}$. *pā- pāt urverwandt mit lat. pāscō 'lasse weiden, füttere', toch, pās-pask-' hüten' (Pokorny I,787). Das asl. Verb sspasti, -ati hat die allgemeine Bedeutung 'hüten, schüzen', 'halten' im Sinne von 'bewahren' (Machek 356; Frinta 57; Mikl Term 40; Ivanov $105 \mathrm{ff.}$.

Für das Altrussische gibt SREZNEVSKIJ folgende Bedeutungen für pasti ipf. an: 'stereč', past1, rukovodit', nastavljat', upravljat' (Srezn II,885). Im Altserbischen dagegen hat pasti nur die Bedeutung 'weiden', sspasti und sspasati die weitere Bedeutung des lat. servare (Daničić II,278). Uber den Sprachgebrauch von sbpasti und sbpasati gibt der Text von Fris selbst Auskunft. Es bedeutet 'halten, erhalten, bewahren'. Somit war es geeignet, den Inhalt des griech. $\sigma \dot{\zeta} \zeta \iota \downarrow$ 'schützen, erhalten, retten, helfen', das auf hebr. hơsê'a zurückgeht, wiederzugeben. 1 Im besonderen MaBe entspricht das slavische szpast $i$ dem hebr. $g a^{\prime} a l$ 'schüzen', das einen speziellen Ausdruck in der Erlösungsterminologie des AT darstellt. Auf dieser Linie liegt etwa auch das lat. servare, spăter salvare ${ }^{2}$ im Unterschied zu redimere und seiner griech. Entsprechung $\lambda u r-$ poũosal auf das hebr. pådăh 'loskaufen' zurückgehend (BthW I,329333). Hier gehort das asl. iskupiti pf. 'erkaufen, loskaufen' und izbaviti pf. hin, dem das ahd. kaufon, archaufon, arlosan entspricht. Auffallend ist die semantische Ubereinstimmung des ahd. haltan mit dem asl. szpasti, -ati. Der Gebrauch dieses Wortes in

1. Vgl. dazu Bthw $I, 329-333$.

2. Vgl. BthG I,303: salvare, salvator ist eine christliche Sprachschópfung. Ubersetzungsvarianten servator, sospitator sind aus der Jupiterpradikation ubernommen. 
der Benediktinerregel entspricht ganz dem des sbpasati in Fris. Von haltan abgeleitet ist das Substantiv haltari $m$. für salvator und ghaltnissi f. salus 'Heil, Erretung'. ' Dafür sind sspasitelb und sbpasenije genaue Entsprechungen. Wahrend sbpasitelb $\mathrm{m}$. eine Neubildung für den Erlöserbegriff darstellt, läbt sich für sbpasenije n. im Aruss. und Aserb. der profane vorchristliche Gebrauch nachweisen. Im "Dogovor Igorja" (945 g.) $i$ da vbzvraščajutsę 8 b spniemb vb svoju storonu beleutet sbpasenije 'Heil, Wohlbehaltenheit' im profanen Sinn (Srezn III,787). Weiterhin gibt SREZNEVSKIJ noch 'izbavlenie ot bedy, ot pogibeli, nevredimost', blagopolučie' als Bedeutungen an (Srezn III,787). Ahnlich bei DANIČIĆ: obrěsti vy město spasenija; postignuti někoje město i tu polučiti sbpasenije (Daničić III,247). Wie diese Belege zeigen, war die Form szpasenije schon ein bestehendes Wort, welches wie die Verbalformen, den Bedeutungswandel aus dem profanen sprachgebrauch zum biblischen Terminus durchgemacht hat. Seine Bedeutungsentwicklung schreitet (wie auch die entsprechenden Ausdrücke in den Vorbildsprachen) von 'Schützen und Erretten vor zeitlichen Gefahren, aus zeitlichen Nöten' $z u$ 'Befreiung von geistiger Not und Sünde' bis zum messianischen Heil, dem eschatologischen Besitz aller Güter (BthW I, 329). Wie die Wortschatzuntersuchung der Bibel zeigt, ist die Erlosungsterminologie keineswegs einheitlich. Daraus resultiert auch die Vielfalt in der wahl der asl. Ausdrücke. Als terminologisch gefestigt erweisen sich sopasti pf., izbaviti pf., iskupiti pf.. izdrěšiti pf.; als beherrschend sind jedoch die beiden ersten anzusehen. Wahrend in der Wortgruppe sbpasti, -ati eher das statische Moment mitklingt, wird durch das Wort izbaviti ein dynamischer Be-

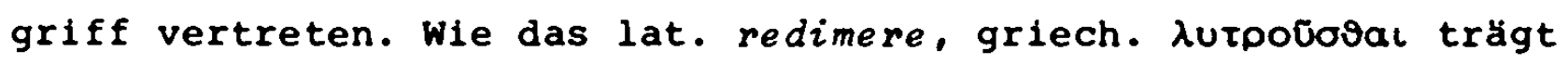
die Wortfamilie izbaviti den historischen Aspekt der Actio; 8bpas-

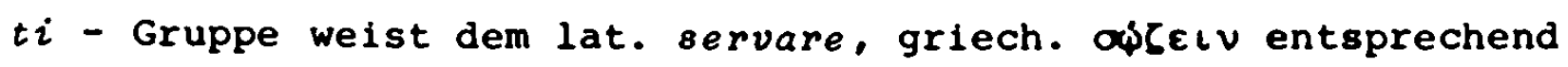
auf das Resultat der Actio und spricht somit den eschatologischen Aspekt an (HthG I,303). In diesem sinne stimmt asl. sopasenije mit griech. owrnoia und ahd. gihaltnissi genau uberein.

1. Vgl. Ibach 80,262: "In B (Benediktinerregel) komot halton in der allgemeinen Bedeutung 'huten, schützen, bewahren, retten' vor. In der Bedeutung 'die Seele bewahren, retten' gehort halton in den Bereich des religiosen Heils ... eine weitere Bedeutung von haltcon: 'Recht bewahren, einhalten, vorschriften befolgen', dann 'in Tugenden bewahren'." Vgl. dazu Fris I,18 die Bedeutung 'ich habe nicht gehalten', Fris II,24 '(Eide), die wir nicht halten', Fris III,73 'bewahre, erhalte mich in allem Wohl'. Vgl. auch Raumer 358; BrauneEbbinghaus 202. 
8 b $p$ a $8 t i$ pf., $t_{\text {b }} p$ a 8 a $t i$ ipf. s.o. unter sopasenije und sipasitels.

$s \quad e_{t} t^{b}$ adj. 'heilig'. Zur Etymologie dieses Wortes wurden verschiedene Erklärungen gegeben. Nach HOLUB-KOPEČNY sind im Baltoslavischen wahrscheinlich zwei Wurzeln verschmolzen: $\hat{k}_{k}$ uen $(t)-$ 'heilig, geweiht' und *suent- 'stark' (362). Nach POKORNY ist

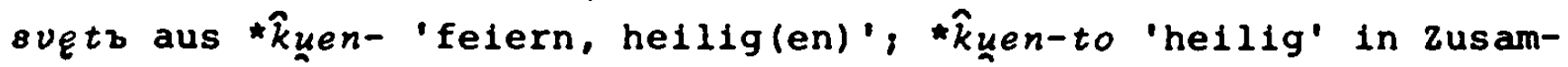
menhang mit av. sponta- 'heilig' $(=11 t$. '̌veñtas) zu stellen (I, 630). Be1 *suento-, sunto 'rege, rüstig, gesund' führt POKORNY nur germanische Bildungen ăhnlicher Bedeutungen auf, allerdings wird diese AusschlieBlichkeit als unsicher vermerkt. BRUCKNER weist auf die ursprünglich in den Eigennamen enthaltene Bedeutung des slavischen $8 v_{\text {etz }}$ 'stark' hin, stellt aber keine etymologische Verbindung zu idg. *syento- in ahnlicher Bedeutung her, sondern zeigt die Verwandtschaft mit av. sponta-, lit. \&veñtas etc. 'heilig' auf. 1 VASMER und TRAUTMANN zeigen die Urverwandtschaft des lit. Sveñtas mit asl. svętr, apreub. suenta- in Ortsnamen swentegarben, Swento-mest, lett. svinu, svinêt 'feiern' (Vasmer II,597; Trautmann 311). Ebenso wie BRUCKNER weist auch MACHEK auf die heidnische Bedeutung des asl. svętb 'stark' hin, welche in dem Namen Sveto-plzks (Svatopluk), der als "mocnopluký, majlcl mocné pluky" $z u$ verstehen ist, erhalten blieb. 2

AuBer in den schon erwähnten Eigennamen lassen sich die Spuren der ursprünglichen Bedeutung 'stark' in der altserbischen Wortgruppe osveta, osvetite $b$, osvetiti = vindicta, vindex, vindicare finden (Daničĺ́ II,321-322). Den Sinnzusammenhang von osveta 'Rache, Blutrache' mit ursl. *8vętü = 'stark' verdeutlicht MIKLOSICH an der Parallele des griech. \&uxh' 'Wehr, Abwehr, Schutz, Stärke, Kraft', \&גরino 'Abwehrer, Răcher' (Miklosich, 138-139). FRINTA weist auf die ursprüngliche Bedeutung 'stark' in dem čech. Wort s vatá kost 'Rückgrat' (starker Knochen) (51).

Als christlicher Terminus ist svetb allen slaven gemeinsam und mit seiner ursprünglichen Bedeutung loder besser: mit seiner anderen Bedeutung) in der asl. Literatur nicht mehr erhalten. Der Ubergang von 'stark' $z u$ 'heilig' hat sich schon in der vorhistorischen

1. Vg1. Brückner SEJP 537: "Świętopelk, Śwlętoslaw, świętowit znaczy to samo co 'jary, silny' (= Jaropelk, Jaroslaw, Jarowit)".

2. Vg1. Machek 487. Dazu auch Polak 125, der urs1.*8vętb zu den heidnisch-rel1giosen Termini zahlt. Ex weist ebenso wie Machek auf av.sponta 'magisch,stark 
Zeit vollzogen. Wie BUSLAEV, so vertritt auch MOSzYŃSKI die Ansicht, daB der Heiligkeitsbegriff bei den slaven vor der Annahme des Christentums schon bekannt war. Er schreibt: "... o ile ograniczymy się do wskazówek dzisiejszego folkloru, svetb znaczy tyle co 'czysty' takie 'zobowiązujący, uroczysty' , ...szczególnie czczony." (Moszyński II,716). Im Gegensatz zu Ahd., wo man den Begriff der Heiligkeit verschieden wiederzugeben versuchte, ehe er sich in dem Wort heilag festsetzte, blieb im Asl. svetb fur 'heilig' konkurrenzlos. 1 Die Voraussetzungenzur Ubernahme dieses Ausdruckes mit der Bewegung von 'stark' $z u$ 'heilig' in den christlichen Wortschatz waren nicht allein von der Bedeutung 'magische Stärke, Macht' her gegeben, denn der biblische Heiligkeitsbegriff des AT baut zunächst auf der Macht, stärke, auf der Wucht des sich offenbarenden Gottes auf. "Die Macht des Heiligen hat das gesamte Denken und Tun des alttestamentlichen Menschen geprägt" (BthW I, 688). Mit Heiligkeit im eigentlichen Sinn wird die absolute würde Gottes bezeichnet. Als "der ganz Andere" ruft er durch seinen Einbruch eine scharfe Trennung zwischen dem Heiligen und dem Profanen hervor. Eben dieser Gegensatz zum Profanen ist ein wesentlicher Bestandteil des Wortes 'heilig'. Christus wird dann heilig genannt, wenn der Gegensatz zum Profanen hervorgehoben werden soll (HthG I,656). $\mathrm{Zu}$ Gott gehörend ist gleichbedeutend mit heilig.

In der Theologie des NT sieht der Mensch in der Heiligung sein Lebensziel, das Heilige ist zugleich seine sittliche Norm. Deshalb können auch Ausdrücke čistb 'rein' (keusch), pravbdbnb 'gerecht' und vor allem bozii 'göttlich, gottgeweiht, Gottes-' synonym mit suets 'heilig' gebraucht werden. 2

u $c h r a n i t i$ pf. 'bewahren, erhalten, schützen' servare, sinnverwandt mit szpasti in Bezug auf das statische Moment in der Erlösungsterminologie. AuBer in Fris III komnt es noch in "Molitva na dbjavola" vor und wird dort im gleichen sinn verwendet. Zahlreicher ist sbchraniti belegt, das ebenfalls das erlobsende,

1. Vgl. dazu Ochs 109: "Um die wiedergabe des Begriffes sanctus bemūhte sich die Sprache auf verschiedenen Wegen: saltg, wth, haer, ... gotedeht 'in Gott geweiht', gotelih 'sacer' (bel Notker) und die vielen usschreibungen fur Heilige: alle gotes holden, gotes drata, gotes drutthegana, gotes frivnt." Vgl. ferner Frings, 21.

2. Aus der ursprünglichen Heiligkeitsauf fassung heraus wird der Gebrauch von božii als Prădikat zu mošti verståndlich: "gottliche" bedeutet 'heilige' (Reliquien), ebenso 'heilig' für Christus erscheint nicht mehr "ungewöhnlich" 
erhaltende Handeln Gottes bezeichnen soll. Im Altserbischen sind beide Formen in der Bedeutung conservare vertreten. Im christlichen Sinne wird nur sbchraniti verwandt (Daničić III,261-262). Das gleiche ist auch im Altrussischen zu beobachten, wo sbchrani-

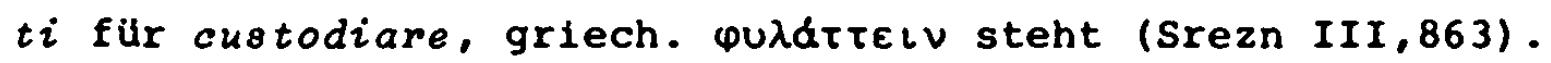

wie oteti ist auch $u-, 8 b$-chraniti in der Erlösungsterminologie nicht produktiv geworden; daraus labt sich schlieBen, das es, obwohl im christlichen Sinne verwendet, keinen Bedeutungswandel erfahren hat.

$v \check{e} r a$ f. 'Glaube', davon věrovati ipf. 'glauben'. Auch 'Glaubensbekenntnis, Religion' wird mit dem Wort věra bezeichnet. Die Etymologie von asl. věra geht auf die Ableitung idg. * Wurzel *uēr- 'Freundlichkeit' zurück. Die Bedeutungen von germ. *wēra 'Vertrag, Gelübde, Bündnis', aisl. vārar 'Treuegelübde'. ags. woer f. 'Vertrag, Treue, Schutz', ahd. wära auch 'Wahrheit' ', mnd. wäre 'Vertrag, Friede' (Pokorny 1,1165 ) stehen in enger Beziehung $z u$ baltoslavisch * $k \bar{e} r \bar{a}$ f. 'Wahrheit, Glaube' (Trautmann 351): Aus den asl. Belegen läBt sich die ursprüngliche nichtchristliche Bedeutung von věra nicht erschließen, da das Wort nur in rein christlichem Sinne verwendet wird. Nur indirekt, aus den syntaktischen Verbindungen kann man den früheren Sinn herauslesen: vbdajati se vo věre kogo bedeutet credere semetipsum (LLP I, 377). Diese Ausdrucksweise steht im engen zusammenhang mit dem Sachverhalt, der für die die Blutrache ablobsende Periode zur Regelung der Rechtsverhăltnisse von gröBter wichtigkeit war. Aus der Einsicht heraus, daB die Rachepflicht des Geschädigten und seiner Sippe erhebliche Nachteile zur Folge hatte, bemihte man sich um Versöhnung. Man schritt zur langen Friedenszeremonie, deren ziel das Erreichen der věra war, d.h. Waffenstillstand auf bestimmte Zeit. ${ }^{2}$ MIKLOSICH gibt dazu folgende Erklärung: "vjera, vera, asl. věra ist das dem Beleidiger gegebene Wort, daB binnen eines festgesetzten Zeitraumes von den Beteiligten gegen ihn und die seinigen nichts feindliches unternomen wird; Waffenstillstand vjera entspricht genau dem

(Vgl. Vondrak, 70). Der Gebrauch des Wortes božii für 'heilig' mag auch unter dem Einflub des Ahd. zustandegekommen sein.

1. Vgl. Feist 484. Dort der Binweis auf A. Meillet, Etudes 169, der véra fúr echt slavisch halt und auf B.Birt, Beitr. 23,337, der es als germ. Entlehnung ansieht.

2. Vgl.Kadlec, 115: "przystepowano do dxugiej ceremonil pokojowej. ktorej celem bylo osiqgnifele w 1 a $x$ llać. treuga, franc. trève czyli rozejmu na czas pewien. 
1tal. treuga, franz. trève, mlat. treuga, aus ahd. triva, triuwa nhd. Treue (Miklosich, 139). Im Altrussischen bedeutet vĕra 'Wahrheit', dann auch 'Schwur, Eid': $\iota_{b z ̌} a$, a ne věra premože na zemli - entgegengesetzt stehen sich hier Lüge und Wahrheit gegenüber; o božii věrè steht als eine andere Lesart für o božii pravdě in der kurzen Redaktion der Russkaja Pravda in der Jaz. Handschrift (Vašica 3 158): A čego syskb ne imetb, i imb vb tomb prisuživati věru krestnoje oělovanbe - hier bedeutet věra 'Eid' (Srezn I,490). Wie die Belege im Altserbischen zeigen, wurde das Wort věra im Sinne von ' Zusicherung, verbindliche Erklärung' gebraucht: davǎe svoju ruku $i$ svoju věru; na moju věru na kralevu. Dazu führt DANIčIć aus: "věra, fides, die man gibt, damit man um etwas nicht zu fürchten braucht" (Daničić I,197). Im Gegensatz dazu bedeutete nevěra perfidia, nach GEORGES II, 1589 'Wortbrüchigkeit, Treulosigkeit' (Daničić II,134-135). Im Altpolnischen blieb bis zum 17. Jh. die Accusativform wiere ( $n a$ mq wierę) erhalten, mit der die Bestätigung der Wahrheit ausgedrückt wurde (Brückner SEJP 611; Frinta 12,68; Machek 567).

Das Wort věra beinhaltete also ursprünglich 'Wahrheit, Versprechen, Zusicherung, Eid' bevor es zum christlichen Terminus 'Glaube' wurde. Eine ähnliche Entwicklung kann auch für lat. fides $f$. und griech. niorıs beobachtet werden. WALDE-HOFMANN weist für fides die Bedeutungen 'Treue, Glaubwürdigke1t; Bürgschaft, Kredit; Schutzverhältnis; Vertrauen, Glaube' auf. Die Grundbedeutung ist "auf die sittliche Persönlichkeit sich beziehende Garantie"; damit hängt foedus 'Treuebund, Bündnis, Vertrag' zusammen (Walde-Hofmann I,494). Auch riorıs bedeutet 'Treue, Vertrauen, Beglaubigung, Bürgschaft'. 1 Mit dieser Wortwahl folgten die griechischen und die lateinischen Ubersetzer dem Sinn der hebr. Ausdrucksweise, die den Glauben mit Hilfe von zwei Wurzeln wiedergibt: "die eine (aman) legt die Betonung auf die GewiBheit, Festigkeit, die andere (batah) meint den Elan des Glaubens und Vertrauens" (BthW I,568).

Die semantischen Berührungspunkte zwischen dem ursprünglichen Begriff des Wortes věra und dem neuen christlichen Inhalt 'Glaube' sind in der theologischen Aussage des christlichen Glaubensbegriffes enthalten. Die Bedeutung 'Wahrheit' entspricht der wichtigsten Eigenschaft der gottlichen Botschaft: sie ist wahr. "Wenn Wahrheit

1. Vgl. Frisk II,487. Vgl 
Gott zugesprochen wird, herrscht die Bedeutung von zuverlässigkeit, Festigkeit, Verläblichkeit, Treue vor, die jede entsprechende menschliche Haltung uberragt." 1 Der Glaube als Heilsakt bedeutet primarr "die Annahme der Botschaft von der einmaligen Heilstat Gottes in Christus und die Unterwerfung unter den dekretierten Heilsweg." (HthG I,530). Der sprachliche Zugriff in der Ausdrucksweise věrl jęti 'die zusicherung, das Versprechen Gottes annehmen, ergreifen', welche die ältere Form des späteren vĕrovati darstellt, entspricht genau diesem Sachverhalt (Jagić Entst 285). Hier spielt auch der rechtliche Aspekt des Wortes vĕra aus der Versöhnungspraxis mit hinein: Gott als der "beleidigte" Teil gibt dem Menschen sein Versprechen, womit eine Rechtsgemeinschaft entsteht, welche in der Bundschliebung ihren Ausdruck findet. In ein solches (Rechts-) Verhältnis zu Gott begibt sich der Mensch durch den Glaubensakt. Es ist möglich, daB die heidnische Vorstellung des răchenden Gottes, die auch dem AT nicht fremd ist, die Ubertragung des Denkmodells aus dem die Blutrache ablösenden Versöhnungsakt begünstigt hat. Aus den Volksliedern zitiert BUSLAEV "ot boga ot starog krvnika", worin Gott in der heidnischen Vorstellung des Bluträchers gesehen wird (123). Der sündige Mensch, der die Untat beging (Erbsünde), ist auf die Gnade des Rächers (Gottes) angewiesen, durch das Vergehen wird er schuldig, so dab der Andere vollkommen Macht uber ihn gewinnt. Das Leben des Sünders ist in seiner (Gottes) Hand. Von ihm erhält er vĕra das Friedenswort.

Es ist anzunehmen, daB die mit dem Wort věra verknüpfte Vorstellung noch lebendig war, als es in den christlichen wortschatz überging. In seinem Gebrauch war es nicht auf den rechtlichen Bereich eingeschränkt, denn die Grundbedeutung 'Wahrheit' scheint noch deutlich durch. Der christliche Begriff knüpt an beide Bedeutungen an, die allgemeine und die speziell rechtliche, wobei der Rechtsaspekt in den Vordergrund tritt.

zur Bezeichnung des Glaubensbegriffs hat das slavische keine anderen wörter. Sinnverwandt mit věrovati, věriti ist up̧vati, das die zweite Bedeutungskomponente von 'glauben' im sinne von 'hoffen, vertrauen' des oben erwähnten hebr. batach aufnimmt. Das von dem Verb gebildete substantiv upzvanije n. ist in der Paralle-

1. Vgl. HthG II,795, Bthw I,568: "Das hebr. Wort für Wahrheit, Echtheit, Wirklichkeit heiBt émet und für den gebräer ist die wahrheit nicht dew Irrtum gegenubergestellt, sondern dem Nichts, dem, was er Eitelkeit, Nichtigkeit 
le zur Wortbildungsvariante věrovanije n. zu sehen, die nur in Bes belegt ist.

$v \check{e} r \circ v a t i$ ipf. 'glauben' s.o. unter věra.

$z \quad b \quad l \quad d \check{e} i \mathrm{~m}$. eigentlich 'Ubeltăter, Verbrecher' wird zur Bezeichnung des Teufels gebraucht. Es entspricht in Bezug auf Form und Inhalt dem lat. malefactor, dem ahd. ubiltāto und steht für griech. kaxoũoros, kaxorolos in der asl. Ubersetzungsliteratur. Das zweigliedrige Kompositum aus $z$ zlo $n$. 'das Böse' und dě-ti 'tun' + Suff. -b, zblo-dĕ-b hat sein Gegenstück in dobrodě $i \mathrm{~m}$. 'der Mensch, der Gutes tut'. 'Es wăre zu untersuchen, ob es als eine Lehnübersetzung aus einer der Vorbildsprachen angesehen werden sollte, oder ob sich derartige Wortbildungen in paralleler Entwicklung aus der struktur der slavischen sprache erklären lassen. 2

In der Wahl des Wortes zblodèi zur Bezelchnung des Teufels kann es sich nicht um eine Bedeutungsentlehnung aus den in Frage kommenden Vorbildsprachen handeln, denn die entsprechenden Komposita gehen über die allgemeine Bedeutung 'Ubeltäter, Verbrecher' nicht hinaus. Got. missataujands für griech. rapaßdins bedeutet

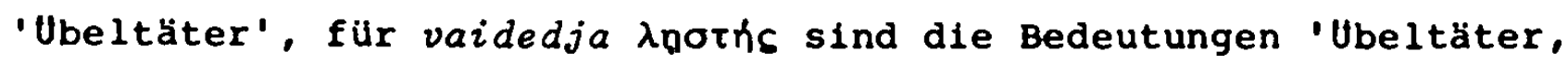
Plünderer, Räuber' angeführt (Schulze GG 348, 62). Das ahd. substantivierte Adjektiv ubeltātīg, das nomen agentis ubiltato, ubilwurhto haben nur die Bedeutung 'Ubeltater, Sünder' (Schützeichel 205-206). Das gleiche gilt für lat. malefactor 'Ubeltăter' und griechische Komposita (Georges II,778, Liddel-Scott 862,864).

Im Altrussischen wird zblodé $i$ als spezielle Bezeichnung für den Dieb gebraucht. ${ }^{3}$ Für eine solche Bedeutungseinengung liegen in der altslavischen Literatur keine Beispiele vor.

Der Benennung des Teufels, als des Inbegriffs alles Bösen, mit dem Wort zъloděi liegt eine tabuistische Intention zugrunde. Es ist eigentlich ein Ersatzwort, wie es auch in den anderen sprachen Vor-

nennt (si:qer). Darum heibt auch Gott der émet, der wahrhelt, richtiger der Treue, der Zuverlassigkeit."

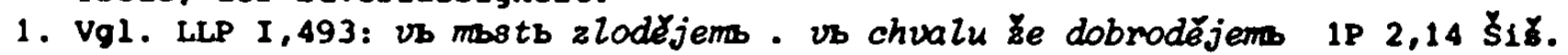

2. Schumann 64 betrachtet es als Lehnubersetzung aus dem Griechischen. Diese AusschliéBlichkeit ist wegen lat. malefactor, and. ubiltäto, got. missatcujands nicht haltbar.

3. Als den schlimsten unter den Verbrechern hat man den Dieben die schandlichste Strafe zugedacht. Vgl. Vladimirskij-Budanov 298 , die russischen Chroniken aus dew 12. Jh. berichten von der Todesstrafe durch Erhängen als einer speziellen Art des Strafvollzugs für Diebe: "knjaz' uprekaet galilan, לto oni knjazej-Igorevičej povesili 'kakb zloděevb' to jest' vorov." 
bilder hat. Schon das griech. Wort, das in die deutsche Sprache als Lehnwort aufgenommen wurde, ist nicht des Teufels eigentlicher Name, sondern es "umschreibt den Gefährlichen verhüllend" (Tschirch 3 46-47); wörtlich bedeutet diabolos 'Verleumder'. Das griech. oaravãs ist wiederum ein hebräisches Lehnwort, das eigentlich 'Widersacher' bedeutet, also auch eine tabuistische Umhüllung darstellt.

In Fris I,28-29 steht abloděi einmal für den Teufel, ein andermal für a 11 e Teufel, womit wohl böse Geister gemeint sind. 1 Das hätte sprachlich unterschieden werden können, und zwar gibt es in der kirchenslavischen Literatur das Wort běsz $m$. für 'Dämon, böser Geist'. 2 Es ist immerhin beachtenswert, daB es an der besagten Stelle nicht vorkommt. Die ganze Stelle in Fris I, 28-29 erinnert sehr an den entsprechenden Passus der Abschworrungsformeln in den ahd. Texten. Im săchsischen Taufgelöbnis muß der Schwörende die heidnischen Götter verwerfen, sie stehen für böse Geister, die dem Reich des Teufels angehören, jedenfalls vom Standpunkt des Missionars als solche angesehen werden (Ehrismann I,298). Auch lateinische Formeln hatten die Abschwörung der Dämonen, angeli, der Genossen des Teufels; "Das Reich des Teufels in germanische Auffassung übertragen, bilden die höheren und die niederen Götter." (Ehrismann I,298). Auch in den altpolnischen Denkmälern werden heidnische Götter oder Dämonen als Teufel bezeichnet. ${ }^{3}$ So tritt das Wort sotona 'Teufel' auch manchmal im Plural auf und bedeutet dann nicht den Teufel als das böse Prinzip, oder - nach dem Katechismus - den Anfürer der gegen Gott empörten Engel (angeli), sondern ebendiese bösen Geister (=Dämonen), die in die Hölle hinabgestürzt wurden. Diese sind auch in Fris I,28-29 gemeint. Danach hat zblodęi in Fris zwei Bedeutungen: 'Teufel', für den es asl. Literatur dijavols m., vragb m., navadbnica m., lqkavyi m. und das in Fris vorkommende neprijaznb und sotona als Bezeichnungen

1. Ahnllcher Sprachgebrauch liegt in Euch 37b 9-13 vor: chranesta d8je moje ... otoveego abloděe $i$ otb vsekoje sěti nepriězniny. Im übertragenden sinne wird in VencNov $58 \mathrm{~b}$ zloděĕ statt diavoli von Menschen ausgesagt. Vgl. LLP I,484 unter dijavolb. Die bisherige Meinung, zbloděi sei als Teufelsbezeichnung nur in Fris vertreten, kann nicht mehr aufrechterhalten werden. Vgl. dazu Vašica 162.

2. Vg1. Jagic Entst 305; LLP I,159-160; Meyer 263: "Uralt ist das Wort und Begriff für das dămonische Wesen, den běsu ...".

3. Vgl. Klich 15: "bogowe poganow dyabli (daemonia)" F1.95,5. In Pul. 90,6 wird der Mittagsdamon wit dew Wort dyabel belegt: "od ... dyabla poludnego (ab .. daemonio meridiano)"; ebenso der vormittägliche Dämon in PuX. 90,6. 
gibt, ferner 'Dämon, böser Geist', der im Asl. běsz, und demonı genannt wird. 1

Die volkstümliche Teufelsbezelchnung zbloděi ist von der literarischen Umschreibung staryi zъloděi zu unterscheiden (s.u.).

$z b l o d \check{e} i n_{b}$ adj. poss. abgeleitet von zbloděi 'des Teufels'. In dieser Bedeutung kommt das Wort nur in Fris vor; für 'verbrecherisch, boshaft' ist es nur noch in Supr belegt (LLP I,686).

1. Es kommt vor, daB für den Begriff 'Damon' sotona oder dijavolb, auch in Mehrzahl, gebraucht wird. Dagegen wird der Teufel nicht mit běsb, demonb bezeichnet. 
C. U m s $h r$ e 1 b u n g e n

$d \check{e} \imath a \quad s \quad o t o n i n a$ 'Teufelswerke' (Werke des Satans). Mit diesen Worten werden böse Taten bezeichnet, die der Mensch durch die Anstiftung Satans begeht. Letztlich sind darunter 'Sünden' zu verstehen, wie aus dem Sinn der Predigt hervorgeht. Diese in Fris II,19-20 enthaltene Umschreibung kann auf das lateinische sprachliche Vorbild opera satanae zurückgeführt werden, das in einer lateinischen Musterpredigt enthalten ist. 1 GRAFENAUER bringt ein zitat aus dem XV. Sermo des hl. Bonifatius, in dem die Sünden, als Teufelswerke bezeichnet, aufgezăhlt werden: "Quid sunt ergo opera diaboli?" (Grafenauer, 12). Das Zitat aus der besagten Musterpredigt lautet: "haec sunt opera Satanae...", was genau dem asl. Wortlaut entspricht: ježe sptz děla sotonina.

Eine andere Umschreibung für 'Sünden' stellt der Ausdruck

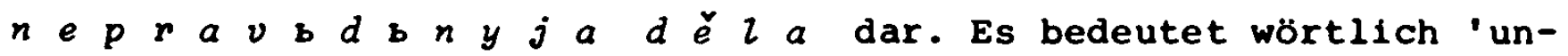
gerechte Werke', die Sünden werden als Handlungen, die gegen das Gesetz Gottes verstoßen, angesehen. Die Umschreibung kommt in Fris III, 28 vor und findet in den ahd. Beichten ihre sprachliche Entsprechung, wie z.B. in der Fuldaer Beichte: unrehtero unerco (Steinmeyer 327 ).

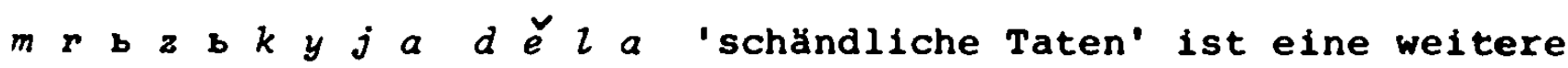
Umschreibung für 'Sünden'. Sie kommt in Fris II,18-19 vor und entspricht dem Sinne nach am năchsten dem lat. vitia 'Schandtaten'. Auch dieses ist in der Musterpredigt enthalten: "dimittamus vitia et credamus remissionem peccatorum nostrorum" (S.440, Zeile 23). $v \check{e} \check{c}$ b $n \circ j e \quad v e s e l i j e$ ist eine Umschreibung des paradiesischen zustandes. Im Letzten ist es mit dem Begriff des ewigen Lebens, des Reiches Gottes, des Himmels und Gottes Herrlichkeit identisch. Als Paraphrase von Mt 25,34 kommt es in Fris I,34 vor. Zum Vergleich ein zitat aus der Musterpredigt: "ubi est laetitia et gaudium sine fine..." (s.441, Zeile 14).

$z \quad \boldsymbol{z} l o d \check{e} i n a \quad 0 \quad b \quad l \quad a \quad s \quad t \quad b$ 'Macht des Teufels' entspricht potestas diaboli in der Musterpredigt. Grěšbiky izbaviti otb zblo. deinyje oblasti in Fris III,69-71 stimmt mit "ut nos a potestate diaboli liberaret" in der lat. Predigt überein (S.438, Zeile 34).

1. Vgl. Withelm Scherer, Eine lateinische Musterpredigt aus der Zeit Karls des Großen, in: Zeitschrift für das Altertum, 12, Wien 1865, 436-446. Vgl. 440, Zeile 3 . 
$z \quad b \quad l \quad b \quad d \quad l \quad s \quad t a r y i$ ist eine literarische Umschreibung für den Teufel als den Urgrund des Bösen. Aus demi $X$. Sermo des Bonifatius gibt GRAFENAUER folgende stelle an: "Sed antiquus hostis invidendo de tanta gloria hominis ..." (Grafenauer, 118, Anm. 81).

Die Umschreibung staryi zbloděi kommt noch in Can Venc, Vajs 144,2 vor: staryi zbloděi (i) zavidě ti s(vę)št(e)numu žitiju leider ohne Vorlage. AuBerdem findet sich noch in Euch $63 \mathrm{~b} 10$ staraago zъloděa für griech. Tóv $6 \dot{\varepsilon}$ apxéxaxov kai Búvıov, das wörtlich 'Unheil stiftend aus der Tiefe' bedeutet. Die slavische Ubersetzung gibt den sinn der griech. Aussage wieder, zeigt sich doch in formal-sprachlicher Hinsicht von ihr unabhăngig. Naher liegt das lat. antiquus hostis, das aber in Bes 16, 80aß $20 \mathrm{mit}$ drevlb$n i i$ voins übersetzt wird. In Meth 9, Lavrov 74,15 steht staryi vragb für 'Teufel', leider ohne Vorlage. Die Umschreibung zъlodě $i$ staryi aus Fris II,74 muB von der einfachen Bezeichnung des Teufels mit zbloděi in Fris I und III unterschieden werden. 1

1. Vgl. dazu Vašica $159-163$.

Für griech. apxexakov steht in Supr 522,1 provyi zblz. 


\section{Darstellung und Auswertung der Ergebnisse}

A. G e s a m $t u$ b e r s 1 c h $t$

Tabelle I

In der nachstehenden Tabelle sind alle untersuchten wörter in alphabetischer Ordnung verzeichnet. In den zehn Rubriken werden die wichtigsten Ergebnisse kurz zusamengefast dargestellt.

In der Rubrik 1 sind die altslavischen Wörter in genormter Schreibweise aufgefuhrt. Das zeichen + bedeutet, daB der Gebrauch des wortes in der Bedeutung nur auf Fris oder auf noch ein weiteres Denkmal beschränkt ist.

Rubrik 2 gibt an, welcher Lehngutgruppe das betreffende Wort angehört: $F w=$ Fremdwort, $L w=$ Lehnwort, Lủs = Lehnübersetzung, Lủt $=$ Lehnübertragung, Ebi $=$ Eigenbildung, Lupg $=$ Lehnumprägung und Eupg = Eigenumprăgung.

In der Rubrik 3 wird der christliche Begriff angegeben, welchen das asl. Wort in Fris bezeichnet. Auf die Bedeutungsschattierungen wird dabel keine Rücksicht genommen.

Rubrik 4 gibt die einzelnen Teile von Fris an, in denen das Wort vorkommt.

Rubrik 5 gibt AufschluB uber das Vorkommen des Wortes auBerhalb Fris: "oft" bedeutet, das das Wort auch in der ubrigen asl. Literatur vielfach Verwendung fand; "MP" heist, daB es nur in der mährisch-pannonischen Gruppe belegt 1st: "alt" weist auf das Vorkommen des Wortes in den ältesten asl. Texten hin. Die $\mathrm{Ziffern}$ geben die $\mathrm{Zahl}$ der Belege auBerhalb Fris an.

Rubrik 6 gibt die Sprache an, aus der das Wort entlehnt ist, bzw. aus der das Vorbild für die altslavische Nachahmung stammt: $\underline{a}=$ nur ahd.,$\underline{1}=$ nur lat.. $q=$ nur griech.,$\underline{a}+1$ = belde Sprachen sind in gleicher Weise beteiligt. Ein danebenstehender, nicht unterstrichener Buchstabe bezeichnet die Sprache, deren EinfluB aus formalen Gründen möglich ist, aber nicht notwendig anzunehmen ist, oder aber textgeschichtliche Gründe dagegen sprechen.

Rubrik 7 bezeichnet den Sprachbereich, dem das wort angehorte, bevor es in den christlich-religiösen Wortschatz übernommen wurde: $a=$ Allgemeinsprache; $b=$ Rechtsbereich; $c=$ Familienbereich; 
$d=$ heidnisch-religiöser Wortschatz; $e=$ sozialer Bereich. Rubrik 8. Der Buchstabe $T$ bescheinigt die terminologische Qualität des Wortes. Als Kriterium dafür ist nicht unbedingt die Verbreitung des Wortes in der asl. Literatur anzusehen. Auch die nur beschränkt verbreiteten (oder vielleicht nur beschränkt überlieferten) wörter haben sich durchaus in ihrem wirkungskreis als Termini behauptet. Entscheidend ist dafür der terminologische Gebrauch des Wortes, den man aus dem Kontext ersehen kann.

Rubrik 9 gibt die Wortart an: $S=$ Substantiv; $V=$ Verb; $A=$ Adjektiv; $P=$ Partizip.

Rubrik 10 enthält die wichtigsten Synonyme, bzw. lexikalische Varianten $z$. T. auch Wortbildungsvarianten aus der ubrigen altslavischen Literatur. Sie sollen Antwort auf die Frage geben, welche Wörter an stelle des untersuchten hätten gewählt werden können. Diese Angaben erheben keinesfalls Anspruch auf Vollständigkeit, die zu erreichen weder möglich, noch im Rahmen dieser Arbeit notwendig war. Es soll damit lediglich die vielfalt der Ausdrucksmöglichkeiten innerhalb des asl. christlichen wortschatzes gezeigt werden. Eine besondere Beachtung gilt den ermittelten griechischen Lehnwörtern und den Lehnbildungen und -umprägungen, die auf griech. Vorbilder zurückgehen. Sie sind unterstrichen. 


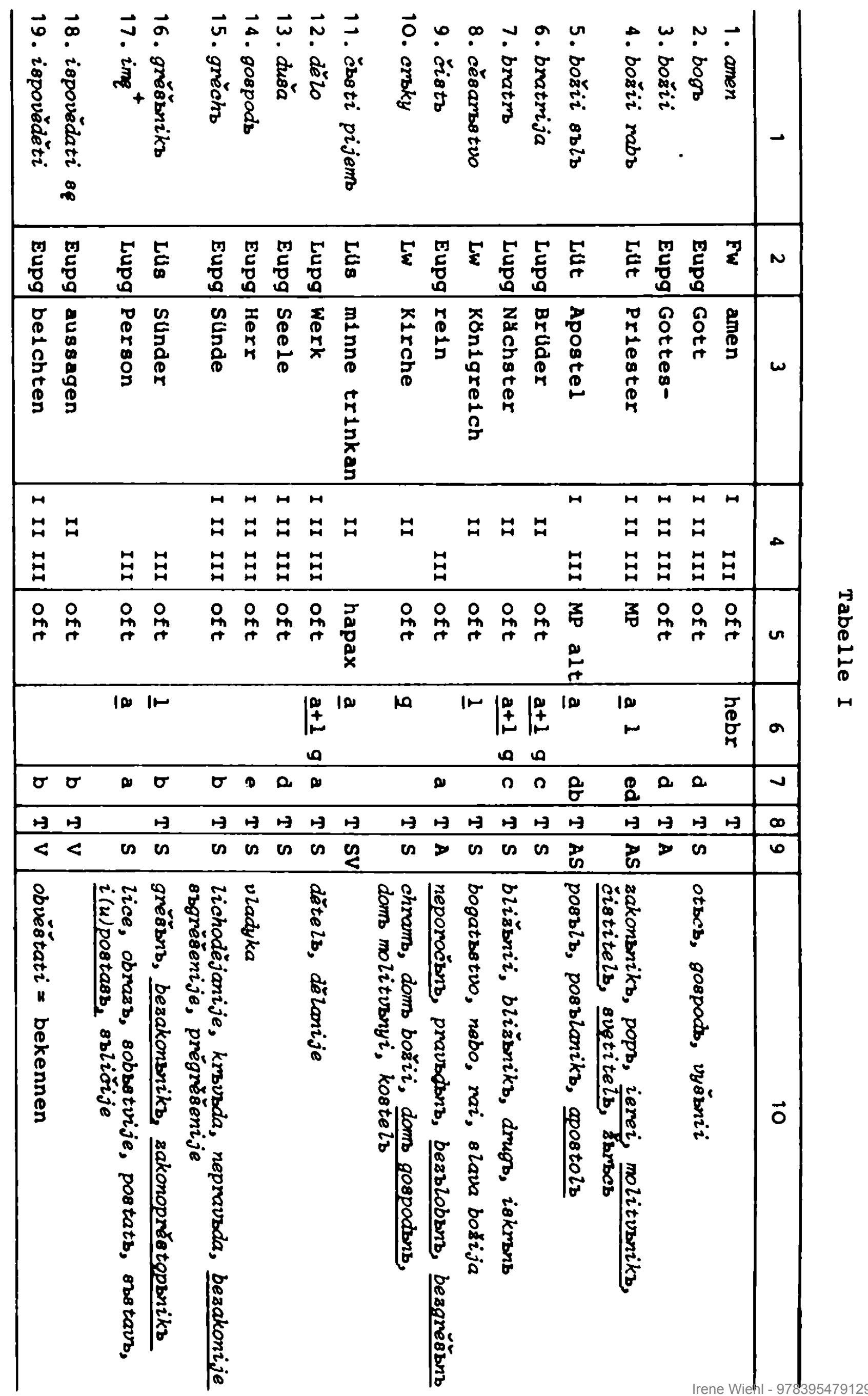




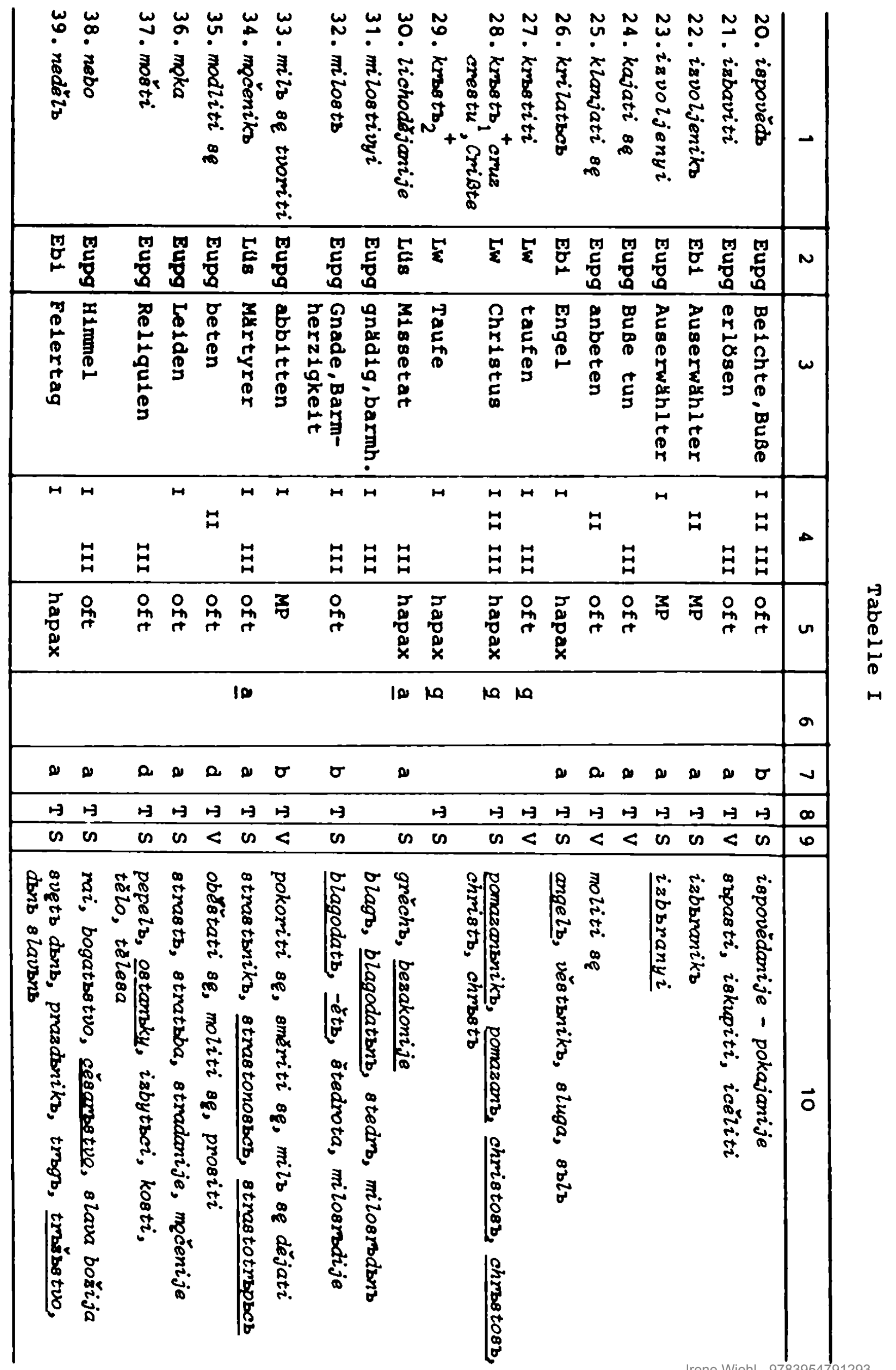




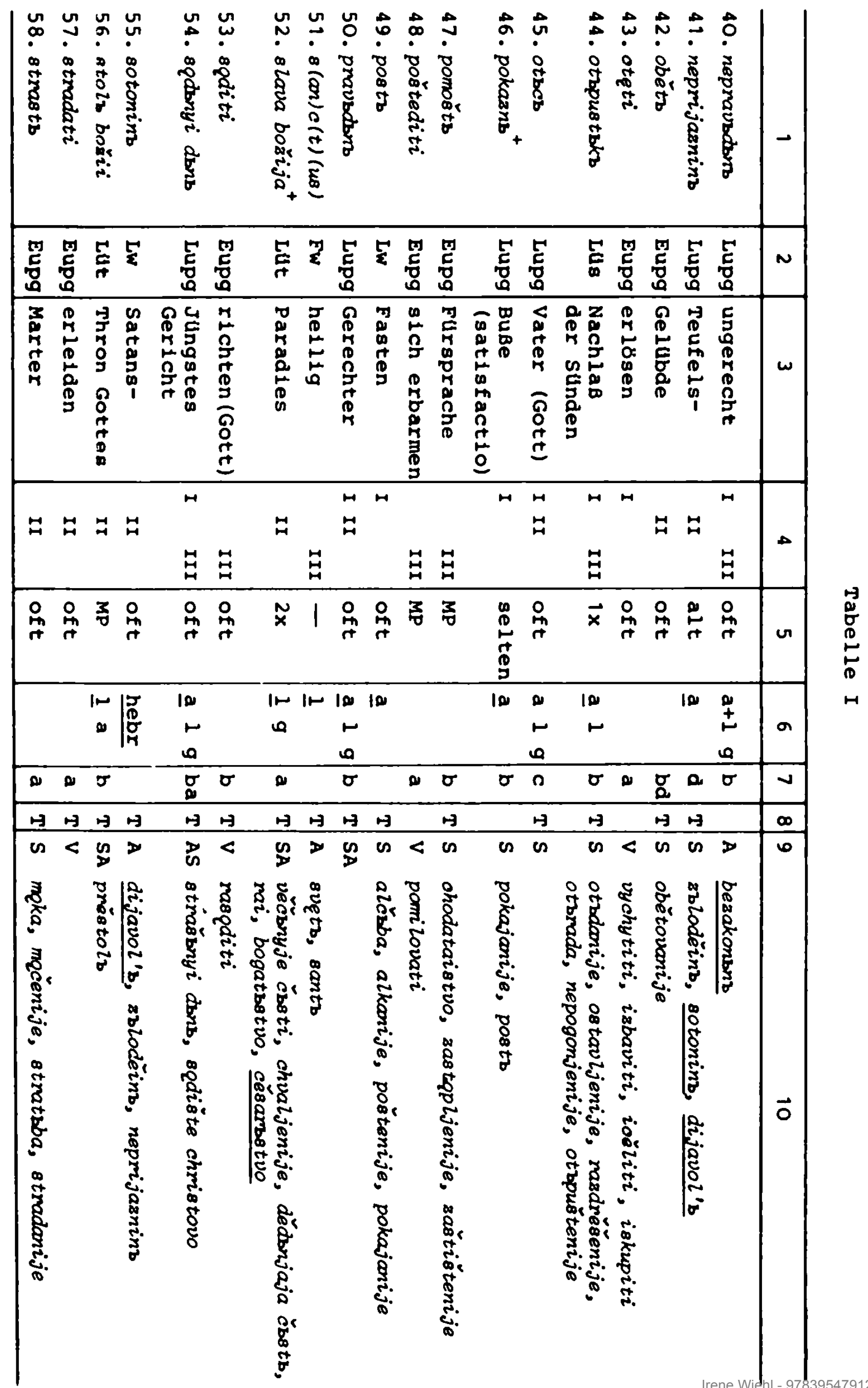




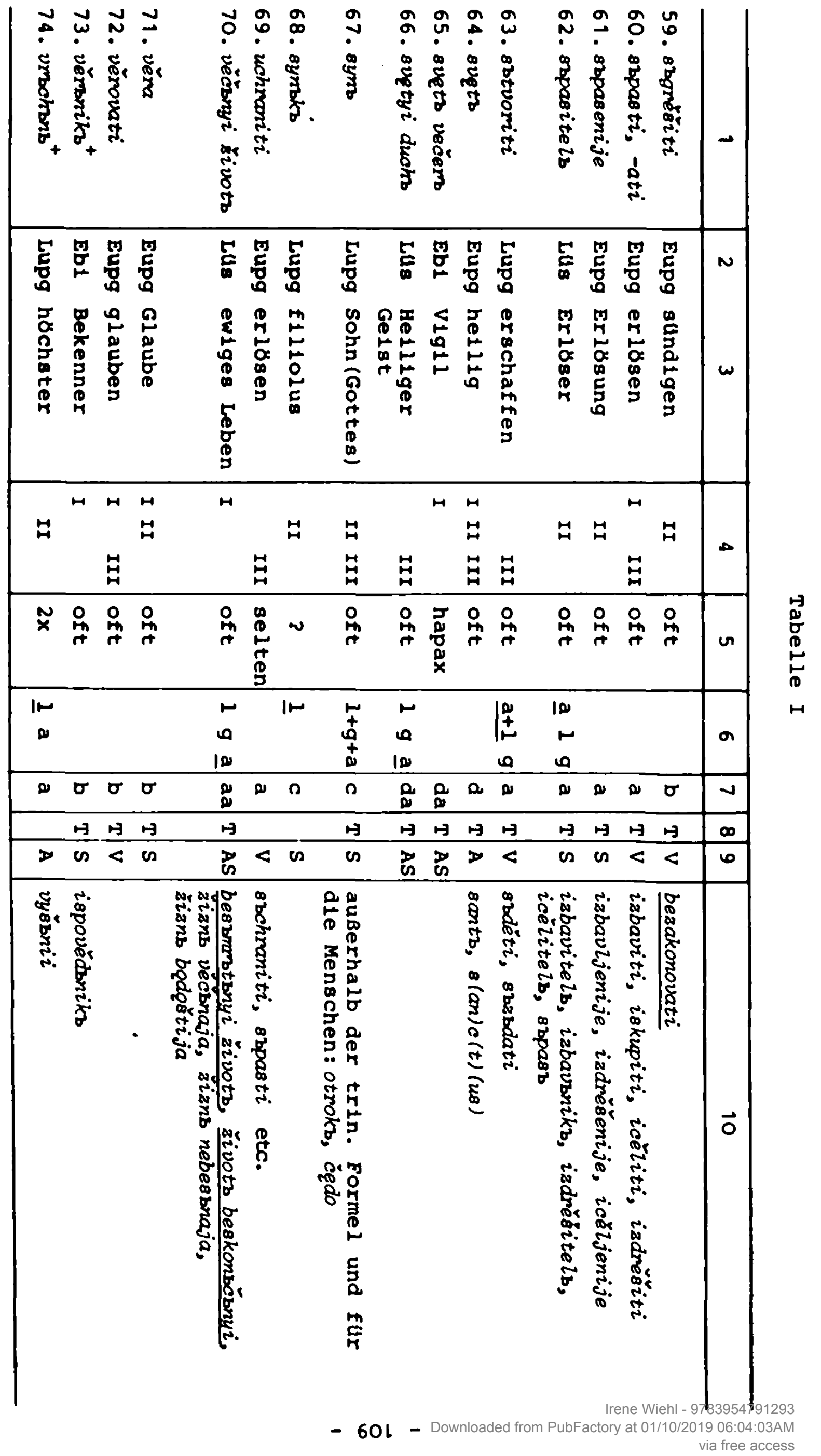




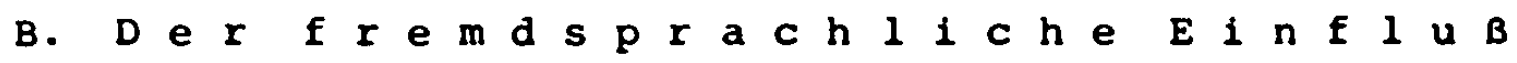

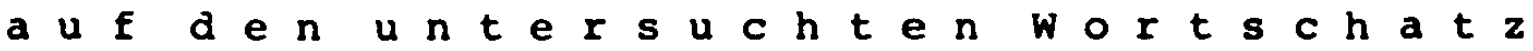

1. Die Einteilung des Lehngutes. Tabelle II

AuBeres Lehngut: 9

Fremdwörter : 2

amen

sanctus
Lehnwörter: 7

cèsarbstvo krbstb

krbstiti postb

krbstb $_{1}$ sotonins

\section{Inneres Lehngut: 71}

\section{Neubildungen: 20}

Lehnübersetzungen: 10 Lehnübertragungen: 5 Elgenbildungen: 5

\section{čbsti pijems}

grěs̆nikz

iichodéjanije

mqcenikb

otspustbks

szpasitelb

s vetyi duchs

věcbnyi životb

$v$ bsemogy

saglagolati se božii rabb

božii 8 zlb

slava božija

Btols božii

zakonbniks iavoljenikb

krilatbcb

nedělz

8 vetb večers vérbnikb

\section{Umprägungen: 51}

Lehnumprägungen: 15 Eigenumprăgungen: 36

bratrija
bratrb
delo
imę
nepravbdb
neprijazn
otbcb
pokaznb
pravbdbnb
sqdbnyi d
sotvoriti
synb
synskb
vrschsnb
vostati

\section{bogb}

božiz

cistb

duša

gospodb

grĕchz

ispovědati sę

ispovédĕti

ispovédb

izbaviti

$i z$ voljenyi

kajati $8 \boldsymbol{q}$

klanjati $8 \varepsilon$

milostb

milostivyi

mils se tvoriti

modiliti 8

$m q k a$ mošti

nebo

obéts

oteti

pomosts

postediti

sqditi

stradati

strastb

şgrěs̆iti

szpasati, ospasti

s bpasentje

svętr

uchraniti

věra

vérovati

zъlodéi

ablodéins 
Das äußere Lehngut besteht aus 2 Fremdwörtern, dem hebr. amen und dem lat. sanctus, ferner aus 7 Lehnwörtern: 4 griech., 1 hebr., 1 lat. und 1 ahd.(?). Alle Lehnwörter cěsarbstvo, crbky, krbstiti, krbstb, (Christus), krbstb, (Taufe), postb, sotoninb sind $v$ or $l i t$ e $r$ r $i$ c h e Entlehnungen, die zum altesten Bestandteil des christlichen altslavischen Wortschatzes gehören.

Die Lehnübersetzungen gehen vorwiegend auf ahd. Vorbilder zurück. In formaler Hinsicht bietet die Gruppe der Lehnubersetzungen ein verschiedenartiges Bild: 1 Lehnwendung čbsti pijemb, 2 Komposita lichodějanije und vbsemogy, 2 feste Wortverbindungen (= Lehnübersetzungen aus Umprägungen) svetyi duch b und věčnyi životb, ein präfigiertes reflexives Verb zaglagolati $8 \varepsilon$ und 4 Ableitungen aus den christianisierten stämmen grěšnikz, mqčenikb, szpasitelb und otbpustbkb. Das Wort mqčsnikz könnte auch $z u$ den Eigenbildungen gezählt werden, da der Vergleich mit seinem ahd. Vorbild nicht absolut zwingend für eine Lehnübersetzung spricht. Ebenso besteht Unsicherheit darüber, ob sspasite $l_{b}$ und otopustbkb allein vom lateinischen Vorbild abhängen.

Die Lehnübertragungen bestehen fast alle aus festen Wortverbindungen, die ebenso wie die Lehnübersetzungen aus einem Adjektiv und einem Substantiv bestehen. Die Adjektive stehen an Stelle von Genitiven der Vorbildsprachen, worin sich die besondere Eigenheit des slavischen manifestiert, die prädikativen Substantive mit Adjektiven aufzulösen. Bei der Lehnübertragung zakonbnikb handelt es sich um ein nomen agentis, gebildet mit dem in Fris besonders produktiven suffix-ikb, das den zweiten Te11 des ahd. Kompositums ersetzt.

An den Eigenbildungen ist ebenfalls das suffix -ikb beteiligt: vĕrbnikb und $i z v o l j e n i k b$ sind zwei weitere Ableitungen aus den christianisierten stämmen. Wie die bereits genannten, besteht die Eigenbildung svets večerb auch aus der verbindung von einem Adjektiv und Substantiv. Mit Ausnahme von věčsnyi životb treten in den Neubildungen die Adjektive bořii und svętb auf, durch die das "profane" Substantiv "geheiligt" wird.

Uberblickt man alle neu entstandenen wörter, so kann man nicht übersehen, daB sich unbeachtet der vorgenommenen Einteilung zwei Sondergruppen herausheben: 1. die Ableitungen von den 
christianisierten Stämmen, 2. die aus zwei Teilen bestehenden festen Wortfügungen.

Bei der großen Gruppe der Umprägungen war es wegen Mangel an brauchbaren zuverlässigen Kriterien schwierig, die Grenze zwischen den Lehn- und Eigenumprägungen $z u$ ziehen. Darum sollte der Wert dieser Differenzierung nicht überschatzt werden. Jedoch für die Fälle, bei denen sich mit Bestimmtheit sagen lieB, daB sie w o $r t g$ e $t r a$ den Vorbildsprachen folgen, hat sich die durchgeführte Einteilung gelohnt. Das betrifft das Wort ime für ahd. namo in der Bedeutung 'Person', ferner synbkb lat. filiolus, das in der Pluralform neben bratrija für lat. fratres als Anrede des versammelten Christenvolkes in den lateinischen Homilien bekannt ist. Weiterhin düfte auch die Entsprechung von pokaznb $\mathrm{zu}$ ahd. harmscara und neprijazns $\mathrm{zu}$ ahd. unholdo als gesichert angesehen werden. Ebenso kann vrbchbns auf lat. summus zurückblicken, vzstati auf ahd. ar-, ufstân, sqdbnyi dbnb auf ahd. tuomestag. Für lat. opus und ahd. werk steht immer délo, und nepravbdbnb hat seine Bedeutung (im christl. Sinne) von ahd.unreht und lat. injustus entlehnt. Unsicher wird es aber mit pravbdbnb, das zwar wie die negierte Form seine Entsprechung im Lat.-Ahd. hat, dennoch darüber hinaus eine eigene Bedeutungsentwicklung zeigt; pravbdbnb wird wahlweise auch für 'heilig' verwendet. Ein Problem für sich stellte die Einordnung von synz und otbcb als Lehnumprägungen dar. Hier wird der Mangel an entsprechenden Kriterien zur Unterscheidung der einzelnen Kategorien besonders spürbar. Einerseits bedarf es nicht unbedingt des $w \circ r t e s$. um den Begriff 'Sohn' und 'Vater' zu übersetzen. Sowohl die Begriffe in dem Verständnis als auch die Worte in ihrem sinn sind so eindeutig, daB keine sprachlichen Wahlmöglichkeiten gegeben sind. Da aber diese Worte die gottlichen Personen bezelchnen und als solche zum festen Bestand der trinitarischen Formel gehören, ist die Entscheidung für Lehnumprăgung gefallen.

Von den vielen Eigenumprăgungen könnte man einige in die Kategorie der Lehnumprägungen elnordnen: gréchb, sbgrěsiti, ispovĕdéti, ispovèdb, izbaviti, meka, sъpasti, szpasenije, strasts, $s$ tradati. Der Vergleich dieser slavischen worter mit ihren Entsprechungen in den Vorbildsprachen verhilft nicht zur sicheren Entscheidung. In den meisten Fällen können Parallelentwicklungen angenommen werden, ihre zuordnung ist auf mehr oder weniger Ver- 
mutung gestutzt. Da der Gewinn aus der Unterscheidung zwischen Eigen- und Lehnumprägungen für die Charakterisierung des christlichen Wortschatzes nicht sehr groB ist, wird der Wert der nachstehenden Ubersicht über das Verhältnis der Lehngutarten zueinander durch den gemachten Vorbehalt nicht wesentlich geschmalert.

2. Der Anteil der Lehngutgruppen am religiösen Wortschatz von Fris. Tabelle III

\begin{tabular}{|c|c|c|c|c|c|c|c|}
\hline Fw & LW & Lüs & Lut & Ebi & Lupg & Eupg & Insgesamt \\
\hline 2 & 7 & 10 & 5 & 5 & 15 & 36 & 80 \\
\hline 2,68 & 8,98 & 12,68 & 6,38 & 6,38 & 198 & 44,38 & \\
\hline \multicolumn{5}{|c|}{ Lehnwörter + Neubildungen: } & \multicolumn{3}{|c|}{ Umprägungen : } \\
\hline \multicolumn{2}{|c|}{11,58} & 25,28 & $=$ & & \multicolumn{2}{|c|}{63,38} & \\
\hline
\end{tabular}

Von den 80 wörtern, die den religiösen Wortschatz von Fris ausmachen, sind also die meisten, 63,38 (51) Umprägungen, wobei auf Lehnumprăgungen 198 und auf Eigenumprăgungen 44,38 entfallen. Die nächstgrößte Gruppe bilden die Lehnübersetzungen mit 12,68 (10). gefolgt von 11,58 (9) Fremd- + Lehnwörter (in der Tabelle einfachheitshalber unter Lehnwörter zusammengefaBt) . Lehnübertragungen und Eigenbildungen halten sich mit je 6,38 (5) die Waage. Zăhlt man die Neubildungen des inneren Lehngutes mit den Lehnwörtern zusammen, so ergibt sich das endgültige Verhältnis von 36,78 neu entstandenen wörtern 2463,38 Erbwörtern. Das christliche Begriffsgut im Wortschatz von Fris ist also überwiegend mit Hilfe des alten Wortbestandes zum Ausdruck gebracht worden. Doch ist die zahl der hinzugekommenen Neubildungen beachtlich. Die Frage, wie sich die Worter in Bezug auf ihren Inhalt auf die formalen Gruppen verteilen, soll anschliebend behandelt werden.

3. Verteilung der christlichen Begriffe in ihrer inhaltichen Differenzierung auf die formalen Gruppen.

Von den wichtigsten in Fris erscheinenden christilchen Begriffen werden 15 durch Umprăgungen heimischer worter ausgedrückt: bogb, dußa, grěchb, ispovědb, izbaviti, milostb, nebo, 
sopasenije, svęto, věra, zblodé, sqdbnyi dbnb, sъtvoriti, vostati, kajati 8 . Durch Lehnwörter werden folgende 4 bezeichnet: cessarbstvo, crbky, krbstiti, krbstb. Als Lehnübersetzungen erscheinen 3: sbpasitelb, svetyi duchr, verbnyi zivotb; als Lehnubertragungen und Eigenbildungen je $1:$ boxi $i$ sb $z_{b}$ und $k r i-$ latbcb. Abgesehen von dem Wort für 'Kirche', das in der Bedeutung 'Gotteshaus'. 'Einheit der Christen' und 'Kircheninstitution' vorkommen kann, bezeichnen die aufgezăhlten wörter die Grundbegriffe des christlichen Glaubens. Diese werden uberwiegend mit Hilfe von den mit neuem christlichen Inhalt gefülten Erbwörtern ausgedrückt. Darunter befinden sich nur 4 Lehnwörter.

Zur Bezeichnung der konkreten Tatbestände der kirchlichen Organisation oder des Kultus dienen folgende Ausdrücke: $\varepsilon_{b 8} t i$ pijemb, otbpustbkb, mqEeniks (Lüs); bozii rabb, zakonbnikb (Lü); $i z v o l j e n i k b$, nedĕlb, svętb večerb, vĕrbnikb (Ebi);postb (Lw) und morti (Eupg). Aus dieser Gegenuberstellung ergibt sich, daB zwischen den formalen Gruppen auch ein inhaltlicher Unterschied zu verzelchnen ist. Die eigentlichen Glaubensinhalte, die zentralen Vorstellungen und Auffassungen der neuen Religion werden durch wörter ausgeärückt, die zum gröBten Tell die Gruppe der Umprägungen ausmachen, dagegen sind die Bezeichnungen für die mehr äuBeren Einrichtungen der Kirche bei den Neubildungen zu finden.

4.Der Anteil der einzelnen Vorbildsprachen am christlichen Wortschatz von Fris

Auf Grund der in der Tabelle I dargestellten Ubersicht ergibt sich im Hinblick auf die fremdsprachliche Beeinflussung des religiösen Wortschatzes von Fris folgendes Bild: 17 Wörter zeigen ihre Abhängigkeit vom Ahd., 8 wörter vom Lat., 6 wörter vom Lat+Ahd., 4 sind griechische vorliterarische Entlehnungen und 2 sind hebräischer herkunft. Auf die formalen Lehngutgruppen verteilt, entfallen von den vom Ahd. beeinflusten wörtern 1 auf Lw, 8 auf Lüs, 3 auf Lüt und 5 auf Lupg. Die lateinisch beeinflubte Gruppe hat $1 \mathrm{Fw}, 1 \mathrm{Lw}, 2$ Lús, 2 Lut und 2 Lupg. In der griechischen Gruppe sind nur Lehnwörter enthalten, in der hebräschen 1 Fw und $1 \mathrm{Lw}$. Die worter, bel denen die Beeinflussung sowohl vom Ahd. als auch vom Lat. erfolgen konnte, sind sämtlich Lupg. zur Veranschaulichung soll die nachstehende Tabelle dienen. 
Tabelle IV

\begin{tabular}{|l|c|c|c|c|c|}
\hline & And & Lat & Lat+Ahd & Griech & Hebr \\
\hline Fw & & 1 & & & 1 \\
\hline Lw & 1 & 1 & & 4 & 1 \\
\hline Lüs & 8 & 2 & & & \\
\hline Lüt & 3 & 2 & & & \\
\hline Lupg & 5 & 2 & 6 & & \\
\hline Zus. & 17 & 8 & 6 & 4 & 2 \\
\hline
\end{tabular}

Das hier dargestelite, aus den Einzeluntersuchungen gewonnene Ergebnis zeigt, das der religiobse Wortschatz der Freisinger Denkmäler am stärksten vom Althochdeutschen beeinflust ist. ${ }^{1}$ Nur halb so groB ist die Abhängigkeit von der lateinischen Sprache. Die griechischen sprachlichen Elemente sind nur durch vorliterarische Entlehnungen vertreten.

1. Nach Ansicht von Prof. W. Mitzka, Marburg, sind auBer den aufgezahlten noch 7 weitere Worter eindeutig auf den althochdeutschen Einflub zurackzufuhren. Es seien: bratrb - bruder, delo - werk, nepravbdbrb - wonreht, otbcb - atto, pravbdbm - reht ('heilig'), sbtvoriti - skaffon, vrbchbnb hohisto, stolb - stôl. Dies ergab eine mit Prof. Mitzka gefuhrte Unterredung, die leider erst nach AbschluB der Arbeit stattgefunden hat. 


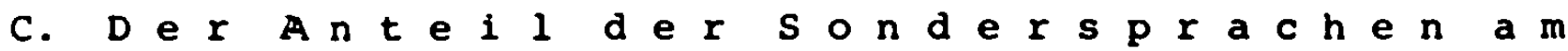

$r e l i g i o s e n w \circ r t s c h a t z v \circ n F r i s$

Bezogen auf die verschiedenen Lebensbereichebilden sich aus der Allgemeirsprache Sondersprachen heraus, die sich durch einen Komplex bestimmter Ausdrücke auszeichnen; sie werden von den besonderen Gruppen, wo sich Menschen mit gleichen Interessen geistiger oder naterieller Art zusammenschlieBen, geprăgt und verstanden (Teeuwen $11 \mathrm{ff}$.). In dem MaBe, wie sich die verschiedenen Kulturzweige von Religion, Recht, Staatswesen, Kunst etc. entwickeln, werden auch in den Sondergruppen besondere Sprachmittel geschaffen und entwickelt.

Bei den einzelnen Wortuntersuchungen wurde angestrebt, am zusammengetragenen Material zu zeigen, welchem besonderen Sprachbereich das betreffende wort angehörte, aus dem es in den religiösen Wortschatz übernommen wurde. Das ziel dieser Bemühung war zu zeigen, welche Sondersprachen an der Bildung des christlichreligiosen wortschatzes von Fris beteiligt waren und ihren Anteil an ihm mengenmäBig $2 u$ bestimmen.

Diese Fragestellung, die vor allem die Gruppe der Umprăgungen betrifft, sall auch auf die drei Gruppen der Neubildungen erweitert werden, denn einer Neubildung liegt immer schon eine Umprăgung zugrunde. Ganz gleich wie eine Lehnübersetzung oder - ibertragung formal beschaffen ist, immer wird der Wortkern eine Umprăgung sein, die in ihrem Inhalt durch Präix, Suffix, ein Kompositumteil oder ein hinzugefügtes wort modifiziert wird. In Anbetracht dieser Tatsache erscheint es berechtigt und zweckmäBig, die wörter aller Lehngruppen auf ihre zugehörigkeit zu den Sondersprachen $\mathrm{zu}$ befragen.

Die mit Hilfe der Tabelle I durchgefuhrte zăhlung brachte folgende Ergebnisse:

$\begin{array}{lrl}\text { Aus der Allgemeinsprache sind } & 34 \text { wörter } \\ \text { aus dem Rechtswesen } & 22 \\ \text { aus dem heidnisch-religiösen } & & \\ \text { Bereich } & 21 & \text { " } \\ \text { aus dex Familienbereich } & 5 & \text { " } \\ \text { aus der sozialen Bereich } & 2 & \text { " }\end{array}$
christlich-religiösen Wortschatz von'Fris beteiligt. 1 
Da mehrere worter zweiteilig sind, erscheinen sie doppelt in der vorgenommenen zăhlung. Die Lehnwendung $\chi_{b s} t i$ pijem: ist in der Berechnung nicht berücksichtigt.

Am gröbten ist also der Anteil der Allgemeinsprache; $z u$ gleichen Teilen sind zwei groBe Gruppen vertreten: die wörter aus dem Rechtswesen und der heidnisch-religiöse Wortschatz. Mit weitem Abstand folgen die worter aus dem familiăren und sozialen Bereich.

Beachtenswert ist die groBe Beteiligung des Rechtswortschatzes an der Schaffung der christlichen Terminologie und insbesondere des Bußwesens. Wie aus den Einzeluntersuchungen hervorgeht, haben oft gerade die rechtlichen Aspekte der gewählten wörter die Anknüpfungspunkte zur Ubernahme in den christlichen Wortschatz geliefert. Dafür gibt es innere und ăuBere Gründe. Erstens stand die neue christliche Lehre mit ihrem hohen $s i t t 11$ $c h$ e $n$ Anspruch der im Bereich des Rechts und der Rechtssprechung gebräuchlichen Sprechweise am năchsten, konnte von ihr am besten aufgenommen werden; zweitens trug die auBere organisation der Kirche, ihre Jurisdiktion und die offentliche BuBpraxis weitgehend dazu bei, daB es in der sprache zur Verschmelzung der beiden Lebensbereiche kam: des religiósen und des rechtlichen.

Auf die Frage der Rechtswörter im Wortschatz von Fris wird in dem dafür vorgesehenen Exkurs noch näher eingegangen.

Die Tatsache, daß aus der heidnisch-religiösen Begriffswelt sehr viele worter übernommen und mit neuem christlichen Inhalt gefüllt wurden, verdient ebenso eine besondere Beachtung. Doch in diesem Bereich hat sich die sprache verschieden verhalten. Bei manchen Ausdrücken $k$ am es zur lexikalischen Trennung, wie 2.B. das Wort tréba nur heidnisches Opfer bezeichnete, dagegen Zrstva für christliches Opfer gebraucht wurde. Es ist anzunehmen, daB viele worte, die aus theologischen Gründen zur Bezeichnung christlicher Begriffe für nicht geeignet befunden wurden, aus der Sprache ganz verschwunden sind, oder in der Umkehrung der Werte ihren Platz noch behielten. Ein Beispiel dafür ist die oben erwahnte ukrainische Teufelsbezeichnung, oder das litauische Wort für den Teufel. 
D. Verteilung der untersuchten

wrrter a u f $r i s$ I. II und III

In der folgenden Aufstellung werden die worter unter drei Rücksichten mit den einzelnen Teilen von Fris in Beziehung gebracht, und zwar im Hinblick auf:

a) die Zugehörigkeit zu den einzelnen Lehngutgruppen,

b) die fremdsprachliche Beeinflussung,

c) die Hăufigkeit ihres Vorkommens in der asl. Literatur.

Fris I enthàlt:
a) 2. b) $1 \mathrm{Fw}$
davon 1 hebr
4 LW
n 1 ahd
3 griech
3 Lùs
" 3 ahd
2 Lüt
" 2 ahd
4 Ebi
6 Lupg
2 ahd 3 ahd $+1 a t$
1 ahd+lat+griech
19 Eupg

Von den insgesamt 39 wörtern entfallen 5 auf das äuBere Lehngut, das sich aus 1 hebr. Fw, 1 ahd. Lw und 3 griech. Lw zusammensetzt. Von den insgesamt 34 wortern des inneren Lehngutes sind 19 fremasfrachlich unabhängig, 7 vom Ahd. und 3 vom Ahd+Lat. beeinfluBt.

c) 5 hapax legomena: krilatbcb, nedělb, svętb večerb, krbstb, 'Christus', krbstb 2 'Taufe'.

2 in der Bedeutung von Fris nur einmal belegte worter: věronikz 'Bekenner', pokaznb 'satisfactio'.

5 selten vorkommende und auf MP elngeschränkte Ausdrucke: zъlodě $i$, milb eq tvoriti, božii sblb, bozii rabb, izvoljenyi, otzpustbkz.

Fris Il enthält:
a) u. b) $\mathrm{OFw}$
4 Lw davon 1 hebr 2 griech 1 lat
2 Lủs " 2 ahd
3 Lut " 1 ahd 2 lat
1 Ebi
7 Lupg " 1 ahd 2 lat 4 and 1 at
17 Eupg 
Von den insgesamt 34 wortern entfallen 4 auf das äuBere Lehngut, das sich aus 1 hebr. Lw, 2 griech. Lw und 1 lat. Lw zusamensetzt. Von den insgesamt 30 wortern des inneren Lehngutes sind 18 fremdsprachlich unabhängig, 4 vom Ahd., 4 vom Ahd+Lat. und 4 vom Lat. beeinflubt.

c) 2 hapax legomena: ¿bsti pijemb, krbstb, (cruz) 'Christus', 1 in der Bedeutung von Fris nur einmal belegtes Wort: vrbchbnb 'höchster' als Epitheton Gottes,

1 in der Bedeutung von Fris nur dreimal belegtes Wort: s lava bořija 'Paradies'.

1 seltenes Wort in der asl. Literatur: synbkb,

3 selten vorkommende und auf MP eingeschränkte Ausdrücke: zbloděi, stolb božii, božii rabb in den Bedeutungen: 'Teufel', 'Thron Gottes', 'Priester'.

\section{Fris III enthalt:}

a) u. b) $2 \mathrm{Fw}$ davon 1 hebr 1 lat

1 Lw

- 1 griech

7 Lủs

* 5 ahd 2 lat

3 Lüt

- 3 ahd

O Ebi

6 Lupg

" 2 ahd

3 and + lat+griech

24 Eupg

Von den insgesamt 43 wortern entfallen 3 auf das auBere Lehngut, das sich aus 1 hebr. Fw, 1 lat. Fw und 1 griech Lw zusammensetzt. Von den insgesamt 40 wortern des inneren Lehngutes sind 24 fremdsprachlich unabhängig, 10 vom Ahd., 2 vom Lat. und 3 vom Ahd +lat. beeinfluBt.

c) 3 hapax legomena: lichodějanije, zaglagolati sę, krbstb, (CriBte) 'Christus',

1 in der Bedeutung von Fris nur einmal noch in Fris $I$ belegtes Wort: otzpustbkb (von dem Beleg bei SREZNEVSKIJ abgesehen),

1 in der Bedeutung von Fris nur in Fris vorkommendes Wort: zъloděinz 'Teufels-'

1 in der Bedeutung von Fris nur zweimal belegtes Wort: ime 'Person'.

1 in der Bedeutung von Fris nur noch in Bes und Euch vorkommendes Wort: milosts 'Gnade',

6 in der Bedeutung von Fris selten vorkommende und auf MP 
beschränkte Ausdrücke: zъloděi, zakonbnikb, pomos̆tъ, poštęditi, božii rabr, božii sblz.

Fris III zeigt den stărksten fremdsprachlichen EinfluB. Es enthălt die meisten in der Abhängigkeit vom Ahd. entstandenen Ausdrulcke. Auch die Einwirkung des Lateinischen ist in Fris III am gröBten. Fast gleich, doch etwas schwächer, macht sich das Althochdeutsche im christlichen Wortschatz von Fris I geltend. Auffallend ist der geringe EinfluB des Lateinischen auf Fris I. Dafur versammelt es fast alle Eigenbildungen, die meistens hapax legomena sind. Es erhebt sich die Frage, ob dieser Tatbestand den religiosen Wortschatz von Fris I als volkstumlich $z$ u charakterisieren berechtigt, demgegenüber Fris III stark unter dem lateinisch-deutschen liturgischen EinfluB zu stehen scheint. Für das letztere spricht vor allem die Verwendung des Fremdwortes sanctus, das als liturgiesprachliches Element angesehen werden kann.

Fris II hebt sich von Fris I und III dadurch ab, daB in seinem christlichen Wortschatz der lateinische EinfluB verhältnismäBig am stärksten ist, und daB seine fremdsprachliche Abhängigkeit am geringsten ist. Jedoch muB dieses Ergebnis mit den in ihm verwendeten auf lateinische Muster zurückgehenden Umschreibungen zusammen gesehen werden.

Die Beantwortung der Frage nach dem Verhältnis des untersuchten Wortschatzes $z u$ dem übrigen Altslavisch ergibt fur die einzelnen Teile von Fris folgendes: Fris I und III enthalten im gleichen Maße nur einmal oder sehr selten verwendete worter, aber doppelt soviel im Vergleich mit Fris II. Die in Fris III vorkommenden hapax legomena unterscheiden sich von denen in Fris I dadurch, daB sie fast nur aus Lehnubersetzungen bestehen, wăhrend sich der gröbere Teil der hapax in Fris I aus Eigenbildungen zusammensetzt. In allen Teilen ist die lexikalische Gemeinsamkeit mit der mährisch-pannonischen literarischen Gruppe offensichtlich. Auch sind sie untereinander durch einige worter verbunden, die sie von der übrigen asl. Literatur unterscheiden: krbsts 'Christus', zъloděi 'Teufel' (wenn man von den 2 weiteren Belegen absieht), otbpustbks (das aber in II nicht vorkommt).

$O b$ sich in den dargelegten Ergebnissen irgendwelche Kriterien für das $A l t$ e $r$ des Denkmals und seiner einzelnen Teile erblicken lassen, oder ob die Isoliertheit des Wortschatzes auf e $t h n \circ g r a p h i s c h$ e Gegebenheiten zuruckzufuhren ist, 
läbt sich schwer entscheiden. Im allgemeinen gilt, das die einmalig oder selten vorkommenden wörter die frühsten Versuche darstellen, die neuen Inhalte auszudrücken. Aus welchen Gründen auch immer werden sie von geeigneteren Ausdrücken verdrăngt und haben daher nur ein kurzes Leben. Auf die andere, die erste in keiner Weise ausschlieBende Möglichkeit, kann im Rahmen dieser Arbeit nicht năher eingegangen werden, da das auBerhalb ihrer zielsetzung liegt. 
E. D i e ste l l ung des relligi o s e $n$

wortschatzes von Fris inder

a s l. christ 1 ichen s r a che

1. Die Verbreitung der wörter von Fris in der asl. Sprache

Die Frage nach dem Verhältnis des religiösen wortschatzes von Fris zu dem übrigen Asl. ist schon teilweise in dem vorangegangenen Kapitel behandélt worden. Dort war der Blick auf die Differenzierung der Fris - Teile gerichtet, hier soll in der nachfolgenden Zusammenfassung die Gesamtübersicht vermittelt werden. Wiederum läbt sich der untersuchte Wortschatz in Gruppen einteilen. Die erste machen die worter aus, die zu dem gemeinsamen neutralen Wortvorrat aller slavischen Sprachen gehören, die sowohl in der Bedeutung als auch in der phonetischen Gestalt weitgehend ubereinstimmen. Sie bilden auch in der christlichen Terminologie einen festen Bestandteil. Charakteristisch für sie ist, daB sie entweder keine anderen lexikalischen Varianten haben oder höchstens nur Wortbildungsvarianten. Dazu gehören: bogъ, du§a, grëchъ, nebo, otscb, synz, svętb, svętyi duchb, věra, kajati sq, modiiti se.

Weitaus zahlreicher ist die zweite Gruppe, die ebenso einen festen Bestandteil der asl. christlichen Sprache ausmacht, in der aber die ganze Vielfalt der Ausdrucksweise zum Vorschein kommt. sie sind mehr oder weniger gleich in der asl. Literatur verbreitet, und es lassen sich für sie verschieden viele synonyme in der asl. Sprache finden. Ihre Bedeutung (bzw. Verwendung) in Fris entspricht der in den anderen asl. Denkmälern. Zusammen - es sind 51 wörter - bilden die beiden Gruppen den großen Tell des religiösen Wortschatzes, den Fris mit dem des ubrigen Asl. gemeinsam hat. Die restlichen 29 machen den Teil des Wortschatzes aus, der Fris von den anderen asl. Denkmalern unterscheidet oder mit einigen von ihnen besonders verbindet. Im einzelnen sieht es folgendermaBen aus:

9 Worter gehören der mährisch-pannonischen Gruppe (MP) an. Ihre Verbreitung ist also auf die zu dieser Gruppe zahlenden Denkmäler beschränkt und darum relativ gering,

3 sind in der Bedeutung von Fris nur auf die Mp-Gruppe beschränkt; sie kommen nur vereinzelt in einigen von ihnen vor: zblodëi 'Teufel', ispovédb 'BuBsakrament', milostb 'Gnade'.

5 worter, die in der Bedeutung von Fris nirgendwo mehr anzu- 
treffen sind: věrbnikb 'Bekenner', pokaznb 'satisfactio', vrbchbnb 'summus' als Epitheton Gottes, synbkb 'filiolus', im Pl. als Anrede für christliche Gemeinde, zъloděinz 'des Teufels',

2 nur auf Fris beschränkte worter: sanctus, otbpustbkb,

2 in der Bedeutung von Fris nur noch in den Homilien von Kliment vorkommende Ausdrücke: imę 'Person', slava boxija 'Paradies', 8 hapax legomena, deren Besonderheiten schon oben besprochen wurden.

Der verhăltnismäBig hohe Anteil, 35,58 des religiósen Wortschatzes, der vom übrigen Asl. abweichenden worter weist auf eine aus dem Rahmen des überlieferten asl. Schrifttums herausfallende Ubersetzungstradition hin. Zugleich wird sie aber durch die MPworter $(11,58)$ mit dem măhrisch-pannonischen literarischen Schaffen deutlich verbunden.

\section{Vergleich der christlichen Terminologie von Fris mit der}

\section{übrigen asl. Ausdruckswetse}

Im Rahmen der vorliegenden Arbeit kann nur ein flüchtiger Einblick in die auBerhalb Fris stehende, in der religiósen Literatur beheimatete und reich überlieferte christliche Terminologie der asl. Sprache gewăhrt werden. Doch ist der Vergleich selbst mit dem spärlich zusammengetragenen lexikalischen Material lohnend (s.o. Tabelle I).

Zunächst ist die Vielfalt der Versuche, die neuen Begriffe in geeignete Worte zu kleiden, eindrucksvoll. Hierbei ist der Anteil der griech. Lehnworrter beachtlich; ferner fallen die vom Griechischen abhängigen Wortbildungen auf. Es bedürfte eingehender Untersuchung des asl. christlichen Wortschatzes, un die zum Vergleich angeführten lexikalischen Varianten lehngutmäBig zu klassifizieren. Manche Hilfe leistet dabei die Darstellung von SCHUMANN, auch wenn sie nicht erschöpfend ist $\left(\right.$ Schumann $\left._{2}\right)$. Danach können viele der aufgezăhlten Worter als Ergebnisse der griechisch-slavischen Ubersetzungstätigkeit gewertet werden.

Im Vergleich mit dem ubrigen christlichen wortschatz zeichnet sich die formale struktur des in Fris enthaltenen religiobsen Wortschatzes durch Einfachheit aus. Vielfach sind es Komposita und Derivate, die sich für die vorwiegend einfachen stammworter von Fris zum Austausch anbieten. In der folgenden Gegenüberstellung soll das verdeutlicht werden: 
In Fris verwendete Wörter

cistb

delo

gréchb

grěšnikb

ime 'Person'

ispověds

krbstb 'Taufe'

milostb

medenikz

moka

obẽtb

otzpustbkz

pomošts

posts

strastb

\section{Andere Bezeichnungen}

neporocsnz, bezblobsnz,

dětelb, délanije

sıgră̋enije, prěgrěrenije

bezakonbnikz, zakonoprestQpbniks

sobbstvije, sbstavb, sblitije

ispovědanije

krbrtenije

blagodatb

8 trastonosbcb, strastotrbpbcb

mprenije

obétovanije

otъpuðtenije, otъdanije,

ostavijenije

zastopljenije, chodataistvo,

załtiztenije

połtenije, alkanije

stradanije 


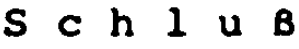 \\ Zusammenfassung aller Ergebnisse}

Die Untersuchung des religiösen Wortschatzes der Freisinger Denkmăler ergab, daB der gröbte und wichtigste Teil der christlichen Begriffe durch Umprägungen der schon vorhandenen worter ausgedrückt wurde. Die meisten Worter hat die Allgemeinsprache zur Verfügung gestellt. Zu gleichen Teilen sind auBerdem noch zwei Sprachbereiche wesentlich an dem religiösen Wortschatz beteiligt. der heidnisch-religiöse und der rechtliche. Das Rechtsdenken, das in der Wahl der Ausdrücke in Erscheinung tritt, steht im Vordergrund.

Die Umdeutung der Erbworter hat sich verschieden stark vollzogen; viele worter behielten neben der neuen, christlichen auch noch ihre ursprüngliche Bedeutung, andere wiederum haben den Sinngehalt völlig verändert, so dab ihre frühere Bedeutung nur noch rekonstruiert werden konnte.

Mehr als ein Drittel der religiösen Termini sind Neubildungen, in denen die fruchtbare Einwirkung des christentums auf die altslavische Sprache offenbar wird. Der geringe Anteil von Fremd- und Lehnwörtern unter ihnen gibt ein Zeugnis für die geistige Leistung der Ubersetzer. Unter den Lehnübersetzungen und -übertragungen befinden sich stammerwandte Ableitungen von Umprägungen, die zwar nach fremdem Vorbild geschehen, doch eine eigensprachliche Leistung darstellen, sie machen ein Drittel der Neubildungen aus; hier tritt die Produktivitat der christianisierten Wortstamme in Erscheinung.

In den Freisinger Denkmälern sind Bezeichnungen für fast alle christlichen Grundbegriffe enthalten; es zeigt sich, dab die meisten von ihnen mit den Ausdrücken des übrigen Altslavischen übereinstimmen. Zugleich werden in Fris seltene oder nur einmal vorkommende wörter gebraucht, bei denen es sich vorwiegend um Eigenbildungen handelt. Die Ausstrahlung dieser Neubildungen war sehr gering, meistens blieben sie einmalige Versuche ohne Nachahmung. Das dürte in erster Linie für das hohe Alter der Denkmăler sprechen; so gehören 2.B. die Lehnwörter für 'Engel' und 'Apostel' der späteren literarischen Tätigkeit an, da sie schon ein verănajertes Bewubtsein voraussetzen, wăhrend die dafür in Fris ver- 
wendeten Ausdrücke krilatbcb und bozi $\boldsymbol{s}_{\mathrm{b}} l_{\mathrm{b}}$ dem noch im Umdenken begriffenen BewuBtsein entsprechen.

Durch einige seltene Wörter von Fris, die in beschränkter $\mathrm{Zahl}$ auch in den mährisch-pannonischen Texten auftreten, lassen sich Spuren der Ubersetzungstradition der Freisinger Denkmäler in dem măhrisch-pannonischen Schaffen verfolgen. Ahnlich ist die Beziehung der Freisinger Denkmäler $z u$ den homiletischen Werken des hl. Kliment, der Ryler Blatter und der kroatisch-glagolitischen Benediktinerregel. 1

Die Analyse der fur die christlichen Begriffe verwendeten Ausdrücke hat ferner ergeben, daB sich alle fremdsprachlich beeinfluBten Wörter (etwa die Hälfte des gesamten religiösen Wortschatzes) aus dem Althochdeutschen und Lateinischen erklären lassen, zum Teil $m$ ü $s$ e $n$ sie sogar auf diese sprachen zurückgefürt werden. Wie aus der Tabelle IV ersichtlich, uberwiegt der althochdeutsche EinfluB (etwa die Hälfte der in Frage kommenden wörter). 2 Auch die Einwirkung der lateinischen Sprache ist beachtlich, besonders, wenn die auf lateinische literarische Muster zurückgehenden Umschreibungen in Betracht gezogen werden. Im Verhältnis zum Griechischen zeigt sich in vielen Fällen eine Parallelentwicklung, es gibt aber keine zwingenden Grüde, griechische sprachliche Vorbilder anzunehmen. Untersucht man dagegen die zum Vergleich herangezogenen Synonyme aus dem übrigen Altslavischen, so zelgt sich, daß dort häufig griechische literarische Entlehnungen auftreten oder solche Ausdrücke, die sich nur aus der griechischen Ubersetzungstätigkeit erklăren lassen.

zieht man einerseits die Tatsache des deutsch-lateinischen Einflusses auf den Wortschatz der Freisinger Denkmäler in Betracht (wobei deutsch uberwiegt), bedenkt andererseits, daB die meisten dort verwendeten Bezelchnungen fur christliche Begriffe den Grundstock des altslavischen christlichen wortschatzes uberhaupt dar-

1. Auf die lexikalischen Ubereinstimungen der Freisinger Denkwaler mit der kroatisch-glagolitischen Benediktinerregel wird in dem dafar bestimmten Exkurs der vorliegenden Arbeit ausfürlicher hingewiesen.

Uber den zwischen dem Wortschatz der Homilien des hl. Kliment und der Freisinger Denkmaler bestehenden Zusammenhang soll in einer spdteren Veroffentlichung berichtet werden.

Auf die lexikalischen und textlichen Gemeinsamkeiten der Ryler Blatter mit den Freisinger Denkwălern hat bereits I. Gošev in seiner edition: Rilski glagoliteski listove, Sofija 1956 (Folia glagolitica Rylensia = Ryl) hingewiesen.

2. Vgl. Fußnote 1. auf S. 116 der vorliegenden Arbeit. 
stellen, kommt man zu dem SchluB, daB die althochdeutsche Sprache einen wesentlichen Anteil an der Schaffung der slavischen christlichen Terminologie hat.

Die Untersuchung des religiösen Wortschatzes stellt nur einen Tellbeitrag zur Erforschung der gesamten Lexik der Freisinger Denkmäler dar. Er lst aber insofern von ausschlaggebender Bedeutung, als gerade im religiösen Wortschatz alle Sprachverănderungen konzentriert auftreten. Die durchgefuhrte Analyse hat die $\mathrm{U} n$ a b $h$ a $n g l g k$ e $1 t$ dieses Wortschatzes von dem $g$ r 1 e $h 1-$ $s c h e n$ literarischen Einflub erwiesen und hat zugleich annehmbare Gründe für das $h \circ h$ e $l t$ e des Denkmals gellefert. Beides weist auf eine von der Missionsarbeit Cyrills und Methods unabhängige Ubersetzungstradition hin. Dadurch wird ein wesentlicher Beitrag zur Diskussion uber den Begriff "Altslavisch" geliefert und die Bedeutung der Freisinger Denkmăler für die slavische Sprachgeschichte ausgewiesen. 


\section{Die Rechtswörter in den Freisinger Denkmälern}

Die Untersuchung der Umprăgungen, d.h. der wörter, die die Sprache aus eigenem, schon vorhandenem wortschatz für neue Inhalte zur Verfügung gestelit hat, ergab, daB es sich dabei zum groben Teil (22 von $80=27,58)$ um Ausdrücke handelt, die dem Rechtsbereich angehören. Diese Tatsache steht keineswegs isoliert da, im Gegenteil, sie stellt ein Glied in der Traditionskette von Ubertragungen der christlichen Verkündigung in die sprachen der missionierten völker; so stellte einmal die lateinische sprache ihren Rechtswortschatz zur Verfügung, so rezipierte die neue Lehre auch die althochdeutsche Sprache (Teeuwen 33: Tschirch 3 85: Tschirch, 145: Tschirch $282 \mathrm{ff.l}$. Worter, die in vorchristlicher germanischer zeit spezifische Rechtsausdrücke gewesen sind, wurden zur Bezelchnung christlicher Inhalte ubernommen. Es zeigt sich darin, das die Germanen, wie auch urtümliche völker überhaupt, keine wesentliche Trennung zwischen Recht und Religion kannten (Wesche 19, 20; Loening $14 \mathrm{ff.}$.). Die Sprache verrät, daB das Rechtsdenken und die Beobachtung altüberkommener Rechtsformen eine hervorragende Rolle bei den Germanen spielten.

Die Wiedergabe des Glaubensinhalts mit den Sprachmitteln, die im Dienste der Gerichtsbarkeit standen, stellt einerseits ein theologisch-hermeneutisches Problem dar: es erhebt sich die Frage, ob die Assoziationen, die dem rechtlichen wortschatz anhingen, den Glaubensinhalt entstellt oder gar verfalscht haben. Andererseits bringt die theologische Fragestellung manche wertvolle Anregung für den Wortforscher; das sprachwissenschaftliche Interesse, insbesondere das der historischen wortforschung richtet sich darauf, das sprachliche juridische substrat aus den überlieferten Texten herauszufinden.

Von der Tatsache ausgehend, dab worter des Rechtsberelches den neuen religiösen Begriffen substituiert wurden, daB also manche Rechtswörter im religiösen kleid uberliefert worden sind, wurde versucht, threr ursprünglichen Bedeutung nachzugehen und ihre Funktion im Rechtsleben $z u$ bestimen. Sie werden zusammenfassend aufgezăhlt: věra, milostb, milb se tvoriti (Ausdrücke, die der vorstrafrechtlichen Periode angehören), stolb, sqditi, sqdbnyi 
dbnb, pomortb, ispovědati se - ispovedeti, ispovedb, postb, pokaznb, pravbdbnz - nepravbdъnb, grĕchъ, sъgrěziti, obĕtb, въlъ.

Um wiederholungen $z u$ vermeiden, wird hier auf die Bedeutung der genannten worter nicht năher eingegangen; es darf vielmehr auf das in den einzelnen Wortuntersuchungen Gesagte verwiesen werden.

Darüber hinaus (auBerhalb des religiossen Wortschatzes) soll versucht werden, jenen Ausdrücken nachzugehen, die die Spuren he1mischer Rechtsgepflogenheiten erkennen lassen, die auf die altslavische Rechtspraxis (in welchem Raum?) bezogen werden können. Auf diesem Gebiet sind die zahlreichen Arbeiten von VASICA beispielgebend, der sich um der Erforschung der großmährisch-juridischen Terminologie verdient gemacht hat. 1 Sein Interesse galt nicht nur den Rechtsdenkmalern, wie die von ihm durchgefuhrte Rechtsanalyse der anonymen Homilie des Clozianus zeigt (Slavia 25, S. 221-233). Der Text von Fris, besonders Fris II stellt auch für einen rechtswissenschaftlich nicht gebildeten Beobachter eine Fundgrube auf die Rechtspraxis bezogener Ausdrücke dar.

In der BuBpredigt (Fris II) ist vom Jüngsten Gericht die Rede. Eindringlich wird den zuhorern das Gerichtsgeschehen vor Augen geführt. Von den 1rdischen Gegebenheiten ausgehend wird auf das Gericht Gottes verwiesen, Gott wird als oberster Richter vorgestellt. Der Glaube an ein Endgericht ist alt. Im AT weden die Funktionen der am Gericht Beteligten genau bestimmt. Die Vorstellung von Gott als Richter ist auch der Antike nicht fremd. ${ }^{2}$ Von den Kirchenvatern ist es Origines, der der Vorstellung des Weltgerichts sehr konkrete Formen verleiht. Er schreibt: "Wer mobchte daran zweifeln, daB es ein richtiges Gericht Gottes ist (von welchem Paulus im Römerbrief 2,15 spricht), wo Ankläger und Verteidiger und zeugen verwendet werden? ... Und dieses Gericht Gottes sollen wir Menschen uns zum Vorbild nehmen und nicht glauben, es könne ohne Ankläger, Verteldiger und zeugen jemals ein gerechtes Gericht geben (nec putemus unquam sine accusante, et defendente, et testi-

1. J. Vał̌ica, Metodéjúv płeklad nomokanonu, in: Slavia 24, 1955, S. 9-41, Anonymnl homilie rukopisu Clozova po strance právni, in: Slavia 25, 1956, s. 221-233, K lexiku Zakonu sudneho ljudem, in: SR 10, 1957, S. 61-66, Práni odkaz cyrilometodejsksy, in: slavia 32, 1963, S. 331-339; K otazce púvodu zakona sudného 1judem, in: Slavia 30, 1961, S. 1-19.

1. Vgl. Steinleitner, Die Beicht im Zusammenhange mit der sakralen Rechtspflege in der Antike $83 \mathrm{ff} ., 96,121$, 24 den altestamentlichen Vorstellungen vgl. BhH III,1674 unter 'Satan'. 
buss iustum haber posse iudicium)." (Grotz 275).

Der Autor von Fris II denkt ebenfalls sehr konkret; um die gewünschte wirkung zu erzielen, stellt er das Geschehen am Jüngsten Gerricht so dar, wie man es von der wirklichen Gerichtsbarkeit her kannnte. Der Vergleich dieser Darstellung mit der Schilderung des Recchtsgangs bei KADLEC ( $\mathrm{Kadlec}_{3} 132$ ), der sich auf germanische Recchtsquellen beruft und für die slaven ähnliche Verhältnisse anniammt, zeigt eine auffallende inhaltliche Ubereinstimmung. Dadurch lasssen sich die in Fris verwendeten worte in ihrer rechtssprachlichnen Bedeutung erkennen. Im folgenden sollen die betreffenden Stelleen der Predigt im Wortlaut zitiert werden. Des besseren Verständnissses wegen wird hierfür die Ubertragung der Fris - Textes in das geenormte Altslavisch von WEINGART benutzt (Weingart, 122-132).

66

$$
\text { ... i jesmb }
$$

bratrbja, pozbvani $i$ po-

běżeni, jegože ne možmb

nikyimb ze lica ni ukry-

$70 \underline{t i}$ nikakoze ubega-

ti, $n b j e(s t b)$ stati prědb

stolomb bozbjemb $8 \mathrm{~b}$

sqpbrbnikomb narimb,

sb ablodejemb staryimb.

$75 i$ jestz se prědb bozbi-

ma oxima vbsjako-

mu svoimi usty

$i$ svoimb glagolomb

79 ispovédati, ...

83 da kb tomu dbni, synbci, myslite, ide ne ka-

85 mo se ukloniti, $n \mathrm{~b}$

je prédb bozbima ozima

stati $i$ sbjQ prbjo imeti, ...

Die zur gerichtlichen Sprechweise zăhlenden worter sind untersttrichen. Davon sind stolb und ispovédati se schon im religiósen Woortschatz behandelt worden. Die Ubrigen sollen nun in den Grundfoormen aufgefuhrt werden. Die Angabe der Bedeutung und der Verweis auuf die stellen in den worterbüchern, an denen sie als Rechtsworteer ausgewiesen :werden, sind beigefugt. 
$p \circ z$ b $v$ a $t i$ pf. 'berufen, vorladen' (Srezn II,1085; Maruranić VII, 1067; Danitić II,341); 0 ze v m., klasti posvy na koho= pohănét $k$ soudu koho (Arch SCSI'; Jiređek HSSP 281-282); pozwat (Linde IV, 447): pozew (Linde IV,442).

$p \circ b \bar{e} d i t i$ pf. 'besiegen, zwingen'. Im Original steht $b$ bgeni, das AnlaB $z u$ verschiedenen Deutungen gab. 2 Es wird vorgeschlagen, pobijeni von inf. pobiti zu lesen, worauf noch năher eingegangen wird. MIKLOSICH (LP 581) gibt für $p \circ b i t i$ pf. die Bedeutungen ferire, occidere, ... an, DANICIC (II,321) occidere, evertere, beides nicht im rechtlichen sinne.

u $k r$ y $t i$ s \& pf. 'sich verbergen, sich verstecken'. Bei SREzNEVSKIJ ist die Form 8 bkryti se in der Bedeutung 'sich entfernen, flüchten, verbergen' (II,727).

$u b e ̀ g$ a $t i$ ipf. 'flüchten, weglaufen'. In LLP I, 156 ist das Wort bëgunz m. qui fugit iudicium aufgeführt. Es stammt aus einem rechtlichen Text, NomUst' 20a 13: jako da ne mbnitb sę pbri bĕgunb. $u k l \circ n i t i \& \&$ pf. 'sich entfernen, entgehen'.

$s \quad a t i$ ipf. 'vor Gericht erscheinen, sich stellen' (Srezn III, 506; Danicić III, 168; us $t \& n i e$ (Jirecek HSSP, 381)

$p r$ b $j \& i m$ e $t i$ ipf. 'einen Rechtsstreit halten' (Srezn III, 505-506; Sobolevskij, 74, Wortregister von Bes; Danicić II,277).

$\boldsymbol{s} \& p$ b $r$ b $n i k$ b. 'Widersacher, Ankläger vor Gericht' (Srezn III,626; supeŕ, supariz (Jirecek HSSP, 355).

Mit den angeführten wörtern ist es leicht, eine Beziehung zwischen den in der Predigt aufgezeichneten, das Jüngste Gericht begleitenden Umständen und den Erscheinungsformen der weltlichen Gerichtsbarkeit herzustellen.

Den Rechtsgang leitete der Kläger mit der Ladung des Beklagten ein; er muste sich mit zeugen in die Wohnung des Gegeners begeben, um ihn in rechtmäBiger Form vor Gericht $z u$ laden. Dieser Akt hieB

1. Die Belege für pozev stammen aus Osvęcim (polnisches Milieu), das entsprechende tschechische wort ist pohon, bei Jirexek HSSP 252.

2. Vostokov 31 liest bijeni von biti 'schlagen'; Vondrak, 73 hat pobezdeni 'incitati', so deutete das Wort auch Dobrovsky (Kopitar XIII-XLIV), so auch Grivec, 17. Pogalnik Glossar gibt wabljeni von wabiti 'invitare', 'vocare' = 'eintaden' an. 
bei den Franken *manjan, ahd. manón, latinisiert mannire, mannitio, admallare, admonere (Brunner II,1/2,443-444). Die Nordgermanen nannten die Ladung etefna, was heute mit 'stäbung' übersetzt wird, weil der Kläger mit dem $S t a b$ in der Hand sein Recht vom Gegner verlangte ( $\mathrm{Kadlec}_{3}$ 134). Im Verlauf der späteren Entwicklung nahmen die eigens dafür bestimmten Gerichtsboten die Ladungen vor (Kadlec $_{3}$ 135; Brunner II, 1/2,450). Auch diese trugen Stäbe, die zur Beglaubigung und zur Ubertragung der in ihnen versinnbildlichten Königsmacht dienten. 1 Diese Tatsache erscheint in Verbindung mit dem Wortlaut von Fris II als besonders wichtig. Es bietet sich an, das rätselhafte Wort $b$ bgeni als pobijoni von pobiti (bei Mikl LP 581 ferire, occidere) $z u$ lesen und auf 1 . s $t$ a b e $1 \mathrm{n}$ 'mit einem Stabe berühren' zurückzuführen (Grimm DW X, II Abtlg. 1,361), oder 2. Im Sinne von $s$ t $a$ b $e n$ 'mit einem stab schlagen, prügeln' $z u$ verstehen (Grimm DW X, II Abtlg. 1,367). Im ersten Falle würde das Wort pobiti = 'stäbeln' einer mit dem Akt der Ladung verbundenen formalen Handlung (Pauly-Wissowa 6,1904) Ausdruck verleihen. Es ist bekannt, daB das Gerichtsverfahren unter der Herrschaft des strengsten Formalismus stand, wobei es sich um eine "überhaupt für das Recht primitiver Kulturstufen charakteristische Erscheinung handelt" (Hoops RGA 2,162-163). "Die Parteien hatten alle ihnen obliegenden Handlungen persönlich vor zeugen und unter genauster Beobachtung bestimmter Wortformen, von entsprechenden symbolischen Handlungen begleitet, vorzunehmen." (Schröder 90). Indes sind bei weitem nicht alle Einzelheiten über das germanische Gerichtsverfahren überliefert (Kadlec 3 138; Schröder 90).

Bei der zweiten Deutung des Wortes pobiti könnte es sich um eine ideelle Verwendung des stabes handeln, wobei an ein symbolisches Schlagen an die Wand des Hauses des Beklagten gedacht werden müBte, 2 analog zum Schlagen an die Mauern der Stadt. Es kann aber auch an eine materielle handlung des Schlagens gedacht werden, wie z.B. für den Fall anzunehmen wäre, wenn der schuldige bei einem

1. Vgl. Grim RA II,380: "Ubrigens erscheint der gerichtsbote mit einem stab in der hand (wahrscheinlich einem langeren, als des Richters), wie alle boten stäbe tragen ...". Vgl. auch Grim DW X, II Abtlg. 1, 365: "auch boten und abgesandte tragen stäbe ... zugleich zur beglaubigung und zur ubertragung der in ihnen versinnbildlichten konigsmacht dienen."

2. Vgl. Grimm DW X, II Abtlg. 1,348: "der budell sull usgehen, und haben ein stab uns slagein ahn die mauern und rufen allen den ..." weisth. 2, 93 (v.j. 1463) 
schweren Vergehen vor dem Gericht $z u$ erscheinen sich weigerte. "Gewaltsam konnte in der Regel kein Freier vor Gericht gebracht werden, am wenigsten nach der ersten Ladung; ... Eine Ausnahme galt vermutlich bei Verbrechen, die schon das Altertum mit Todesstrafe belegte ..." (Grimm RA II,477).

Um der Ladung zu entgehen (ukloniti $8 \xi$ ) hatten sich die Schuldigen versucht $z u$ verstecken (ukryti $s k$ ), oder sie nahmen die Gerichtsboten gefangen, wobei es nicht selten zu Schlagereien kam. 1 Auch diese quellenmäBig bezeugte Tatsache könnte für die Deutung des b bgeni als pobijeni (auch) pobbjeni 'geschlagen' in Anspruch genommen werden. War der Gerichtstermin (sqdbnyi dbnb) mitgeteilt, der Beklagte geladen (pozbvani), so muBte er sich stellen (stati, bzw. stojati), vor dem Richterstuhl (stolb) erscheinen (Kadlec 137). Im wesentlichen spielte sich der ProzeB wie ein Kampf der Parteien (prbje iméti) ab; der Rechtsstreit (prbja) fand vor den Augen des Richters (prědz bożbima očima) statt (Schröder 91). Der Kläger, der "Widersacher" (sqpbrbnikb) trug seine Klage vor und forderte den Gegner zur Antwort auf; der Beklagte muBte ihm Wort für Wort (Schroder 91; Kadlec 3 139; Brunner II, 1/2,459) antworten ( $i$ jestb se... svoimi usty $i$ svoimb glagolomb ispovedati Fris II,75-79), wobei seine Antwort nur ein Bekennen oder ein Leugnen sein konnte.

Am Jüngsten Gericht übernimmt der Teufel die Rolle des Widersachers (8z zblodějemb staryimb). Diese Vorstellung geht auf das AT zurück, in dem nach weltlichen Vorbild ein Ankläger vor Gericht auftritt, der rechts vom Angeklagten stehend, seine Vergehen vor Gott aufzahlt (BhH III,1674). In dieser Funktion erscheint auch der Teufel, dem dann die Bezeichnung 'Satan' hebr. haşsâtān "der Verleumder" (Widersacher) zuteil wird. Damit sich der sündige Mensch, der als Angeklagter vor dem richtenden Gott stehen wird, vor seinem Widersacher, dem Teufel wirksam verteidigen $(s \& \ldots$ otb jego zavěštati Fris II,95-96) kann, hat Christus das Sakrament der BuBe eingesetzt (postavilb). Das läBt sich sinnvoll in den Rahmen des großen Gerichtsdramas einordnen, in dem die Rollen festgelegt sind und in dem Christus als Fürsprecher auftritt, der dem Beklagten hilft (BhH,550-551,504).

1. Vgl. Kadlec 137: "Zarówno w Czechach, jako też i w Polsce i na Rusi pozywani uciekali sie do róznych wybiegów, by zapobiedz urzędowemu ogroszeniu pozwu: ukrywali się przed woznymi urzędowymi, albo ich więzili, często bili czy to ich samych, czy tez ich urzędowych towarzyszy." 
"Das Jüngste Gericht und die sakramentale Beichte werden hăufig zueinander in Beziehung gesetzt" (Weisweiler 250). Wăhrend dort der Teufel als Kläger auftritt, Gott Richter ist, und der sündige Mensch als Angeklagter steht, ist hier (in der Beichte) der Sünder sein eigener Ankläger, sein Bekennen der wichtigste Akt des Prozesses, der dem ganzen den Namen gibt und ais Richter fungiert der Priester, der auch das Urteil spricht und Strafe auferlegt. 1 In Fris I,25-26 wird es so ausgedrückt: da bimb ... pokaznb vbzęlb jakoze ty mi zadejeri.

Darüber hinaus lassen sich noch weitere rechtssprachliche Ausdrücke nennen, die nicht in Beziehung zum Gerichtsgeschehen stehen. Im folgenden werden sie zusammen mit den zuletzt erwăhnten Wörtern, als Fortsetzung der begonnenen Aufstellung, in der gleichen Weise aufgeführt:

$p \circ 8 t a v i t i$ pf. 'einsetzen, bestimmen' (Srezn II, 1256-1258; DaniCí́ II, 382-384).

$z a d e ́ t i$ pf. 'auferlegen, bestimmen' (Srezn I,911; Danilić $I$, 355): zadati (LLP I,635; Mikl LP 209).

$z a v \check{e} \nsucceq$ $t a t i \quad s \&$ ipf. 'sich verteidigen'. S.o. unter zaglagolati $8 \varepsilon$.

$0 \quad b \quad l \quad a \quad s \quad t \quad b \quad f$. 'Macht, Herrschaft', 'Mach-, Herrschafts-, -bereich, -gebiet' (Srezn II,516-517; Jirecek HSSP 197: 1. potestas, 2. provincia; Danicić II,183-184).

$p \circ r q \check{c} a t i$ pf. 'übergeben, unter rechtlichen Schutz stellen' (Srezn II,1219; Daničić II,372-373; poruka, poručnik Jirecek HSSP 270,271: Mikl LP 632).

o $k l e v$ e $t$ a $t i$ pf. 'beschuldigen, verleumden, vor Gericht anzeigen' (Srezn II,641,642; Mikl LP 497).

$p r e x s q p a t i$ ipf. 'Ubertreten (das Gesetz)' (Srezn II,1699 1700; Daničić II,504; Mikl LP 746).

$r \circ t a$ f. 'Eid, Schwur' (Srezn III,176,177; Danilie III,56; Jirečk HSSP 316,317 ).

1. Vgl. Weisweiler 252: "Noch der Codex Iuris Canonici, Can. $880 \$ 1$ nennt den Priester in seiner Funktion als Beichtvater iudex." 
$t$ b $m$ b $n i c a$ f. 'Gefängnis' (Srezn III,1083; Mikl LP 1022; DaniCić III,336; Jirełek HSSP 368).

$t a t b b a$ f.. $t a t v a$ f.. $t a t$ b $b i n a$ f. 'Diebstahl, Raub' (auch das gestohlene Gut) (Srezn III,927,928; Danicić III, 278; Jirełek HSSP 367 ).

$r a z b o i$ m. 'Totschlag, Raubmord' (Srezn III,21; DaniEic III, 20: Jireðek HSSP 309).

Die wörter für 'Diebstahl' und 'Mord' gehören zum Sündenkatalog. Die Sündenbezeichnung geht parallel mit den Benennungen strafbarer Vergehen, und so ist der Wortschatz des Strafgesetzes dem der Bußbestimmungen gleich.

Von insgesamt 37 wörtern aus der Rechtssprache gehören 19 gleichzeitig dem religiösen Wortschatz an. Diese zahlen können jedoch keine absolute Geltung für sich beanspruchen, da es sich einerseits bei den zum religiösen Wortschatz gezăhlten wörtern zum Teil um bloBe Verwendungen der worter im religiösen Bereich handeln kann (z.B. wenn sqditi zur Bezeichnung der richterlichen Tätigkeit Gottes verwendet wird), andererseits hatten einige der nur als Rechtsausdrücke aufgeführten wörter (wie z.B. zadéti, postavi$t i$, oblastb, die im Dienste einer religiösen Aussage stehen) zum religiösen Wortschatz gezăhlt werden können. Der Mangel an sicheren Kriterien und ausreichendem Wortmaterial macht sich dabei empfindlich bemerkbar, die Einordnung der wörter muste daher weitgehend der subjektiven Beurteilung uberlassen bleiben.

Zu dem Begriff "Rechtswörter" (gelegentlich auch "Rechtsausdrücke") mus gesagt werden, daB damit nicht nur die juristische Terminologie im strengen sinne angesprochen wird, es gilt vielmehr, mit diesem Begriff alle mit dem Rechtsleben verknüpften Ausdrücke $z u$ erfassen. Damit dürte auch die diesem Exkurs zugrundeliegende Intention umrissen sein. 


\section{Freisinger Venkmäler und die kroatisch-glagolitische}

\section{Benediktinerregel. Ubereinstimmung im Wortgebrauch}

Bei der Untersuchung des Wortschatzes der Freisinger Denkmăler zeigte sich in mehreren Fällen eine auffallende Ubereinstimung mit der von A. PAVIC herausgegebenen, aus dem 14. Jh. stammenden kroatisch-glagolitischen Benediktinerregel (Regule sv. Benedikta, in: Starine VII,57-129). Die für die Benediktinerabtei in Rogova angefertigte Handschrift ist nach Ansicht von PAVIC keine Originalubersetzung des lateinischen Textes; es handelt sich um die Abschrift einer sehr viel älteren kroatischen Ubersetzung, die, nach dem Alter des Klosters zu urteilen, im 11. Jh. entstanden sein muB.

Die betreffenden stellen beider Texte werden original zitiert gegenübergestellt; falls notig werden auch die lat. Entsprechungen der Vorlage angegeben. Die zitate richten sich in der Reihenfolge nach dem Text der Benediktinerregel. Die Seitenzahlen beziehen sich auf die Ausgabe von PAVIC. 1

Benediktinerregel

73. vě̉ni ¿ivot'

ukloni se ot z'la

valjubiti

césarstvo

74. priemljurte

75. ugotovaite

77. na sudni dbnb

78. vanenavidé

79. duъe emu poruxenich'

(animarum sibi commissarum)

80. razumib samb

(tractet apud se)

82. z'lich' dělb ostaviti se

84. oblasti

95. nepriězni

98. mi esi na pomošt' bils
Freisinger Denkmäler

I.34 vuecBni Bivuot

II,84-85 necamoze vcloniti

II,34 uz liubiBe

II.63 zezarbtuo

II,3-4 neprigemzioki

I.35 ugotoulieno

I,31-32 nazodni den

II,33-34 uz nonauvideBBe

I.29 poronBo

II,29 Izami razumeti

II,17-18 OzBtanem zich mirzcih del

III,71 oblazti

II, 32-33/nepritannina

III,20 mirabite napomoki biti

1. Nach fast 100 Jahren gab Ivan ostojit den Regeltext in lat. Transskription in seinee dreibandigen Werk "Benediktinci u trvatskoj", Split 1963-1965 heraus. Gegenuber der ersten bedeutet die numehr vorliegende Edition einen Fortschritt. Fur obige Darstellung ist der Text von Pavic ausreichend. 
101. $i$ malomogus̆ti (et aegrotos)

116. i ot togo ovoego obeta

cini proßenbe $i$ po imenu

s vetacb, kichb $v^{\prime}$ onomb

oltari morti sutb

(De qua promissione sua

faciat petitionem ad nomen

Sanctorum, quorum reliquiae

Ibi sunt)

123. postavitb ego

(constituet eum)

124. klevete

125. starostb
II 48 malo mogoncka

II,38I obeti nas8e

III, 19 Iuseh 8 moki

II, 21 oclevuetam

II, 3 BtaroBti

In der obigen Aufstellung sind nicht alle lexikalischen Gemeinsamkeiten der beiden Texte erfaBt, da sich dieser Exkurs sewuBt darauf beschränkt, lediglich einen Hinweis zu liefern. 1

AuBer diesen, hier dargestellten, wurden lexikalische Ubereinstimmungen auch in den ubrigen kroatisch-glagolitischen Schriften festgestellt. Eine eingehende Untersuchung dieser Beziehungen könnte vielleicht zu der Lbsung der immer noch ungeklärten Heimatfrage der Freisinger Denkmäler beitragen. In der vorliegenden Arbeit konnte auf dieses problem nicht năher eingegangen werden, da ihr Hauptinteresse sich nicht auf die Wortgeographie richtet.

1. Dieses Thema wurde von der Verfasserin in einem besonderen Aufsat: behandelt, der im Rahmen der Veroffentlichungen "Regulae Benedicti Studia", larburg/L. - Rochefort 1974 erscheinen wird. 
Alphabetisches Verzeichnis der untersuchten Wörter.

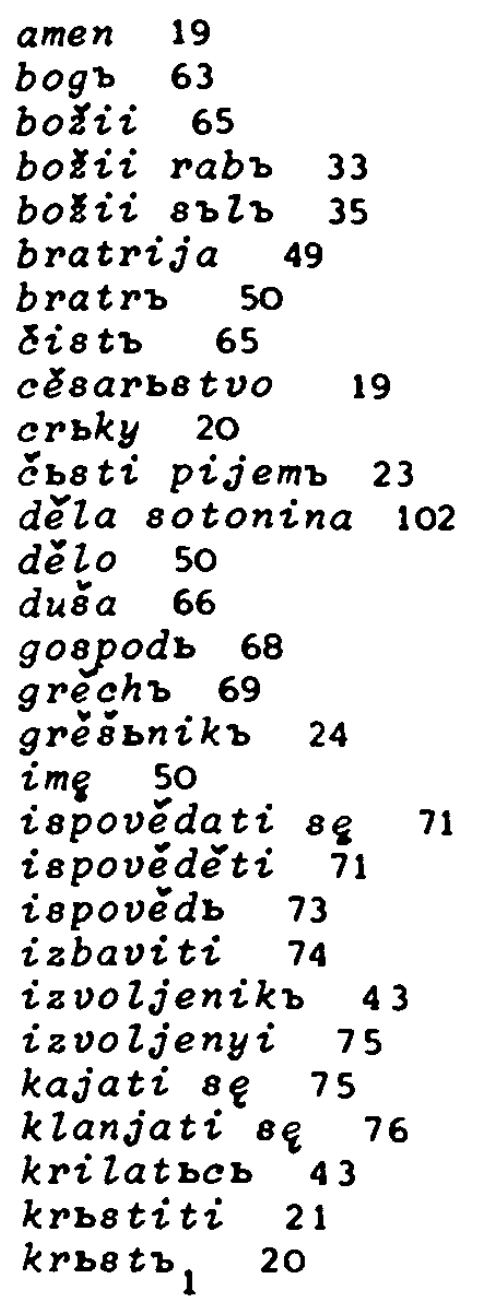

(se) abdicare 32

abrenuntiare 32

absolutio 73

absolvo 73

amicitia 53

amicus 53

angelus 45

anima 66

animadvertere 75

animus 66

antiquus hostis 103

auxilium 89

beatus 57

benevolentia 5377

benignitas 77

caesar 19

castus 66

certus 66

claritas 38

clementia 77

coelum 86

commiseratio 77

compassio 77

compunctio 55

condere 60

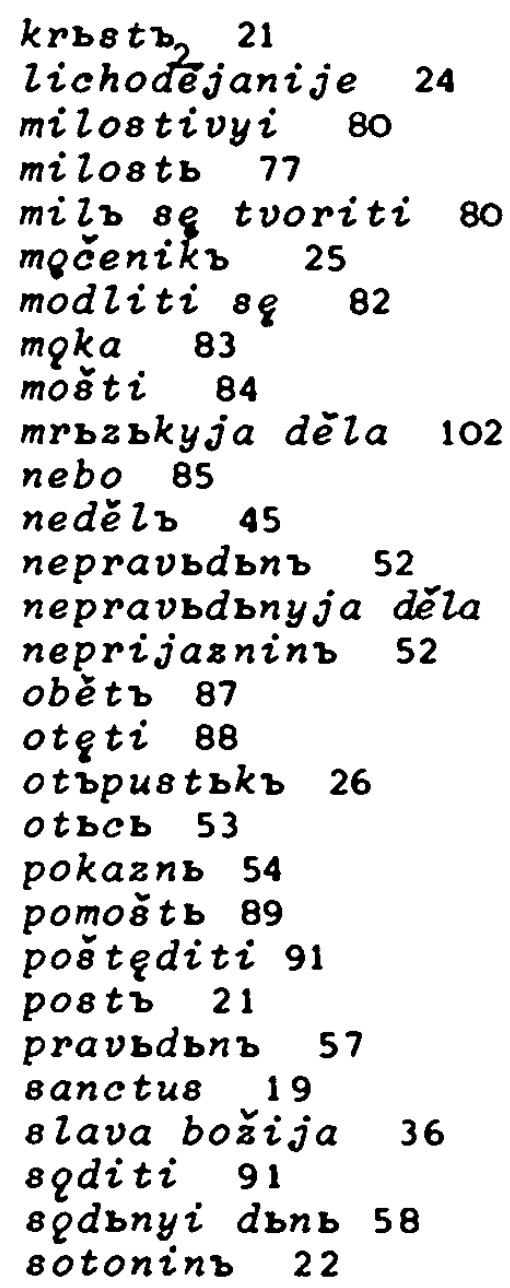

Lateinisches Wortregister

$\begin{array}{lllll}\text { confessio } & 55 & 73 & 76 \\ \text { confessor } & 24 & 47 & 48 \\ \text { confiteri } 24 & 70 & 71 & \\ \text { conservare } 96 & & & \\ \text { contritio } & 55 & 73 & 75 & 76 \\ \text { creare } 24 & 60 & & & \\ \text { creatio ex } & \text { nihilo } & 59 \\ \text { creator } 24 & 60 & & \\ \text { creatura } 60 & & & \\ \text { credere } 96 & & & \\ \text { crimina publica } & 56 \\ \text { cruciari } 92 & & \\ \text { cruciatus } 92 & & \\ \text { culpa } 70 & & & \\ \text { custodiare } 96 & & \\ \text { daemonium } 100 & & \\ \text { defendere } 32 & & \\ \text { demere } 89 & & & \\ \text { delictum } 24 & 70 & & \\ \text { delinquere } 24 & & \\ \text { deus } 68 & & & \\ \text { dies iudicil } 58 & & \\ \text { dominus } 68 & & & \\ \text { electus (dei) } & 43 & 57 & 75 \\ \text { eripere } 74 & 88 & 89\end{array}$

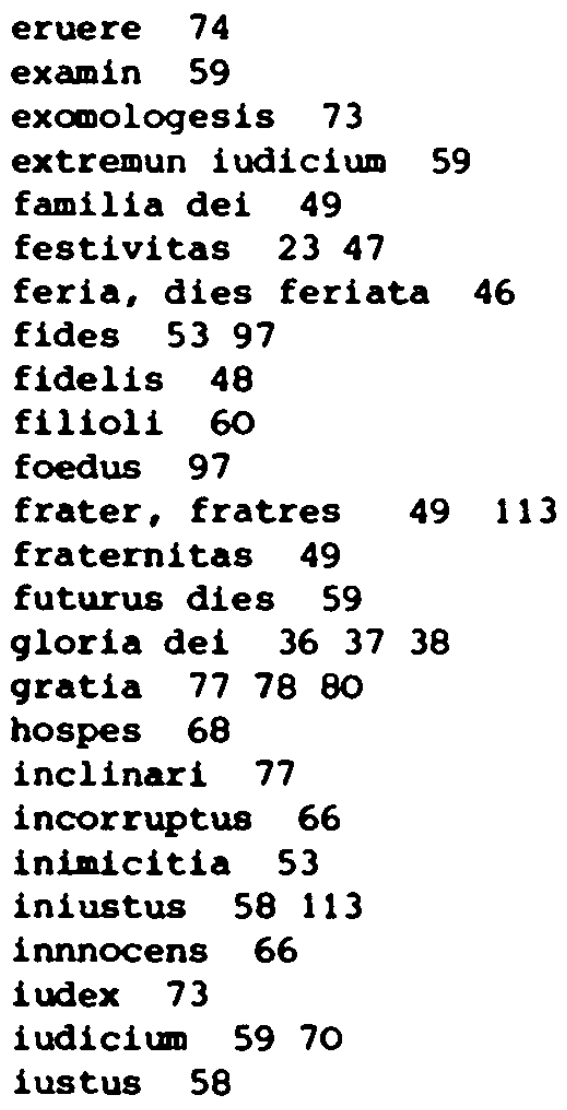




lamentari 75
largitas 77
legatio 36
legatus 36
lex dei 41
liber leges continens 42
liberare 74
maiestas 38
malefactor 99
malignus 53
malus 53
martyr 48
misereri 91
misericordia $77 \quad 7880$
mundus 66
munus 87
natalitia 23
nebula 85
nuntius 3645
omnipotens 31
opinio 39
opera bona 50
opera diaboli 102
opera misericordiae 50
opera satanae 50102
opus 50113
parcere 91
pasco 92
pater 5468
pati 92
passio 25838492
pax 4973

peccare 69

peccator 24

perfidia 97

persona 5051

pietas 77

poena 55

poenitentia 5573

poenitentiam agere 75

poenitere 5575

potestas diaboli 102

princeps 61

privilegium 79

pronis vultibus adorare 76

proximus 4950

purgatus 66

purus 66

raptus mulieris 89

reconciliatio 73

redemptor 28

redimere 749293

regeneratio 49

rei possessor 68

regnum coelorum 86

reliquiae 84

remissio 26

renuntiare 32

res creata 60

(re-) surgere 61

sacer 66

sacerdos 41

sacrificium 87

salus 93 salvare 2692

salvator 2693

sanctus $1995 \quad 112 \quad 124$

satisfactio $55 \quad 5673 \quad 76$

secunda nativitas 49

securus 66

sedes 39

servare 929395

servus dei 34

simplex 66

solemnitas 2347

spiritus sanctus 29

sponsio 88

summus $61 \quad 113124$

supplex 81

supplicare 81

supplicem esse 81

supplicium 81

testamentum 88

thronus 3940

treuga 96

tribunal 40

venerabilis 66

venia 77

verus 66

vesper 47

vindicare 9394

vita aeterna 30

vitia 102

vocare 132

votum 8788

Griechisches Wortregister

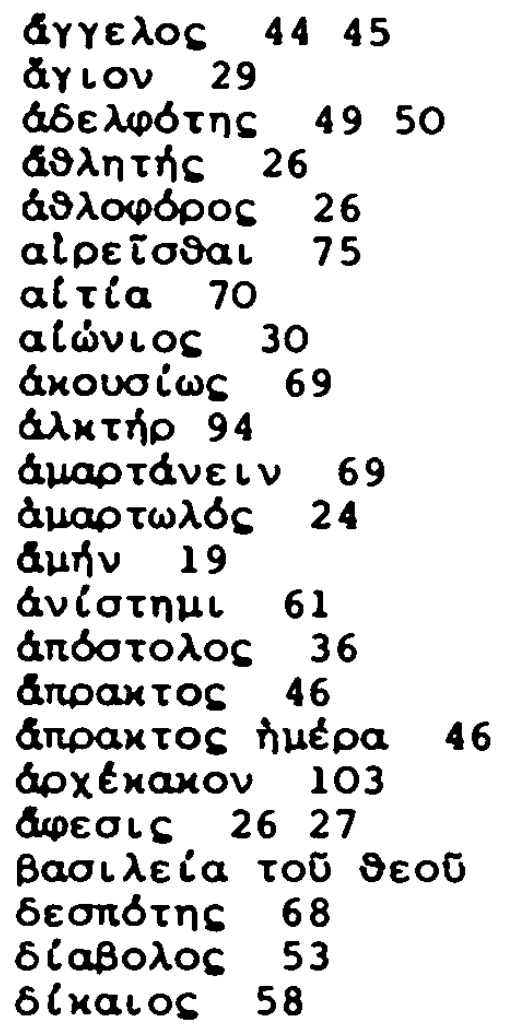

Sเxaเooúun 57

6ठEA 38

ठठEૂ TOŨ ЭEOU $36 \quad 37$

ธOU์

SUUdHEเS 84

EYEipW 61

EגEOS 7880

EEOHOגOYEโV 71

EEOHOגornoLs 7173

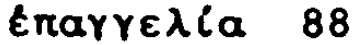

EாเTLนLA 55

Eprov 50

Eoxh 88

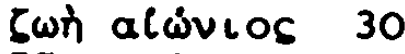

కकov 30

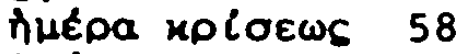

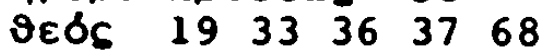

opóvos 4041

Opovios 6రEns 40

19 xaxia 75

xaxotrolos 99

xaxoupyos 99

kolua 70 xplais 59

$x<i \zeta \omega \quad 59$

xuplaxbv 2046

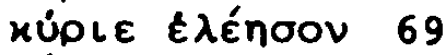

xúplOS 68

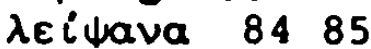

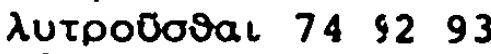

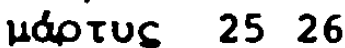

Heoitns 90

Hetdvola 55 i3 76

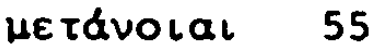

He taVoEโV 55 i5

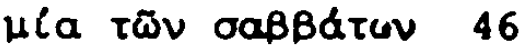

ठHoגorew 72

ठHOגOYOULEVWS 72

oठxeló́s 69

olpavoi 86

róonua 84

rdoos 8492

maĩs 60

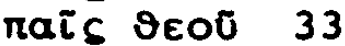

raviokpatLxós 31

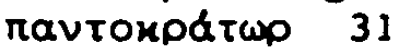




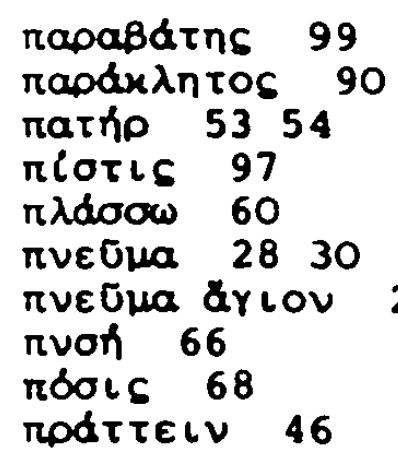

mapabdins 99

rapdxintos 90

matho 5354

riorts 97

$\pi \lambda d \sigma o w ~ 60$

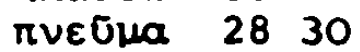

TVEUนLa ärLOV

rvơ 66

rools 68

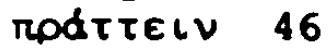

TOEOBUS 36

TOOOKUVETV 82

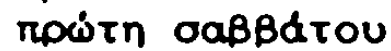

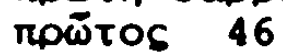

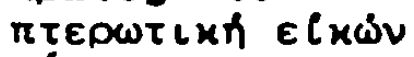

oábBatov 46

oatavăs 22100

O\$LELV 277492

oẃlata 84

owtho 2728 owrnpla 2893

पeloeoral 91

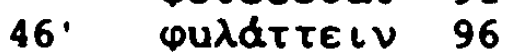

Xdols 7779

44 XpLOTós 20

xpiw 69

$x \rho \dot{\phi} 5 \omega \quad 69$

ฟuxh 6768

\section{Althochdeutsches Wortregister}

\begin{tabular}{|c|c|c|}
\hline abantlob & & gotes drata \\
\hline ablâz & & gotes drutthegana \\
\hline alles uual tando & 31 & gotes friunt \\
\hline lmahtIg & & gotes holden \\
\hline htsagen & & gotes mann \\
\hline archaufan 7492 & & gotes sedale \\
\hline arlosan & & gotes scalh \\
\hline armaherzi 80 & & haer \\
\hline armiherzida 80 & & haltan 9272892 \\
\hline arstan 61113 & & haltari 2793 \\
\hline ar-standan 61 & & harmscara $54 \quad 56113$ \\
\hline atto 54116 & & heilag 95 \\
\hline oiginta 56 & 72 & himil, himila 8687 \\
\hline oijehan 71 & 12 & hohisto 116 \\
\hline $\begin{array}{l}\text { bruder, brudera } \\
\text { buozza } 56\end{array}$ & 49116 & $\begin{array}{ll}\text { hriuwan } & 75 \\
\text { intsagen } & 32\end{array}$ \\
\hline êwarto 4142 & & koufan 7492 \\
\hline $\begin{array}{l}\text { ewig lib } 30 \\
\text { ewin, ewinig } 30\end{array}$ & & $\begin{array}{l}\text { kristen, kristenen } \\
\text { martaron } 25\end{array}$ \\
\hline farsagen 32 & & martyr 25 \\
\hline fasto & & martyra 83 \\
\hline firsagên 32 & & martyrunga 83 \\
\hline (sih) fersprehhan & 32 & miltida \\
\hline (sih) firsprehhan & 32 & minne trinkan 23 \\
\hline forsagên 32 & & missetat1 2425 \\
\hline ganada & & namo 5051113 \\
\hline enennida 51 & & nebul 85 \\
\hline gihaltnissi 93 & & reht $56 \quad 58116$ \\
\hline gotedeht 95 & & reht weinon 56 \\
\hline Eelih 95 & & riuun 75 \\
\hline tes boto 35 & & Iva \\
\hline
\end{tabular}

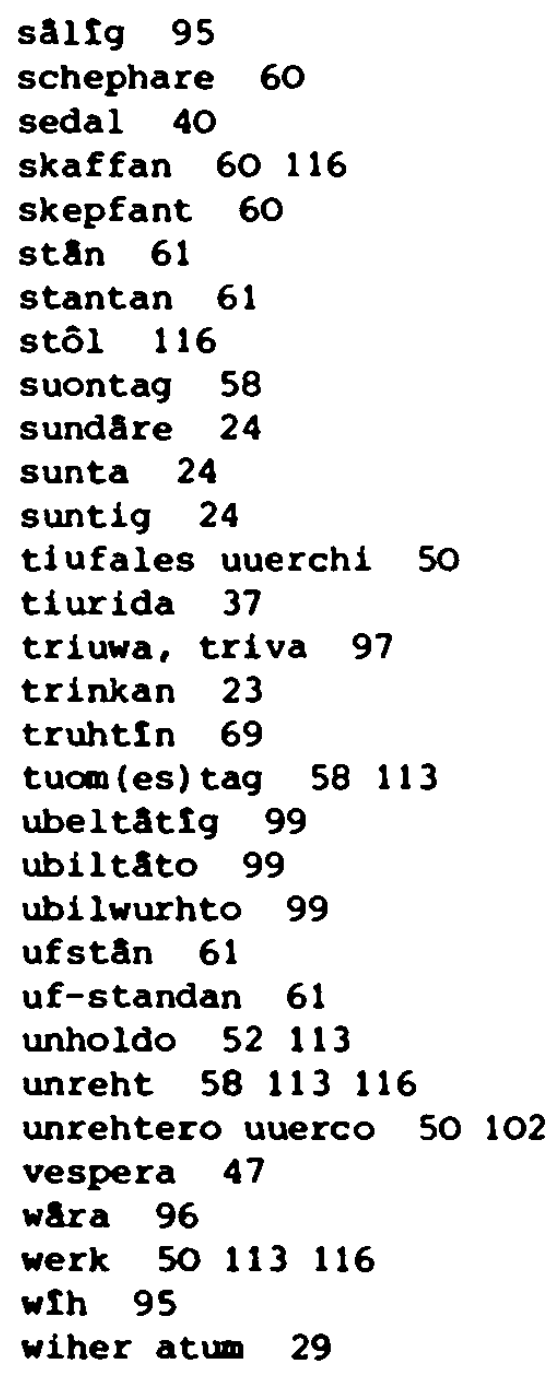




\section{A b k u r z u n g e n}

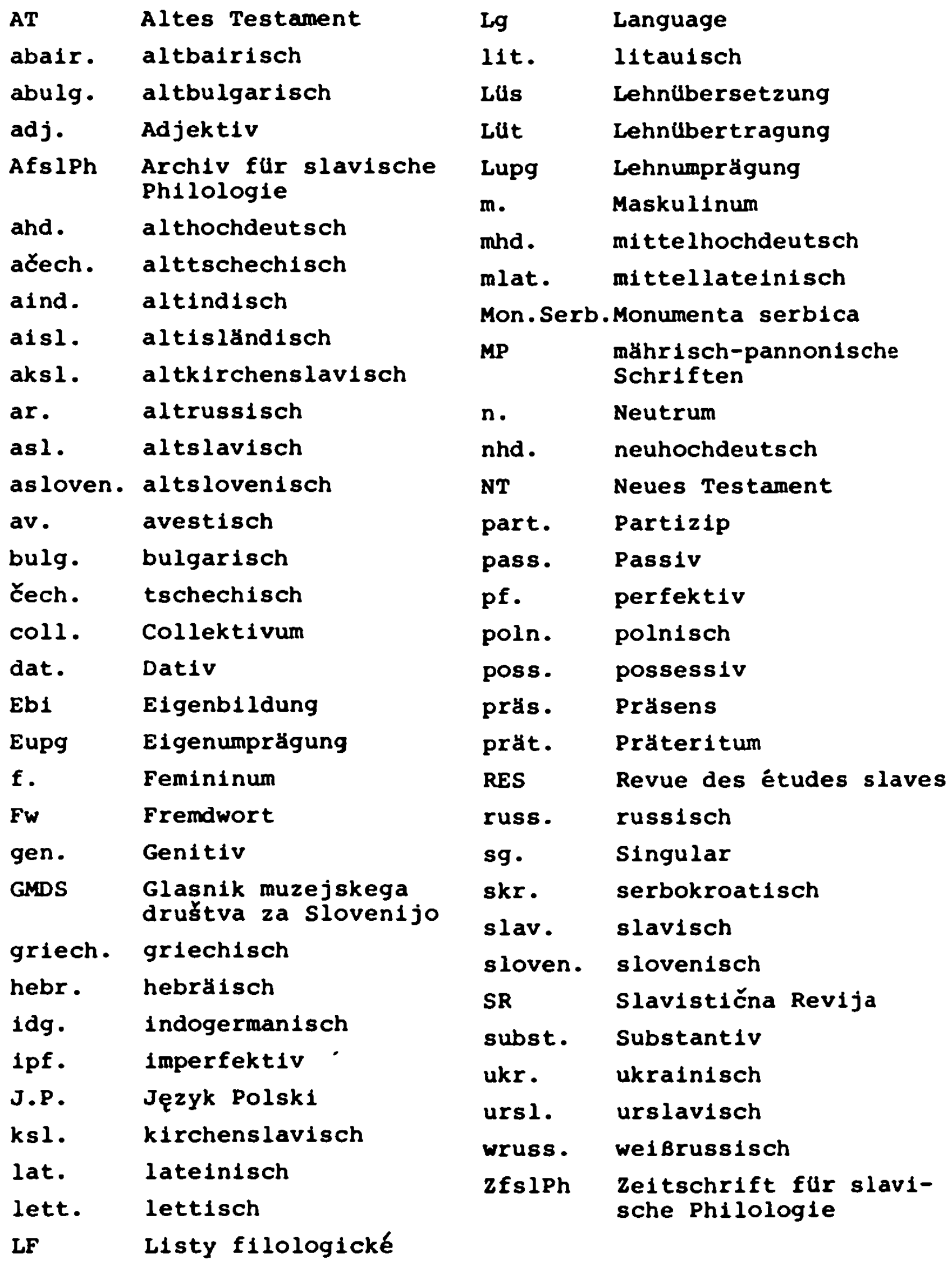

Für die asl. Texte wurden die Abkürzungen des "Lexicon linguae palaeoslovenicae" (LLP) Ubernommen. 
L 1 t e r a t u r e r z e ich $\mathrm{n} i \mathrm{~s}$

\section{A. Slavische Texte}

Bes = Gregoril Magni papae Homiliae in evangelia (Besedy na evangelije papy Grigorija Velikago). Edition in Vorbereitung, im Besitz der CSAV, Prag.

CanMis = Canon missalis croatico-glagolatici Vaticani (Illirico 4).

Ed. J. Vajs, Najstariji hrvatskoglagolski misal, Zagreb 1948 . clem $=$ Sermo de translatione reliquiarum s. Clementis (Legenda

Chers.), Ed. J. Vałica, Slovo na prĕnesenije mołtem prěslavnago Klimenta neboli legenda Chersońska, Acta Academiae Velehradensis 19, 1948, 38-80.

Cloz = Glagolita Clozianus, codex glagoliticus saec. XI. Ed. A.

Dostál, Pragae 1959. Darín die Anonyme Homilie (AH) 1b 21-3a 20. Dijav = Oratio contra diabolum. Ed. A.I. Sobolevskij, Materialy 1 issledovanija $v$ oblasti slavjanskoj filologii $i$ archeologii, Sankt-Peterburg 1910, 41-45.

Euch = Euchologium Sinaiticum. Ed. R. Nahtigal, Euchologium Sinaiticum, starocerkvenoslovanski glagolski spomenik, I-II, Ljubljana 1941-1942. Darín 1. Cinz nadb ispoveda(jQ) štilimb sę 66b$80 a$ (S. 177-244): 2. Zapovedi s(vę) tychb o(tb) cb 102a 5-105b 25 (S. 319-330).

Fris = Fragmenta Frisingensia. Ed. F. Ramovక - M. Kos, Brizinski spomeniki, Ljubljana 1937.

Kij = Folia Kijevensia. Ed. V. Jagí́, Glagolitica, Wien 1890. Klim = Homilie des hl. Kliment. Ed. F. Miklosich, PouCenije na pamjatb apostola 111 mucenika, Die christliche Terminologie der slavischen Sprachen, Wien $1876,3-6$. (Klim ist eigene Abkurzung und nicht identisch mit Klim des LLP)

Molitva ispovědaniju grěchovъ. Ed. A.I. Sobolevskij, Izvestija otd. russk. jaz. 1 slov. T.10, Kn.4, 1905, 74-76.

Mon.Serb. = Monumenta Serbica. Ed. F. Miklosich, Wien 1859 . Muðenije papy Stefana. Ed. A.I. Sobolevsk1j, Sankt-Peterburg 1905. MuXenije sv. Apolinarija. Ed. A. Sobolevskij, Izvestija otd. russk. jaz. i slov. T.8, Kn.2, 1903, 106-118. Nejstarł̧ brevisf chrvatsko-hlaholský (prứ breviár vrbnický). Ed. J. Vajs, Prag 1910. Nicod = Evangelium Nicodemi. Ed. L'. Stojanović, Nekoliko rukopisa $1 z$ Becke carske biblioteke, Glasnik srpskoga učenog drułtva, 
kn. 63, Beograd 1885, 89-120.

Nom = Methodil Nomocanon (Ustjuzskaja kormCaja). Edition in Vorbereitung, im Besitz der CSAV, Prag.

PouXenije na pamjatb sv. Ap. Marka. Ed. A.Ch. Vostokov, Grammati-

Ceskija ob"jasnenija na tri stat'i Frejzingenskoj rukopisi in: Filologi Ceskija nabljudenija A.Ch. Vostokova. Izd. I.I. Sreznevskij, Sankt-Peterburg 1865, 2-4.

Prag = Fragmenta Pragensia. Ed. V. Vondrák, 0 pưvodu Kijevských

listú a Prazských zlomků .... Praha 1904, 87-90, 105-110.

Regule sv. Benedikta. Ed. Armin Pavić, Starine, kn. VII, Zagreb

$1875,57-129$.

Ryl = Folia glagolitica Rylensia. Ed. I. Gošev, Rilski glagoliłeski listove, Sofija 1956.

Sinsluz = Fragmentum liturgiarii (sluzebnik) sinaiticum. Ed. R. Nahtigal, Razprave II, Ljubljana 1925, 272-278.

Slovo bolęztichb radi. Ed. A.I. Sobolevskij, Materialy $i$ issledovanija v oblasti slavjanskoj filologii 1 archeologii, SanktPeterburg 1910, 100-103.

Sud = Lex iudicalis de laicis (Zakon sudnyj ljudem), (Ustjuzskaja korm (aja). Edition in Vorbereitung, im Besitz der CSAV, Prag. Supr = Codex Suprasliensis, Ed. S. Sever'janov, Suprasl'skaja rukopis', Sankt-Peterburg 1904. Darin die 40. Homilie: Slovo svętaago Epifanija ... 447 28 -47112, 447-471.

Syntagma XIV titulorum ... Ed. V.N. BeneSevic, Drevne-slavjanskaja kormaaja XIV titulov bez tolkovanij, tom I, Sankt-Peterburg 1906.

Trin = Oratio ad s. Trinitatem. Ed. A.I. Sobolevskij, Materialy 1 issledovanija $v$ oblasti slavjanskoj filologii 1 archeologii, Sankt-Peterburg 1910, 45-47.

Venc $=$ Vita palaeoslovenica $s$. Venceslai antiquior. Ed. J. Vajs. SbornÍk staroslovanských literárních památek o sv. václavu a sv. Lidmile, Praha 1929.

Vind = Fragmenta Vindobonensia. Ed. V. Jagić, Glagolitica, Wien 1890, in: Denkschriften d. k. Akademie d. Wissenschaften, Bd. $38,10-14$. 


\section{B. Althochdeutsche und lateinische Texte}

Biblia Sacra iuxta vulgatam clementinam, denuo ediderunt complures Scripturae Sacrae Professores Facultatis theologicae Parisiensis et Seminarii Sancti Sulpitii, Romae - Tornaci - Parisis 1956.

Die lateinischen Pönitentialbücher der Angelsachsen, Hrsg. Friedrich Kunstmann, Mainz 1844.

Eine lateinische Musterpredigt aus der Zeit Karls des Groben. Hrsg. Wilhelm Scherer, in: Zeitschrift für das Altertum 12, Wien $1865,436-446$.

Steinmeyer $=$ Die kleineren althochdeutschen Sprachdenkmäler. Hrsg. Elias von Steinmeyer, Berlin 1916.

\section{c. Wörterbücher, Nachschlagewerke}

Arch LLP = Belegmaterial aus dem Archiv der Redaktion des Lexikon linguae palaeoslovenicae = slovnik jazyka staroslověnského, Prag.

Arch SČl = Belegmaterial aus dem Archiv der Redaktion des StaroCeský slovnik, Prag.

Bauer = Griechisch-deutsches worterbuch $2 u$ den Schriften des

Neuen Testaments und der übrigen urchristlichen Literatur von Walter Bauer, 5. Aufl., Berlin 1958.

Berneker = Erich Berneker, Slavisches etymologisches Wörterbuch,

2. Aufl., Heidelberg 1924.

Berynda = Leksikon slavenorosskij ... Pamvy Beryndy, Kyjiv 1627. $\mathrm{BhH}=\mathrm{Biblisch-historisches} \mathrm{Handwörterbuch,} \mathrm{hrsg.} \mathrm{von} \mathrm{Bo} \mathrm{Reicke}$ und Leonhard Rost, 3 Bde, Gottingen 1966.

BthW = Bibeltheologisches Worterbuch, hrsg. von Johannes Bauer,

3. Aufl., 2 Bde, Graz - Wien - Koln 1967.

Brückner SEJP = Aleksander Brückner, slownik etymologiczny języka polskiego, Kraków - Warszawa 1927.

Du Cange $=c$. Du Cange, Glossarium mediae et infimae latinitatis ... cum suppl. digessit G.A.L. Henschel. Editio nova a Leopold Favre, 9 Bde, N1ort 1883-1887.

Dal' = Vladimir Dal', Tolkovyj slovar' Zivogo velikorusskago jazyka, 3.Aufl., 4 Bde, Moskva 1903.

Danitić = Djuro DaniCić, Rjęnik iz književnih starina srpskih,

3 Bde, Belgrad 1863-1864 (Photomechanischer Nachdruck Graz 1962). 
Feist = sigmund Feist, Vergleichendes wörterbuch der gotischen Sprache, 3. Aufl., Leiden 1939.

Fick = August Fick, Vergleichendes worterbuch der indogermanischen Sprachen, 2. Aufl., 2 Bde, Göttingen 1870.

Fraenkel = Ernst Fraenkel, Litauisches etymologisches worterbuch,

2 Bde, Heidelberg 1955-1962.

Frisk = Hljamar Frisk, Griechisches etymologisches Wörterbuch,

2 Bde, Heidelberg 1960-1970.

Gebauer = Jan Gebauer, slovnlk staročesky, Dil I. (A-J), Dil II.

$(\mathrm{K}-\mathrm{N})$, Praha 1903-1916.

Georges = Heinrich Georges, Ausfuhrliches lateinisch-deutsches

Handwörterbuch, 2 Bde, 11. Aufl., Hannover 1962.

Graff = Eberhard Graff, Althochdeutscher Sprachschatz oder wörterbuch der ahd. Sprache, 6 Bde mit Index von H.F. MaBmann, Berlin 1834-1846.

Grimm DW = Jacob und Wilhelm Grimm, Deutsches Wörterbuch, Leipzig $1854 \mathrm{ff}$.

Holub - Kopečný = Josef Holub - Frantiłek Kopečný, Etymologický

slovnlk jazyka českého, Praha 1952.

Hoops RGA = Johannes Hoops, Reallexikon der germanischen Alter-

tumskunde, 4 Bde, StraBburg 1911-1919.

HthG = Handbuch theologischer Grundbegriffe, hrsg. von Heinrich

Fries, 2 Bde, München 1962-1963.

Jireček HSSP = Hermenegild Jireček, - Prove - Historický slovar slovanského práva, Praha - Brno 1904.

Jungmann $=\mathrm{J}$. Jungmann, Slovnlk česko-nemecký, 4 Bde, Praha

1835-1839.

Kluge = Friedrich Kluge, Etymologisches worterbuch der deutschen

Sprache, 17. Aufl., bearbeitet von Walter Mitzka, Berlin 1957. Kuzela - Rudnyćkyj = Zeno Kuzela - Jaroslau Rudnyćkyj, Ukrainischdeutsches worterbuch, Leipzig 1943.

Liddell - Scott $=H$. Liddel and R. Scott, A Greek-English Lexicon. New Edition Oxford 1953.

LLP = slovník jazyka staroslověnského, Lexicon linguae palaeoslovenicae, hrsg. von Josef Kurz, Bd. I. und II. bis

'nasytiti', Praha 1958 ff.

Lexer $=$ Mathias Lexer, Mittelhochdeutsches Handworterbuch, 3 Bde, Leipzig 1872-1878.

LThK = Lexikon für Theologie und Kirche, begr. von Michael Buch- 
berger, hrsg. von Josef Höfer und Karl Rahner, 10 Bde + Reg. Bd., 2. Aufl. Freiburg/Br 1957.

Linde $=$ S.B. Linde, Slownik jezyka polskiego,I-IV, 2. Aufl.,

Lwów 1854-1860.

Machek = Václav Machek, Etymologický slovnik jazyka českého a slovenského, Praha 1957.

Mažuranić = vladimir Mažuranić, Prinosi za hrvatski pravnopovjestni rječnik, (A-sagnuti), Zagreb 1908-1919.

Meyer $A W=$ Karl H. Meyer, Altkirchenslavisch-griechisches worter-

buch des Codex Suprasliensis, Glückstadt und Hamburg 1935.

Mikl EW = Franz Miklosich, Etymologisches Wörterbuch der slavi-

schen Sprachen, Wien 1886.

Mikl LP = Franz Miklosich, Lexicon palaeoslovenico-graeco-latinum, Vindobonae 1862-1865.

Pauly - Wissowa = C. Pauly - G. Wissowa, u.a., Realenzyklopädie

der klassischen Altertumswissenschaft, Stuttgart $1892 \mathrm{ff}$.

Pleteršnik = M. Pleteršnik, slovensko-nemški slovar, 2 Bde,

Ljubljana 1894-1895.

Pokorny = Julius Pokorny, Indogermanisches etymologisches worterbuch, 2 Bde, Bern - München 1959.

Preobraženskij = A.G. Preobraženskij, EtymologiČeskij slovar'

russkogo jazyka, Moskva 1910-1914.

Rudnyćkyj = Jaroslav B. Rudnyćkyj, An Etymological Dictionary

of the Ukrainian Language, vol. I, $I_{2}$ ff. (dzerkalo),

winnipeg 1962-1974.

Sad-Aitz = L. Sadnik und R. Aitzetmüller, Handwörterbuch $z u$ den altkirchenslavischen Texten, Heidelberg 1955.

Schmoller = Alfred Schmoller, Handkonkordanz zum griechischen

Neuen Testament, 9. Aufl., unveränderter Abdruck der erwei-

terten 7. Aufl., Stuttgart 1951.

Schrader $=0$. Schrader, Reallexikon der indg. Altertumskunde,

2. Aufl. hrsg. von A. Nehring, Berlin 1917-1929.

Schulze GG = Ernst Schulze, Gothisches Glossar, Magdeburg 1848 . Schützeichel = Rudolf Schützeichel, Althochdeutsches worterbuch, Tübingen 1969.

Siebenschein = Hugo Siebenschein, Česko-německÝ slovnlk, 2 Bde,

Praha 1968; Německo-Český slovnlk, 2 Bde, Praha 1970.

sSS = Slownik starożytności slowiańskich, Mrsg. Wladyslaw 
Kowalenko, Gerard Labuda, Tadeusz Lehr-Splawifski u.a. Bd. I. ff., Wroclaw - Warszawa - Kraków 1961 ff.

Slawski SIE = Franciszek slawski, slownik etymologiczny języka polskiego, Bd. I. ff. bis ' $k$ ', Kraków 1952-1969 ff.

Srezn = I. Sreznevskij, Materialy dlja slovarja drevnerusskago jazyka, 3 Bde, Petersburg 1893-1912.

ThWNT $=$ Theologisches Worterbuch zum Neuen Testament, hrsg. von Gerhard Kittel, 8 Bde, Stuttgart 1933-1969.

Trautmann BSLW = Reinhold Trautmann, Baltisch-slavisches worterbuch, Gottingen 1923.

Vasmer = Max Vasmer, Russisches etymologisches Worterbuch, 3 Bde, Heidelberg 1953.

Vostokov, A.Ch., Slovar' cerkovno-slavjanskago jazyka, Petersburg 1858-1861.

Walde-Hofmann = A. Walde - J.B. Hofmann, Lateinisches etymologisches worterbuch, 2 Bde, 3. Aufl., Heidelberg 1938. worterbuch der litauischen Schriftsprache, hrsg. von M. Niedermann u.a. Heidelberg 1932-1968.

Zorell = Francisco Zorell SJ, Novi Testamenti Lexicon Graecum, Paris 1911.

\section{Sekundärliteratur}

Auty $=$ R. Auty, The Western Lexical Elements in the Kiev Missal, in: Slavisch-deutsche Wechselbeziehungen in Sprache, Literatur und Kultur, Berlin 1969.

Benveniste $=$ Emile Benveniste, Le vocabulaire des institutions indo-européennes, 2 Bde, Paris 1969.

Betz, Werner, Der EinfluB des Lateinischen auf den althochdeutschen Sprachschatz. 1. Der Abrogans, Heidelberg 1936. ders., Lateinisch und Deutsch, in: Der Deutschunterricht, $1951,1,21-26$.

Betz $\boldsymbol{1}_{1}$ ders., Deutsch und Lateinisch. Die Lehnbildungen in der althochdeutschen Benedktinerregel, Bonn 1949.

Betz $_{2}=$ ders., Die früdeutschen Spiritus-Ubersetzungen und die Anfänge des Wortes 'Geist', in: Liturgie u. Mönchtum 20, 1957. Birnbaum, Henrik, Zur Sprache der Methodvita, in: Cyrillo-Methodiana (Slavistische Forschungen 6, 1964), 229-361.

Bohác, Antonin, Vliv romanštiny na slovanskou terminologii cirkevnou, in: Listy filologické 35, 1908, 369-374; 432-444. 
Brăuer = Herbert Brăuer, "Tun" und "machen" im Altkirchenslavischen und Altrussischen, in: Orbis scriptus (Festschrift Dm. Tschiževskij), München 1966, 125-134.

Brückner $_{1}=$ Aleksander Brlickner, Wierzenia religijne 1 stosunki rodzinne, in: Encyklopedya polska, tom IV, część 2., dzlal V. Krakow 1912, 149-187.

Brückner $_{2}=$ ders., Cyrillo-Methodiana, In: AfslPh 28, 1905, 161-229.

Brunner = Heinrich Brunner, Deutsche Rechtsgeschichte, Bd. I, II/2, München - Leipzig 1906-1928.

Buslaev = F. Buslaev, o vlijanii christianstva na slavjanskij jazyk. Opyt istoril jazyka po ostromirovu evangeliju, Moskva 1848 .

Čech = Eduard Čech, Učen1k - mučenik - zvolenik (Studie ke vzniku staročeské clrkevnl terminologle), in: slovanské studie, hrsg. von J. Kurz, M. Murko, J. Vašica, Praha 1948.

Cejtlin, R.M., O principach sostavlenija slovarja staroslavjanskogo jazyka, in: Voprosy slavjanskogo jazykoznanija 6, 1962 , 113-139.

Cibulka, J., Der Zeitpunkt der Ankunft der Brüder KonstantinCyrillus und Methodius in Măhren, in: Byzantinoslavica 26, 1965, 318-364.

ders., Velkomoravský Kostel v Modré u Velehradu a začatký křestanstui na Moravě, Praha 1958.

Ciszewski I = Stanislaw Ciszewski, Prace etnologiczne, 4 Bde, Bd. I, Warszawa 1925.

Clemen = Carl Clemen, Die Reste der primitiven Religion im ältesten Christentum, Gieben 1916.

Coleman, Evelyn S., Die Lehnbildungen in Notker Labeos ConsolatioUbersetzung: Ein Beitrag zur Lehngutforschung, (Diss. Maschinenschrift) Harvard University, 1963.

dies., Zur Bestimmung und Klassifikation der wortentlehnungen im Althochdeutschen, in: Zeitschrift f. dtsch. Spr. 21, 1965, $1 / 2,69-83$.

Dombois = Hans Dombois, Das Recht der Gnade, Witten 1961. Dostál. Antonin, Die widerspiegelung der byzantinischen Welt in der altesten Periode der slavischen Sprachen, besonders im Altkirchenslavischen, in: Berliner byzantinische Arbeiten 9. 1957, 36-47.

Eggers $_{1}=$ Hans Eggers, Die altdeutschen Beichten, in: Beitr. 2. 
Gesch. d. dtsch. Spr. u. Lit. 77, 1955, 1-3, 89-123; 80, 1958, 3, 372-403; 81, 1959, 1, 78-122.

Eggers $_{2}=$ ders., Gotisches in der Altbairischen Beichte, in: Zeitschrift f. Mundartforschung 22, 1954/55, 127-144.

Eggers $_{3}=$ ders.. Deutsche Sprachgeschichte I. Das Althochdeutsche, Hamburg 1963.

Ehrismann = Gustav Ehrismann, Geschichte der deutschen Literatur bis zum Ausgang des Mittelalters. I: Die althochdeutsche Literatur, München 1959.

Ehrismann, ${ }_{1}$ ders.. Die worter für 'Herr' im Althochdeutschen, in: Zeitschr. f. deutsche Wortforschung $7,173 \mathrm{ff}$.

Encyklopedya polska, tom IV, częś 2., dzial V. Opracowali Aleksander Brückner, Lubor Niederle, Karol Kadlec, Krakbw 1912. Feist, Ekkehard, Der religiobse Wortschatz der althochdeutschen Tatianübersetzung in seiner Abhängigkeit vom Latein der Vorlage. Studien zur Lehngutforschung, (Diss. Maschinenschrift) Freiburg 1953.

Finsterwalder, Paul Wilhelm, Wege und ziele der irischen und angelsächsischen Mission im Fränkischen Reich, in: Zeitschr. f. Kirchengeschichte 47 (N.F. X), 1928, 203-226.

Fraenkel $1_{1}=$ Ernst Fraenkel, Slavisch gospodb, litauisch viępats, preubisch waispattin und Zubehor, in: ZfslPh 20, 1948-1950, 51-89.

Frček, Jan, K textove kritice sinajského euchologia, in: slavia 18, 1949, 31-46.

Freisinger Denkmăler - Brižinski spomeniki - Monumenta Frisingensia, Entwurf und Redaktion: Jože Pogačnik, München 1968.

Freudenthal $=$ K.F. Freudenthal, Arnulf.-karolingische Rechtsworter, (Diss. Goteborg) Tubingen 1949.

Frings $_{1}=$ Theodor Frings, Germania Romana, in: Teuthonista. Zeitschr. f. dtsch. Dialektforschung u. Sprachgeschichte $3 / 4$, 1932 .

Frings $_{2}=$ ders.. Antike und Christentum an der wiege der deutschen Sprache, Berlin 1949.

Frinta = A.Frinta, Náboženské názvosloví československé. Jazykozpytný rozbor s doklady z našl reformačnl literatury. praha 1919.

Gabka, Kurt, Theorien zur Darstellung eines Wortschatzes, Halle (Saale) 1967 . 
Gneuss, Helmut, Lehnbildungen und Lehnbedeutungen im Altenglischen, Berlin 1954.

Götz = Leopold Karl Götz, Das russische Recht, Bd. III, Stuttgart 1911.

Grafenauer, Ivan, Poglavje iz najstarejšega slovenskega pismenstva, In: Časopis za slovenski jezik, književnost in zgodovino $7,1931,1-4,68-117$.

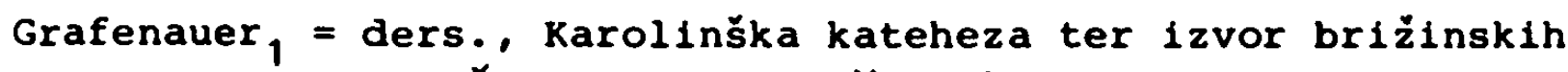
spomenikov in Čina nadb ispovědaještiimb sę, in: Razprave Znanstvenega društva v Ljubljani 13, 1936.

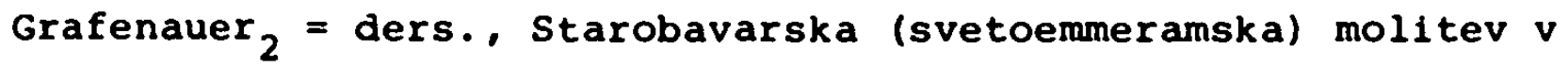
starem slovenskem in $v$ stcsl. jeziku, in: slovenski jezik $I$, 1-4, (Glasilo Slavističnega društva) Ljubljana 1938, 8-54. Grimm RA = Jacob Grimm, Deutsche Rechtsaltertümer, 4.Aufl., 2 Bde, Leipzig 1899.

Grivec, Franz, Drugi frisinški spomenik in Cirilova književna šola, In: Glasnik muzejskega društva 22, 1941, 106-115.

Ders.. O cerkvenoslovanskih prvinah v drugem frisinškem spomeniku, in: Slavistična revija $2,1949,126-137$.

Ders., Frisingensia, in: SR 4, 1951,71-76.

Ders., Frisingensia, in: SR 8, 1955, 169-182.

Ders.. Iz Cirilove književne šole, in: slovo 9-10, 1960, 5-13. Grivec $_{1}=$ ders., Zarja stare slovenske književnosti. Frisinški spomeniki v zarji sv. Cirila in Metoda, Ljubljana 1942.

Grivec $_{2}=$ ders.. Frisingensia, in: SR 3, 1950, 107-124. Grivec $_{3}=$ ders.. Konstantin und Method. Lehrer der Slaven, Wiesbaden 1960 .

Grotz = Joseph Grotz S.J., Die Entwicklung des BuBstufenwesens in der vornicănischen Kirche, Freiburg 1955.

Gunnarsson, Gunnar, Das slavische Wort fur Kirche, in: Uppsala Universitets Ársskrift 7, 1937.

Haugen, E., The Analysis of Linguistic Borrowing, in: Lg 26, 1950, $210-231$.

Ders.. The Norvegian Language in America. A Study in Bilingual Behavior, Philadelphia 1953.

Ders., Rezension $z u$ Helmut Gneuss' Lehnbildungen und Lehnbedeutungen im Altenglischen, in: $\operatorname{Lg} 32,1956,761-766$.

Hautkappe = Franz Hautkappe, Uber die altdeutschen Beichten und ihre Beziehungen zu Cäsarius von Arles (Forschungen und Funde, Bd. IV, H. 5), Münster 1.W. 1917. 
Heinze = Richard Heinze, Supplicium, in: Archiv f. lat. Lexikographie u. Grammatik 15, 1908, 89-105.

Horálek, Karel, K otázce lexikálnich bohemismú v staroslověnských památkách, in: Slovanské studie, Praha 1948, 115-119.

Ibach = Helmut Ibach, $\mathrm{zu}$ Wortschatz und Begriffswelt der althochdeutschen Benediktinerregel, in: Beitr z. Gesch. d. dtsch. Spr. u. Lit. (Ausg. Halle/Saale), 78, 1956, 1-10; 79, 1957 , 106-185, 80, 1958, 190-271.

Jireček $_{1}=$ Hermenegild Jireðek, Slovanské právo $v$ Čechách a na Moravě, 3 Bde; Bd.I. Od prunich zpráv do konce X. stolet1, Praha 1863.

Isačenko $_{1}=$ ders.. Jazyk a pôvod frizinských pamiatok, Bratislava 1943.

Isačenko $_{2}=$ ders.. K voprosu ob irljandskoj misil u pannonskich

i moravskich slavjan, in: Voprosŷjjazykoznanija 7, 1963,

43-72.

Isačenko $_{3}=$ ders.. Die althochdeutschen Belchten und ihre altslavische Ubersetzung, in: ZfslPh 18, 1942, 283-309.

Isačenko $_{4}=$ ders., Nachtrăgliche Bemerkungen zur Frage der ăltesten deutsch-slavischen Beziehungen, in: Zfsiph 19/2, 1947 , 303-311.

Ivanov $=$ V.V.Ivanov, $k$ etimologil russkogo pasti, in: Sbornik statej po jazykoznaniju, Moskva 1961, 105-119.

Jagí́ Entst = Vatroslav Jagić, Entstehungsgeschichte der kirchen-

slavischen Sprache. Neue bericht. u. erw. Ausg., Berlin 1913. Jagíc - Festschrift. Zbornik u slavu Vatroslava Jagía, Berlin 1908.

Jagić, Vatroslav, Meine zusätze zum Studium der Werke des slav. Klemens, in: AfslPh 27, 1905, 384-412.

ders., Zur slavischen Mythologie, in: AfslPh 37, 1920, 492-511. Jagí́ $\mathfrak{q}_{1}=$ ders., Zum altkirchenslavischen Apostolus, 3 Bde, Wien 1919 .

Jucquois, Guy, V.sl. bogatb 'riche', bogb 'dieu' et apparentés, In: Die Sprache 11, 1965, 131-135.

Jungmann, J.A., Die Abwehr des germanischen Arianismus, in:

zeitschr. f. kath. Theologie 69, 1947, 36-99. ders.. Die lateinischen BuBriten in ihrer geschichtlichen Entwicklung, Innsbruck 1932. 
Kadiec $_{1}=$ Karol Kadlec, O prawie karnem u zachodnich slowian przed X.wiekiem, in: Encyklopedya polska, Tom IV, część 2., dzial V., Kraków 1912, 114-127.

Kadlec ${ }_{2}=$ ders.. 0 prawie prywatnem u zachodnich slowian przed x. wiekiem, in: Encyklopedya polska .... 90-113.

$\mathrm{Kadlec}_{3}=$ ders.. O sadownictwie 1 przewodzie saqdowym u slowian do w. X. , in: Encyklopedya polska .... 128-148.

Kăhler, Ernst, Der Niederschlag kirchengeschichtlicher Bewegungen, in: Das Problem der Sprache in Theologie und Kirche, 1959. 68-84.

Kainz = Friedrich Kainz, Sprachpsychologisches zum Thema "Religion und Sprache", in: Die Sprache 1, 1949, 101-115.

Karlinskij, A.E., Problematika Freijzingenskich otryvkov, in: Voprosy jazykoznanija $i$ metodiki prepodavanija inostrannych jazykov, Alma-Ata 1965, 7-18.

Keppen, Petr Iv., Sobranije slovenskich pamjatnikov nachodjaščichsja vne Rossii. Hrsg. von Petr Keppen: Kn. I. Pamjatniki sobrannyje v Germani1, Sanktpeterburg 1827, 1-20; I-IX. Kiparsky $=$ V. Kiparsky, Die gemeinslavischen Lehnworter aus dem Germanischen, in: Annales Academiae scientiarum Fennicae, Ser. B, Bd. 32, Nr.2, Helsink1 1934.

Klich = Edward Klich, Polska terminologja chrześcijańska, Poznan 1927.

Koeniger $=$ Albert Michael Koeniger, Die Sendgerichte in Deutschland. München 1907.

Kolarič $=$ Rudolf Kolarič, Sprachliche Analyse, in: Freisinger Denkmăler, Red. Jože Pogačnik, München 1968, 18-106. Kolarič $\check{L}_{2}=$ ders., Ali so Brižinski spomeniki ves starocerkvenoslovanski?, in: Studia 2 filologil polskiej 1 slowiahskiej 5. 1965, 145-153.

Kopitar = Jernej Kopitar, Glagolita Clozianus..., Vindobonae 1836, XXXIII-XLVII.

Kotljarevskij = A. Kotljarevskij, o pogrebal'nych obyčajach jazy¿eskich Slavjan, Moskva 1868.

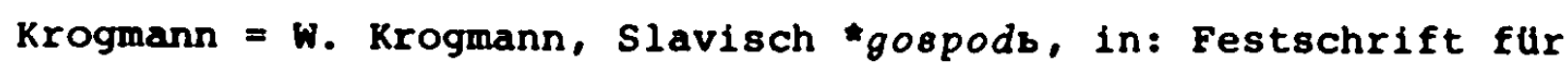
Max Vasmer zum 70. Geburtstag (Slavistische Veroffentlichungen Bd. 9), Wiesbaden 1956, 253-258.

Kronasser, Heinz, Handbuch der Semasiologie, Heidelberg 1952. Lau, Hermann, Die angelsăchsische Missionsweise im Zeitalter des 
Bonifaz, Diss. Preetz 1909.

Loening = Otto Loening, Deutsche Rechtsgeschichte, Dússeldorf 1947.

Luginbühl, Emil, Studien zu Notkers Ubersetzungskunst, Berlin 1970.

L'vov = A.S. L'vov, Očerki po leksike pamjatnikov staroslavjanskoj pis'mennosti, Moskva 1966.

Mareš $_{1}=$ Frantisek Vaclav Mareš, Česká redakce clrkevnl slovanštiny v světle Besěd Řehoře Velikého, in: Slavia 32, 1963, 417-451.

Mareš $_{2}=$ ders.. Pražské zlomky a jejich pưvod, in: Slavia 20, $1951,219-232$.

Masser, Achim, Die Bezeichnungen für das christliche Gotteshaus

in der deutschen Sprache des Mittelalters, (Philolog. Studien

u. Quellen, H. 33) Berlin 1966.

Meyer $=$ Karl H. Meyer, Die slavische Religion, in: Carl Clemen,

Die Religionen der Erde, München 1927, 261-277.

Melich = Johann Melich, Die Namen der Wochentage im Slavischen,

in: Jagić-Festschrift.... Berlin 1908, 212-217.

Meriggi 1 = Bruno Meriggi, Slavo-comune *bogu, in: zbornik za filo$\log 1$ ju 1 lingvistiku $8,1964,33-44$.

Meriggi $2=$ ders.. "Unus deus" di Helmold, in: zbornik za filologiju i lingvistiku 7, 1964, 15-22.

Meurer $=$ Christian Meurer, Die rechtliche Natur der Pönitenzen

der katholischen Kirche in historischer Entwicklung, in:

Archiv f. kath. Kirchenrecht 49 (N.F. 43) 1883, 177-217. Michálek, Emanuel, Český právni jazyk udob1 předhusitského a doby Husovy (Rozpravy Československé Akademie Věd 80, 2), Praha 1970.

Mikl Term = Fr. Miklosich, Die christliche Terminologie der slavischen Sprachen, in: Denkschriften d. Wiener Akademie d. wissenschaften, phil.-hist. Classe 24, Wien 1876.

Miklosich, $=$ ders.. Die Blutrache bei den Slaven, in: Denkschriften... 36, Wien $1888,127-210$.

Miklosich ${ }_{2}=$ ders.. Denkmal der neuslovenischen Sprache, in:

Slav. Bibliothek 2, 1888, 127-210.

Moszýnski = Kazimierz Moszýnski, Kultura ludowa slowian. Bd. II, Kraków 1934.

Mroček-Drozdovskij, P.N., Materialy dlja slovarja pravovych 1 bytovych drevnostej po Russkoj Pravde, in: ̌̌tenija v Ob- 
ščestve Istoril i Drevnostej Rossijskich, 1917, kn. III, 1-129.

Nahtigal, ${ }_{1}$ Rajko Nahtigal, Freisingensia. I-II, in: Ćasopis za zgodovino in narodopisje 12, 1915, 1-12, 77-122.

Nahtigal $_{2}=$ ders.. Važnost lat. dela brižinskega kodeksa in njegovih pripiskov za vprašanje o postanku in domovini slovenskih odlomkov. Freisingensia III, in: Časopis za slovenski jezik, književnost in zgodovino 1, 1918, 1-63.

Neunheuser $=$ P. Burkhard Neunheuser OSB, Gnade, Geistesgaben, Heiliger Geist in mittelalterlicher und neutestamentlicher sicht. Terminologische und sachliche Probleme (Liturgie u. Mönchtum, 20), Limburg/L. 1957.

Nikolí́ = Svetozar Nikolić, Nomina Agentis u staroslovenskom je-

ziku, in: Južnoslovenski filolog 27, 1966-1967, 1-84.

Oblak = V.Oblak, zur würdigung des altslovenischen Codex Supra-

sliensis.... in: AfslPh 15, 1893, 338-370.

Ochs $=$ Ernst Ochs, Die Heiligen und die Seligen, in: Beitr. $z$.

dtsch. Spr. u. Lit. 45, 1921, 102-112.

Ohijenko = Ivan Ohijenko, Dochrystyjanśki viruvannja ukrajinśkoho narodu, Vinnipeg 1965.

Pirchegger $=S$. Pirchegger, Untersuchungen über die altslovenischen Freisinger Denkmaler, Leipzig 1931.

Pogačnik, = Jože Pogačnik, Die Entstehung des mittelalterlichen slovenischen Schrifttums, in: Das heidnische und christliche Slaventum, Wiesbaden 1970, 148-158.

Pogačnik Glossar = ders., Glossar, in: Freisinger Denkmäler, Mürchen 1968, 227-261.

Polák = Václav Polák, Slovanské náboženstvi, in: Vznik a počatky Slovanü, I, Praha 1956, 119-132.

Porzig = Walter Porzig, Die Gliederung des indogermanischen

Sprachgebiets, Heidelberg 1954.

Preidel = Helmut Preidel, Slavische Altertumskunde des östlichen

Mitteleuropas im 9. und 10. Jahrhundert. Teil I, Grăfeling

be1 München 1961.

Raumer = Rudolf Raumer, Die Einwirkung des Christentums auf die

althochdeutsche Sprache, Stuttgart 1845.

Reiffenstein = Ingo Reiffenstein, Das Althochdeutsche und die

irische Mission im oberdeutschen Raum, Innsbruck 1958.

Rheinfelder,$=$ Hans Rheinfelder, Confiteri, confessio, confessor 
im Kirchenlatein und in den romanischen Sprachen, in: Die Sprache 1, 1949, 56-67.

Rheinfelder ${ }_{2}=$ ders., Gloria. Festgabe für Karl Vossler (Münchener romanistische Arbeiten, 1), München 1932.

Richter = Gerlinde Richter, Zur Bedeutungsgeschichte der ahd. missa-Bildungen, in: Beitrăge z. Gesch. d. dtsch. Spr. u. Lit. $85,1963,311-334$.

Rittmayer, Lore, Untersuchungen zum Wortschatz der ahd. Isidorbersetzung. Ein Beitrag zur Lehngutforschung, (Diss. Maschinenschr.) Freiburg 1958.

Rudolf, R., Die Bayernmission und die deutschen Lehnworter in der slovakischen Kirchenterminologie, in: ZfslPh 18, 1942, 257-283.

Saturnik = Theodor Saturnlk, o právu soukromém u slovanú v dobách starsich, in: L. Niederle, Slovanské starozitnosti, odd1I kulturnl, dilu II, svazek 2 (= Kap. VII), Praha 1934.

Schmidt, A. Wilhelm, Lexikalische und aktuelle Bedeutung. Ein Beitrag zur Theorie der Wortbedeutung. Berlin 1963.

Schmidt $=$ Kurt Dietrich Schmidt, Das Christentum und die althochdeutsche Sprache, in K.D. Schmidt, Germanischer Glaube und Christentum, Göttingen 1948, 85-112.

Schnerrer = Rosemarie Schnerrer, Altdeutsche Bezeichnungen für das Jüngste Gericht, in: Beitr. 2. Gesch. d. dtsch. Spr.u. Lit. 85, 1963, 248-312.

Schröder $=$ R. Schröder, Deutsche Rechtsgeschichte, 7.Aufl., Berlin - Leipzig 1932.

Schulz = Hans-Dietrich Schulz, Ahd. sprehhan in den Glossen, in:

Beitr. 2. Gesch. d. dtsch. Spr. u. Lit. 85, 1963, 1, 132-172. Schumann, = Kurt Schumann, Zur Typologie der Lehnprägungen, in: ZfslPh 32, 1965, 61-90.

Schumann $_{2}=$ ders., Die griechischen Lehnbildungen und Lehnbedeutungen im Altbulgarischen, Wiesbaden 1958.

Schütz, Karl, Die Lhnprăgungen der Reichenauer Glossare Rb, Rc, Rd, Rs und Rf, Diss. Bonn 1958.

Schwarz, Ernst, Bemerkungen zur slavischen Lehnwortkunde, in: AfslPh 40, 1926, 284-292.

Schwarz, Heinz-Otto, Die Lhnbildungen der Notkerschen Psalmenübersetzung, (Diss. Maschinenschr.) Bonn 1957. Šetka, Jeronim, Hrvatska krščanska terminologija. Bd. I, Šibenik 1940, Bd. II, Makarska 1964. 
Skok, Petar, La terminologie chrétienne en Slave: L'eglise, les prêtres et les fidèles, in: RES 7, 1927, 177-198.

Sobolevskij, $=$ A.I. Sobolevskij, Materialy $i$ issledovanija v oblasti slavjanskoj filologii $i$ archeologii, in: Sbornik otd. russk. jaz. Akad. Nauk, 88, Nr. 3, S.-Peterburg 1910.

Sobolevskij ${ }_{2}$ = ders., Cerkovno-slavjanskije teksty moravskago proischoždenija, in: Russkij filologičeskij vestnik 43, 1900 , 150-217.

Sotiroff, George, $Y$ a-t-il en une écriture autochtone en terre slave avand le temps de Cyrille et Methode, in: Canadian Slavic Studies 1, 1967, 79-94.

Sprockhoff, Paul, Althochdeutsche Katechetik, Diss. Berlin 1912.

Sreznevskij ${ }_{1}=$ I.I. Sreznevskij (Hrsg.), Filologičeskija nabljudenija A.Ch. Vostokova, Sanktpeterburg 1865.

Stanislav = Ján Stanislav, Slovenské slovo nepriaznik, stsl. nepriěznb 'diabolus', in: Slavia 25, 1956, 2, 254-257.

ders.. Doterajsie výskumy o Frizinských pamiatkach, in: Byzantinoslavica 4, 1933, 303-331.

Steinleitner = Franz Seraph Steinleitner, Die Beicht im Zusammenhange mit der sakralen Rechtspflege in der Antike, Diss. München 1913.

Stender-Petersen = Adolf Stender-Petersen, Slavisch-germanische Lehnwortkunde, Göteborg 1927.

Stránská = Drahomira stránská, Nové přlspevky o slovanskćh oby¿ejlich s hlediska slovanských starožitnosti, in: Vznik a počátky Slovanú, I, Praha 1956, 133-157.

Teeuwen $=$ st.W.J. Teeuwen, Sprachlicher Bedeutungswandel bei Tertullian. Ein Beitrag zum Studium der christlichen Sondersprache (studien zur Geschichte und Kultur des Altertums, Bd. 14, H. 1), Paderborn 1926.

Tschirch, = Fritz Tschirch, Geschichte der deutschen Sprache. I. Die Entfaltung der deutschen Sprachgestalt in der Vor- und Frühzeit, Berlin 1966.

Tschirch $2=$ ders., Religion und Sprache, in: Solange es HEUTE heibt. Festgabe fur Rud. Hermann, Berlin 1957, 260-292. Tschirch $_{3}=$ ders. Weltbild, Denkform und Sprachgestalt. Grundauffassungen und Fragestellungen in der heutigen Sprachwissenschaft, Berlin 1954.

Undol'skij, V.K., Ob otkrytil 1 izdanil tvorenij Rlimenta, episkopa slovenska, in: Besedy Obščestva ljubitelej rossijskoj 
slovesnosti, I, Moskva 1867, 31-38. Urbańczyk = Stanislaw Urbańczyk, Religia pogańskich slowian,

Kraków 1947.

Vaillant = André Vaillant, L'Eucologe du Sinai, particularités de la langue du texte, in: Byzantinoslavica 21, 1960, 1, 75-87. Vašica, Josef, Metodějưv překlad nomokanonu, in: Slavia 24, 1955 , 9-41.

ders., Anonymnl homilie rukopisu clozova po stránce právni, in:

Slavia 25, 1956, 221-233.

ders., K lexiku Zakonu sudného ljudem, in: Slavistična revija 10, 1957, 61-66.

ders., Právni odkaz cyrilometodějský, in: slavia 32,1963, 331-339.

Vašica $_{1}=$ ders., Jazyková povaha zakona sudného ljudem, in: Slavia $27,1958,521-537$.

Vašica ${ }_{2}=$ ders., $K$ otázce púvodu zakona sudného ljudem, in: slavia $30,1961,1-19$.

Vašica ${ }_{3}=$ ders. , Literárn1 památky epochy velkomoravské 863-885. Praha 1966.

Vašica 4 = ders., Slovanská liturgie sv. Petra, in: Byzantinoslavica $8,1939-1946,3,1-54$.

Vašica ${ }_{5}=$ ders., Zur großmährischen und alttschechischen Hymnologie, in: Das heidnische und christliche Slaventum, Wiesbaden 1970, 159-163.

Vladimirskij-Budanov = M.F. Vladimirskij-Budanov, Obzor istorii russkago prava, 5.Auf1., Sanktpeterburg - Kiev 1907.

Vondrák, Václav, Althochdeutsche Beichtformeln im Altkirchenslavischen und in den Freisinger Denkmälern, in: Afs $1 \mathrm{Ph} 16$, $1894,118-132$.

ders., Zur Frage nach dem Verhältnisse des Freisinger Denkmals zu einer Homilie von Klemens, in: AfslPh 28, 1906, 256-260.

Vondrák $_{1}=$ ders.. Frisinské památky. Jich vznik a význam v slovanském pisemnictvi, Praha 1896.

Vondrák $_{2}=$ ders.. Studie $z$ oboru clrkevněvneslovanského plsemnictvi (Rozpravy, III, Nr. 20), Praha 1903.

Vondrák $_{3}=$ ders.. Vergleichende slavische Grammatik, 2 Bde, 2. Aufl., Gottingen 1924-1928.

Vostokov = A.Ch. Vostokov, Grammatičeskija ob''jasnenija na tri stat' 1 Freijzingenskoj rukopisi, in: I.I. Sreznevskij, Filologičeskija nabljudenija A.Ch. Vostokova, Sanktpeterburg 
$1865,1-74$

Wahmann = Paul Wahmann, Gnade. Der altdeutsche Wortschatz im Bereich der Gnade, Gunst und Liebe, in: Neue Deutsche Forschungen, Abtl. Deutsche Philologie, Bd. 4, Berlin 1937, 1-178. Wartburg, Walter von, Einfuhrung in Problematik und Methodik der

Sprachwissenschaft, Tübingen 1962. Weingart $_{1}=$ Miloš Weingart, Československý typ cirkevnej slovančiny, Bratislava 1949.

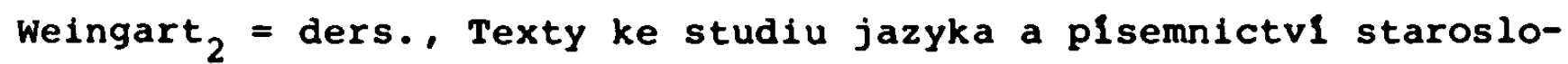
věnského, Praha 1938.

Weisweiler = Weisweiler, Josef, BuBe, Halle (Saale) 1930. ders., Deutsche Frühzeit, in: Deutsche Wortgeschichte, Bd. 1, 2.Aufl., Berlin 1959, 51-104. Wesche $=\mathrm{H}$. Wesche, Geschichte des deutschen Heidentums, in: Beitr. z. dtsch. Spr. u. Lit. 61, 1937, 1-116. Wetter = Gillis P:son Wetter, Altchristliche Liturgien II: Das christliche Opfer (Forschungen zur Religion und Literatur des Alten und Neuen Testaments, N.F. 17) Göttingen 1922. Wienecke = Erwin Wienecke, Untersuchungen zur Religion der Westslaven, Leipzig 1940.

Wróblewski = Tadeusz Wróblewski, 'Demony', in: Slownik starożytnosci slowiańskich, Bd. I, Wroclaw - Warszawa - Kraków 1961. 337.

Zagiba, Franz, Die Missionierung der Slaven aus "Welschland" (Patriarchat Aquileja) im 8. und 9. Jahrhundert, in: CyrilloMethodiana (Slavist. Beitrăge, 6), Köln - Graz 1964, 275-311. Zawiastowicz-Adamska = Kazimiera Zawiastowicz-Adamska, Pomoc wzajemna $i$ wspóldzialanie w kulturach ludowych, in: Prace 1 materialy etnograficzne 8-9, 1951, 1-154. Zigel, Feodor, Slovanské právo, Prag 1912.

\section{E. Historische Quellen}

Die Chronik des Thietmar von Merseburg, neu bearb. von Robert Holtzmann, Leipzig 1939.

Conversio Bagoariorum et Carantanorum, hrsg. von Milko Kos, in: Razprave znanstvenega drusttva 11, 1936, 126-156. Fontes historiae religionis slavicae, coll. C.H. Meyer, Berolini 1931.

Mansikka, V.J.. Die Religion der Ostslaven, I. Quellen, Helsinki 


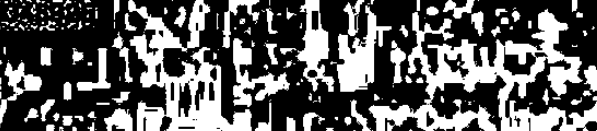

34 ato

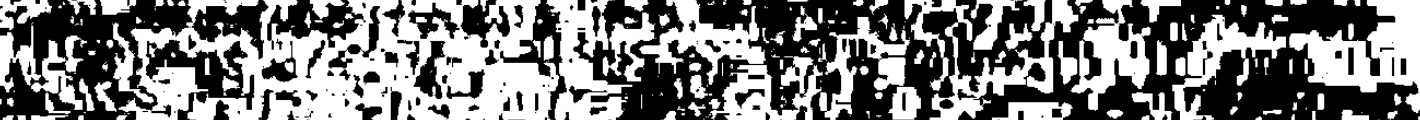

of

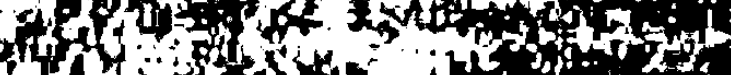

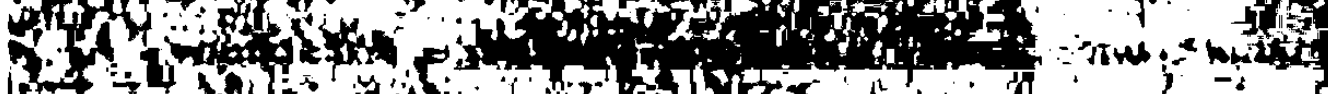

Patsing

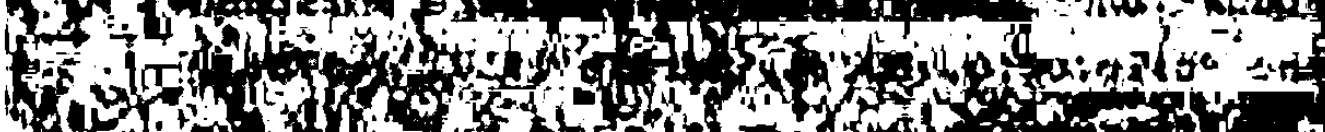

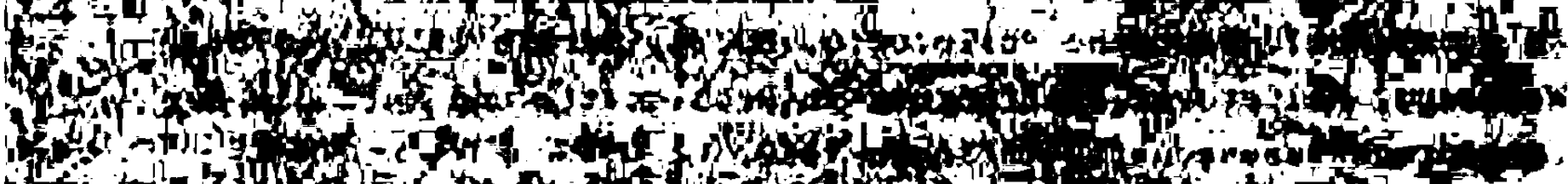
she

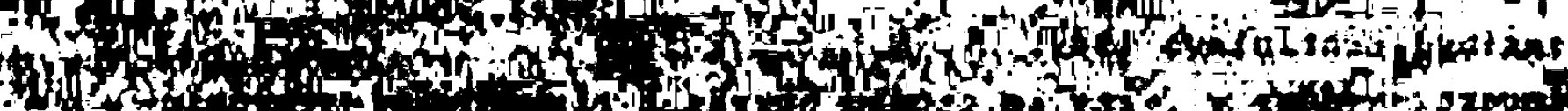

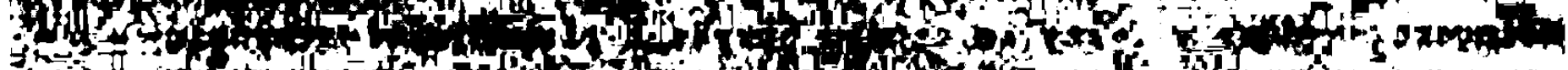

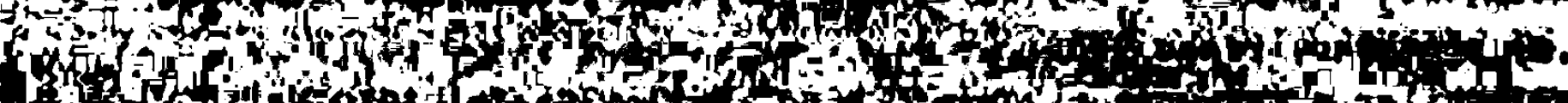

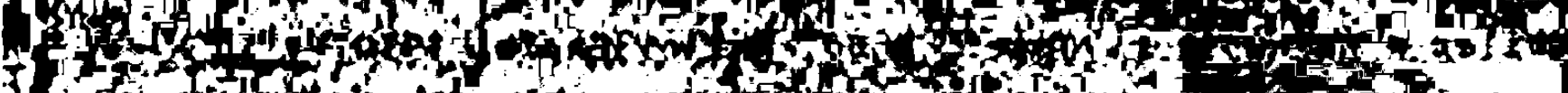
if

Gyt

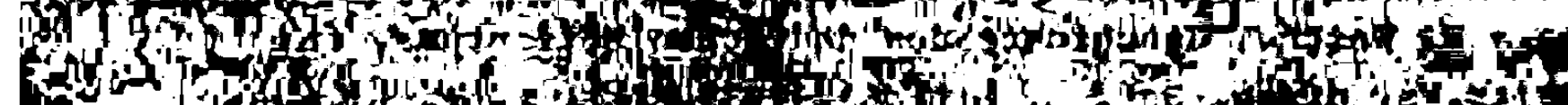

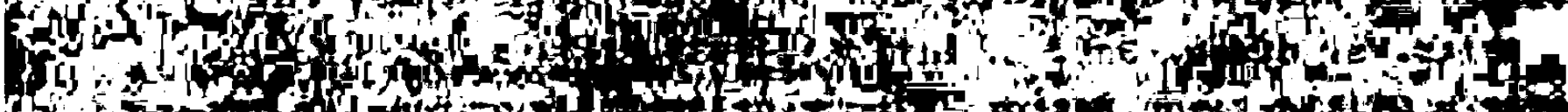

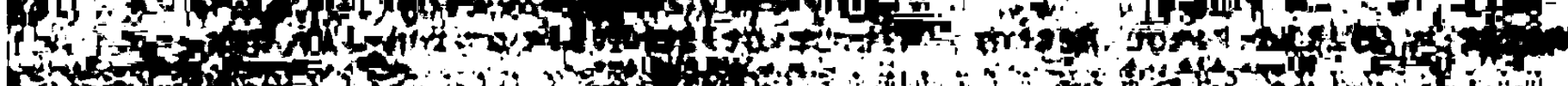

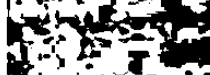

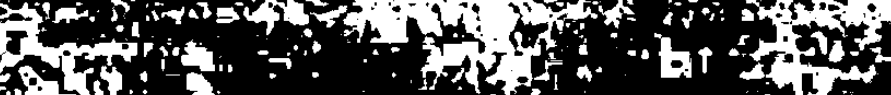

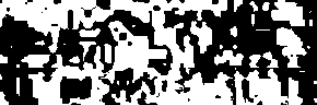

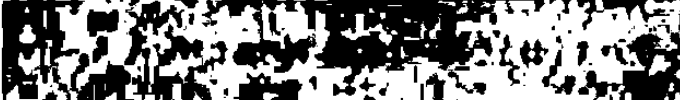

$\because$ in

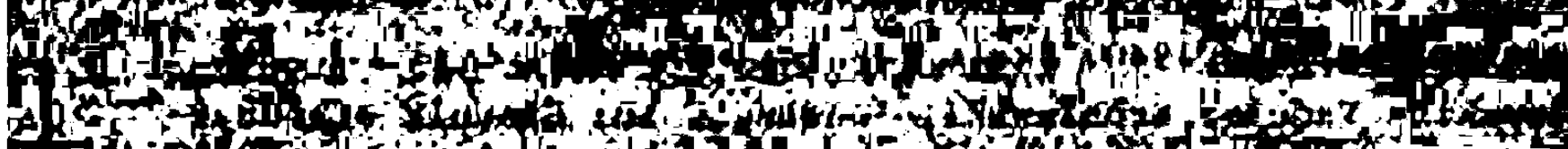

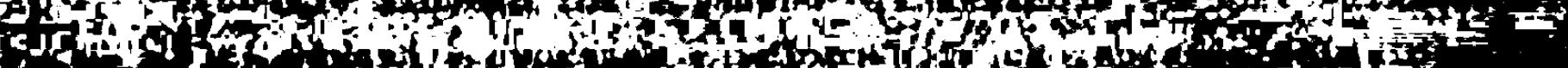

Fis

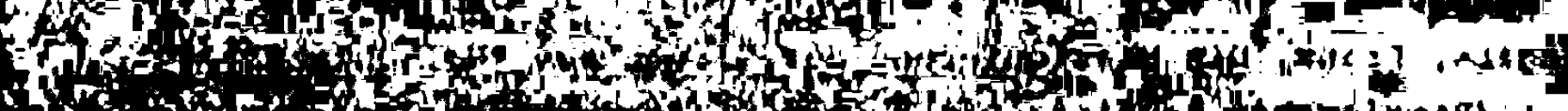

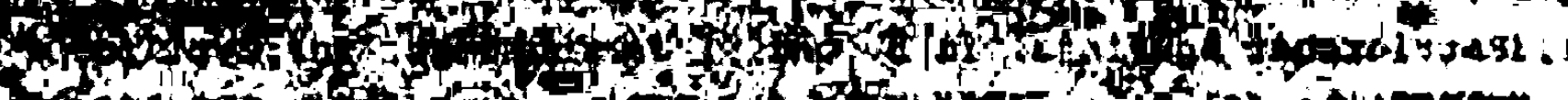

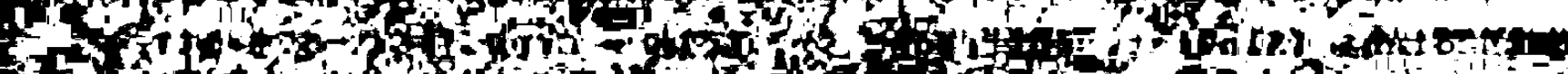
P.

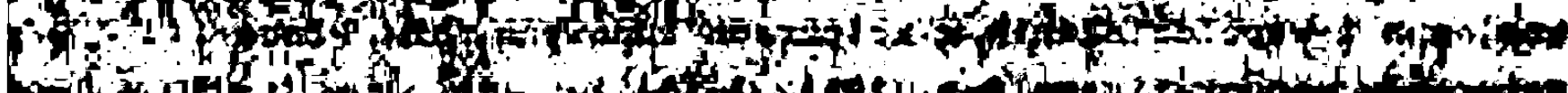

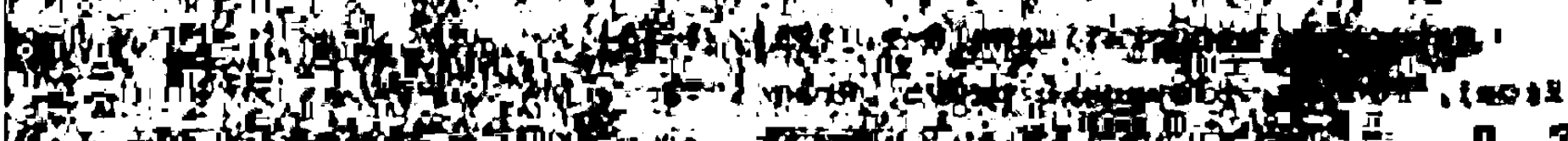

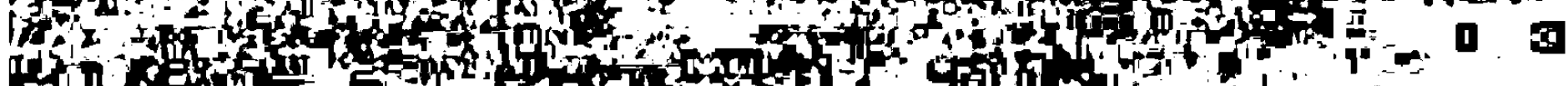

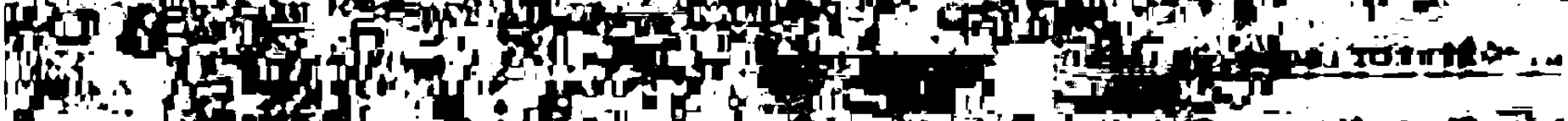
5 ty Af

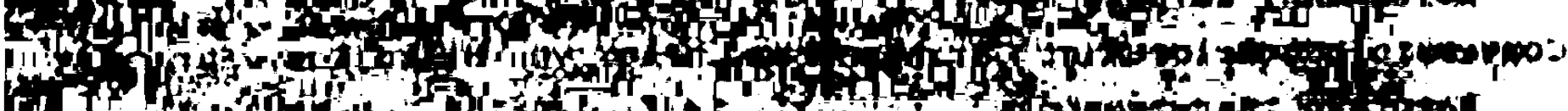

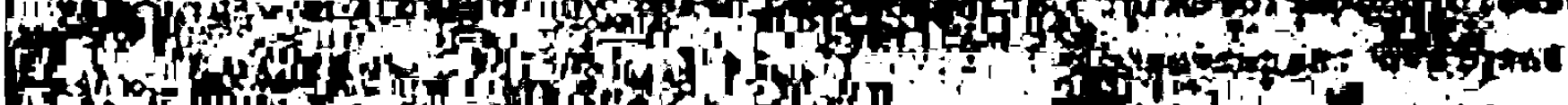

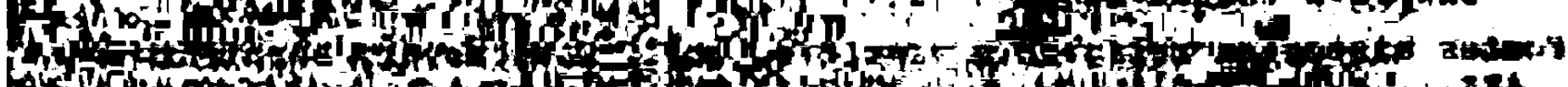

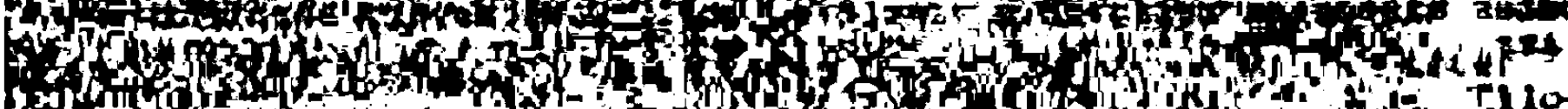
(1) Proto 
00046925

$-161-$

Fris I

78

incoulirf Ponat Reoks Zlougha.

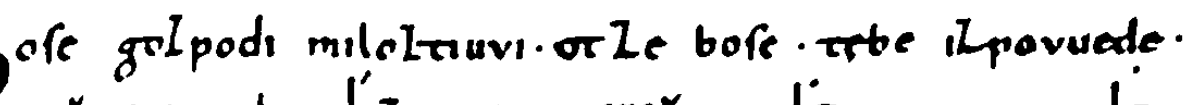

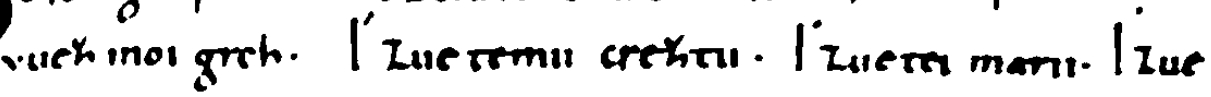
ternu michadu. luutem enlaterm bofiem. I hueteman pe

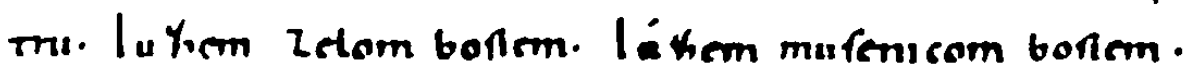

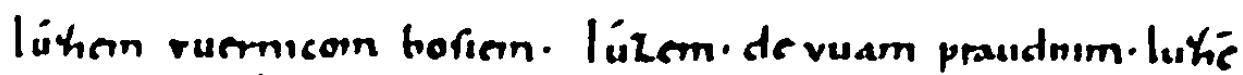

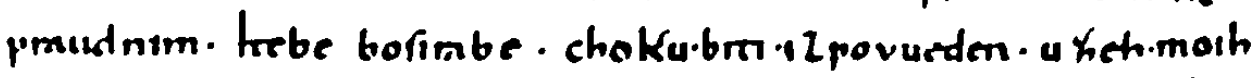
gred. I vuerulu.damilienatien Iuere beuri. itire.na on

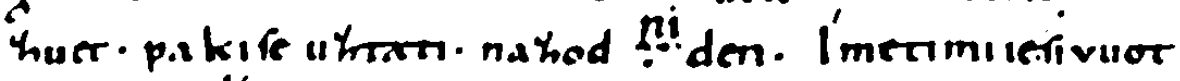
pokem. I'me nimile.or pukne moith grechou. Bore

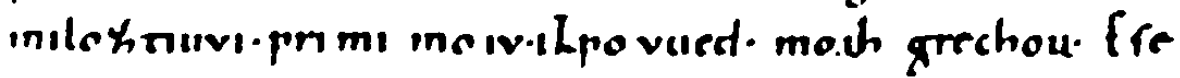

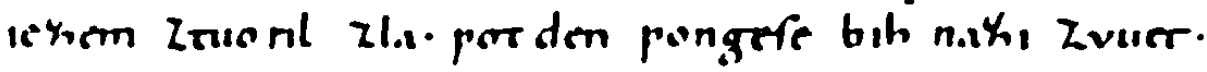

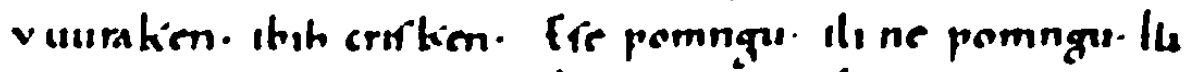
vuolu. ili ne violu. Il, virede ili ne vuede. It une prausl

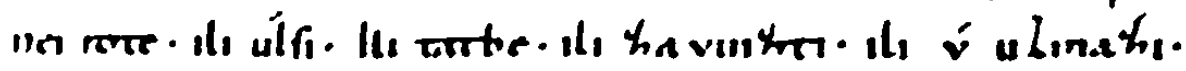

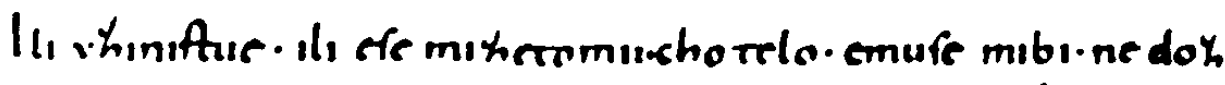

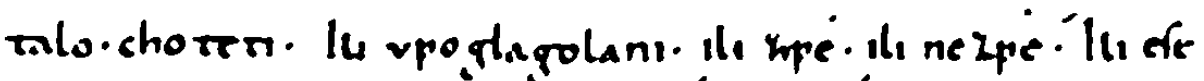

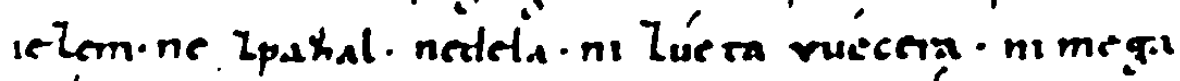

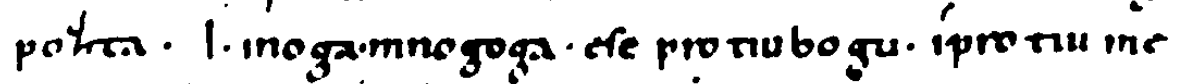

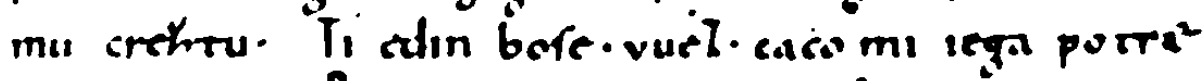
ba vielisa. Bote gripodi miloynvi. rebe is inil monv. od fill potte nith greth. l.odinct mmo zich.

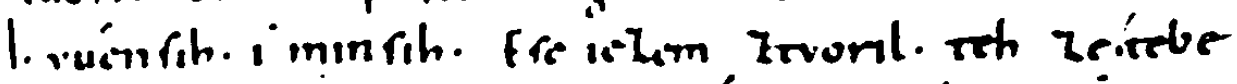

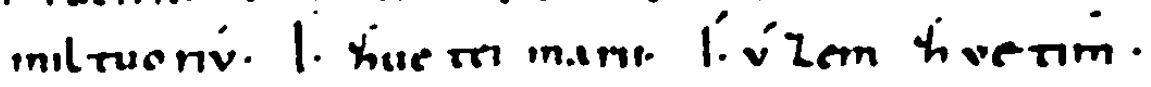

Irene Wiehl - 9783954791293

Downloaded from PubFactory at 01/10/2019 06:04:03AM

via free access 
00046925

$-162-$

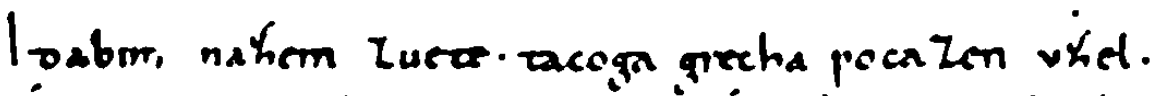
a cafe a mi zadener. ia core tua milo zT. mebe liubo. Bore nimde Zenebeke víe Zeda rmotru. Iavuih národ. Dabins hlodau ozél. ormime vhem. Ilo ociem Milatervul bofe tebe poromfo me tele. Í. mo dufú. I more Hovuetha. Ime dela 1 mi vucln. f' mo vueru. imor fivuot. lidabim uhlural . nalodn!.

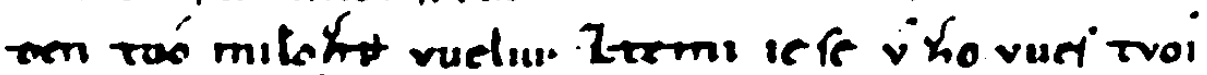
$m$ vhon. Prodere ot ha mega. I Lududient.ppr

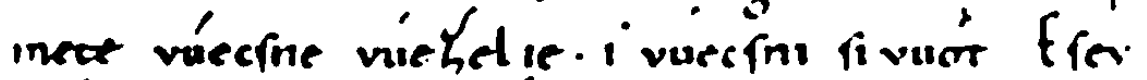

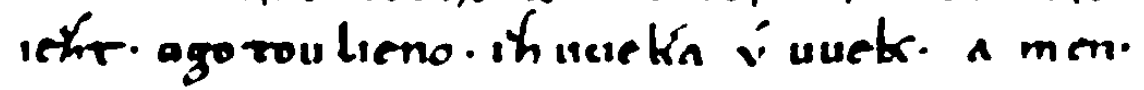

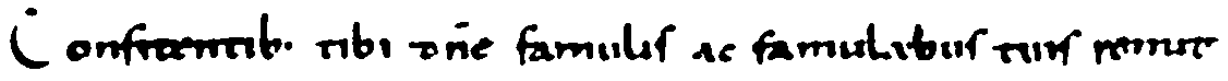

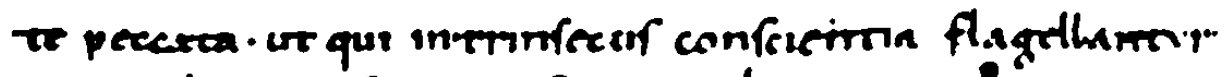

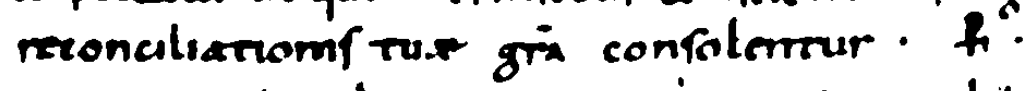

1 省

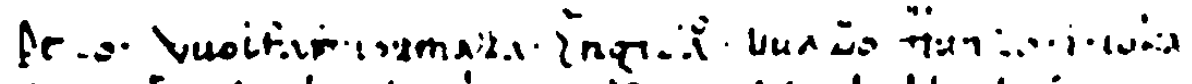

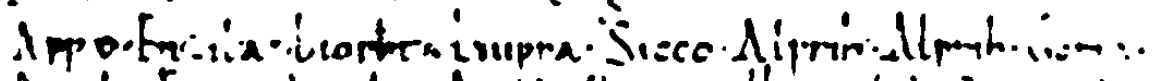

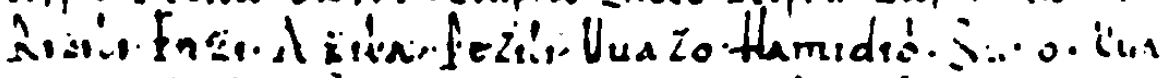

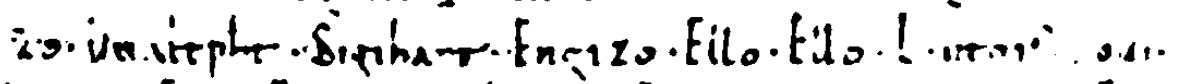

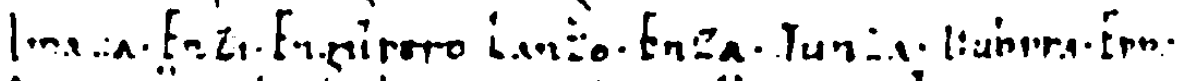
1.s2d cimfisin Arri-mone.

Irene Wiehl - 9783954791293

Downloaded from PubFactory at 01/10/2019 06:04:03AM
via free access 
00046925

$-163-$

Fris II

Eoç bi baed nas neze grefil avudkigamube fren Aaroth neprigon lióka nikoligofe per fale nermugr neftens redeleumoki núvury Kigomubefren bone felavuizaubur ne prial ninu unzigan odfzhuurbofigy lowe nanarodzlo vueAki Arater I pexila bor do neamoka lb $\mathcal{Z}_{r e}$ dutemirt Ipagibra tria pomenem Ze das Zino unuebofi na refomle bowmu of
Aanom Rich mirzab del Efefume dela fow nina Efarebu auorim bratra oclovuccam $f_{f e}$ ramia Efordzbar Efoputo ugongonige Eforot Chor fe lh nepalem nuge pre faporm Efene nauuilt nizee teh del marlene pred bofima olzma mo fece pocomu Zinze un dear lami razumea efebefe pruux Zlou uezi yliza tazie aco fe imurgelim tere ne prizanina uz nenauve deffe Abofice uzliubife

Irene Wiehl - 9783954791293

via free access 
00046925

- $164-$

199.

dibozomu nine ýcircu uvedechu linm vah ich slanam ze lmod nizab iuizeleznet lim Ze im IZeAt ich voofich Uelepenth pigem loben nafferm bozeckachu luime nezem oz cepafgenige bofie te utedfatus teles nafich idir nafich temi temrite dd, Tigeremofem imulate bogu briphofize ano bum ece tage deth Zinhi inam Ze mod nafinem detar isfeo Im romuge vurph ni detare onibo lar nemo ala Gorpotido na netrovuechu feg dant nomoge viat nd naborachu boz li viryartien froge: oburachu naga ode frent úgormuleno iz achu malo mogoncka fom docon 17 voo uimetrofie bozickacho/lenco cofoficm Igrom mrZna Zigreahu Aran brotra bozuaini ib nd bodcraver Zuoge bgent fgofenemotom

Irene Wiehl - 9783954791293

via free access 
00046925

$-165-$

nikiteliza niucn ge pres bofima ofima n nicacofé ubega. Aart 1210 prio imize me nugefare prod infegelim bovvedul Aolom bofigom It naf gozbod Zuencruz zopirnicom nafim Zerlodgem Aarm ifegret bali telelmaffih igeflle pred bofi izpafred dufnoffib ton bozzleatine balouvani ma ofima vasio mu Yuormi vin go pozledge pozfino 17 uorm glagolom uncalalge im fele num izbovucder froge nafempuete chifo dozfor od gुgo. Zaver. Kon igemuzeoten Auorl labobad, do preife naffi leflooco brolibolizi zlo Araptacho neboie ve pechur medime upr oxftomudine Zirlo nizfe ogni perpactiv mullare ide nea imeris inachu ipoleto mozevelonma nu vurfachu ifelelmoduri

Downlene Wiehl - 9783954791293

ia free access 
00046926

$-166-$

160.

Te raiztgaches sontur. mus ninge nafu prau dnu vucrun iprusbo 12 hovecdine tolemofim tzorm efeoni to vac. lico Arafius Asorife diporomuZinzi bofi raba prilzuane rop im grech, visila pofte Tr. inm 12povvedni bo dere grectoon misufin

Irene Wiehl - 9783954791293
Downloaded from PubFactory at 01/10/2019 06.04:03AM

19 06:04:03AM
via free access 
00046925

- $167-$

Fris III

Tazze baghagolo connic. lureb zuerib zloderu. Iuzemiago dauity. luzeb 6 moki. detom. IuZem iego Damirafte napomoki lepocim. Tore une brin. Kibogu morbgre ruiu ubog uze mo chou. Dabim citto iz goki. lu iega Zin; pouned zauorl. Lod Iu Zunea dub.Dan puzac orboga pret. in imena. edin bog Bogu upe mogokemu. gozpod Zuner. izpouuede uthe move ife Zuor nebo.ly greche. Irice marie. comlo. Tofe izeo ie yzeh nepraud nib det. ga milorfa. Irée incpraudnega pomifleza. marace. Irece mic fre iefom uliede tzuo bahela. Iscee pe ril.ili neuluede.nubmi tra. lures boribZal. ili lubmi Zpe ilibde?.

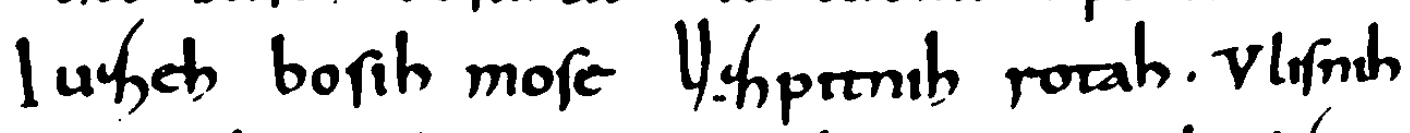

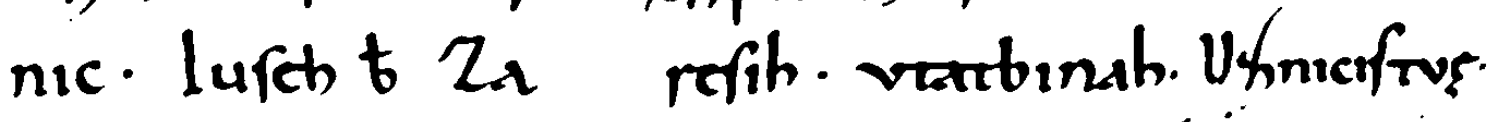

Irene Wiehl - 9783954791293
Downloaded from PubFactory at 01/10/2019 06:04:03AM

via free access 
00046925

$-168-$

161.

Yhacomzrue. Vlichogeten. miloz. dabim nez vichoper. Yuzmatrute ramen. inchroden luuhemlichodiani. Ffe natiudinem dine. refom Iruorl priuuo prectruma ofima bogre octroge dine Zroial.igdafe pr ponefe xpen bith. Sare derhoda. Sutumm. dodiniz negodine. Togo 1 mraum - comufdo uZego ihpoumeten bodo. poZuom dite. Tebe Bogu. Isče mari.l sc̈o bofe milofinvun laurenchu gozpodi. porufo ula mora IuZom huerim. Itecte Zloucich Imora bofi rabe. Cauthe dela. Imoie pomif moit grachou. liadle lenic. Imoie Trakfe. chocu caict dicofe. I moie telo. Imor himizla imam ache fuluot. Imour dufu. mebore pottedifi. Daimi Crifte bofi hinu.

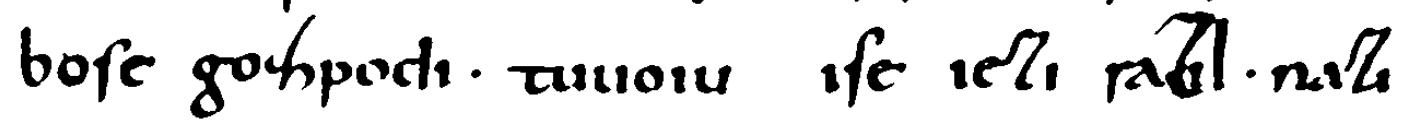

Irene Wiehl - 9783954791293
Downloaded from PubFactory at 01/10/2019 06:04:03AM

via free access 


\section{Zuuder protigrer} mbe ifbanum.or flodane oblazn. ychranime ouriga fla. 17pazome vusfom blafe. $\Lambda M F N$.

Sermo. InNatrivi TATE. ScA RIAE'UIRGINIS Amen GT TC.I. C:OR BIN I AN I. CONFGSSORIS

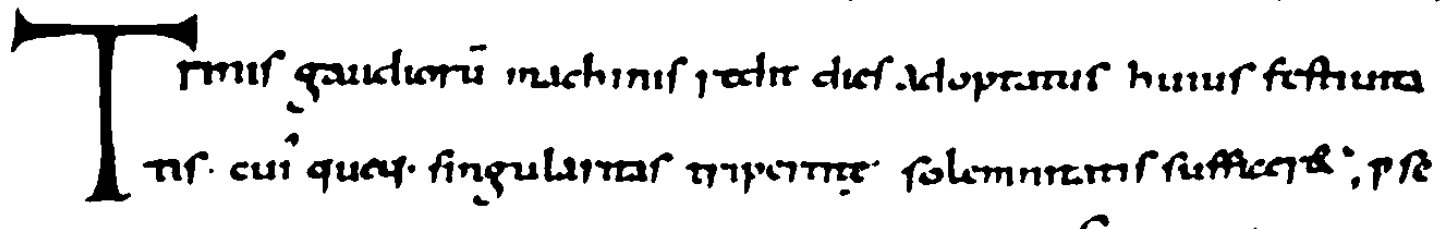

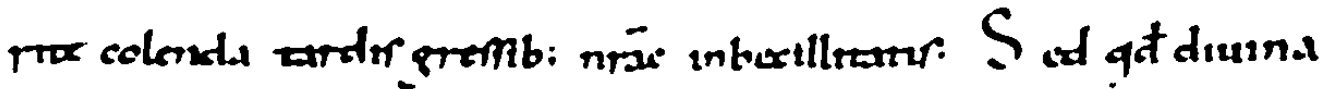

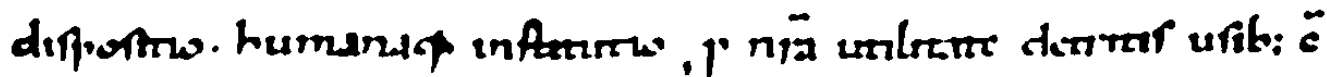

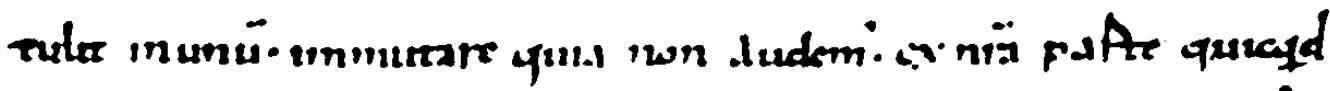

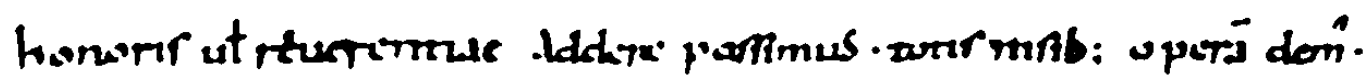

P

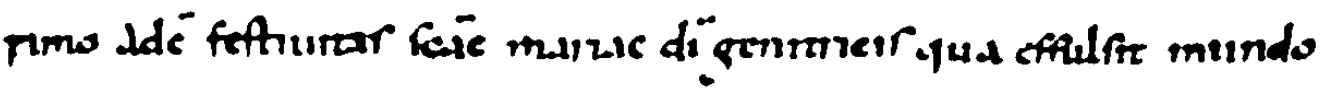

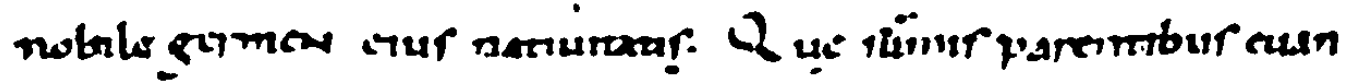

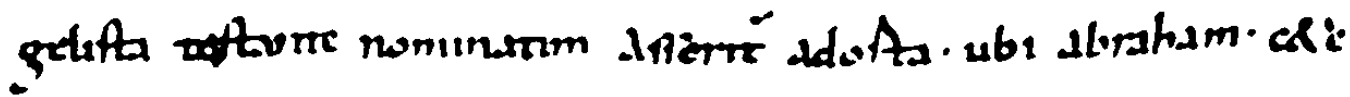


$\therefore \because$ storeror

$\therefore$.

$\because$ 


\section{SLAVISTISCHE BEITRAGE}

Verzeichnis der bisher erschienenen Bănde

1. Maurer,J.: Das Plusquamperfektum im Polnischen. 1960,64 S. - 2. Kadach,D.: Die Anfange der Literaturtheorie bei den Serben. 1960, V, 182 S. - 3. Moskalik,M.: Janka Kupala, der Sănger des weibruthenischei Volkstums. $1961,241 \mathrm{~S}$. - 4. Pleyer,V.: Das russische Altglaubigentum. 1961, 194 S. - 5. Mihailović,M.: Tempus und Aspekt im serbokroatischei Prăsens. 1962, VIII, 64 S. - 6. Rósel,H.: Aus Vatroslav Jagićs Briefwechsel. 1962,75 S. - 7. Schmidt,A.: Valerij Brjusovs Beitrag zur Li, teraturtheorie. 1963, $159 \mathrm{~S}$. - 8. Minde, R.: Ivo Andríc. 1962, $198 \mathrm{~S}$. - 9. Panzer,B.: Die Funktion des Verbalaspekts im Praesens historicum des Russischen. 1963, $106 \mathrm{~S}$. - 10. Mrosik,J.: Das polnische Bauerntum im Werk El1za Orzeszkowas. 1963, $211 \mathrm{~S}$. - 11. Felber,R.: Vojislav Ili: 1965, 271 S. - 12. Augustaitis,D.: Das litauische Phonationssystem. 1964, 155 S. - 12a. Auras,C.: Sergej Esenin. 1965, 211 S. - 13. Kosch mieder-Schmid,K.: Vergleichende griechisch-slavische Aspektstudien. 1967, 196 S. - 14. Klum,E.: Natur, Kunst und Liebe in der Philosophie vladimir Solov'evs. 1965, $333 \mathrm{~S}$. - 15. Albrecht, E.: Das Türkenbild in der ragusanisch-dalmatinischen Literatur des XVI. Jahrhunderts. 1965, 256 S. - 16. Gesemann,W.: Die Romankunst Ivan Vazovs. 1966, 131 S. 17. Perisić,D.: Goethe bei den Serben. 1968, 304 S. - 18. Mares,F.V.: Die Entstehung des slavischen phonologischen Systems und seine Entwic lung bis zum Ende der Perlode der slavischen Spracheinheit. 1965, 87 - 19. Holzheid,S.: Die Nominalkomposita in der Illasubersetzung von $N$ I. GnediC. 1969, 92 S. - 20. Chmielewski,H.: Aleksandr Bestuzev-Marli: skij. 1966, 134 S. - 21. Schaller,H.W.: Die Wortstellung im Russische 1966,389 S. - 22. Hielscher,K.: A. S. Puškins Versepik. 1966, 169 S. - 23. Küppers,B.: Die Theorie vom Typischen in der Literatur. 1966,35 S. - 24. Hahl-Koch,J.: Marianne Werefkin und der russische Symbolismu 1967, 126 S. - 25. Gardner,J.: Das Problem des altrussischen demest1schen Kirchengesanges und seiner linienlosen Notation. 1967, IX,270 S - 26. Baldauf,L.: Der Gebrauch der Pronominalform des Adjektivs im Li tauischen. 1967, $104 \mathrm{~S}$. - 27. Kluge,R.-D.: Westeuropa und RuBland im Weltbild Aleksandr Bloks. 1967, 393 S. - 28. Kunert,I.: J. U. Niemcewicz: Splewy historyczne. 1968, II, $132 \mathrm{~s}$. - 29. Steinke, K.: Studien über den Verfall der bulgarischen Deklination. 1968, $\mathrm{X}, 133 \mathrm{~S}$. -30 . Tschöpl,C.: Vjaceslav Ivanov. 1968, $235 \mathrm{~S}$. - 31 . Rehder,P.: Beitrăge zur Erforschung der serbokroatischen Prosodie. 1968, $247 \mathrm{~S}$. - 32. Kul man,D.: Das Bild des bulgarischen Mittelalters in der neubulgarischen Erzählilteratur. 1968, $276 \mathrm{~S}$. - 33. Burkhart,D.: Untersuchungen zur Stratigraphie und Chronologie der sudslavischen volksepik. 1968, III, 549 S. - 34. Güther, H.: Das Groteske be1 N. V. Gogol' 1968, 289 S. - 35. Kazoknieks,M.: Studien zur Rezeption der Antike bei russischen Dichtern zu Beginn des 19. Jahrhunderts. 1968, 269 S. - 36. Schmidt, H.: Hus und Hussitismus in der tschechischen Literatur des 19. und 20 Jahrhunderts. 1969, 296. S. - 37. Schneider,S.: Studien zur Romantech nik Miroslav Krlezas. 1969, 285 S. - 38. Stephan,B.: Studien zur russischen Castuska und ihrer Entwicklung. 1969, 358 S. - 39. Girke,W.: Studien zur Sprache N. S. Leskovs. 1969, VIII, 220 S. - 40. Marez, F. V.: Diachronische Phonologie des Ur- und Fruhslavischen. 1969, $126 \mathrm{~S}$. - 41. Wosien,M.-G.: The Russian Folk-Tale. 1969, 237 S. - 42. Schulz, R.K.: The Portrayal of the German in Russian Novels. 1969, V, $213 \mathrm{~S}$. - 43. Baudisch,G.: Das patrlarchalische Dorf im Erzăhlwerk von Janko 
M. Veselinović. 1969, 225 S. - 44. Stollting,w.: Beitrăge zur Geschichte des Artikels im Bulgar18chen. 1970, VII, 296 S. - 45. Hucke,G.:Jurij Fedorovic Samarin. 1970, 183 S. - 46. Hocherl,A.: Zur Ubersetzungstechnik des altrussischen "Judischen Krieges" des Josephus Flavius. 1970, 183 S. - 47. Sappok,C.: Die Bedeutung des Raumes fur die Struktur des Erzăhlwerks. 1970, 154 S. - 48. Gusk1, A.: M. Ju. Lermontovs Konzeption des literar1schen Helden. 1970, 225 S. - 49. Lettmann,R.: Die abstracta 'um' und 'razum' bel Belinskij. 1971, 167 S. - 50.Lettmann-Sadony,B.: Karolina Karlovna Pavlova. 1971, 181 S. - 51. Brümer, C.: Beitrage zur Entwicklungsgeschichte der fruhen Romane L. M. Leonovs, $1971,231 \mathrm{~s}$. - 52. Schmidt,C.: Bedeutung und Funktion der Gestalten der europäisch ostlichen Welt im Werk Thomas Manns. 1971, $366 \mathrm{~S}$. - 53. Eschker,W.: Untersuchungen zur Improvisation und Tradierung der Sevialinka an Hand der sprachlichen Figuren. 1971, 275 S. - 54. Schmidt О.: Нензвестний поэт П.Д.Бутурлин. Анализ творчества. 1971, 229 S. 55. Mónke,H.: Das Futurum der polnischen Verba. 1971, 184 S. - 56.Raekke,J.: Untersuchungen zur Entwicklung der Nominalkomposition im Russischen seit 1917. - 57. Muller-Landau,C.: Studien zum Stil der Sava-Vita Teodosijes. 1972, 183 S. - 58. Dippe,G.: August Senoas historische Romane. 1972, $177 \mathrm{~S}$. - 59. Hetzer,A.: Vjaceslav Ivanovs Tragodie "Tantal" 1972,202 S. - 60. Andreesen, $W .:$ Untersuchungen zur Translation von Sub. stantiven zu Adjektiven im Altrussischen. 1972, 151 s. - 61. Neureiter, F.: Kaschubische Anthologie. 1973, VIII, 281 S. - 62. Gavrin,M.: Kroatische Ubersetzungen und Nachdichtungen deutscher Gedichte zur zeit des Illyrismus. 1973, $226 \mathrm{~S}$. - 63. Grahor,0.: France in the Work and Ideas of Antun Gustav Matos. 1973, 247 S. - 64. Doring,J.R.: Die Lyrik Paster. naks in den Jahren 1928-1934. 1973, XXVI, $390 \mathrm{~S}$. - 65. Högemann-Ledwohn E.: Studien zur Geschichte der russischen Verserzahlung in der zweiten Hälfte des 19. Jahrhunderts. 1973, $428 \mathrm{~S}$. - 66. Gonschior,H.: Die geneigten Vokale als Reflexe altpolnischer Längen im Worterbuch von Jan Mączyfski. 1973, $391 \mathrm{~S}$. - 67. Talev,I.: Some Problems of the Second South Slavic Influence in Russia. 1973, XIV, 430 S. - 68. Auerbach,I.: Nomina abstracta im Russischen des 16. Jahrhunderts. 1973, VI, $368 \mathrm{~S}$. - 69. Holthusen,J.: RuBland in Vers und Prosa. 1973, 212 S. - 70. Guski,H.: Die satirischen Kombdien V.I.Lukins (1737-1794) . 1973, 250 S. 71. Sternkopf,J.: Sergej und Vladimir Solov'ev. 1973, XXXI, 667 S. 72. Wenzel,F.: SPLIT. Ein Verfahren zur maschinelien morphologischen Segmentierung russischer worter. 1973, IX, 203 S. - 73. Bachmann, E.: Ivo KozarCanin - Leben und Werk. 1974, $250 \mathrm{~s}$. - 74. Schmidt,B.: St1lelemente der münlichen Literatur in der vorrealistischen Novellistik der Serben und Kroaten. 1974, 309 S. - 75. Jakoby, W.: Untersuchungen zur Phonologie und Prosodie einer kajkavischen Mundart (Gornja Stubica) 1974, X, 256 S. - 76. Schultze,B.: Der Dialog in F. M. Dostoevskijs Idi, 1974, 314 S. - 77. Hilf,E.A.: Homonyme und thre formale Auflosbarkeit il System Sprache, dargestellt an altruss18chen Berufsbezeichnungen. 1974, 129 S. - 78. Wiehl, I.: Untersuchungen zum Wortschatz der Freisinger Denl mäler. Christliche Terminologle. 1974, 169 S. - 79. Pribie,R.: Bonaventi ra's Nachtwachen and Dostoevsky's Notes from the Underground. A Compari. son in Nihilism. 1974, $155 \mathrm{~s}$.

\section{IN VoRBereItUng fUR ENDE 1974:}

80. Ziegler,G.: Moskau und Petersburg in der russischen Literatur (ca 1700-1850). Zur Gestaltung eines literar1schen Stoffes. VI,198 S. - 81. worn,D.: Aleksandr Bloks Drama Peenja sud'by, Ubersetzt, kcmentiert unc interpretiert. $x, 545 \mathrm{~S}$. - 82. Timberlake, A.: The Nominative Object in Slavic, Baltic, and West Finnic. $265 \mathrm{~S}$. 